


\section{Propositions}

1. Changing diets is an important option for more sustainable water use in arid and semi-arid regions.

(this thesis)

2. Appropriate grassland-utilization patterns enhance the supply of ecosystem services and reduce negative effects on both household livelihoods and the environment.

(this thesis)

3. Livelihood analysis can provide new perspectives on resource and ecosystem management, especially when micro-level household livelihood responses are linked to macro-level policies.

4. Properly accounting for ecosystem service values in economic policy is critical to human well-being and stimulates strategies for sustainable natural resource use.

5. The essence of natural resources management is balancing interests.

6. PhD research is challenging, because new ideas and skills continuously have to be developed.

7. Deadlines are a primary condition for getting a PhD done.

Propositions belonging to the thesis, entitled

Effects of land-use change on grassland ecosystem services in Inner Mongolia and their implications for livelihoods and sustainable management

Bingzhen Du

Wageningen, 30 January 2019 
Effects of land-use change on grassland ecosystem services in Inner Mongolia and their implications for livelihoods and sustainable management

Bingzhen Du 


\section{Thesis committee}

\section{Promotor}

Prof. Dr R. Leemans

Professor of Environmental Systems Analysis

Wageningen University \& Research

\section{Co-promotors}

Dr R.S. de Groot

Associate Professor, Environmental Systems Analysis Group

Wageningen University \& Research

Prof. Dr L. Zhen

Professor, Institute of Geographic Sciences and Natural Resources Research Chinese Academy of Sciences, Beijing, People's Republic of China

\section{Other members}

Prof. Dr P.F.M. Opdam, Wageningen University \& Research

Dr H.J. König, Leibniz Centre for Agricultural Landscape Research, Germany

Dr J. de Vente, Spanish National Research Council, CEBAS-CSIC, Spain

Dr L.L. Willemen, ITC, University of Twente, Enschede

This research was conducted under the auspices of the Graduate School for Socio-Economic and Natural Sciences of the Environment (SENSE) 


\title{
Effects of land-use change on grassland ecosystem services in Inner Mongolia and their implications for livelihoods and sustainable management
}

\author{
Bingzhen Du
}

\section{Thesis}

submitted in fulfilment of the requirements for the degree of doctor at Wageningen University by the authority of the Rector Magnificus, Prof. Dr A.P.J. Mol, in the presence of the

Thesis committee appointed by the Academic Board to be defended in public on Wednesday 30 January 2019 at 1.30 p.m. in the Aula. 


\section{Bingzhen Du}

Effects of land-use change on grassland ecosystem services in Inner Mongolia and their implications for livelihoods and sustainable management, 201 pages

PhD thesis, Wageningen University, Wageningen, the Netherlands (2019)

With references, with summary in English

ISBN 978-94-6343-398-3

DOI https://doi.org/10.18174/466451 
谨以此书献给我的老师、父母和亲友们

To my dearest teachers, family and friends 



\section{Table of Contents}

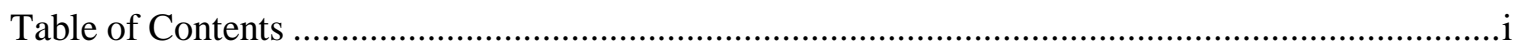

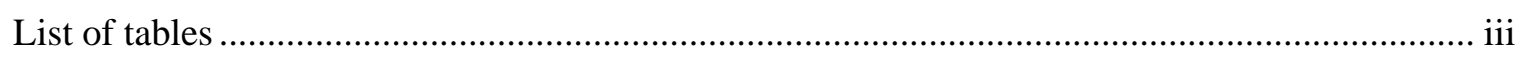

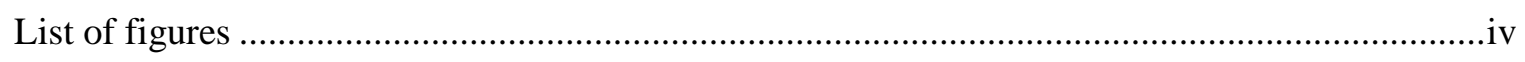

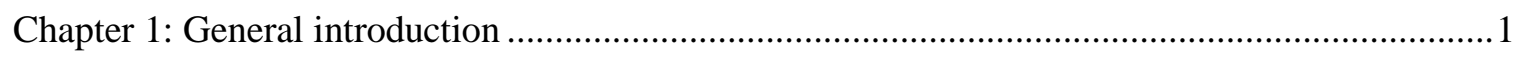

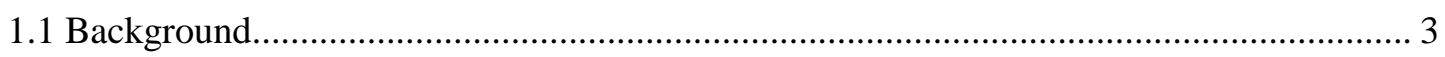

1.2 The study area: the Inner Mongolia Autonomous Region................................................ 3

1.3 Changes in National Land-use Policies in the study area............................................... 5

1.4 Changes in the local socio-ecological systems in the study area...................................... 8

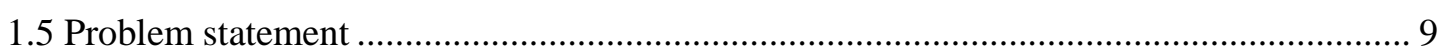

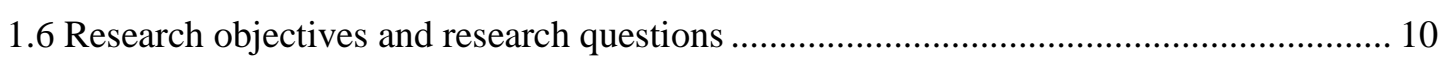

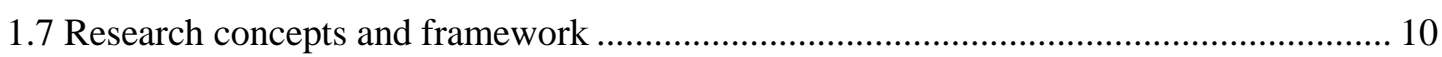

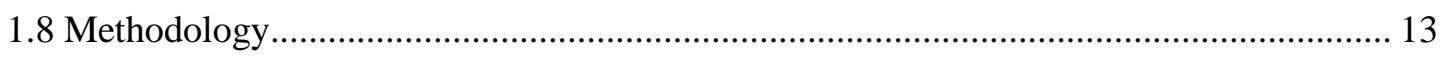

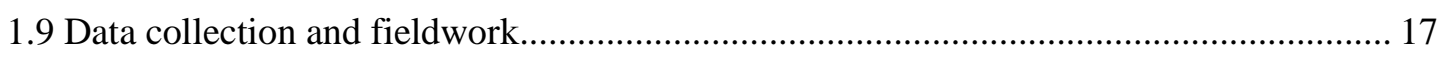

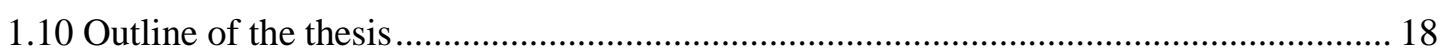

Chapter 2: Changing patterns of basic household consumption: policy-oriented adaptive

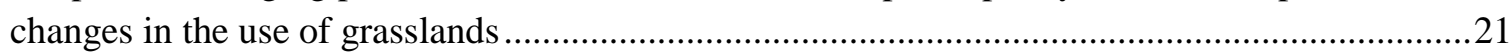

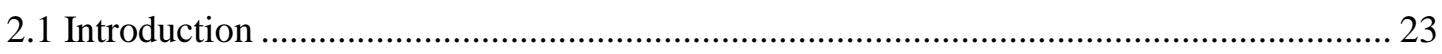

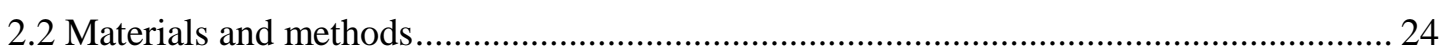

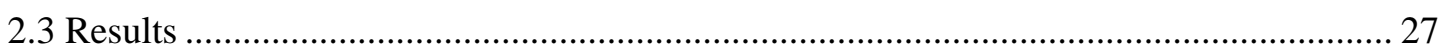

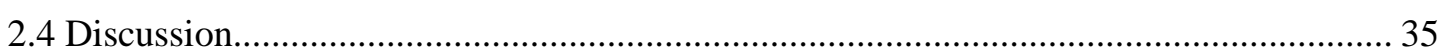

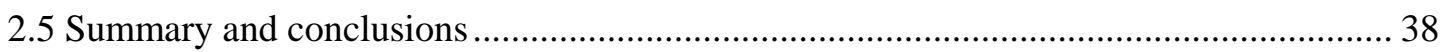

Chapter 3: Changing Food Consumption Patterns and Impact on Water Resources in fragile

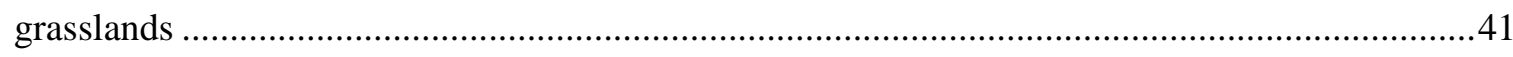

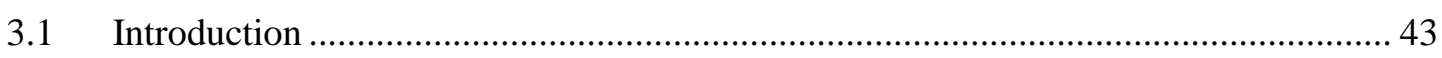

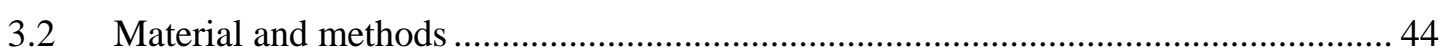

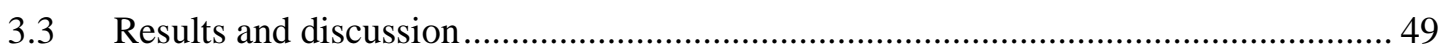

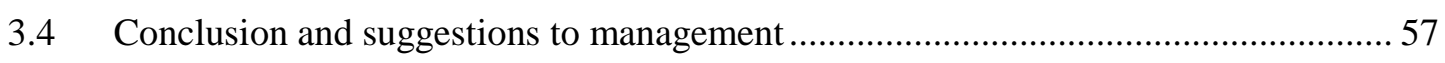

Chapter 4: Effects of Grassland Conservation Policy on Household Livelihoods and

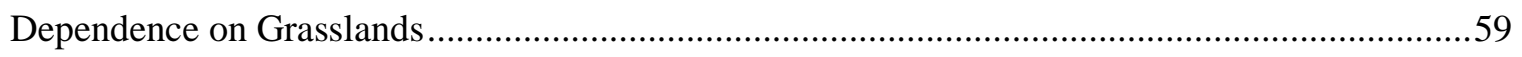

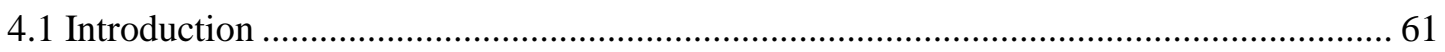

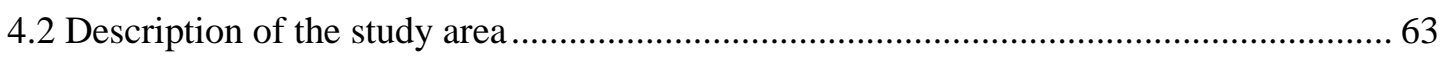

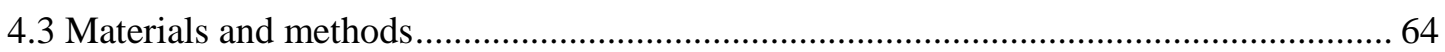

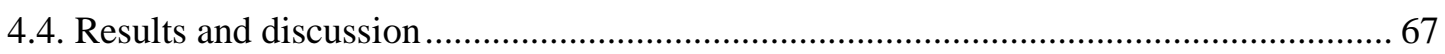

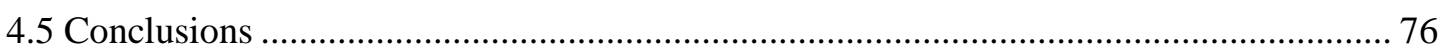


Chapter 5: Comparison of ecosystem services provided by grasslands with different

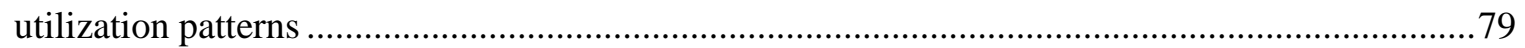

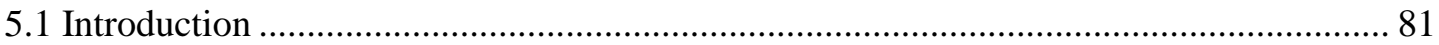

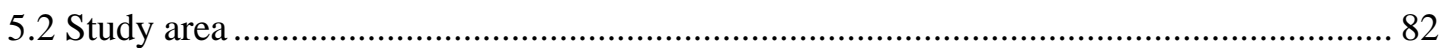

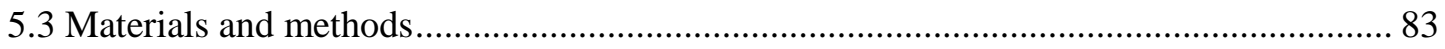

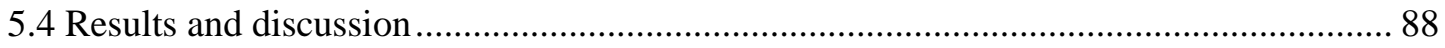

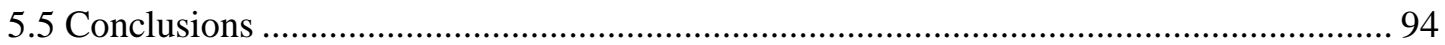

Chapter 6: Herders' willingness to accept versus the public sector's willingness to pay for

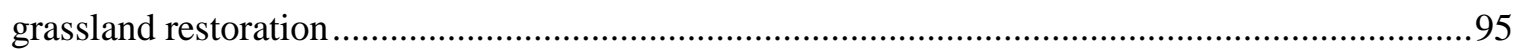

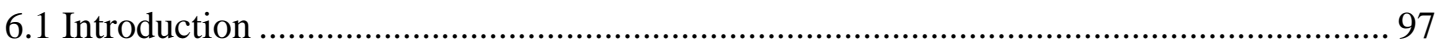

6.2 PES programs implemented in the Xilin Gol League grassland of the Inner Mongolia

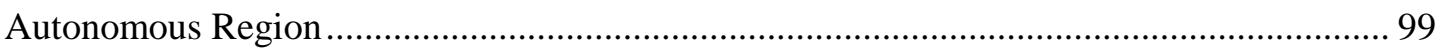

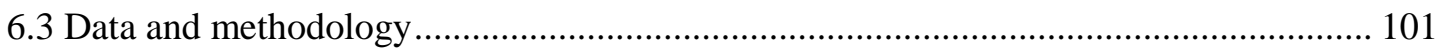

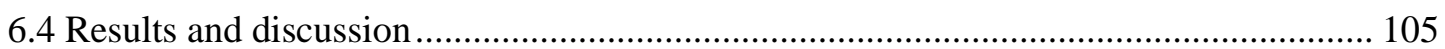

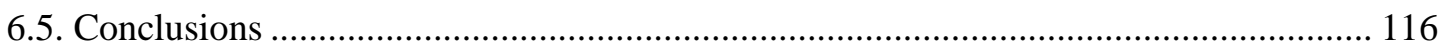

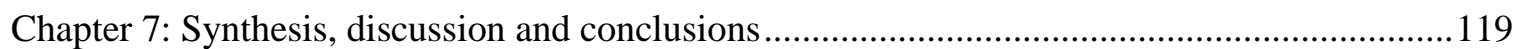

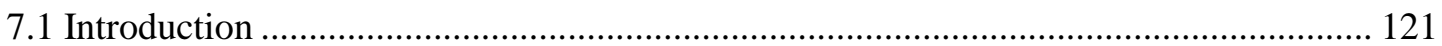

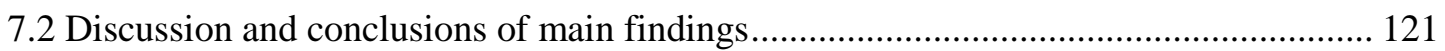

7.3 Discussion of research methods and comparison with literature.................................. 135

7.4 Synthesis and management recommendations .......................................................... 136

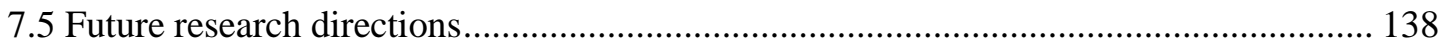

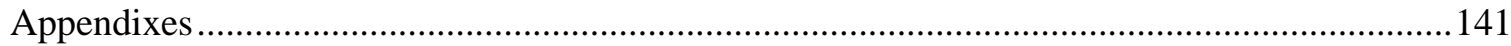

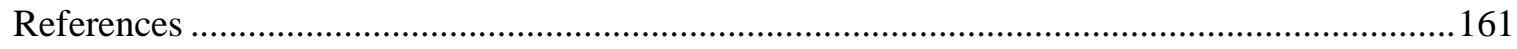

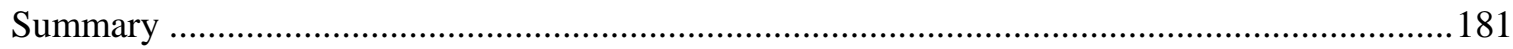

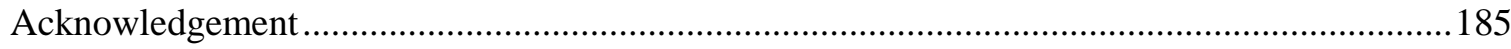

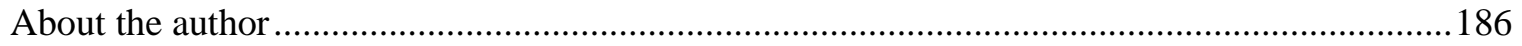

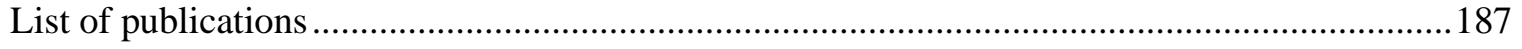




\section{List of tables}

Table 1.1 Development of National land-use policies in the Inner Mongolia Autonomous since 1978 .

Table 1.2 Major uses of dry-land ecosystem services identified in the literature ..........15

Table 2.1 Household characteristics of survey................................... 29

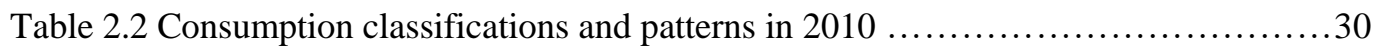

Table 2.3 Variations in annual food, fuel, and water consumption per capita..............31

Table 3.1 Land-use patterns in the study sites...................................47

Table 3.2The Characteristics of the households that participated in the survey............50

Table 3.3 The variation of food consumption per capita per year......................52

Table 3.4 Indirect water consumption from major food consumption items..............54

Table 4.1 Selection of indicators for livelihood assessment .........................66

Table 4.2 Results of the livelihood analysis for the three banners in the Inner Mongolia Autonomous Region...................................................... 70

Table 4.3 The per capita fuel and food consumption in the three banners of the Inner Mongolia Autonomous Region...........................................74

Table 4.4 Changes in household dependence on local grasslands from 1995 to $2010 \ldots . .77$

Table 5.1 Characteristics of the five grassland utilization patterns in the Inner Mongolia Autonomous Region........................................................84

Table 5.2 Proposed indicators for assessing ecosystem services under the different grassland

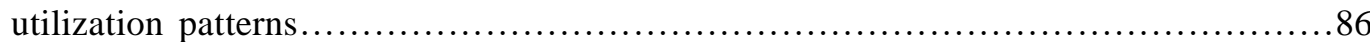

Table 5.3 Basic characteristic of the study plots................................. 87

Table 5.4 Household consumption of provisioning services..........................89

Table 5.5 Scores for ranking ecosystem services in the three parts of the study area as a function of the grassland utilization patterns (intensities). .........................90

Table 5.6 Differences in soil properties and habitant qualities among the study area........92

Table 6.1 Demographic information for the study region...........................97

Table 6.2 Proportion of total land resources accounted for by converted sloping land and the area in which grazing is prohibited.............................................. 101

Table 6.3 Responses to questions designed to reveal the awareness and attitudes of the interviewees.

Table 6.4 Comparison of the income structure of respondents before and after the payment for ecosystem services programs. ..108

Table 6.5 The relationship between the bid amount and the proportion of the households that were willing to accept (WTA) that amount for the conservation of grassland in Inner Mongolia.

Table 6.6 The relationship between the bid amount and the proportion of the government officials willing to pay (WTP) that amount for the conservation of grassland in Inner Mongolia................................................................112

Table 6.7 Responses to questions designed to reveal the perceptions of payment for ecological services (PES): herders versus officials.............................114

Table 7.1 Scores for ranking ecosystem services in the study areas as a function of the grassland utilization patterns. 


\section{List of figures}

Figure 1.1 The location of the study areas in the Inner Mongolia Autonomous Region......4

Figure 1.2 The pathway from ecosystem structure and processes to human well-being......11

Figure 1.3 The conceptual framework for socio-ecosystem interaction....................12

Figure 1.4 Research framework and steps............................................13

Figure 2.1 Location map of study sizes in the Inner Mongolia Autonomous.................25

Figure 2.2 Changes in food consumption patterns by number of households................32

Figure 2.3 Changes in fuel consumption patterns by number of households................32

Figure 3.1 The geographic location and coverage rate of grassland in the Inner Mongolia

Autonomous Region............................................................ 45

Figure 3.2 Water requirement per unit of land area for producing consumable items......56

Figure 4.1 Maps of the land coverage types and locations of the survey sites in the Inner

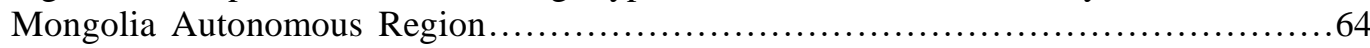

Figure 4.2 Main components of herders' livelihood in the study area....................65

Figure 4.3 Household perceptions....................................................68

Figure 5.1 Location of the study area and map of the study sites........................83

Figure 6.1 Location of the survey sites in Xilin Gol of the Inner Mongolia Autonomous

Region....................................................................... 100

Figure 6.2 Functional relationships between the bid amount and the associated WTA consensus rate and probability density .......................................... 110

Figure 6.3 Functional relationships between the bid amount and the associated WTP

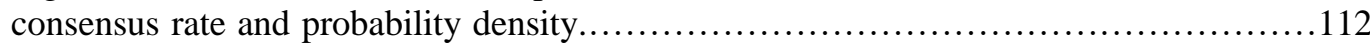

Figure 7.1 Change of habitat quality in Inner Mongolian grasslands.......................124

Figure 7.2 The producing places for purchasing food products........................128 


\section{CHAPTER 1}

General introduction

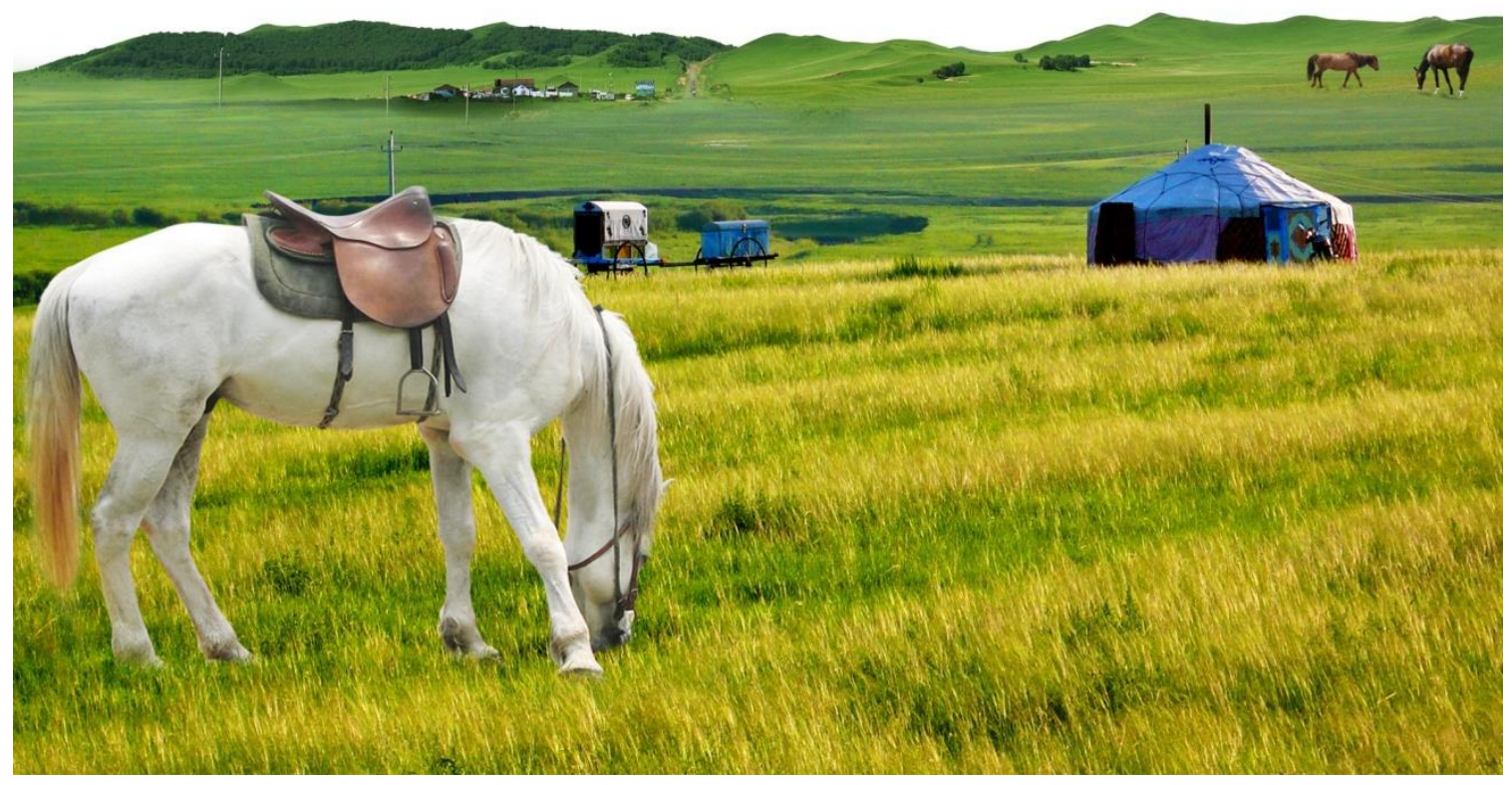




\subsection{Background}

Grasslands are among the ecosystems with high species richness in the world (Wilson et al. 2012) and they provide a wide range of ecosystem services. Grasslands play an important role in the global carbon cycle. As most of their biomass is belowground, carbon accumulation rates are high and decomposition of organic material is slow (Gibson 2009). Grasslands are the main forage resource for livestock. They facilitate infiltration of water into the soil and thus to the maintenance of hydrological cycles. Grasslands also contribute to the landscape beauty of many regions. They are thus multi-functional systems that are important for human well-being. Simultaneously they are exposed to unsustainable use and conflicting interests. Widespread grassland degradation occurs around the world. This results in a loss of ecosystem functions, biodiversity and economic potential (Sala et al. 2000).

Grasslands in China cover almost half of its land area and nearly $80 \%$ occurs in arid and semiarid regions (Ren et al. 2008). Many types of grassland are degraded during the past decades and this reduced their productivity and biodiversity, and led to sandstorms and desertification. This is now a substantial environmental problem in northern China (Akiyama and Kawamura 2007). Grassland degradation and desertification are defined as processes of retrogressive grassland succession resulting from human activities (e.g. overgrazing, reclamation) and unfavourable natural conditions (Zhang et al. 2013)

Regional land-use changes are triggered by several land conservation policies that were introduced by the Chinese government. Such policies include wind and sandsource control around Beijing and the Tianjin project. Both focused on afforestation and grassland maintenance (Xu et al. 2011). The sloping land conversion program (SLCP), which was initiated in 2000, converts arable land to grasslands or forests in the agro-pasture zone (Yin and Yin 2010; König et al. 2012) and the grazing prohibition policy, that was implemented in 1987, requires livestock fencing and bans livestock from degraded areas ( $\mathrm{Li}$ et al. 2007; Li \& Huntsinger 2011). The government recently excluded herders from vast areas of land and attempted to move them into 'minority villages', where these herders are expected to survive by producing milk for the dairy industry using a limited and fixed grassland area. These land-conservation policies resulted in abandoning nomadic pastoralism in favour of individual farming with fenced herding and increasing herd densities $(\mathrm{Wu} \& \mathrm{Du}$ 2008). All these changes in grassland ecosystems have fundamentally changed their use.

Grasslands degradation and their consequences need to not only be analysed locally by focusing on specific degradation processes, but also at landscape, regional and coarser scales. Various methods, including remote sensing, plot-based measurements, experiments, expert knowledge and assessment of stakeholder experience (Reed et al. 2009) should be used. My research aims to better understand the dynamics of degraded grassland and to mitigate degradation processes and facilitate restoration.

\subsection{The study area: the Inner Mongolia Autonomous Region}

The grassland extent of the Inner Mongolia Autonomous Region (IMAR) is the largest in China. It covers a total of 7.9 million $\mathrm{km}^{2}$, which is two-third of IMAR's total territory (Figure 1.1). Most Chinese grassland types are found in IMAR. The major ones are 'typical steppe' (35\%), 'semi-desert and desert steppe' (21\%) and 'meadow steppe' (10\%) (Zhao et al. 2007). IMAR's grasslands are used for livestock 
husbandry and crop farming. These activities currently shift from individual farms to larger operations as the population that is engaged in husbandry and farming, has substantially decreased over the last fifteen years (Cheng et al. 2001).
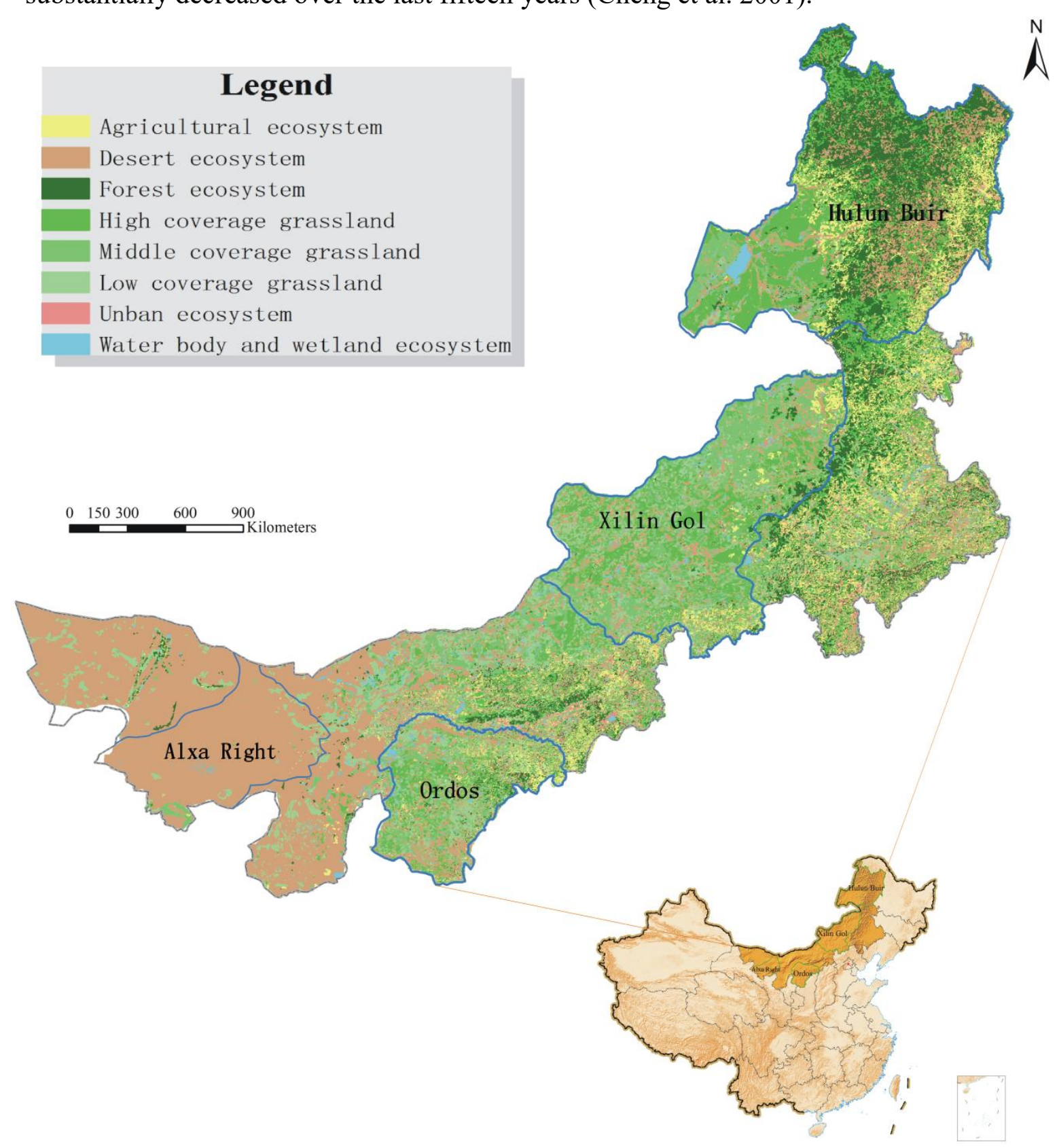

Figure 1.1 The location of the study areas in the Inner Mongolia Autonomous Region

For my PhD study, four typical sites (three sites in city/league level, one supplemental site in banner level) are selected from southwest to northeast gradient, which captures the different uses and dependency of ecosystem services. These sites are:

(1) Hulun Buir $\left(265000 \mathrm{~km}^{2}\right)$ is located in the north-eastern IMAR. This site is a transitional pastoral area where the meadow steppes are the most productive type of grasslands. Hulun Buir has become the largest milk and meat producer in China.

(2) Xilin Gol (202 $600 \mathrm{~km}^{2}$ ), which is IMAR's north central area, is dominated by typical steppe. Half of this region was a traditional pastoral area and the other half was a farming area. 
(3) Ordos, (86 $\left.800 \mathrm{~km}^{2}\right)$, which is located in IMAR's south-western area, is dominated by semi-desert steppe and has the most arid ecosystem with the lower biomass than Hulun Buir and Xilin Gol. Ordos leads the economic development due to the rapid development of mining.

(4) Alxa Right (banner level) in western of Ordos $\left(72600 \mathrm{~km}^{2}\right)$ was selected as supplemental site to capture the herder's adaptive strategy in extreme dry climate condition (only in chapter 4). Alxa Righ is bounded by the Baba Jilin desert to the north, is covered by desert steppe and desert, and has an arid climate. Traditionally, local herders were described as the people who live on the back of camels, but most of them no longer raise camels but only raise a few cattle, goats and sheep. Besides small gardens for household use, no significant agriculture exists.

\subsection{Changes in National Land-use Policies in the study area}

The development of China's land-conservation policies can be divided into four stages: (1) the start-up period after the founding of New China (October 1949 to September 1956), (2) the all-round construction period (September 1956 to May 1966), (3) the Cultural Revolution period (May 1966 to October 1976) and (4) the stagnation period (November 1976 to November 1978) (Jiang 2003). Starting from the land reform in 1950, the development of China's land policies has gone through the collective land-ownership period and the peoples' commune period. From the 1950 s to the 1970 s, afforestation and dam construction projects were limited to a few places. After adopting the reform and accessibility policies in 1970, the government put forward the land-reclamation, farmland-construction, ecological restoration and agricultural development-acceleration policies. In 1978, the State Council approved the Three North Shelterbelt Project, which aimed to increase forest cover. In June 1986, the rural household responsibility system, which should halt ecosystem degradation, was formally established for the whole of China.

Intensive land reclamation and utilization resulted in land degradation. This intensified the conflicts between land use and environmental protection. To protect farmland and promote sustainable agriculture, the State Council announced in July 1994 a national policy on demarcation, protection and supervision of farmland for the whole of China. In August 1998, the local governments in, for example, Inner Mongolia, Gansu, Shanxi and Sichuan, should restore reclaimed lands (including cultivated land), which had adverse environmental effects, back to forests and grasslands. In 2000, the conversion of degraded farm land into forests (and grasslands) was approved by the central Chinese government for most of China (i.e. the so-called 'Sloping land conversion program'). In September 2006, the State Council furthermore set a goal that all arable land extent should be kept at $\geq 120$ million ha for food security (i.e. 93.8\% of the total arable land in 2000). Table 1.1 summarizes major national milestones in evolution of China's land policies since 1978.

IMAR'S grasslands have had a unique role in the evolution of China's land policy over the last half century. Due to unfavourable natural conditions (e.g. drought and sand storms) and human impacts (e.g. deforestation, overgrazing and land reclamation), the severity of environmental problems, such as soil erosion, land degradation and alkalization, particularly increased in IMAR. Although several major land policies have been implemented in this region, the region's most influential 
program is the Returning Grazing Land to Grassland (RGLGP). This is detailed below.

Table 1.1 Development of National land-use policies in the Inner Mongolia Autonomous since 1978

\begin{tabular}{|c|c|c|c|}
\hline & Year & Description of the policy & Aim of the policy \\
\hline \multirow[t]{3}{*}{$\begin{array}{l}\text { Resources } \\
\text { Development }\end{array}$} & 1978 & $\begin{array}{l}\text { Three North Shelterbelt } \\
\text { Project }\end{array}$ & $\begin{array}{l}\text { Fundamentally change the hazards of sand } \\
\text { storms and condition of soil and water loss in } \\
\text { the Chinese northwest, North and northeast } \\
\text { regions. }\end{array}$ \\
\hline & 1986 & $\begin{array}{l}\text { The Rural Household } \\
\text { Responsibility System }\end{array}$ & $\begin{array}{l}\text { Mobilize the enthusiasm of the farmers, } \\
\text { liberating agriculture productivity, to solve } \\
\text { the problem of food and clothing of farmers. }\end{array}$ \\
\hline & 1994 & $\begin{array}{l}\text { Regulations on the } \\
\text { Protection of Basic } \\
\quad \text { Farmland }\end{array}$ & $\begin{array}{l}\text { Special protection of basic farmland to meet } \\
\text { the needs of China's future population and } \\
\text { national economic development of } \\
\text { agricultural products to promote the } \\
\text { sustainable development of agricultural } \\
\text { production and other economic sectors. }\end{array}$ \\
\hline \multirow[t]{2}{*}{$\begin{array}{l}\text { Protection } \\
\text { (conservation, } \\
\text { restoration } \\
\text { and } \\
\text { rehabilitation) }\end{array}$} & 2000 & $\begin{array}{l}\text { Sloping land conversion } \\
\text { program (SLCP, also called } \\
\text { Grain for Green Project) }\end{array}$ & $\begin{array}{l}\text { To alleviate the situation of soil and water } \\
\text { loss on sloping farmland in the upper reaches } \\
\text { of the Yangtze River and the Yellow River, to } \\
\text { improve the ecological environmental } \\
\text { conditions in western China, adjust the } \\
\text { structure of agricultural economy and } \\
\text { promote the sustainable development of the } \\
\text { whole society. }\end{array}$ \\
\hline & 2003 & $\begin{array}{c}\text { Returning Grazing Land to } \\
\text { Grassland } \\
\text { Program(RGLGP) }\end{array}$ & $\begin{array}{l}\text { Limit use of grasslands to protect the } \\
\text { grassland ecosystem (c.f. Appendix 1). }\end{array}$ \\
\hline \multirow[t]{3}{*}{$\begin{array}{l}\text { Green } \\
\text { (sustainable) } \\
\text { development }\end{array}$} & 2007 & $\begin{array}{l}\text { Further improvement of } \\
\text { SLCP }\end{array}$ & $\begin{array}{l}\text { To consolidate the achievements of returning } \\
\text { farmland to forests and to solve the problems } \\
\text { of farmers' living and long-term livelihood. }\end{array}$ \\
\hline & 2011 & $\begin{array}{l}\text { Further improvement of } \\
\text { RGLGP }\end{array}$ & $\begin{array}{l}\text { Taking the social economic issue in the } \\
\text { program, improving the payment } \\
\text { mechanism. }\end{array}$ \\
\hline & 2014 & $\begin{array}{l}\text { Provisions on the } \\
\text { Economical and Intensive } \\
\text { Use of Land }\end{array}$ & $\begin{array}{l}\text { To carry out the policy of rational land } \\
\text { utilization and effectively protect arable } \\
\text { land, enhance the carrying capacity of land } \\
\text { resources for economic and social } \\
\text { development, and promote the construction } \\
\text { of an ecological civilization. }\end{array}$ \\
\hline
\end{tabular}

\subsubsection{Goals and developing process of 'Returning Grazing Land to Grassland' policy}

Due to the impact of both natural and human factors, such as overgrazing, $90 \%$ of usable natural grasslands have been affected by desertification by different extents. This not only restricts the development of animal husbandry and affects herders' incomes and regional economic development, but it also threatens ecological security. In 2003, eleven provinces and autonomous regions in western China began to implement the pasture measures of the RGLGP. In August 2011, the 'returning grazing land to grassland' policy was further improved. This policy is designed to restore grasslands, improve their productivity and promote the coordinated development of grassland ecology and animal husbandry by means of constructing fences, improving re-seeding methods, implementing grazing bans, rotational grazing and other measures, while simultaneously providing participating farmers and herders with economic compensation. The targets at the early stage of this policy- 
implementation process are to restore degraded grasslands and prairies, further improve the household grassland-restoration responsibility system, establish grassland protection, forage-livestock balance and rotational grazing systems, guide farmers and herders to change production methods, improve livestock species and raise and stabilize farmers' income.

\subsubsection{Main measures and scope of implementation of 'Returning Grazing Land to Grassland'policy}

In 2003, the State Council issued measures to return grazing land to grassland. In 2011, the council proposed a new initiative to improve the 'Returning Grazing Land to Grassland' policy. Grazing bans and rotational grazing are the main used measures and most areas in IMAR have implemented the program but Xilin Gol and Ordos are the most advanced (Appendix 1).

With grassland restoration, soil erosion by wind and water was reduced and biological diversity significantly increased (Wang 2006). From 2000 to 2010, the vegetation cover in Ordos grasslands increased from $30 \%$ to over $75 \%$, the forage yield of mountain ridge grassland and sandy grassland increased by $30 \%$ and the grassland community structure significantly improved (Liu 2010). On the social-economic aspect, Gao et al. (2013) studied the villages (gacha) Uxin Banner and Ordos City and showed that animal husbandry still mainly provides income to herder families. Their income rose from 1998 to 2010 and slightly decreased after 2005. Fodder shortage caused by grazing bans and grassland protection resulted in a rise in feed costs (e.g. feed purchase price, transportation costs and the amount of labour). For herders, who depend solely on forage offered by the state, maintaining the original livestock numbers was impossible and thus their income decreased (Bao 2006; Li et al. 2005). Other surveys found that the proportion of income from other herding services in the total income of herder families increased by $8 \%$ and the proportion of animalhusbandry income fell by $14 \%$. This indicates the diversification of the income structure of herder families (Tian 2011).

\subsubsection{Shortcomings of the 'Returning Grazing Land to Grassland' policy}

This section is based on previous studies (e.g. Bao 2006; Zhen et al. 2010a), which show that some problems emerged when implementing the RGLGP. These problems are summarized below.

First, the compensation standards are arbitrary and subsidy regulations are inflexible (Nie 2008). For example, in IMAR's relatively underdeveloped western pastoral areas, the capacity of herders to invest in grassland restoration is very limited because the current subsidies do not support needed income levels. Without economic benefits, mobilizing herders to participate in the program is difficult (Fan 2003). Many different grassland types under this program have different degradation severities and carrying capacities, so subsidy standards should be better differentiated.

Second, the Program fails to properly resettle affected people. So far, no systematic and effective resettlement program is formulated. Unsolved problems include how herders in banned-grazing areas shall be transferred; whereto they are resettled or migrated; how their living allowance are calculated; whether their living allowances increase with increasing price levels; and how to provide them with housing and medical insurances. These problems have hindered the effective implementation of the Program (Hanguan et al. 2003). 
Third, appropriate measures to restore degraded grassland ecosystems should be regional specific and cover both the extent and the causes of degradation (Jun et al. 2007), but the program does not provide such diversified grassland restoration methods. In addition to the required measures, grassland improvement, desertification control and rodent and pest control should also be included (Xu et al. 2014).

Finally, several social issues are also emerging. The program directly and immediately affects the herders' income level. Some herders allow their livestock to graze areas where grazing is prohibited, and some herders do not like this. This creates conflicts between the management personnel and herders, and likely result in social unrest ( $\mathrm{Li}$ et al. 2005). The program also changed traditional production methods and living habits of herders. The government should thus pay attention to these social and emotional problems (Bao 2006).

\subsection{Changes in the local socio-ecological systems in the study area}

As the changes of policy intervention coincide with other divers (e.g. social development and urbanization), the local social system has adapted to manage household practices to effectively deal with the ecosystem dynamics based on ecological knowledge. Primary social (human) systems involve property rights, use of land and natural resources, and world views and ethics concerning the environment and resources (Appendix 2). Ecological systems refer to the ecosystems and their environments (Ostrom 2009). When these systems are combined, socio-ecological systems emerge. In IMAR, such socio-ecological systems are rapidly transformed from traditional self-sufficiency systems in the 1950s to important milk and mutton producing systems now. The will be detailed below.

\subsubsection{The socio-ecological system in 1950s}

In the 1950s, IMAR's local people depend mainly on husbandry (Appendix 3a). The local grassland ecosystems supplied most forage needed for their households and thus support the local livelihoods and their primarily nomadic way of life. Their whole economic system was rather closed with limited trading (i.e. only leather products were traded). They mainly consumed meat and milk. Horses and camels were the main transportation means and they were also used for their 'free choice grazing' and regular moving activities (Zhen et al. 2010a). Because of the region's low population density, local ecosystems were stable and people lived within the natural boundaries.

\subsubsection{The socio-ecological system in 1995}

Similar to other regions in the world, increased human demand on natural resources rapidly led to more intensive land uses, such as intensive grazing and farming and more urban areas (Appendix 3b). This has led to overgrazing, deforestation since 1990 (Lu et al. 2011). Grassland degradation created many problems, such as soil erosion, water scarcity (both for agricultural and ecological water needs), reduced soil nutrients and loss of productive soils (Kang et al. 2007). IMAR's ecosystems are frail with a thin layer of loose sand that are easily blown by the strong spring and autumn winds (e.g. Zhang 1998), and increased erosion risks when the soil is exposed. As the government implemented the 'Protection of Basic Farmland' policy in 1994, the local people also have reclaimed grasslands for plant cultivation. Their market-trade system was facilitated by the improved transportation systems. This stimulated the local people to produce more meat, milk products, leather or wool and enhance their incomes. 


\subsubsection{The socio-ecological system in 2010}

Since ecosystem degradation adversely affects the productivity and human well-being, local, provincial and state governments urgently want to control this trend (Chen 2005). To alleviate ecosystem degradation and protect the Inner Mongolian grasslands, the Chinese government started to implement ecological rehabilitation projects around 1998 (Yin and Yin 2010; König et al. 2014a). During this grasslandrestoration process, the economic systems totally changed. Trading increased incomes and satisfied the increased daily household consumption. Local people stop traditional nomadic grazing and start settling and modernized their lives. In addition, artificial landscapes were developed for tourism (Appendix 3c). Since, IMAR has rapidly become a well-known tourist attraction.

\subsection{Problem statement}

Ecological problems that are caused by ecosystem degradation, are serious in IMAR's grasslands (Abubakar 1997; Wang and Cheng 1999; Gu et al. 2008; Benjamin 2012). The main problems include soil desertification (Hoffmann et al. 2008; Li et al. 2003), decline in the water balance (Ohte et al. 2003; Chaolun et al. 2008; Yue et al. 2008; Wilske et al. 2009; Qiu et al. 2011), changes in vegetation (Katoh et al. 1998; Zhao et al. 2004; Chen et al. 2005; Bai et al. 2010; Dong et al. 2011; Zhao et al. 2011; Yan et al. 2012) and climate change ( $\mathrm{Li}$ et al. 2012; Shi et al. 2012; Barthold et al. 2013). All the studies on these problems show that burgeoning water demands and the limited availability of clean fresh water are a major consequence of IMAR's ecosystem degradation and could well aggravate the degradation. Until 2010, the total area of degraded grasslands in IMAR has increased to 25 million ha. This covers more than a quarter of the total useable grasslands. As a result, 400 million people are likely affected directly or indirectly and many wildlife species have moved to other areas or have become extinct. The direct annual economic losses are estimated at CNY 54 billion ( 7.8 billion US\$).

The degradation of the IMAR's grasslands and its ecosystem services thus regionally constrain further social and economic development and human well-being. IMAR's grassland ecosystems supply almost all the fodder needed for livestock production and support the region's herders and their primarily nomadic lifestyle in many ways (Zhen et al. 2010a).

The Chinese government has been implementing ecological rehabilitation projects in the area since 1998 (Yin and Yin 2010; Li et al. 2007; Li and Huntsinger 2011; Hoffmann et al. 2011; König et al. 2014a), but these projects often focus on single environmental issues (i.e. desertification, afforestation and grazing) and neglect the needs of local communities. Local herdsmen, for example, often refuse to change their lifestyle and continue using the land and its ecosystem services in traditional ways. To analyse these complex circumstances, a research project of Chinese Academy of Sciences (CAS) started in 2011 to address the "Use Patterns of Ecosystem Services and its Environmental-Effects Assessment." This CAS project initially focussed on a case study in the Inner Mongolian grasslands and aimed to: (1) analyse the utilization patterns of ecosystem services and their spatial and temporal evolution; to (2) reveal the environmental effects of human exploitation of selected ecosystem services; and to (3) develop a computer model (i.e. a simulation platform) to analyse environmental impacts based on different ecosystem utilization patterns to support policy making. 
This $\mathrm{PhD}$ research is part of this overall CAS project and addresses several important problems: the environmental protection programs that are implemented in the Inner Mongolian grasslands, need to be more integrated. Their social, economic and environmental effects (costs and benefits) should be more clearly identified and quantified, and trade-offs between the ecosystem services and other management goals (including conservation) should be better understood. Also, stakeholder perceptions of rangeland management and Payments for Ecosystem Services (PES) have thus far not been studied. This makes developing more sustainable livelihood and management strategies difficult.

\subsection{Research objectives and research questions}

In accordance with the above described issues and challenges, my $\mathrm{PhD}$ study aims to analyse the interactions between the people and the ecosystems in IMAR in an integrated manner. The study especially focuses on analysing the different utilization patterns of ecosystem services and the livelihood dependence of local herders and other stakeholders in four selected study sites (Figure 1.1). Based on these field studies, I explore how the resulting insights can be used to develop more sustainable management practices of the Inner Mongolian grasslands.

To achieve this objective, the following research questions (RQs) will be addressed and investigated for the three study sites:

RQ1 What are the spatial and temporal variations of land-cover changes since 1998, when the restoration program started, and what are the effects on habitat quality?

RQ2 a) How have basic household consumption patterns changed under different management regimes in the selected study sites?

b) What are the main factors affecting current household consumption?

RQ3 What are impacts of changing food consumption patterns on water resources conservation?

RQ4 How has people's livelihood dependence on local ecosystems and their utilization patterns changed in the last 15 years?

RQ5 What are the trade-offs between selected ecosystems services as a consequence of the changing grassland utilization patterns?

RQ6 What recommendation can be given to design feasible strategies and incentives for sustainable management of IMAR's grassland ecosystems?

The ultimate goal of my $\mathrm{PhD}$ study on ecosystem services use in IMAR is to contribute to improved management of the ecosystems and the development of a truly coupled human and ecological system. An effective management framework should have a broad spatial coverage extending from sites to landscapes, biomes and continents, and include active participation of inhabitants, their knowledge and technical know-how, since their input is crucial for effective ecosystem conservation and management.

\subsection{Research concepts and framework}

For my research, I used the Ecosystem Approach (CBD 2000; de Groot et al. 2002) and the concept of Ecosystem Services (Millennium Ecosystem Assessment 2005; TEEB 2010) as the main elements of a comprehensive framework to investigate the effects of land-use change on ecosystem services and peoples' livelihood. 


\subsubsection{Conceptualizing socio-ecosystem interaction}

People interact with natural components of ecosystems in coupled socio-ecological systems (Liu et al. 2007). Ecosystems, which are self-organized and functional units of the natural world, provide a variety of services that are important to maintaining human livelihoods (Millennium Ecosystem Assessment 2003). A core component in socio-ecological systems is human utilization of ecosystem services. With population growth and increasing demands for ecosystem services, ecosystems are increasingly pressurized and this has led to loss and degradation of two-thirds of the world's ecosystems services (Millennium Ecosystem Assessment 2005). This growing demand can no longer be met by tapping unexploited resources (Ayensu et al. 1999). The total use of ecosystem services is estimated to increase with population increase and a large-scale ecosystem collapse this century within 60 years is likely if current global use levels are not halved (IPBES 2018).

Ecosystem-Services Analysis can be divided into three main parts in general. The first part focuses on the natural parts of ecosystems by analysing the interactions between ecosystem elements, such as water, soil, plants and animals. Many chemical and physical ecological processes are described and their interrelations explored (Schultz et al. 2007; Benjamin et al. 2012). The second part of ecosystem-services studies involves their valuation. This requires an interdisciplinary research that combines both of ecological, social and economic approaches. The resulting findings are relevant for both scientists and decision makers, and indicate the importance of ecosystem services and can inform on better management actions (Costanza et al. 1998; de Groot and Hein 2007; Bagstad et al. 2013).

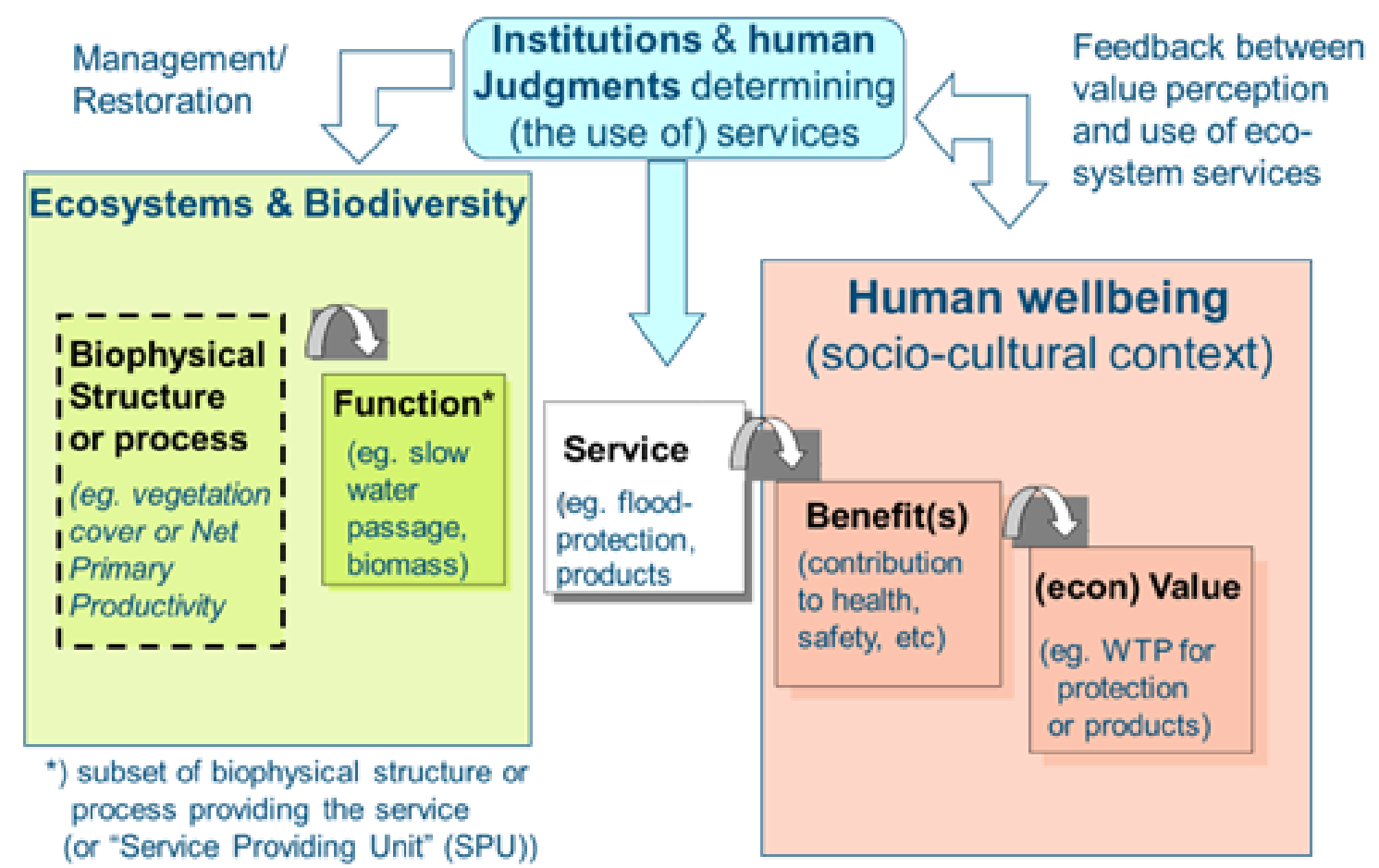

Figure 1.2 The pathway from ecosystem structure and processes to human well-being (Adapted from de Groot et al. 2010)

The last part analyses interactions between humans and ecosystem services. Although some scholars have studied coupled socio-ecological systems as complex adaptive systems (Levin 1999; Gunderson and Holling 2001), most of the previous studies 
focused on either ecological variables (e.g. landscape patterns, wildlife habitat and biodiversity) or human variables (e.g. socio-economic processes, social networks, agents and governance) (Schultz et al. 2007). The links are partly discussed but only a few are actually quantified (Worm et al. 2006; Nelson et al. 2009; Braat and de Groot et al. 2012; Bagstad et al. 2013). Although an increasing number of interdisciplinary programs have integrated ecological and social sciences to study coupled socioecological systems (Liu et al. 2007), variables that link natural and human components (e.g. use of ecosystem services), are insufficiently studied. TEEB (2010) developed a framework of human well-being dependencies and uses of ecosystem services and benefits for improving human understanding of interrelations between ecosystems and human consumption (Figure 1.2). Such a framework provides a scientific basis for decision making on human impact on ecological system, and aims to solve the conflict between conservation and livelihoods.

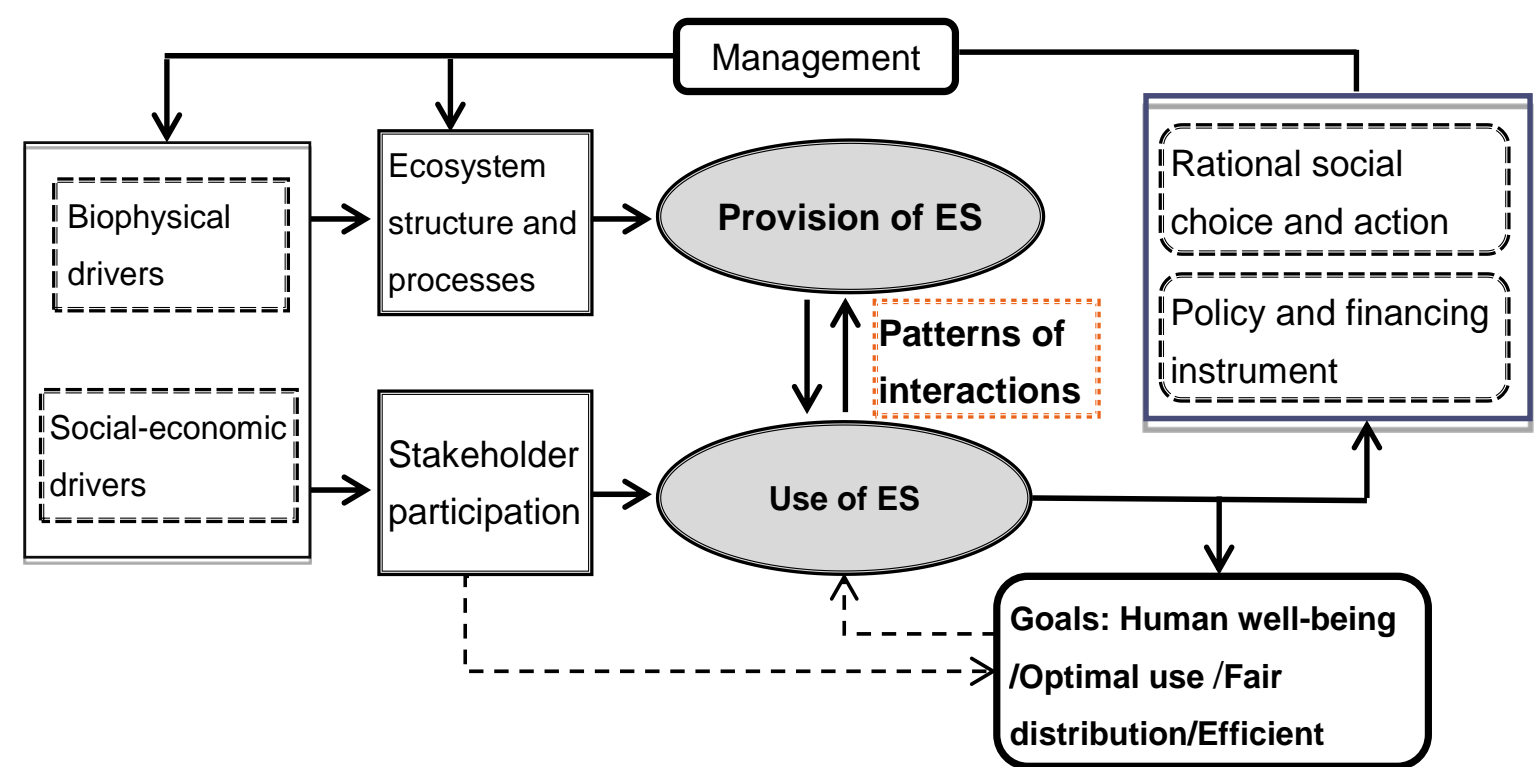

Figure 1.3 The conceptual framework for socio-ecosystem interaction

The conceptual framework of my thesis is developed (Figure 1.3) to analyse interactions between provisioning ecosystem services, use of ecosystem services and management of ecosystem services. For analysis of human use of and reliance on ecosystem services in a specific area, identifying site specific categories of ecosystem services first is essential. This should include all the different services. Key socioeconomic factors that drive human use of ecosystem services, include access to ecosystem services, income level, education level, policy intervention and institutional settings, stakeholders' behaviour and perceptions, their preferences and willingness to pay (WTP) for use of ecosystem services (or willingness to accept (WTA) for losses of use of ES) and technical and cultural difference (Loomis et al. 2000; Zhen et al. 2014).

\subsubsection{Research framework}

Despite the essential role of ecosystem services in sustaining all human activities in IMAR, they are often ignored in the consumer' choice in allocating the natural resources, even in methods that should encourage sustainability. Therefore, my $\mathrm{PhD}$ study is based on the first hand data from householder surveys. I start from the basic Ecological and Social Development Indicators that describe the influence of human 
utilization patterns of ecosystem services. And subsequently I investigated the structural variation of IMAR's regional social-ecological system by linking it to ecosystem service use for the social and ecological analysis. My $\mathrm{PhD}$ framework is organised into four major steps (Figure 1.4, Appendix 4).

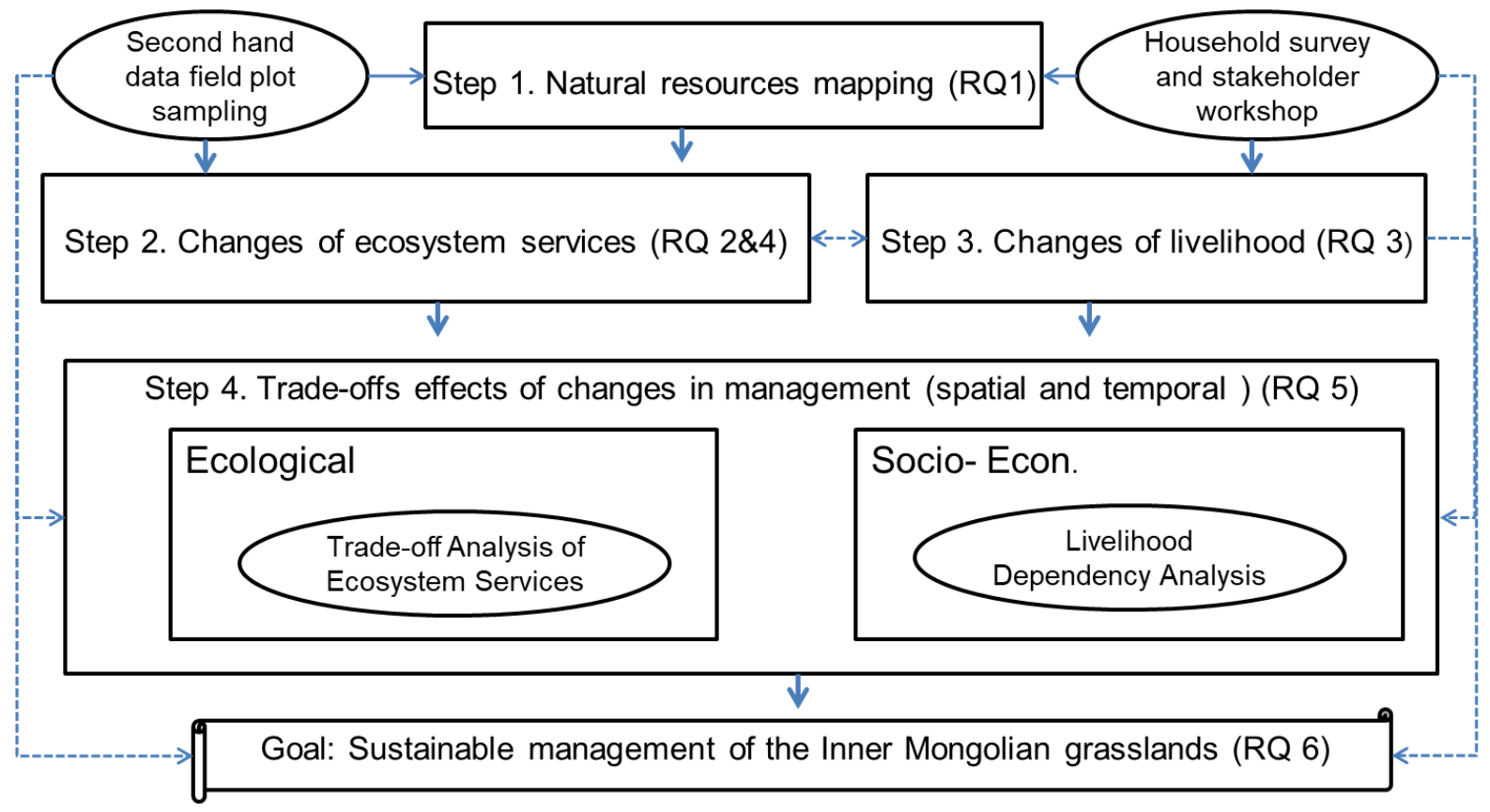

Figure 1.4 Research framework and steps

\subsection{Methodology}

This section describes which methods were applied to answer the various RQs which largely coincide with the four steps (Figure 1.4):

\subsubsection{Natural resources mapping}

The Natural-Resources-Mapping method (Tallis and Polasky 2009) was adopted for my $\mathrm{PhD}$ research. This is a specific tool to map different natural resources and human-constructed features in the landscape. It is based on local knowledge, scientific literature reviews and evaluating relevant books and documents from main involved management and governmental organizations. This information has been complemented by Land-Use Cover-Change (LUCC) data which were provided by the Institute of Geographic Sciences and Natural Resources Research (IGSNRR). Statistic data of specify study sites were provided by local government. I organized workshops with stakeholders to extract information on implemented policies and projects. Additional information on past and present land-use changes for different settlements and environmental circumstances was gathered from government report.

\subsubsection{Livelihood dependency analysis}

Livelihoods comprise the activities that people do to earn a living (DFID 2001; Sternberg et al. 2010). Livelihood analysis can be divided into two key components: livelihood assets and livelihood strategies to deal with local ecosystem. Livelihood assets are defined as the options and constraints available to households and individuals in their livelihood strategies. Livelihood strategies are the behavioural strategies and choices adopted by people to make a living, e.g. how people consume 
and preserve ecosystem services and goods to satisfy their needs. I concentrated in particular on the use of ecosystem goods (provisioning service) to illustrate livelihood dependence on local ecosystem. The main analysis focuses on five main parts: (1) Changing of cultivation activities (alternatives of livestock husbandry and crop farming activities); (2) Changing of asset compositions and source of income (job, agriculture or others); (3) Changing of diet; (4) Changing of fuel consumption (alternative of dung-based bio-fuel, coal, gas and electricity); and (5) Usage of water resources. In addition, the main divers (e.g. ecological condition, policy, climate or others), changing household's behaviour and perspectives of herds were also interpreted.

Household-dependency analysis was used for this researh to identify and evaluate the potential socio-economic and cultural impacts of a proposed development on the lives of people, their families and their communities. In the past, many studies focused only on direct biophysical impacts of proposed developments on society and economic activities (i.e. impacts on water, air, land, flora and fauna). The indirect impacts were often ignored. I have used household-dependency analysis method for my research to analyse effects of developments and influences on human well being in the past fifteen years in IMAR (before and after the implementation of restoration policies that started in 1998). The assessment process relies heavily on involving community members who may be affected by the development, so stakeholder interviews are an important part of the assessment.

\subsubsection{Ecosystem-services analysis}

Ecosystem-services analysis involves the translation of information on complex ecological structures and processes into a limited number of ecosystem functions and services. Ecosystem services are defined as "the contribution of ecosystems to human well-being" (TEEB 2010). Based on reports of The Economics of Ecosystems and Biodiversity (TEEB 2010) and the Millennium Ecosystem Assessment ((Millennium Ecosystem Assessment 2005), ecosystem services can be classified into four main categories: provisioning services, regulating services, supporting services and cultural $\&$ amenity services.

Ecosystem management depends on spatial and temporal fluctuation in the use of ecosystem services (Zhen et al. 2008; Liu et al. 2007). The function model below is formulated to express factors influencing the use of ecosystem services in a specific region:

$$
\mathrm{E}_{\mathrm{u}}=\mathrm{E}_{\mathrm{du}}+\mathrm{E}_{\mathrm{idu}}
$$

Where, $E_{u}$ is total use of ecosystem service, $E_{d u}$ is direct use of ecosystem service and $E_{\text {idu }}$ is indirect use of ecosystem service.

Classifying of direct and indirect use of ecosystem services (Table 1.2) always delivers a relative added value as it depends on the consumers' selection of the services. For example, wood or timber from the forestry would not be available to provide other services once they are consumed as products. Meanwhile, direct and indirect use of services is sometimes interrelated with each other. In Wolong natural reserve in China, the households' use of fuelwood affects panda habitat (Liu et al. 2007), implying that direct use of ecosystem services (fuelwood) is affects an indirect use (e.g. biodiversity) of a specific region. Moreover, interrelations between direct and indirect use also lie in conversion of the services. For instance, converting of a forest into agricultural land can increases food supply, decreases wood and timber 
supply and other ecosystem services, such as clean water, biodiversity or flood control ((Millennium Ecosystem Assessment 2005). The final benefits depend on the known and unknown values of all these services.

Table 1.2 Major uses of dry-land ecosystem services identified in the literature

\begin{tabular}{|c|c|}
\hline Direct use of services (Source) & Indirect use of services (Source) \\
\hline Provision services & Support services \\
\hline Agriculture & Biodiversity (Kaplowitz and Hoehn 2001) \\
\hline Food crops (MA 2005; Kaplowitz and Hoehn 2001; Deutsch and & Nursery (De Groot 2002) \\
\hline Folke 2005; de Groot and Hein 2007) & Primary production (MA 2005) \\
\hline Fruit trees (; de Groot and Hein 2007) & Soil formation (Costanza et al. 1998) \\
\hline Animal feed (Deutsch and Folke 2005; de Groot and Hein 2007) & \\
\hline Vegetables (MA 2005; Kaplowitz and Hoehn 2001) & Regulation services \\
\hline Animal husbandry & Carbon sequestration (Kaplowitz and Hoehn \\
\hline $\begin{array}{l}\text { Meat products (MA 2005; Deutsch and Folke 2005; de Groot } \\
\text { and Hein 2007) }\end{array}$ & 2001; Turner et al. 2003) \\
\hline Milk and egg products (MA 2005; Deutsch and Folke 2005) & Water purification (Kaplowitz and Hoehn 2001) \\
\hline Fuel & Flood prevention (MA 2005) \\
\hline Wood (MA 2005;Costanza et al. 1998; Madubansi and Shackleton & Nutrient regulating (De Groot 2002) \\
\hline 2007; Brouwer and Hoorweg 1997; de Groot and Hein 2007) & Water regulation (TEEB 2010) \\
\hline Dung (MA 2005; Madubansi and Shackleton 2007; Brouwer and & Waste treatment (Costanza et al. 1998) \\
\hline Hoorweg 1997) & Climate regulation (MA 2005; Costanza et al. \\
\hline Forestry & 1998) \\
\hline Firewood (MA 2005; Kaplowitz and Hoehn 2001; Deutsch and & \\
\hline Folke 2005; Madubansi and Shackleton 2007; Brouwer and & Culture services \\
\hline $\begin{array}{l}\text { Hoorweg 1997) } \\
\text { Timber (Kanlowitz and Hoehn 2001. Turner et al 2003) }\end{array}$ & Ecotourism (Kaplowitz and Hoehn 2001) \\
\hline $\begin{array}{l}\text { 1 1moer (Kaplowitz and Hoehn 2001; Turner et al. 2003) } \\
\text { Roofing materials (Kaplowitz and Hoehn 2001; de Gi }\end{array}$ & Recreation (Kaplowitz and Hoehn 2001; Turner et al. \\
\hline Hein 2007) & 2003; Costanza et al. 1998) \\
\hline Fibre & \\
\hline Wood, jute, cotton, hemp, silk, wool (MA 2005) & \\
\hline $\begin{array}{l}\text { Fresh water (MA 2005; Kaplowitz and Hoehn 2001; Deutsch and } \\
\text { Folke 2005) }\end{array}$ & \\
\hline
\end{tabular}

Use of ecosystem services is a function of the following factors;

$$
E_{\mathrm{u}}=\mathrm{f}\left(\mathrm{X}_{\mathrm{av}}, \mathrm{X}_{\mathrm{ac}}, \mathrm{X}_{\mathrm{hz}}, \mathrm{X}_{\mathrm{att}}, \mathrm{X}_{\mathrm{bev}}, \mathrm{X}_{\mathrm{inc}}, \mathrm{X}_{\mathrm{pri}}, \mathrm{X}_{\mathrm{pol}}, \ldots, \mathrm{X}_{\mathrm{n}}\right)
$$

Where, $X_{a v}$ is the availability of ecosystem services and goods, $X_{a c}$ is accessibility of the services and goods, $X_{\mathrm{hz}}$ is household size, $\mathrm{X}_{\text {att }}$ is attributes of consumers to the ecosystem services and goods, $X_{\text {bev }}$ is consumers' behaviour, $X_{\text {inc }}$ is income, $\mathrm{X}_{\text {pri }}$ is price, $\mathrm{X}_{\mathrm{pol}}$ is policy variable.

Availability of ecosystem services determines the spatial and temporal variations of utilization patterns and the total usage in a region. Accessibility can be expressed as the distance between consumers' locations and services. This distance is normally non-linear and a threshold is usual assessed to quantitatively measure accessibility. For example, in the China Wolong natural reserve, a distance threshold is assigned to analyse the use of fuelwood and panda protection (Liu et al. 2003). Barbier's study in Thailand confirms that the 'accessibility' of mangrove areas is an important determinant of mangrove clearing for shrimp farming (Barbier 2005).

The number and distribution of households by size is an important factor driving use of ES and ecosystem change. Several studies have approved relationships between population size, household size and household basic consumption (Zhen et al. 2008; Liu et al. 2007). First, more households mean more housing units, thus generally increasing the amount of land and materials needed for house construction. Second, smaller households have lower efficiency of resource use per capita because ecosystem services are shared by more people in larger households (Liu et al. 2003). 
Policy could be a factor affecting household size. For instance, Natural forest conservation program in Wolong of China led to a large number of new households in 2001 because many households decided to split into smaller ones to more effectively capture subsidies (20\% to $25 \%$ of the average household income) given to households as part of the program, that probably causing increased demand for fuelwood and land for house construction (Liu et al. 2001).

Income level affects the purchasing power, and the consumers' WTP and WTA. The Millennium Ecosystem Assessment (2005) concluded that wealthier populations normally consume more ecosystem services than poorer ones. They also control more ecosystem services than poor people. For instance, the rich can buy a service from elsewhere if it is not available locally. Income also influences demand for and the structure of the ecosystem services. A study in middle-income developing countries found that rising incomes will probably lead to increased demand for protein in human diets (Robertson and Swinton 2005). The resulting change in price will have strong impacts on utilization patterns. Similarly, Xu et al. (2006a) found that the price of electricity affected consumer's use of fuel wood in the Wolong natural reserve. Consumer behaviour can be predicted using consumer preferences (i.e. consumer choices and limitations) and the possibility of use of ecosystem services.

\subsubsection{Trade-off analysis}

To analyse trade-offs I organised workshops in the study area in 2012 and 2013, provisioning services, regulating services and supporting service habitat service were perceived to be of high importance compared with all of other ecosystem services. My research therefore mainly focus on (1) provisioning services, including food, water, fuel (such as dung-based bio-fuel, electricity and gas and coal) and other raw materials derived from Net Primary Productivity (NPP); (2) regulation services (nutrition regulation, including maintenance of the $\mathrm{N}, \mathrm{K} \& \mathrm{P}$ flows through the ecological process from soil to vegetation, then to animal and human); (3) supporting services (habitat services, including importance for biodiversity protection and ecosystem functional types of organisms and their traits; soil retention services (soil type, soil water content and soil bulk density) and bio-mass supporting services for fodders of livestock).

To analyse the trade-offs between the selected ecosystems services in terms of the effects of utilization patterns in the study area, I carried out annual field visits to take plot samples (of soil and vegetation) and conduct interviews with local communities and experts. To analyse the provisioning services, first-hand data of household basic consumption were collected by questionnaire. Plot sample data (e.g. soil water content, soil nutrition and soil bulk density) was measured for the analysis of supporting and regulation services. A series of interviews with local communities and experts were conducted to gather the information of habitat and biodiversity, this interview data together with plot sample data of vegetation (e.g. types and amounts) accounted for the analysis of habitat services (part of supporting services). Moreover, data from national statistical offices was used to support the whole analysis process, especially for the analysis of changes over time.

\subsubsection{Investigating stakeholders' WTP and WTA}

Contingent valuation method (CVM) was used to quantify each household's WTA and each government official's WTP for grassland conservation. To mitigate the hypothetical bias, stakeholder surveys (in 2008 and 2012) and follow-up questions 
were used to determine the potential WTA and WTP for grassland conservation for the herders and the government officials respectively. The formal survey started with a description of the purpose of the survey to participants, continued with gathering of basic demographic data, and concluded with questions intended to reveal the participant's WTA for not overgrazing or not grazing in specific plots, based on the expected annual bid values $\left(10,20,40,80,120,160,200\right.$ and 240 US $\$$ ha $\left.^{-1}\right)$. The expected bids were determined based on the income losses that resulted from land conservation. In each questionnaire, the respondent was asked a follow-up question such as the following: "If grazing activities are restricted to conserve grasslands and your financial losses should be compensated, would you be willing to accept/pay [amount] for the economic loss/conservation to meet this end? (yes/no)." Respondents who answered 'yes' to the question were then asked to indicate their willingness by choosing either yes or no in response to the corresponding bid value. For the analysis of WTA, a logit model (Hanemann 1984) was applied to reveal the relationship between the respondent's willingness to accept a bid ('yes' or 'no') and the corresponding bid value (based on data from the preliminary surveys). The standard form of the model is as follows:

$$
\text { Prob }=1-\left\{1+\exp \left[B_{0}-B_{1} x\right]\right\}^{-1}
$$

Where Prob represents the probability of accepting a bid, $\mathrm{B}_{0}$ and $\mathrm{B}_{1}$ are regression coefficients, and $\mathrm{x}$ is the bid value. The relationship between the bid values and the consensus rate (i.e. the proportion of the households who were willing to accept the corresponding bid value) is shown by the following function:

$$
\mathrm{p}=1 /\left(1+b_{0} \cdot b_{1}^{x}\right)
$$

Where $\mathrm{p}$ is the consensus rate, which represents the percentage of the households who are willing to accept the corresponding bid value, $x$ is the bid value, and $b_{0}$ and $b_{1}$ are regression coefficients, where $\mathrm{b}_{0}=\mathrm{e}^{-\mathrm{B} 0}$ and $\mathrm{b}_{1}=\mathrm{e}^{\mathrm{B} 1}$.

The probability density of WTA is expressed as follows:

$$
\rho=P^{\prime}(x)
$$

Where $\rho$ is the probability density of WTA, and $\mathrm{P}^{\prime}(\mathrm{x})$ represents the probability of a WTA value less than $\mathrm{x}$. To gain the necessary data for WTP, the same method were used for WTA with the same bid values.

\subsection{Data collection and fieldwork}

As data collection methods I conducted household surveys through questionnaires (Appendix 5), workshop and interviews and field observations.

Field investigations of this $\mathrm{PhD}$ research were mainly carried out in the summers of 2011, 2012 and 2013. The field investigation in 2011 took place at end of June for 20 days. It included surveys of a total of 209 households in Hulun Buir, Xiling Gol and Ordos. The households reported all their use of natural resources for one year. In 2012, 35 households (herders) and 36 officials in Xiling Gol, and 29 households in Alxa (herders) were interviewed for adaptive strategy and WTA/WTP. In addition, a workshop was organized for comparative analysis of stakeholder perspectives on policy implementation, climate changes and exploration of grassland's ecosystem services in IMAR. In 2013, 45 household were investigated. An expert workshop was organized and the policy influences on selected ecosystem services were analysed based on 13 experts' knowledge. In addition, information on the available household characteristics, cultivation activities, economic activity etc. was collected to assess the 
total use of natural resources per household. The main part of the fieldwork is designed to identify variations in householders' basic use of natural resources (food, water and fuel consumption for humans) and householders' productive use of natural resources (e.g. livestock cultivation, mining and tourism) under different spatial and temporal situations in IMAR. The satisfaction about income and production mode, the perspectives on future grassland use and expectations about the living conditions of the next generation were also investigated during the interviews.

The data from 16 sample sites (over 60 plots) was collected on soil water content, soil nutrition and soil bulk density and grassland-cover ratio, biomass and plant diversity under different land-use intensity.

\subsection{Outline of the thesis}

In order to address the researchs objective and the research questions, I implemented serveral sequential steps (Figure 1.4). These steps structure this thesis and each chapter addresses a different research question.

Chapter 2 describes the restoration policy-oriented adaptive changes to basic household utilization patterns of food, fuel and water, and their spatial distribution by grassland types in the region. Direct household consumption data were collected in the meadow steppe (Hulun Buir), typical steppe (Xilin Gol) and semi-desert steppe (Ordos) ecosystems using structured questionnaires administered to 209 herders and farmers. In this chapter, I describe the changing changes in local circumstances to satisfy their needs, and to review the grassland-use policy changes and how policies influence livelihoods and household adaptive strategies.

Chapter 3 aims to present householders' total water use, including direct domestic water use like human drinking, cooking and washing and indirect water use for production of food items consumed. To investigate the spatial and temporal distribution of total water use at the household level across different grassland types (meadow steppe, typical steppe and semi-desert steppe) along the grassland transect in the IMAR. This process is threefold: firstly, the basic food consumption patterns of the households were investigated, using household questionnaire surveys and statistical analysis; secondly, the direct and indirect water use behind the food consumption patterns were analysed, and its spatial and temporal variations were explored, using the Virtual Water Content (VWC) approach; thirdly, direct use of water resources and direct water regulating services will be traced based on the water use analysis.

Chapter 4 addresses the effects on household dependence on local grasslands of IMAR and on perceptions of the future of grassland use were analysed in this chapter. The main contents of this chapter are: (1) indicators of changes in the livelihoods of residents of our study area in Inner Mongolia; (2) the dynamics of household livelihoods in response to changes in access to natural assets and in their agricultural activities; (3) the financial adjustments of households to changes in their dependence on local grasslands; and (4) their perceptions of careers for the next generation of their family.

Chapter 5 aims to evaluation of the ecosystem servicers and trade-offs between livelihoods and grasslands ecosystem services of IMAR. In this chapter, four ecosystem services were selected. These are food and raw material provision service, habitat service, soil retention service and soil nutrition regulation service. The analysis based on field survey of quadrats-sampling plots for soil and vegetation at 16 sampling sites including semi- desert stepper, typical stepper and meadow stepper 
grassland ecosystems in the Inner Mongolia at key growth periods of vegetation, and traced the trade-off process between land-use degree (non-used, light used, moderate used, severe used and recovery sites) on household level and their effects on ecosystem services. In this chapter, measuring quantifiable vegetation traits and soil properties during the trade-off process have been identified across a range of abiotic and biotic conditions, and their connection with ecosystem services has been assessed under different conditions. Also the feasible management for this trade-off process was discussed.

Chapter 6 analysis the impacts of a top-down PES program designed by China's central government on the livelihood of herders in the IMAR. Their preferences for key elements of the PES program design were examined, including payment type, amount and means. The WTA of the herders and WTP of the relevant government agencies were estimated for two local PES programs (SLCP and RGLGP). The goal of this chapter is analysing proposed WTA and WTP were to compare WTA with the actual payments to learn whether these payments are satisfactory, and to compare WTA with WTP to learn whether the government recognizes dissatisfaction among program participants and is willing (budget permitting) to improve their situation. These factors will have important consequences for the long-term effectiveness of the programs and for grassland management.

Chapter 7 provides a general synthesis and discussion of the main findings and key conclusions. The synthesis of all my findings from previous chapters answers the research questions (Chapter 1). These answers are also placed in a broader context and they are reflected upon. This reflection helps to draft recommendations to better design feasible strategies to sustainably manage IMAR's grasslands. This chapter also highlights the major contributions, strengths and limitation of this thesis and provides specific recommendations for future research. 


\section{CHAPTER 2}

Changing patterns of basic household consumption: policy-oriented adaptive changes in the use of grasslands

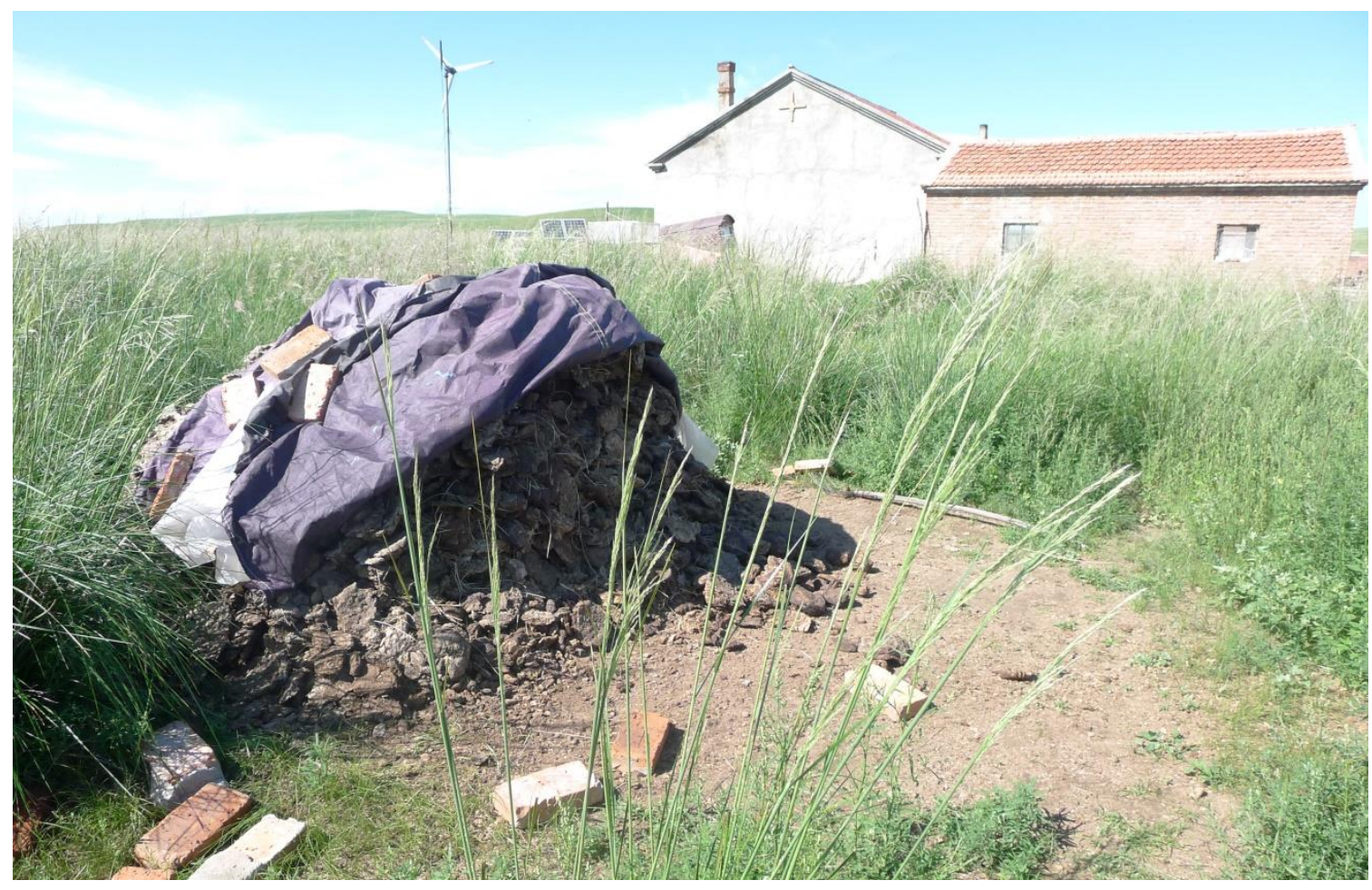

\section{Based on:}

Du B., Zhen L., de Groot R., Goulden C.E., Long X., Cao X., Wu R., Sun C. 2014. Changing patterns of basic household consumption in the Inner Mongolian grasslands a case study of policy-oriented adoptive changes in the use of grasslands. The Rangeland Journal 36(5): 505-517. 


\begin{abstract}
:
Grassland ecosystems, as the basic natural resources in the Inner Mongolia Autonomous Region, are becoming increasingly sensitive to human intervention, leading to deterioration in fragile ecosystems. The goal of this chapter was to describe the restoration policy-oriented adaptive changes to basic household consumption patterns of food, fuel, and water, and their spatial distribution by grassland types in the region. Basic household consumption data were collected in the meadow steppe (Hulun Buir), typical steppe (Xilin Gol) and semi-desert steppe (Ordos) ecosystems using structured questionnaires administered to 209 herders and farmers. In 2010, the householders' intake comprised a low amount of agri-crops, including staple foods, vegetables and fruit with a high amount of meat, which still dominated the patterns of food consumption. However, the number of households preferring this pattern is decreasing and higher amounts of agri-crop and lower amounts of meat consumption pattern is increasing. From1995 to 2010, fuel consumption patterns changed from being dominated by bio-fuels (dung) to being dominated mainly by electricity and gas. However, bio-fuel remains a major energy source for daily life in the meadow steppe ecosystem. In all three surveyed grassland types, the use of coal, electricity and gas increased from 1995 to 2010. The source of domestic water in all three surveyed areas is from groundwater, with an increasing trend to use tap water from a public supply rather than from privately owned wells.
\end{abstract}

Keywords: consumption patterns, food, fuel, grassland, household, restoration policy, water. 


\subsection{Introduction}

The world faces enormous challenges from destruction of ecosystems (Millennium Ecosystem Assessment 2005). This ongoing phenomenon threatens the availability and quality of natural resources, such as arable land, grasslands, fresh water and undeveloped natural areas (Food and Agriculture Organization 2003; World Wildlife Fund 2007; Haftay et al. 2013). Studies on natural resources and ecosystem services have shown that the collapse of ecosystems is caused by over-consumption as populations increase and shift towards more affluent basic consumption patterns that challenge fragile ecosystems (Food and Agriculture Organization 2003; Hoekstra and Chapagain 2008).

Inner Mongolia Autonomous Region (IMAR) has a long tradition of nomadic pastoralism. Since 1990, increasing trends of household basic consumption and population growth have been associated with a transition to intensive grazing, increased crop cultivation and mining activities (Zhen et al. 2010a; König et al. 2014b). These activities have put significant pressure on local ecosystems, as the natural environment is vulnerable to low levels of precipitation with thin soil layers and low soil fertility (Li et al. 2003, 2008; Zhang et al. 2007). The grassland in IMAR acts as an ecological barrier in China separating different eco-zones and the degradation of the grasslands has also negatively influenced the productivity and wellbeing of human populations throughout eastern China and East Asia (Zhang et al. 2007). Therefore, a basket of restoration policy measures for these grasslands have been enforced in the last decade to reverse grassland deterioration ( $\mathrm{Li}$ et al. 2007; Yin and Yin 2010; Li and Huntsinger 2011), such as rotational grazing, seasonal grazing, grazing prohibition, livestock movement, and control of livestock rearing. However, these newly introduced grassland management policies exert great stress on local households' livelihood by fundamentally changing their lifestyles (Xie et al. 2006; Dong et al. 2007; König et al. 2014b) and reshaping the patterns of basic consumption by households.

Previous studies of the grassland ecosystems in IMAR have focused on climate change and its environmental consequences (Bolortsetseg and Tuvaansuren 1996; Dulam 2005; Dong et al. 2013; Liu et al. 2013; Xiao et al. 2013) or on the conflict between agrarian communities and nomads (e.g. Zhang et al. 2007), and most research in this region frequently addressed soil properties, soil erosion, vegetation changes, and the interaction between vegetation changes and soil degradation (Cao et al. 2002; Feng and Zhao 2011; Hoffmann et al. 2011; Li et al. 2011). There have been few socio-economic studies, and most of them have focused on regional land-use preferences, rural reforms, primary production or grassland policy (e.g. Brogaard and Xueyong 2002; Brogaard et al. 2005; Li and Huntsinger 2011; König et al. 2014b).

General research on basic household consumption in IMAR has shown that the pressure on degraded ecosystems has increased as the population has increased and that it results in an unbalanced consumption of ecosystem services (Zhen et al. 2010a). Receveur et al. (1997) indicated that diet varied according to sex, age and community. Gerbens-Leenes and Nonhebel (2002) reported that even small changes in food consumption patterns can trigger large impacts on ecosystems due to the agricultural area required to produce this food. For example, a slight increase in the consumption of meat (one mouthful or $10 \mathrm{~g} \mathrm{capita}^{-1} \mathrm{day}^{-1}$ ) will require the increased intensive use of an additional area of $103 \mathrm{~m}^{2}$ household ${ }^{-1}$ year- ${ }^{-1}$ of the alpine meadow steppe area. Previous research on fuel consumption (e.g. Bhatt and Sachan 2004; 
Madubansi and Shackleton 2007) showed that the most widely used form of biomass for fuel was forest trees; however, in areas where trees are scarce due to natural factors or are an unsustainable human consumption practice, dried dung is used as the primary fuel source. Most studies on food, fuel and water consumption describe changes in a qualitative way (e.g. Fogel and Helmchen 2002; Zhang 2004; GerbensLeenes and Nonhebel 2002; Sun et al. 2014) and do not partition patterns according to consumption quantities and types. Additionally, of what little research has been done in IMAR, most has focused on food and fuel security (e.g. Liu et al. 1998; Wang 2011).

To help fill this research gap, this chapter performed a study designed to reveal the changing patterns of basic household consumption and how the populace adapts to policy changes and changes in local circumstances to satisfy their needs. The purposes of this chapter were to estimate basic household consumption of food, fuel and water; to estimate the spatial and temporal distribution of consumption at the household level over different grassland types (meadow steppe, typical steppe, and semi-desert steppe) in IMAR; and to review the grassland-use policy changes and the process of policy influencing livelihoods and household adaptive strategies. This chapter also aims to provide a better understanding of the changing patterns of consumption of the populace of IMAR who share a similar culture and customs, and who could contribute to the sustainable use of natural resources.

\subsection{Materials and methods}

\subsubsection{Background of study area}

Located in the southern part of the Mongolian Plateau $\left(37^{\circ} 01^{\prime}-03^{\circ} 02^{\prime} \mathrm{N}\right.$ and $95^{\circ}$ $02^{\prime}-123^{\circ} 37^{\prime} \mathrm{E}$ ), IMAR covers 11.8 million $\mathrm{km}^{2}$, and it is the third largest province in China. The region is characterized by an arid to semi-arid continental climate (Yu et al. 2003) with strong climatic gradients and supports varied land-use practices (Figure 2.1). Annual precipitation ranges from $100 \mathrm{~mm}$ to $500 \mathrm{~m}$ and decreases from north-east to south-west. The annual mean, minimum and maximum temperatures in the temperate grasslands are $1.68^{\circ} \mathrm{C},-18.3^{\circ} \mathrm{C}$ and $18.7^{\circ} \mathrm{C}$, respectively (Yu et al. 2003). Hulun Buir, in the northeast of IMAR, is a transitional zone where the meadow steppes meet the Greater Hingaan Mountains. The meadow steppes are the most productive type of grasslands ( $\mathrm{Yu}$ et al. 2003) and develop in areas with moist fertile soils that are rich in organic matter (Kang et al. 2007). The north central area of IMAR, Xilin Gol, borders the semi-desert and is dominated by typical steppe ( $\mathrm{Ji}$ et al. 2009). Typical steppe land is drought-tolerant with multiple vegetation species. The south-western area of IMAR, Ordos, is dominated by semi-desert steppe and is the most arid ecosystem with the least biomass (Yu et al. 2003). Typical steppe and meadow steppe are the predominant grassland ecosystems and are commonly used for grazing and animal production (Kang et al. 2007). The local populace depends mainly on husbandry and the grassland ecosystems to supply almost all of the forage needed for their livestock and to support the livelihood of the region's herders (Zhen et al. 2010a). IMAR is mainly a self-sufficient region, but certain foods need to be purchased, such as rice, flour and fruit. It is also an energy rich region, especially rich in coal. In June 2007, the proven reserves of coal were estimated to be 685.3 billion tons, ranking first of all Chinese provinces (Liu et al. 2012).

The socio-economic situation from north-east to south-west in the study area varies greatly. The north-east (Hulun Buir), a traditional pastoral area, has become the largest milk and meat producer in China. Half of the north central region (Xilin Gol) was a 
traditional pastoral area and half was a farming area. The southwest (Ordos) leads in economic development due to the rapid development of mining. Many inhabitants have moved from the countryside to the cities, caused by restoration policies and more job opportunities and income sources, and the attraction of a modern lifestyle for young people. The general trend in livestock husbandry and crop farming activities is moving away from individual participation to larger-scale operations and population engaged in husbandry and farming has decreased greatly over the past 15 years.

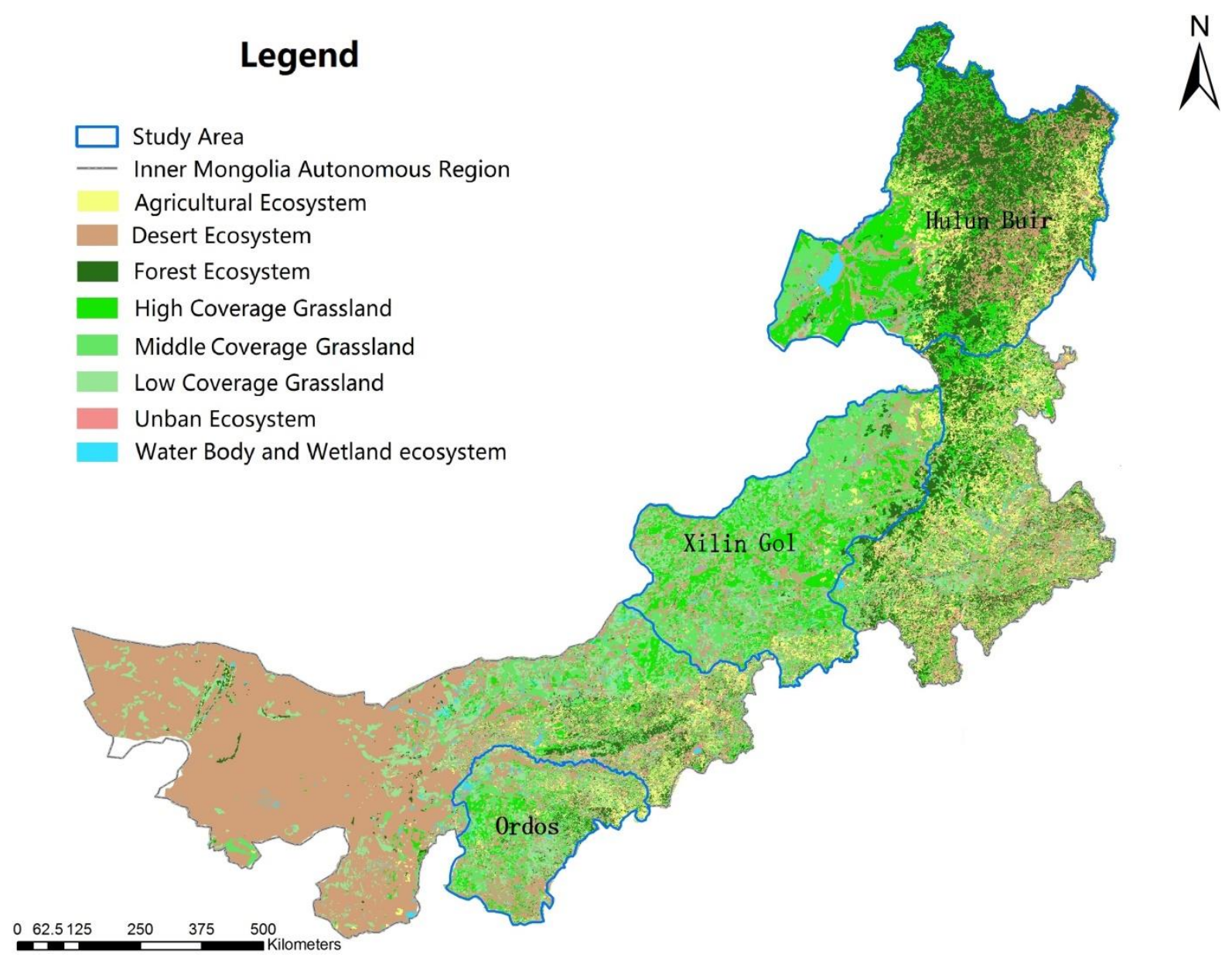

Figure 2.1 Location map of study sizes in the Inner Mongolia Autonomous Region.

\subsubsection{Grassland restoration policy implemented in IMAR}

To reverse the increasing tendency of grassland degradation, a series of policies and counter-measures have been put forward and enforced to alleviate the anthropogenic stress at national and local levels in the past decade; among which the most important one implemented in heavily degraded areas is called 'Fencing grassland, forbidding grazing and moving user'. The policy was brought out around 1998 and broadly extended after several years' experience. The policy included five measures during its implementation, namely (i) seasonal grazing; (ii) rotational grazing; (iii) grazing prohibition; (iv) user moving (also called herder emigration); and (v) livestock-rearing control.

Seasonal grazing means pastures could only be grazed throughout the period of grass growth from April to November. In the winter period, herders feed livestock on 
conserved forage indoors. These policy measures were broadly implemented across grasslands in IMAR, especially in the slightly degraded grassland, such as Hulun Buir, that could be restored by management intervention.

Rotational grazing was implemented in slightly and moderately degraded grassland during the summer grazing period to control grazing intensity. The grassland was fenced and divided into paddocks and then used in rotation.

Grazing prohibition was mainly carried out in severely degraded grassland, such as in the Xilin Gol and Ordos areas. Grazing was forbidden and the objective was to encourage grassland recovery.

User moving (migration) was imposed on severely degraded grassland (e.g. Ordos area), with the aim of improving the living conditions of local residents through migrating to a more favourable area and running more profitable enterprises.

Livestock-rearing control refers to the farming area in the farming-pastoral zone, where limited numbers of livestock could be grazed by the administrative authority, and the objective of the policy was to lower the impact of grazing. Xilin Gol is the typical area influenced by this measure. The number of livestock is limited according to the carrying capacity of local grassland, and nomadism is prohibited and replaced by rearing indoors.

\subsubsection{Research design and data collection}

A survey of 209 households was conducted from June to July 2010. Three typical areas were selected in IMAR on a transect from north-east to south-west (Figure 2.1). Criteria for selection of the areas included (1) representativeness of grassland types, which included meadow steppe (Hulun Buir), typical steppe (Xilin Gol) and semidesert steppe (Ordos); (2) grassland restoration policies having been implemented; and (3) representing the typical production activities of each of the areas. In Hulun Buir, the principal activity is traditional animal husbandry, with livestock rearing as the main land use with $89 \%$ of the population involved in livestock rearing, and arable land accounts for only $0.9 \%$ of the total land area (Hulun Buir Statistics Bureau 2012). In Xilin Gol, $39 \%$ of the population lives on the steppe and arable farming and animal husbandry are predominant. Arable land accounts for only $2.2 \%$ of the total area but produces food for $\sim 43 \%$ of the total population (Xilin Gol Statistics Bureau 2012). In Ordos, there is a combination of arable farming, animal husbandry with a range of grassland types, and mining with $15 \%$ and $18 \%$ of the surveyed populations relying on animal husbandry and arable farming, respectively, and over $31 \%$ of the population working in the mining industry and related services (e.g. transportation) (Ordos Statistics Bureau 2011a; 2011b).

Using a stratified random sampling method (Weber and Tiwari 1992), 10 villages were selected as the survey units, three in Hulun Buir, two in Xilin Gol, and five in Ordos to trace the basic consumption patterns of households. In each of the villages, we selected households randomly for interviews to obtain answers for our questionnaire. Over $65 \%$ of total households of each village was investigated as appropriate sample sizes based on the suggestion of Tabachnick and Fidell (2007) that a sample should be over $50 \%$ when the total households of the survey unit group are lower than 100. Because the survey was carried out using face-to-face interviewing of the respondents or having the respondents complete the questionnaires under the research group members' guidance, a high response rate of $90.5 \%$ was obtained. 
Prior to the formal surveys, test surveys were conducted by using individual interviews and family group discussions with herders and other key informants, and the information collected in the test surveys guided the development of the formal questionnaire. The formal survey contained questions designed to obtain information regarding: (a) background information of households (information on available household characteristics, cultivation activities and other economic activities); (b) the consumption of food (agricultural crops and meat), fuel and water during the year prior (2010); and (c) the consumption of food (agricultural crops and meat), fuel and water around the year 1995 before the implementation of the grassland restoration policy (as recalled by the respondents). The respondents reported the variety and quantity for each category.

Quantities eaten included food from the respondent's own production and food purchased at markets. Out-of-home meals were not taken into consideration, as this survey was conducted in rural and underdeveloped areas where the occasional out ofhome meal happens infrequently, perhaps one or two times per year on special occasions. Additionally, quantifying the amounts for out-of-home meals is very difficult due to the uncertainties in the amounts of materials used for a dish.

The same method was applied to estimate annual water and fuel consumption per capita. The survey collected the total cost or kilograms of water and fuel (e.g. bio-fuel, coal, electricity and gas) bought or gathered in a year for cooking, heating and other domestic uses, as estimated by respondents of each household. For each household visited, we asked the head of each household or a family member who was familiar with the household to answer the questions. The survey revealed that households could accurately recall their consumptions in the year before the survey and the main consumption patterns in 1995. We primarily used closed-ended questions, but added open-ended questions where there was an opportunity to expand on the topics during the interview.

\subsubsection{Data analyses}

The statistics software SPSS, Version 17.0 (SPSS Inc., Chicago, IL, USA) was used for data analysis. Specifically, the results of this chapter applied SPSS functions of frequency analysis and descriptive analysis, including mean values and percentages, for resource consumption and perceptions; used one-way ANOVA to examine significance levels between the three areas; and used 'independent-sample $t$-tests' to identify significant differences of consumption between 1995 and 2010. Cluster analysis is the task of grouping a set of objects in such a way that objects in the same group (clusters) are more similar to each other than to those in other groups. Such analysis is a main task in exploratory data mining and a common technique for statistical data analysis that is used in many fields. In our research, the K-means clustering method was adopted to classify food consumption patterns in 1995 and 2010. For food, water and fuel consumption, We took the weight per capita as an approximation of unit for the sake of simplicity, which increases the comparability and recognition of trends in consumption.

\subsection{Results}

\subsubsection{Basic respondent information}

The respondents of the household survey questionnaire were predominantly male (Hulun Buir 76\%; Xilin Gol 68\%; Ordos 69\%). The average household size of three adult equivalents is consistent with the national average in China reported by NSBC 
(2006). The average age of all respondents was 51 years. Herders in Hulun Buir, Xilin Gol and Ordos had average ages of 43.2, 55.8 and 54.6 years, respectively. The average age of farmers and herders in Xilin Gol was the highest, with $57 \%$ of respondents older than 50 years. This is likely explained by the fact that the government was converting most farmland to grassland and forest, and nomadic grazing was strictly forbidden in Xilin Gol due to the serious degradation of the typical steppe (Zhang et al. 2007). As the farmers and herdsman lose their capital goods, the younger people start new lives in the cities, whereas the older people remain at home.

The herders in Hulun Buir own abundant grassland and most no longer follow a nomadic lifestyle, instead settling near their land and cultivating small parcels of farm land to grow potatoes and vegetables during the spring and summer. In Xilin Gol in 2010, the total land owned was less than half that in Hulun Buir. In Ordos, the inhabitants have the lowest land ownership (Table 2.1). In the past, some farmers and herders in Ordos also owned severely degraded grassland and mineral land, but it has been expropriated by the government for protection or released to individual companies for mining.

The three regions showed significantly different livestock ownership numbers per household (Table 2.1). In Hulun Buir, rearing of sheep and cattle was the major economic activity, whereas lower numbers of cattle and sheep were seen in Xilin Gol due to the implementation of the livestock-rearing control measure. In Ordos, few cattle and sheep are raised. The decision in Ordos to raise more small animals, such as chickens, seems to be a pragmatic response to local government initiatives that have restricted the use of ecosystems for grazing to prevent the continued degradation of the local desert steppe.

The overall annual income of the surveyed households in 2010 was RMB 62359 (US\$9896), 6\% of which came from crop production, 38\% from livestock herding and $56 \%$ from non-agricultural income (e.g. migrant jobs, subsidies and remuneration after land expropriation). The average annual household income in Ordos was highest at RMB 66944 (US\$10 630) followed by Hulun Buir at RMB60 110 (US\$9545) and Xilin Gol at RMB59 800 (US\$9496). In our sample, livestock herding was the most important source of income in Hulun Buir, accounting for $72 \%$ of total income followed by non-agricultural income at $28 \%$. Only $1 \%$ of household income came from crop production. In Xilin Gol, income from livestock rearing showed a significant decrease compared to the level of 1995 (53\%), accounting for only $38 \%$ of total, but the income from crop products and non-agriculture work increased from $18 \%$ and $29 \%$, respectively, to $14 \%$ and $47 \%$, respectively. In Ordos, the incomes from crop production and livestock herding accounted in 2010 for only $1 \%$ and $3 \%$, respectively, of total household income with the remaining $96 \%$ of income originating from off-farm sources. And in 1995, the off-farm income accounted for $35 \%$ of the total income in Ordos. An important component of off-farm income in Ordos was from compensation for land expropriation by the government for the grassland restoration policy or from companies of the mining industry, which accounted for almost $79 \%$ of total income. The income results may indicate that the typical steppe and semi-desert steppe ecosystem cannot provide the basic products to meet household needs and, as such, the herders and farmers are beginning to find new sources of income, such as employment in other areas. 
Table 2.1 Household characteristics of survey

\begin{tabular}{|c|c|c|c|c|c|}
\hline & & \multicolumn{4}{|c|}{ Grassland areas } \\
\hline & & Hulun Buir & Xilin Gol & Ordos & Total \\
\hline \multicolumn{2}{|c|}{ Households surveyed } & 66 & 71 & 72 & 209 \\
\hline \multicolumn{2}{|l|}{ Family size } & 3.2 & 3.2 & 3.4 & 3.3 \\
\hline \multicolumn{2}{|l|}{ Average age } & 43.2 & 55.8 & 54.6 & 51.4 \\
\hline \multicolumn{2}{|c|}{$\begin{array}{l}\text { Average education level } \\
\text { (years) }^{\mathrm{A}}\end{array}$} & 7.8 & 6.3 & 4.7 & 6.3 \\
\hline \multirow{4}{*}{$\begin{array}{l}\text { Land use } \\
\mathrm{Ha}(\%)\end{array}$} & Farmland & $0.1(0 \%)$ & $0.4(1 \%)$ & $1.3(9 \%)$ & $0.6(1 \%)$ \\
\hline & Grassland & $78(100 \%)$ & $30(94 \%)$ & $8.7(63 \%)$ & $37.8(94 \%)$ \\
\hline & Forest & $0(0 \%)$ & $1.4(4 \%)$ & $3.9(28 \%)$ & $1.8(4 \%)$ \\
\hline & Total & $78.1(100 \%)$ & $31.8(100 \%)$ & $13.9(100 \%)$ & $40.2(100 \%)$ \\
\hline \multirow{6}{*}{$\begin{array}{l}\text { Number of } \\
\text { livestock } \\
\text { No. (\%) }\end{array}$} & Sheep & $52.0(68.2 \%)$ & $2.4(27.0 \%)$ & $2.4(8.9 \%)$ & $18.0(49.5 \%)$ \\
\hline & Goat & $3.2(4.2 \%)$ & $0.2(2.2 \%)$ & $6.0(22.3 \%)$ & $3.2(8.8 \%)$ \\
\hline & Cattle & $18.0(23.6 \%)$ & $4.2(47.2 \%)$ & $0.8(3.0 \%)$ & $7.3(20.1 \%)$ \\
\hline & Chicken & $3.0(3.9 \%)$ & $2.0(22.5 \%)$ & $16.9(62.8 \%)$ & $7.5(20.6 \%)$ \\
\hline & Pig & $0.1(0.1 \%)$ & $0.1(1.1 \%)$ & $0.8(3.0 \%)$ & $0.4(1.1 \%)$ \\
\hline & Total & $76.3(100 \%)$ & $8.8(100 \%)$ & $26.9(100 \%)$ & $37.3(100 \%)$ \\
\hline \multirow[t]{4}{*}{$\begin{array}{l}\text { Income, } \\
\text { RMB (\%) }\end{array}$} & $\begin{array}{l}\text { Crop } \\
\text { production }\end{array}$ & $310(1 \%)$ & $8500(14 \%)$ & $1700(1 \%)$ & $3571(6 \%)$ \\
\hline & Livestock & $43000(72 \%)$ & $23000(38 \%)$ & $6000(3 \%)$ & $23459(38 \%)$ \\
\hline & Off-farm ${ }^{\mathrm{B}}$ & $16800(28 \%)$ & $28300(47 \%)$ & $59244(96 \%)$ & $35328(56 \%)$ \\
\hline & Total & $60110(100 \%)$ & $59800(100 \%)$ & $66944(100 \%)$ & $62359(100 \%)$ \\
\hline
\end{tabular}

${ }^{\mathrm{A}}$ Average education level was estimated by the education years that the farmer and herds have finished according to the Chinese education system: 6 years for primary school, 3 years for junior middle school, 3 years senior high school, 4 years for bachelor, 3 years for masters, 4 years for $\mathrm{PhD}$.

${ }^{\mathrm{B}}$ Off-farm income includes income from migrant jobs, government subsidies and income from remuneration from land expropriation.

\subsubsection{Consumption patterns}

\section{Classification of consumption patterns}

The agri-crop and meat products consumed directly, as identified by the respondents, include flour, rice, potato, millet, bean products, vegetables, fruit, mutton, beef, pork, chicken and fish. The results of the ANOVA indicated that consumption of potatoes $(P$ $<0.001)$, fruit $(P<0.001)$, vegetables $(P<0.001)$, flour $(P<0.05)$, pork $(P<0.01)$ and beef $(P<0.001)$ exhibited significant differences in 2010 among Hulun Buir, Xilin Gol and Ordos. The 12 foods noted above were divided into two categories, agri-crop consumption and meat consumption, and used to identify food consumption patterns. The results of the K-means clustering method (Table 2.2) distinguished four food consumption patterns: high agri-crop and high meat (FT1), high agri-crop and low meat (FT2), low agri-crop and high meat (FT3) and low agri-crop and low-meat (FT4).

The dominant categories of fuel consumption were identified as electricity, gas, coal and bio-fuels. The patterns exhibited in fuel consumption are based on the combinations of fuels used: bio-fuel and electricity/gas and coal (FP1), only 
electricity/gas (FP2), electricity/gas and coal (FP3) and only bio-fuel (FP4) (Table 2.2).

Table 2.2 Consumption classifications and patterns in 2010

\begin{tabular}{|c|c|c|c|c|c|c|}
\hline \multirow[t]{2}{*}{ Patterns } & \multirow[t]{2}{*}{ Abbr. } & \multirow[t]{2}{*}{$\mathrm{N}(\%)$} & \multicolumn{3}{|c|}{ Amount (kg capita ${ }^{-1}$ year $^{-1}$ ) } & \multirow{2}{*}{$\begin{array}{l}\text { Classification } \\
\text { references }\end{array}$} \\
\hline & & & Mean & S.E. & Range & \\
\hline $\begin{array}{l}\text { High agri-crop }{ }^{\mathrm{A}}(1) \\
+ \text { high meat }^{\mathrm{B}}(2)\end{array}$ & FT1 & $22(10.5 \%)$ & $\begin{array}{l}(1): 486 \\
(2): 122\end{array}$ & $\begin{array}{c}28.7 \\
5.9\end{array}$ & $\begin{array}{l}393-546 \\
105-153\end{array}$ & \multirow{4}{*}{$\begin{array}{l}\text { K-means } \\
\text { clustering } \\
\text { method }\end{array}$} \\
\hline $\begin{array}{l}\text { High agri-crop }(1)+ \\
\text { low meat }(2)\end{array}$ & FT2 & $68(32.5 \%)$ & $\begin{array}{l}(1): 480 \\
(2): 71\end{array}$ & $\begin{array}{c}30.6 \\
3.3\end{array}$ & $\begin{array}{c}395-527 \\
58-101\end{array}$ & \\
\hline $\begin{array}{l}\text { Low agri-crop (1)+ } \\
\text { high meat }(2)\end{array}$ & FT3 & $79(37.8 \%)$ & $\begin{array}{l}(1): 335 \\
(2): 129\end{array}$ & $\begin{array}{c}20.1 \\
7.8\end{array}$ & $\begin{array}{l}227-383 \\
105-188\end{array}$ & \\
\hline $\begin{array}{l}\text { Low agri-crop }(1)+ \\
\text { low-meat }(2)\end{array}$ & FT4 & $40(19.1 \%)$ & $\begin{array}{l}(1): 315, \\
(2): 72\end{array}$ & 21.0 & $\begin{array}{c}219-384 \\
48-100\end{array}$ & \\
\hline $\begin{array}{l}\text { Bio-fuel }(1)+E / G^{D} \\
(2)+\text { Coal }(3)\end{array}$ & FP1 & $127(60.8 \%)$ & $\begin{array}{l}\text { (1): } 2236 \\
\text { (2): RMB 72, } \\
\text { (3): } 1415\end{array}$ & $\begin{array}{c}247.2 \\
8.3 \\
179.8\end{array}$ & $\begin{array}{c}294-4688, \\
25-191 \\
313-2500\end{array}$ & \multirow[t]{3}{*}{$\begin{array}{l}\text { Categories of } \\
\text { fuels }\end{array}$} \\
\hline Only E/G & FP2 & $22(10.5 \%)$ & RMB 508 & 34.3 & $353-635$ & \\
\hline $\mathrm{E} / \mathrm{G}(1)+\mathrm{Coal}(2)$ & FP3 & $60(28.7 \%)$ & $\begin{array}{l}\text { (1): RMB } 199 \text {, } \\
\text { (2): } 1140\end{array}$ & $\begin{array}{c}19.4 \\
197.4\end{array}$ & $\begin{array}{c}141-281 \\
625-2059\end{array}$ & \\
\hline Wells & WT1 & $153(73.2 \%)$ & $13.76 \mathrm{~m}^{3}$ & 0.7 & $9.9-17.6$ & \multirow[t]{2}{*}{ Water supply } \\
\hline Tap & WT2 & $56(26.8 \%)$ & $12.66 \mathrm{~m}^{3}$ & 0.7 & $9.1-18.9$ & \\
\hline
\end{tabular}

${ }^{\mathrm{A}}$ Agri-crop: flour, rice, potato, vegetable, fruit, millet and beans.

${ }^{\mathrm{B}}$ Meat: mutton, beef, pork, chicken and fish.

${ }^{\mathrm{C}}$ Bio-fuel: dung, core-wood and straw.

${ }^{\mathrm{D}}$ Electricity/Gas.

S.E.: Standard error of mean

N: No. of households

There were no differences in the sources of domestic water consumption, no significant differences according to the spatial $t$-test, and only small discrepancies in the amounts of water consumed in the surveyed sites. The sources of water were mainly classified according to where the water was obtained: private wells (well water - WT1) or public water supply system from taps (tap water - WT2).

\section{Food consumption patterns}

In 2010, large differences could be seen in food consumption patterns (Tables 2.2 and 2.3) between locations associated with each unique ecosystem and culture. Our results showed that FT3 was the dominant consumption pattern in 2010, with $37.8 \%$ of total surveyed households exhibiting this pattern. The FT3 pattern was exhibited in $64.5 \%$, $20.3 \%$, and $15.2 \%$ of the households in Hulun Buir, Xilin Gol and Ordos, respectively (Table 2.2). 
Table 2.3 Variations in annual food, fuel and water consumption per capita $(\mathrm{kg})(1995-2010)^{\mathrm{A}}$

\begin{tabular}{|c|c|c|c|c|c|c|c|c|c|}
\hline & & \multicolumn{8}{|c|}{ Grassland areas } \\
\hline & & \multicolumn{2}{|l|}{ Hulun Buir } & \multicolumn{2}{|l|}{ Xilin Gol } & \multicolumn{2}{|l|}{ Ordos } & \multicolumn{2}{|l|}{ Overall } \\
\hline & & $1995 / 2010$ & $\begin{array}{l}\text { Level of } \\
\text { significance }\end{array}$ & $1995 / 2010$ & $\begin{array}{l}\text { Level of } \\
\text { significance }\end{array}$ & $1995 / 2010$ & $\begin{array}{l}\text { Level of } \\
\text { significance }\end{array}$ & $1995 / 2010$ & $\begin{array}{l}\text { Level of } \\
\text { significance }\end{array}$ \\
\hline \multirow{3}{*}{$\begin{array}{l}\text { Agri-crop } \\
\left(\text { kg year }^{-1}\right)\end{array}$} & Staple food $^{\mathrm{B}}$ & $169.1 / 208.3$ & $P=0.164$ & $209.2 / 211$ & $P=0.685$ & $180.4 / 134.3$ & $P<0.001$ & $186.6 / 183.7$ & $P=0.615$ \\
\hline & Vegetable-Fruit & $101.7 / 157.4$ & $P<0.001$ & $95.3 / 126.3$ & $P<0.01$ & $258.9 / 328$ & $P<0.01$ & $153.7 / 205.6$ & $P<0.01$ \\
\hline & Total agri-crop & $270.8 / 365.7$ & $P<0.05$ & $304.5 / 337.3$ & $P<0.05$ & $439.3 / 462.3$ & $P<0.05$ & $340.3 / 389.3$ & $P<0.05$ \\
\hline \multirow{3}{*}{$\begin{array}{l}\text { Meat } \\
\left(\mathrm{kg}^{-1} \text { year }^{-1}\right)\end{array}$} & Mutton-Beef & $75.7 / 97.2$ & $P<0.05$ & $82.8 / 65.6$ & $P<0.01$ & $51.6 / 35.7$ & $P<0.01$ & $69.8 / 65.3$ & $P<0.01$ \\
\hline & Other meat ${ }^{\mathrm{C}}$ & $20.4 / 30.1$ & $P<0.001$ & $11.8 / 13.9$ & $P=0.287$ & $45.6 / 54.7$ & $P=0.128$ & $26.2 / 33.1$ & $P=0.079$ \\
\hline & Total meat & $96.1 / 127.3$ & $P<0.01$ & $94.6 / 79.5$ & $P<0.05$ & $97.2 / 90.4$ & $P=0.358$ & $96 / 98.3$ & $P=0.265$ \\
\hline \multicolumn{2}{|c|}{ Total food $\left(\mathrm{kg} \mathrm{year}^{-1}\right)$} & $366.9 / 493$ & $P<0.01$ & $399.1 / 416.8$ & $P=0.684$ & $536.5 / 552.7$ & $P<0.05$ & $436.3 / 487.7$ & $P<0.006$ \\
\hline \multicolumn{2}{|c|}{ Bio-fuel $\left(\mathrm{kg}\right.$ year $\left.{ }^{-1}\right)$} & $3248.8 / 2878.6$ & 0.317 & $3673.6 / 1265.2$ & $P<0.001$ & $1626.9 / 199.4$ & $P<0.001$ & $2834.4 / 1407.5$ & $P<0.01$ \\
\hline \multicolumn{2}{|c|}{ Coal $\left(\mathrm{kg}\right.$ year $\left.^{-1}\right)$} & $1049.1 / 20633$ & $P<0.001$ & $287.5 / 690.6$ & $P<0.001$ & $1482.5 / 922.4$ & $P<0.01$ & $939.7 / 1203.9$ & $P<0.01$ \\
\hline \multicolumn{2}{|c|}{ Gas (RMB year $\left.{ }^{-1}\right)$} & $23.4(6) / 126.3(33)$ & - & $0 / 70.3(7)$ & - & $0 / 191.8(17)$ & - & $23.4(6) / 139.0(57)$ & - \\
\hline \multicolumn{2}{|c|}{ Electricity (RMB year ${ }^{-1}$ ) } & $40.6 / 84.4$ & $P<0.001$ & $54.7 / 135.9$ & $P<0.001$ & $56.8 / 215$ & $P<0.001$ & $51 / 146.9$ & $P<0.001$ \\
\hline \multirow{3}{*}{$\begin{array}{l}\text { Domestic } \\
\text { water } \\
\left(\mathrm{m}^{3} \text { year }^{-1}\right)\end{array}$} & Well & $15.7 / 14$ & - & $15.3 / 12.2(45)$ & - & 13.7/14.0(42) & - & $14.9 / 13.7(153)$ & - \\
\hline & Tap & - & - & $0 / 12.7(26)$ & - & $0 / 12.5(30)$ & - & $0 / 12.6(56)$ & - \\
\hline & Total Water & $15.7 / 14$ & - & $15.3 / 12.5$ & - & $13.7 / 13.2$ & - & $14.9 / 13.2$ & - \\
\hline
\end{tabular}

\footnotetext{
${ }^{\mathrm{A}}$ Mean values.

${ }^{\mathrm{B}}$ Staple food: flour, rice, beans and millet.

${ }^{\mathrm{C}}$ Other meat: pork, chicken and fish.
} 
Households in Hulun Buir had the greatest FT3 consumption and households consumed more meat products than other two sites $\left(127.3 \mathrm{~kg}_{\text {capita }}{ }^{-1}\right.$ year ${ }^{-1}$ in Hulun Buir, $79.5 \mathrm{~kg} \mathrm{capita}^{-1}$ year $^{-1}$ in Xilin Gol and $90.4 \mathrm{~kg} \mathrm{capita}^{-1}$ year ${ }^{-1}$ in Ordos) (Table 2.3).

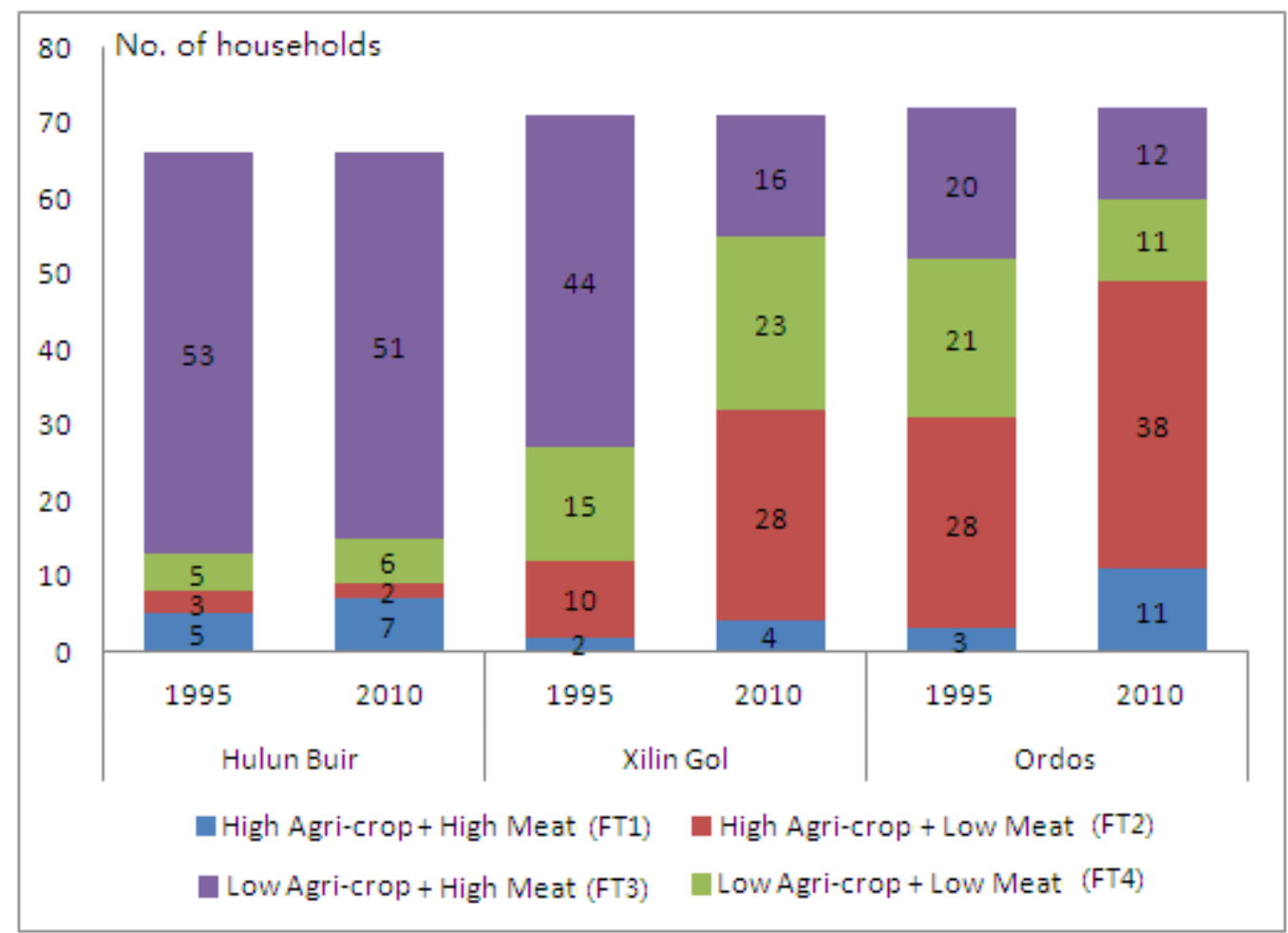

Figure 2.2 Changes in food consumption patterns by number of households (1995-2010)

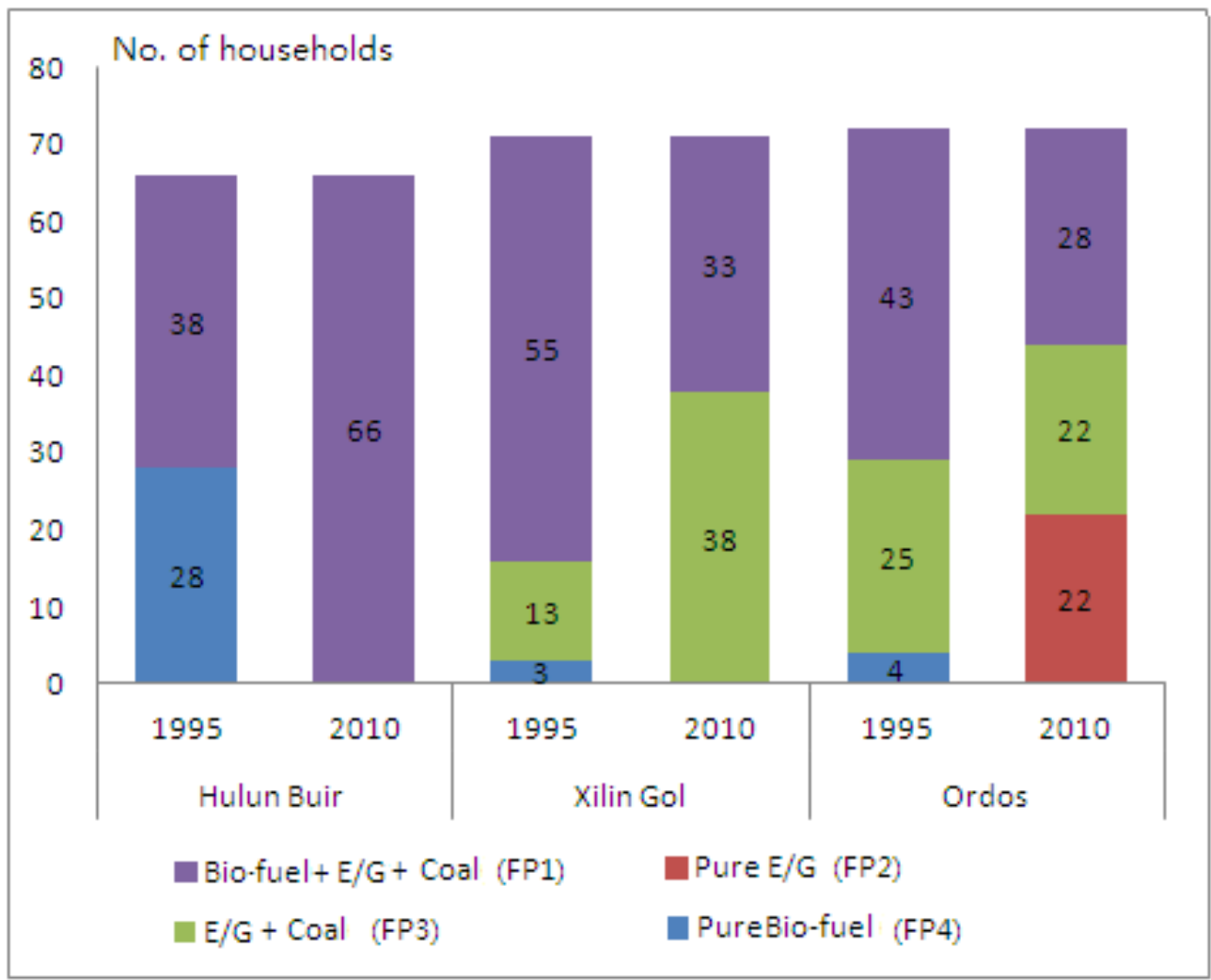

Figure 2.3 Changes in fuel consumption patterns by number of households (1995-2010) 
The second largest food consumption pattern in 2010 was FT2 (32.5\% of households). Of the households in Ordos, Xilin Gol and Hulun Buir, 55.9\%, 41.2\% and 2.9\%, respectively, exhibited the FT2 pattern of consumption. Ordos exhibited over half of the FT2 pattern and consumed higher amounts of agri-crop products $\left(462.3 \mathrm{~kg} \mathrm{capita}^{-1}\right.$ year $^{-1}$ ) than the residents of Hulun Buir $\left(365.7 \mathrm{~kg} \mathrm{capita}^{-1}\right.$ year $\left.^{-1}\right)$ and Xilin Gol (337.3kg capita ${ }^{-1}$ year $^{-1}$ ) in 2010 (Table 2.3 ).

For the other consumption patterns in 2010, 10.5\% exhibited the FT1 pattern and $19.1 \%$ exhibited the FT4 pattern. Of surveyed households exhibiting the FT1 pattern, $50 \%$ were in Ordos (Figure 2.2). In Ordos, daily consumption of vegetables and fruit was higher $\left(328 \mathrm{~kg}\right.$ capita $^{-1}$ year $\left.^{-1}\right)$ than in Hulun Buir $\left(157.4 \mathrm{~kg}_{\text {capita }}{ }^{-1}\right.$ year $\left.^{-1}\right)$ or Xilin Gol (126.3 kg capita ${ }^{-1}$ year $\left.^{-1}\right)$. Additionally, less mutton and beef were consumed in Ordos $\left(35.7 \mathrm{~kg}\right.$ capita $^{-1}$ year $\left.^{-1}\right)$ than in Hulun Buir $\left(97.2 \mathrm{~kg}\right.$ capita $^{-1}$ year $\left.^{-1}\right)$ or Xilin Gol (65.6kg capita ${ }^{-1}$ year $\left.^{-1}\right)$ in 2010. Other variations in the consumption of specific food items were also noted. Ordos had a lower consumption of staple foods $(134.3 \mathrm{~kg}$ capita $^{-1}$ year $\left.^{-1}\right)$ than Hulun Buir $\left(208.3 \mathrm{~kg} \mathrm{capita}^{-1}\right.$ year $\left.^{-1}\right)$ or Xilin Gol $\left(211 \mathrm{~kg} \mathrm{capita}^{-1}\right.$ year $^{-1}$ ). Also, in 2010, the consumption of other meat (e.g. fish, pork and chicken) was much higher in Ordos $\left(54.7 \mathrm{~kg}_{\text {capita }}{ }^{-1}\right.$ year $\left.^{-1}\right)$ than in Hulun Buir $\left(30.1 \mathrm{~kg}\right.$ capita $^{-1}$ year ${ }^{1}$ ) or Xilin Gol $\left(13.9 \mathrm{~kg} \mathrm{capita}^{-1}\right.$ year $^{-1}$ ) (Table 2.3). Of those exhibiting the FT4 consumption pattern, 57.5\% were in Xilin Gol (Figure 2.2). The consumption of staple foods in Xilin Gol was extremely high $\left(211 \mathrm{~kg}\right.$ capita $^{-1}$ year $^{-1}$ in 2010).

The patterns of food consumption shifted gradually from 1995 to 2010 . The FT3 consumption pattern was prevalent for $60 \%$ of households in 1995 , but declined to $40 \%$ of households in 2010 . The FT2 consumption pattern increased from $20 \%$ of households in 1995 to $33 \%$ in 2010 (Figure 2.2). The consumption of vegetables and fruit increased significantly $(P<0.01)$ and mutton and beef consumption declined significantly $(P<0.01)$ during the period from 1995 to 2010 (Table 2.3). The diet of Hulun Buir remained mainly FT3 with high meat consumption, which showed an increase to $127.2 \mathrm{~kg}$ capita ${ }^{-1}$ year $^{-1}$ in 2010 compared to $96.1 \mathrm{~kg}$ capita $^{-1}$ year $^{-1}$ in 1995 . The greatest decline in consumption pattern was that of FT3 in Xilin Gol, where 62\% (44 households) of households exhibited the FT3 food consumption pattern in 1995, but only 23\% (16 households) exhibited this pattern in 2010 (Figure 2.2). In Xilin Gol, consumption of mutton and beef decreased from $82.8 \mathrm{~kg}$ capita $^{-1}$ year ${ }^{-1}$ in 1995 to $65.6 \mathrm{~kg}$ capita $^{-1}$ year $^{-1}$ in 2010 ; whereas vegetable and fruit consumption increased greatly from $95.3 \mathrm{~kg}$ capita $^{-1}$ year $^{-1}$ in 1995 to $126.3 \mathrm{~kg}_{\text {capita }}{ }^{-1}$ year $^{-1}$ in 2010 ; and staple foods remained similar (Table 2.3). As a result, there was an increase in the FT2 pattern in Xilin Gol. Our results (Figure 2.2) also show a small decrease in the FT4 consumption from 1995 to 2010.

In Ordos, the consumption for each item of food changed dramatically (Table 2.3). By 2010 , the consumption of staple foods dropped significantly from $180.4 \mathrm{~kg} \mathrm{capita}^{-1}$ year $^{-1}$ in 1995 to $134.3 \mathrm{~kg}_{\text {capita }}{ }^{-1}$ year $^{-1}$ in 2010 . Although vegetables and fruit showed an increase from $258.9 \mathrm{~kg} \mathrm{capita}^{-1}$ year $^{-1}$ in 1995 to $328 \mathrm{~kg}_{\text {capita }}$ year $^{-1}$ in 2010 , within the category of meat, consumption of other meat has risen slightly, but the consumption of beef and mutton has decreased from $51.6 \mathrm{~kg}_{\text {capita }}{ }^{-1}$ year $^{-1}$ in 1995 to $35.7 \mathrm{~kg}$ capita $^{-1}$ year $^{-1}$ in 2010 (Table 2.3 ).

\section{Fuel consumption patterns}

The three study areas showed large differences in the types and amounts of fuel consumed in 2010. The diverse fuel consumption pattern, FP1, that uses bio-fuel, coal and electricity/gas, was predominant in the three areas, with $61 \%$ of all households 
exhibiting this pattern. In Hulun Buir, $100 \%$ of households exhibited the FP1 fuel consumption pattern, followed by $46.5 \%$ in Xilin Gol and $38.9 \%$ in Ordos (Figure 2.3). Herders in Hulun Buir used an average of $2879 \mathrm{~kg}^{\text {capita }}{ }^{-1}$ year $^{-1}$ of biofuel to support daily needs, including cooking and heating. In addition to bio-fuel, coal consumption was also extremely high in Hulun Buir (2063kg capita ${ }^{-1}$ year $\left.^{-1}\right)$, with most used for heating in the long, cold winters (Table 2.3). The second largest fuel consumption pattern was FP3 (electricity/gas and coal). Of those households exhibiting the FP3 pattern in 2010, 63.3\% were in Xilin Gol and 36.7\% were in Ordos, utilization of the newer forms of energy, electricity and gas, resulting in a significant reduction in the use of bio-fuels and coal.

The households in Ordos showed a more complex range of fuel consumption patterns in 2010 (Figure 2.3). The fuel consumption pattern using only electricity/gas (FP2) increased in recent years with $30.6 \%$ of households in Ordos using gas and electricity for cooking and boiling water in 2010. As a consequence of the significantly higher gas and electricity consumption in Ordos than in other survey sites, predominantly electricity consumption was RMB 215 capita $^{-1}$ year $^{-1}$ (US\$30.5) in Ordos versus RMB 135.9 capita $^{-1}$ year $^{-1}$ (US\$21.6) in Xilin Gol and RMB 84.4 capita $^{-1}$ year $^{-1}$ (US\$13.4) in Xilin Gol, respectively (Table 2.3). Ordos households used the lowest amount of bio-fuels $\left(435 \mathrm{~kg}\right.$ capita $^{-1}$ year $^{-1}$; mainly dry land willow (Salix matsudana).

Compared to 1995, the fuel consumption pattern changed significantly by $2010(P<$ 0.05) except for bio-fuel consumption in Hulun Buir (Table 2.3). Three main changes to the patterns of fuel consumption were noted. First, in 1995, 42.4\% of households in Hulun Buir were using only bio-fuel (fuel consumption pattern FP4). By 2010 the FP4 consumption pattern had disappeared from Hulun Buir and was replaced by the more diverse fuel consumption pattern, FP1. Second, there has been an increase in the use of electricity/gas (consumption patterns FP2 and FP3). For instance, 83\% of households used bio-fuel in Xilin Gol in 1995; however, by 2010, 31\% of households in Xilin Gol had stopped using bio-fuel and switched to electricity, gas and coal consumption. Third, in 1995 there was no consumption pattern using only electric/gas (FP2) and only $18 \%$ of the surveyed households exhibited the FP3 pattern of consumption. By 2010 , however, $10.5 \%$ of households used only electricity/gas, and $29 \%$ of households exhibited the FP3 fuel consumption pattern (Figure 2.3).

\section{Domestic water consumption patterns}

All domestic water consumed came from groundwater. In 2010, the surveyed households in Hulun Buir consumed more water $\left(14 \mathrm{~m}^{3}\right.$ capita $^{-1}$ year $\left.{ }^{-1}\right)$ than those in Xilin Gol $\left(12.5 \mathrm{~m}^{3}\right.$ capita $^{-1}$ year $\left.^{-1}\right)$ and Ordos $\left(13.2 \mathrm{~m}^{3}\right.$ capita $^{-1}$ year $\left.^{-1}\right)$. Decreasing trends in the amounts of water consumed were exhibited in all survey sites. In Xilin Gol this trend was more apparent, where water consumption decreased from $15.3 \mathrm{~m}^{3}$ capita $^{-1}$ year $^{-1}$ in 1995 to $12.5 \mathrm{~m}^{3}$ capita $^{-1}$ year $^{-1}$ in 2010 . Overall, the average domestic water consumed was $13.2 \mathrm{~m}^{3}$ capita $^{-1}$ year $^{-1}$ in 2010 versus $14.9 \mathrm{~m}^{3}$ capita $^{-1}$ year $^{-1}$ in 1995 (Table 2.3).

In 1995, all households surveyed reported that they did not have public water service (tap water) in their household and had to fetch water from privately owned wells or sources outside the home. The surveyed households in Hulun Buir consumed more water $\left(14 \mathrm{~m}^{3}\right.$ capita $^{-1}$ year $\left.^{-1}\right)$ than those in Xilin Gol $\left(12.5 \mathrm{~m}^{3}\right.$ capita $^{-1}$ year $\left.^{-1}\right)$ and Ordos $\left(13.2 \mathrm{~m}^{3}\right.$ capita $^{-1}$ year $\left.^{-1}\right)$. In 2005 , a rural water supply construction project was implemented by the government in some parts of IMAR. The project involved drilling public wells and installing pipelines and taps to ensure the water supply. As a result 
the use of water from a public supply increased from $0 \%$ in both Xilin Gol and Ordos in 1995 to $37 \%$ and $42 \%$ of households, respectively, in 2010 . The project did not cover the area of Hulun Buir, and $100 \%$ of households still acquired water from privately owned wells in 2010. In Xilin Gol, $63 \%$ of households obtained their water from privately owned wells and had an average consumption of $12.2 \mathrm{~m}^{3}$ capita $^{-1}$ year $^{-1}$, which was a lower use per capita than those on the tap water supply $\left(12.7 \mathrm{~m}^{3} \mathrm{capita}^{-1}\right.$ year $\left.^{-1}\right)$. In Ordos, however, the average water consumption in 2010 was $14 \mathrm{~m}^{3}$ capita $^{-1}$ year ${ }^{-1}$ among the $58 \%$ of households using water from privately owned wells, which was higher than the households using tap water $\left(12.5 \mathrm{~m}^{3}\right.$ capita $^{-1}$ year $\left.^{-1}\right)$.

\subsection{Discussion}

\section{Food consumption patterns}

Households in Hulun Buir had the greatest consumption of the FT3 pattern of foods, similar to that found by Liu et al. (2012) who found that IMAR had 124.6\% higher meat consumption than the Chinese average and $79.8 \%$ of China's average vegetable consumption. Consumer preferences in this location were still meat-based to satisfy daily protein and energy consumption requirements. Hulun Buir retained high meat consumption patterns due to the higher land ownership in the meadow steppe and higher livestock ownership, both of which greatly exceed the average levels in IMAR (Table 2.1). Feng and Shi (2006) reported that the meat consumption per household in pastoral areas of IMAR was 2.3 times higher than that in the arable farming areas. Ordos exhibited over $50 \%$ of the FT2 pattern, due to the inhabitants in Ordos consuming higher amounts of agri-crop products than the residents of the other two areas. In Ordos vegetable and fruit consumption of $328 \mathrm{~kg} \mathrm{capita}^{-1}$ year $^{-1}$ exceeded the Chinese national standard of $320 \mathrm{~kg}$ capita $^{-1}$ year $^{-1}$ (Feng and Shi 2006). In Ordos, due to the desert and semi-desert grassland conditions, improved transportation and the implementing of policy measures to prohibit grazing and movement (returning the farmland to forest and grassland, and fenced grazing areas), most herdsmen and farmers no longer rely on the land for their food consumption. Their consumption depends more on purchased food. In the markets, vegetables and fruits are cheaper than meat, resulting in the higher consumption following the FT2 pattern.

The FT1 pattern was high in Ordos because of the high daily consumption of vegetables and fruit, and low consumption of staple foods. In addition, less mutton and beef were consumed, and the consumption of other meats (e.g. fish, pork and chicken) was high. From a nutritional perspective, fish, pork and chicken have less protein than beef and mutton. Beef contains $19.9 \mathrm{~g}$ of protein $100 \mathrm{~g}^{-1}$ whereas pork contains $14.5 \mathrm{~g}$ of protein $100 \mathrm{~g}$ (Wang 2010). Although the amount of meat consumption is higher than average, the protein intake is similar. In households with the FT1 consumption pattern, the average annual income (RMB 70150 or UD\$1110) was higher than the average of all surveyed households (RMB 62359 or US\$980) (Table 2.3). Research has shown that the amounts and categories of food consumption tend to increase as the income level increases (e.g. Mennell et al. 1992; Babatunde and Qaim 2010). Of those exhibiting the FT4consumption pattern, 57.5\% were in Xilin Gol, and these consumed more staple foods, especially flour. This is likely a result of the low income of those with the FT4 consumption pattern and a lack of funds to purchase more diverse meats, vegetables and fruit. Compared to other foods, staple foods were inexpensive and high in carbohydrates that satisfy daily energy requirements. From a nutritional perspective, IMAR does not have undernourishment, even for those with the FT4 consumption pattern. The amounts of food consumed 
under all the food consumption patterns met the energy and protein requirements as recommended by the Chinese Nutrition Society (Chinese Nutrition Society 2010) (Table 2.3).

The increase in the FT2 pattern and decrease in the FT3 pattern indicates that meat products were replaced with agri-crop foods. The socio-economic statistics for rural areas in IMAR also indicated that meat consumption in 2010 decreased by $21 \%$ and vegetable consumption increased by $45 \%$ compared to the levels of 1995 (Inner Mongolia Statistics Bureau 1996, 2011). This is likely because of the large reductions in livestock rearing due to the degradation of the local rangelands and implementation of restoration policies. Feng and Shi (2006) showed that the initial preference for human food consumption is home-produced food from family owned land or local ecosystems (i.e. self-sufficiency). When changing conditions result in insufficient home-produced food, the populace begins to alter the ways food is acquired, including purchasing. For instance in Xilin Gol, the number of livestock is controlled by the carrying capacity of local grasslands ( 1 sheep unit per 1.67 ha grassland). To confront this livestock-rearing control policy measure, the herders/farmers increase cattle rearing to compensate for the loss of goat/sheep grazing due to the control policy, and for having to change from nomadic grazing to stall-rearing. First, cattle can produce milk products, which produce a higher income from selling such products than from goat/sheep rearing. Second, the local government assisted in the introduction of cattle breeds, which improved the profitability of cattle rearing, which encouraged cattle breeding. This change in pattern requires herders and farmers to buy food from markets, and they tend to buy vegetables and fruit, as these are less expensive than mutton and beef.

The internal supply of food affects food consumption patterns according to the results of our survey. When the food accessibility was increased by improvements in transport, the amount of staple foods, fruit and certain vegetables increased significantly. Consequently, the present food consumption patterns rely less on the local ecosystems and are more affected by market trading. Although IMAR was mainly a self-sufficiency region, the herder/farmers now buy food (staple foods, vegetable and fruit) from outside IMAR because (1) the numbers of livestock managed by herders has decreased due to the policy restrictions; (2) the market price of meat is becoming more expensive, and the herders prefer to sell their livestock to get money to increase their expenditure on children's education, housing and medical treatment; (3) a more diverse food consumption pattern has become more popular due to economic development, establishment of a trading market, and transformation of consumption consciousness. Over $85 \%$ of investigated households indicated that they purchase agri-crops in the markets of towns every 1 or 2 weeks.

A moderate increase in the pattern of FT1 consumption and a decrease in the pattern of FT4 consumption from 1995 to 2010 may be due to the higher annual income levels found in 2010 (US\$1982) as compared to those in 1995 (US\$1670). Food consumption tended to increase both in amount and variety, as the income level increased. This was confirmed through comparisons between the three sites. From the perspective of consumption, Gerbens-Leenes and Nonhebel (2002) indicated that the economic situation can affect food consumption, and growth of income causes a shift with greater meat consumption than agri-crop consumption. This research showed the opposite trend with meat consumption decreasing greatly, and the consumption of agri-crops increasing when the original income structure of the area of livestock rearing was seriously affected by the grassland restoration policy, such as in Xilin Gol 
(decreased in meat consumption by $15.1 \mathrm{~kg}$ capita $^{-1}$ year $^{-1}$ ). However, the results of this research also indicated that the food consumption types moved towards diversification when the income increased to a certain level and people started to care about their health to reduce the amount of meat consumption, such as in Ordos.

\section{Fuel consumption patterns}

In Hulun Buir, the pattern of fuel consumption was dominated by pattern FP1 and dried dung from livestock was an important and widely used bio-fuel. The high consumption of dried dung can be attributed to the higher numbers of cattle. In Xilin Gol, the use of bio-fuels decreased from $3673 \mathrm{~kg}_{\text {capita }}{ }^{-1}$ year $^{-1}$ in 1995 to $1265 \mathrm{~kg}$ capita $^{-1}$ year $^{-1}$ in 2010 resulting in a decrease in the FP3 pattern. The decrease in the use of bio-fuels in Xilin Gol can be attributed to the large reductions in number of livestock and intensive crop cultivation. As a result, the dry dung could not satisfy the demands of households. Many households switched to the use of straw for heating $\left(953 \mathrm{~kg} \mathrm{capita}^{-1}\right.$ year $\left.^{-1}\right)$.

Ordos's households used the lowest amount of bio-fuels; most respondents reported that they collected only dying or dead wood due to regulations that prohibit the cutting of live trees. Ordos is under the grazing prohibition and user moving policy measures. The livelihoods fundamentally changed from livestock rearing to becoming employees in retail or freight businesses, which caused a great increase in the FP2 pattern with expanding use of gas and electricity consumption. This result is similar to the results of Sun et al. (2014) who reported that the pattern of household energy use has been influenced greatly by income growth and urbanization.

Usage of coal, gas and electricity by farmers and herdsmen increased in all three area compared to fuel usage in 1995. This may be the result of rapid economic development and government initiatives. The decreasing numbers of livestock and higher energy needs (especially for the fuel consumption for heating; from the reports of respondents, over $60 \%$ households extending the heating period from 'Nov. to next Mar.' to 'Oct. to next Apr.') are also reasons that less dung was used for basic household consumption. From a health perspective, the smoke $\left(\mathrm{CO}, \mathrm{CO}_{2}, \mathrm{NO}\right.$ and suspended particles) from burning dung may be causes of respiratory and ocular diseases. Although more costly, people preferred to use gas and electricity, as these are more convenient, clean and efficient. IMAR is a demonstration area for wind energy application, and 53\% of electricity is produced by wind in IMAR based on the statistics in the yearbook of 2010 for IMAR (Inner Mongolia Statistics Bureau 2011).

The loss of the FP4 consumption pattern in the Hulun Buir area may have resulted from house construction that occurred after the herdsmen had adopted a less nomadic lifestyle and began using more electricity and coal. These dramatic changes were caused by decreases in the numbers of livestock to protect locally degraded grassland ecosystems, which forced people to abandon farming and move to urban areas.

\section{Domestic water consumption patterns}

The decrease in water consumption may be caused by drought. Drought for most of the local populace was more serious in 2010 than in 1995 (Dai et al. 2009; Hu et al. 2012). The relatively dry weather in 2010 and prior years may have caused a decrease in water consumption at all three sites. In 1995, the herders did not experience problems with domestic water consumption from groundwater sources but, by 2010 , some households reported that they needed to store water in dry periods or extreme weather (such as spring and winter). Moreover, land-use changes could have been the 
other trigger for droughts. From the statistics of IMAR in 2008, the region's total water resources amount to 412.1 billion $\mathrm{m}^{3}$, which was a decrease of $5 \%$ compared to the average over many years. The region's total water consumption was 175.8 billionm $\mathrm{m}^{3}$, with water use for agriculture irrigation accounting for $70.2 \%$ (123.4 billion $\mathrm{m}^{3}$ ) of total water consumption. All water consumed came from groundwater, so higher water consumption is likely to have resulted in a lowering of the groundwater table due to land-use changes. For instance, research of Zhao et al. (1999) has indicated that the intensive crop cultivation and grazing may be the drivers that resulted in a lowering of the groundwater table by $0.5-1.3 \mathrm{~m}$ from the $1980 \mathrm{~s}$ to the 1990s.

The surveyed households in Hulun Buir consumed more water than those in Xilin Gol and Ordos, which may also indicate that the local water resources were relatively more plentiful in Hulun Buir. In Xilin Gol, households obtained their water from privately owned wells, which had a lower consumption rate than those on the tap water supply. However, the reverse trend was shown at the Ordos site. This discrepancy may have been caused by water costs, as the water from privately owned wells was free at all three sites, but some charges existed for tap water. In Xilin Gol, the households using tap water were required only to pay RMB 5 per month with no limits on the amount of water used, whereas inhabitants at the Ordos site were required to pay for water consumption based on the actual quantity of water used $\left(\mathrm{RMB} 2.6 \mathrm{~m}^{-3}\right)$. This led to a reduction in the use of water and suggests that the market price of water can reduce water consumption.

\subsection{Summary and conclusions}

Ecosystem degradation, rapid economic growth, and enforcement of restoration policy have greatly impacted on rural life and the basic consumption patterns of households in IMAR. This chapter analysed these patterns, using the main consumption patterns of food, fuel and water as indicators, with spatial and temporal differences as variables for analysis. A household survey was used to acquire firsthand data to estimate actual daily consumption. The consumption patterns were constructed using statistics based on a field-level survey of the study areas.

We compared resources of food, fuel and water consumption patterns for three types of grassland ecosystems and described the temporal trends. The interplay of grassland natural condition, economic development and restoration policy measures have affected basic household consumption patterns. Four conclusions can be drawn from the results of the survey:

(1) The overall food consumption pattern in IMAR was a low consumption of agricrops and a high meat consumption due mainly to the lagging effects of the historic nomadic grazing culture. There was, however, significant spatial variation due to differing economic level, restoration policy measures and ecosystem types and variations in ecosystem services provided by the meadow steppe (Hulun Buir), typical steppe (Xilin Gol) and semi-desert steppe (Ordos) areas. A high percentage of the surveyed households in Hulun Buir retained the low agri-food with high meat consumption pattern. Approximately half of the households in Xilin Gol preferred a low agri-crop with high meat consumption pattern, whereas the other half preferred the low agri-crop with low meat consumption pattern in 2010. Approximately 53\% of the surveyed households in Ordos exhibited the high agri-food with low meat consumption pattern in 2010 . 
(2) Large temporal differences were seen in per-capita food consumption both in types and amounts, with consumption of specific foods changing greatly from 1995 to 2010. Consumption of vegetables and fruit increased significantly, and mutton and beef consumption declined significantly from 1995 to 2010. Although the total amount food consumed increased gradually in general from 1995 to 2010, the number of households exhibiting the low agri-crop and high meat consumption pattern decreased, whereas those households exhibiting the high agri-crop and low meat consumption pattern increased.

(3) Fuel consumption patterns changed from being dominated by the use of bio-fuel in 1995 to being dominated by electricity/gas in 2010. However, dried dung is still a major energy source for daily life in Hulun Buir, with coal being the second most predominant fuel. Trends of coal and electricity/gas consumption showed increases at all three sites, especially for Xilin Gol and Ordos, where livestock rearing is not as prevalent as in Hulun Buir.

(4) Groundwater was the sole domestic water source in the surveyed areas. Some households have begun to use the public water supply instead of privately owned wells as a water source, and may need to begin paying for water consumption in the near future.

(5) Beside the influences of different natural environment conditions and economic development, the grassland restoration policy measures deeply changed pastoral tradition and basic household consumption patterns. Grazing activity was less affected by policy measures of seasonal grazing and rotational grazing than the other policy measures, thus more herders preferred to maintain most of their basic consumption patterns (e.g. in Hulun Buir). However, in the context of grazing prohibition, user moving and livestock rearing control policy measures (e.g. in Xilin Gol and Ordos), the basic household consumption patterns (especially food and fuel) fundamentally changed.

The method of partitioning patterns according to consumption quantities and types is useful in explaining the effects of policy changes on household livelihoods and in providing guidelines for sustainable grassland management, and provides a new viewpoint to resource/ecosystem adaptive management, especially in linking microlevel livelihood responses to macro level policy procedures, which facilitates the further review of policies and enables policy adjustment and amendment by the feedback from livelihood outcomes. 


\section{CHAPTER 3}

\section{Changing Food Consumption Patterns and Impact on Water Resources in fragile grasslands}

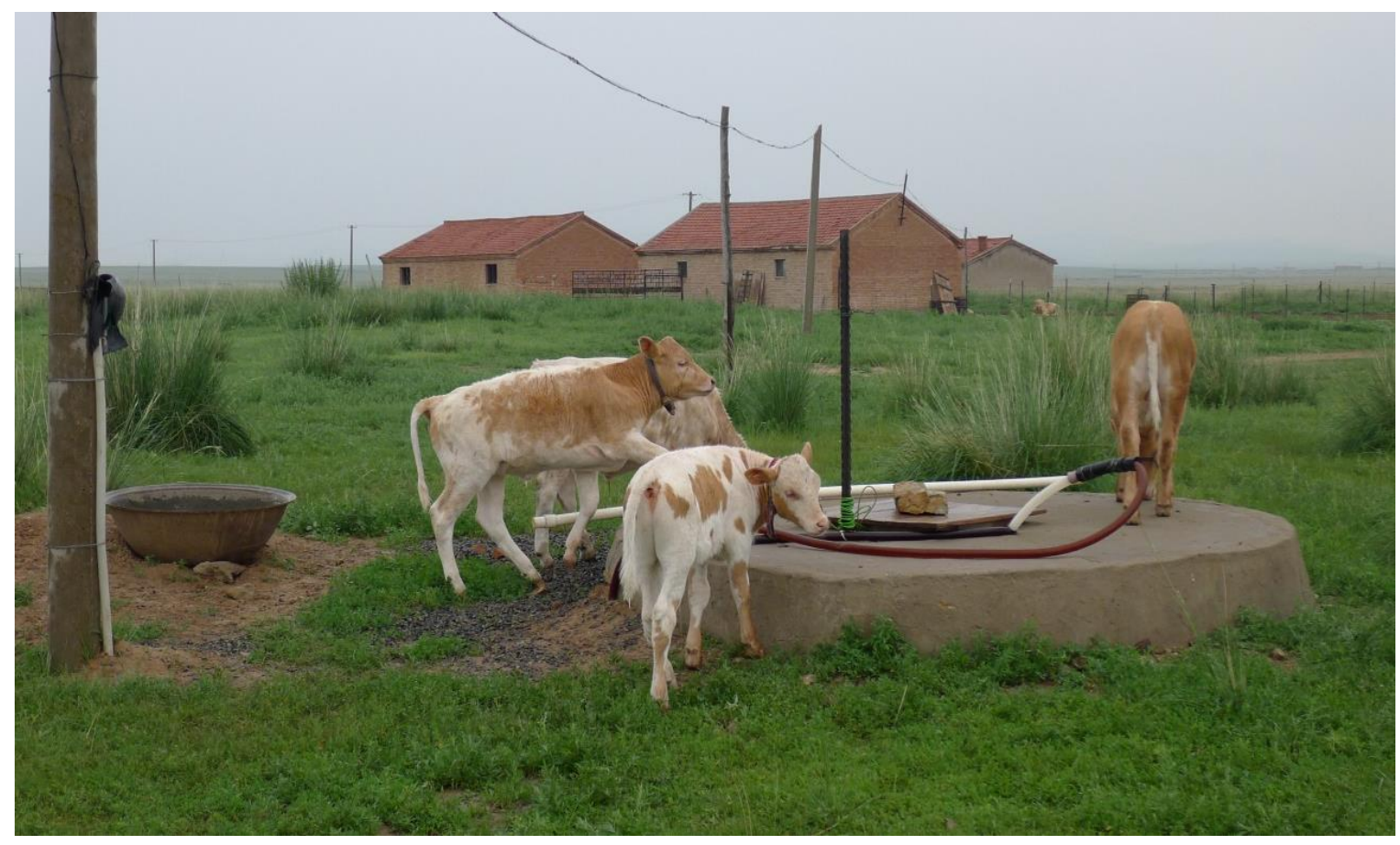

\section{Based on:}

Du B., Zhen L., de Groot R., Long X., Cao X., Wu R. 2015. Changing Food Consumption Patterns and Impact on Water Resources in the Fragile Grasslands of Northern China, Sustainability 7(5): 5628-5647. 


\begin{abstract}
:
A burgeoning population, pressing development needs and increasing household consumption are rapidly accelerating water use in direct and indirect ways. Increasingly, regions around the world face growing pressure on sustainable use of their water resources especially in arid and semi-arid regions, such as Northern China. The aim of this research is to obtain an overview of the cumulative water requirement for direct (domestic) water use and indirect water use for the basic food consumption of the households in Inner Mongolia Autonomous Region (IMAR), in order to reduce the pressure on grassland of Western China by encouraging sustainable water consumption. For indirect water use, we use the Virtual Water Content (VWC) analysis theory to analyse the total consumption package of 15 basic food types that were identified and quantified based on the household survey in 2011. In this survey, domestic water consumption data and food consumption data were collected from 209 representative households with spatial variation across three sub-regions (including meadow steppe in Hulun Buir, typical steppe in Xilin Gol and semi-desert steppe in Ordos) and temporal variation from 1995 to 2010. The results show that the total amounts of food consumption per capita in three sub-regions all show an increasing trend, especially in Hulun Buir and Ordos. Compared to the direct water consumption, the indirect water consumption behind food production made up a major portion of total water consumption, which is affected (1) geographic locations (grassland types); (2) economic development levels and (3) grassland use policy measures. From 1995 to 2010, indirect water consumption displays a decreasing trend in Xilin Gol and Ordos due to the decrease of meat consumption and increase of fruit and vegetable consumption. When considering the amount of land per household, the grassland in Ordos still faces the great threat of high water consumption pressure. Such water consumption may affect water conservation services and productivity of grassland. Therefore, changing diet behaviour and reducing the population can be considered options for sustainable use of water.
\end{abstract}

Key words: Virtual Water Content; Water use; Household survey, Food consumption pattern; Grassland; Adaptive management 


\subsection{Introduction}

Humans depend on the integrity of ecosystems to provide the ecosystem services they need for survival (Millennium Ecosystem Assessment 2003). In many parts of the world, the limited availability of clean and fresh water is a major constraint to further social and economic development, especially in arid and semi-arid regions, such as Northern China Yan et al. 2014). Drought is a matter of vital importance to the grassland of Inner Mongolia Autonomous Region (IMAR), Northern China. A burgeoning population, pressing development needs and increasing household consumption are rapidly increasing the amount of water use (Yan et al. 2014). From previous research (Zhao et al. 2010), limited water resources and overuse of water for grazing/cultivation are the main reasons for grassland degradation in IMAR. To reverse the increasing tendency of water stress and grassland degradation, suitable water consumption in an efficient way needs to be put forward to alleviate anthropogenic stress at national level. Household water use is a combination of both direct water consumption (e.g. domestic water consumption for drinking, washing, flushing and cooking) and the indirect water consumption behind the food production system. Producing food involves large amounts of fresh water use in the processes of plant transpiration, interception loss from vegetation canopies, soil evaporation and channel evaporation in irrigated systems (Zhang et al. 2010). Therefore, humans' consumption of food items is coupled with intensive use of water resources in indirect ways. Increasingly, regions around the world face growing pressures on their water resources. Great concerns have been raised on this issue, especially in the agricultural sector, which accounts for about $70 \%$ of human water use (Molden et al. 2007).

Several scientists have described the complex links between sustainable water consumption and the limited availability of water resources (Yan et al. 2014). Accessible fresh water is scarce and an essential input for many societal, economic and natural systems. For example, China uses $7 \%$ of accessible freshwater to feed $22 \%$ of the global population, and this quantity likely will decrease in many regions with overconsumption due to the reduced water conservation function of ecosystems (FAO 2003; Hoekstra and Chapagain 2008). While demand increases, supplies of clean water are limited and diminishing (WWF 2007). These trends are leading to an escalating competition over water in both rural and urban areas. Particularly important will be the challenge of simultaneously meeting the food demands of a growing human population and expectations for an improved standard of living that requires clean water to support domestic and industrial uses (Millennium Ecosystem Assessment 2005; Cavaliere et al. 2014).

Previous studies showed that even small changes in food consumption patterns can have large impacts on the ecosystem due to the water required to produce this food (Zhen et al. 2010b). For example, in the Netherlands, a hot meal mostly includes some meat, potatoes, noodle and vegetables. Gerbens-Leenes and Nonhebel (2002) reported that even small changes in food-consumption patterns can trigger large impacts on ecosystems due to the agricultural area required to produce this food. For example, a slight increase in the consumption of meat $\left(10 \mathrm{~g} \mathrm{capita}^{-1} \mathrm{day}^{-1}\right.$ or one mouthful) will require the increased use of water of $73 \mathrm{~m}^{3}$ household $^{-1}$ year $^{-1}$, whereas the same increase of potato consumption will result in an increase of water use only $0.5 \mathrm{~m}^{3}$ capita $^{-1}$ year $^{-1}$. The previous researches indicated that changing diet behaviour can be considered as an option to reduce total water use. Changing consumption patterns from non-meat-dominant to meat-dominant patterns in many countries will lead to 
high pressure on water resources required to produce those products (Xiao et al. 2007).

The analysis of the specific water consumption for food production can be quantified by different methods in the present study, such as the crop water productivity (CWP, typically in $\mathrm{m}^{3} \mathrm{~kg}^{-1}$ ) — which is the ratio between produced crop yield and the amount of water consumed (or evapo-transpired) for that production (Bessembinder et al. 2005) - or the inverse ratio, the Virtual Water Content (VWC, typically expressed in $\mathrm{m}^{3} \mathrm{~kg}^{-1}$ ). VWC and CWP differ not only among crop types, but also among regions for an individual crop. For example, Zwart and Bastiaanssen (2004) found that with $1 \mathrm{~m}^{3}$ of water producing higher wheat yields in Wangtong (China) or Grand Valley (USA) than in Meknes (Morocco) or in Tel Hadya (Syria) is well possible.

In order to change consumer behaviour effectively, water uses should be associated with different food consumption patterns of households. In this manner we can find out which household consumption types are eligible for water saving and hence ecosystem degradation reduction. The purposes of this chapter was to estimate householders' total water consumption, including direct domestic water consumption like human drinking, cooking and washing, and indirect water consumption for production of food items consumed; to investigate the spatial and temporal distribution of total water consumption at the household level over different grassland types (meadow steppe, typical steppe and semi-desert steppe) along the grassland transect in IMAR; and to explore the impact of the grassland-use policy on livelihoods and household adaptive strategies. This process is threefold: firstly, the basic food consumption (the foods items commonly consumed by herders to maintain their daily life and substantial livelihood currently) patterns of the households will be investigated, using household questionnaire surveys and statistical analysis; secondly, the direct and indirect water consumption behind the food consumption patterns will be analysed, and its spatial and temporal variations will be explored, using the VWC approach; thirdly, use of water resources will be traced based on the water consumption analysis.

\subsection{Material and methods}

\subsubsection{Area description}

IMAR is located in the southern part of the Mongolian Plateau, which covers an area of approximately 11.8 million $\mathrm{km}^{2}$ with an elevation between $86-3522 \mathrm{~m}$. IMAR is characterized by an arid to semi-arid continental climate (Yu et al. 2003) with strong climatic gradients and grass land-use dominated practices (Figure 3.1). Precipitation decreases and temperature increases from east to west ranged from $100 \mathrm{~mm}$ to 500 $\mathrm{mm}$. The annual mean, minimum and maximum temperatures in IMAR are 1.6, -18.3 and $18.7{ }^{\circ} \mathrm{C}$, respectively (Zhou et al. 2006). IMAR is more than $70 \%$ covered with native grassland ecosystems, which corresponds to $20 \%$ of China's total grassland area (Schiborra et al. 2009). Typical steppe and meadow steppe are the major types of grassland ecosystems found in IMAR, and are most commonly used for grazing and animal production, especially in the last 20 years (Zhen et al. 2010a; Kang et al. 2007). In the northeast, meadow steppe is the most productive type of grassland ecosystem (Yu et al. 2003), developing in areas with moist fertile soils rich in organic matter and includes Stipa baicalensis, L. chinensis and Cleistogenes mucronata (Kang et al. 2007). The north central area of IMAR borders the semi-desert and is dominated by typical steppe ( $\mathrm{Li}$ et al. 2008). Typical steppe is capable of drought tolerance, and includes Stipa grandis, Leymus chinensis, and multiple species of Artemisia and 
Festuca. The south-western area is dominated by semi-desert steppe, in which is the most arid ecosystem, with the least biomass (Yu et al. 2003). Some of the species found include perennials such as Stipa krylovii, Stipa bungeana and Artemisia ordosica (Yu et al. 2003).

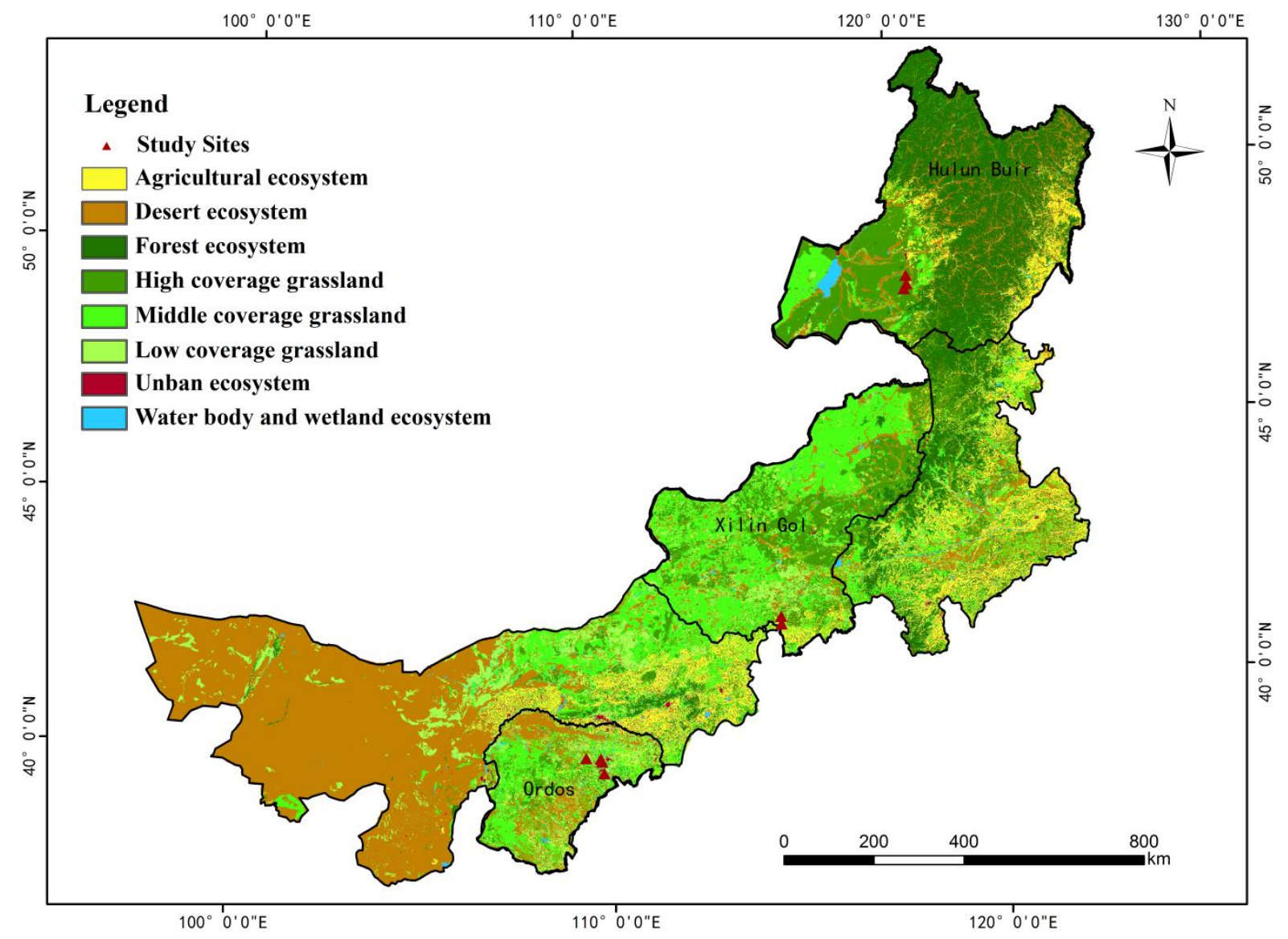

Figure 3.1 The geographic location and cover of grassland in the Inner Mongolia Autonomous Region

Grassland degradation is a widely observed problem, and estimates for IMAR's grassland reported $30 \%-50 \%$ to be degraded ( $\mathrm{Li}$ et al. 2008). In a semi-arid region like IMAR, available water through the hydrological process undoubtedly plays a key role in the functioning of the grassland ecosystems. The effects of water use mechanisms are extremely important to grassland degradation. For example, water shortages affect water transport through changing the soil physical structure and energy balance of the soil, affecting the performances of plant species and root architecture, with consequences for degradation (Zhao et al. 2010; Ji et al. 2009). To reverse the increasing tendency toward water stress and grassland degradation, a series of policies and countermeasures have been put forward and enforced to alleviate the anthropogenic stress at national to household levels in the last decade, the most important of which implemented in badly degraded areas is called the "Returning Grazing Land to Grassland Program" (König et al. 2014a). The grassland restoration policy was brought out around 1998 and broadly extended after several years of experimentation, and the herders' livelihood has been significantly affected through the implementation of the policy. The main measures of this policy are seasonal grazing and rotational grazing (e.g. in Hulun Buir), grazing prohibition and limiting the number of livestock according to the carrying capacity of degraded grassland (e.g. in Xilin Gol and Ordos). 
Increase of agriculture water consumption for food provision will increase the water stress on the grassland ecosystems. From the statistics in 2010 and 1995, IMAR's total water resources amounted to 412.1 billion $\mathrm{m}^{3}$, with a decrease of $24.5 \%$ from the level in 1995 (513 billion $\left.\mathrm{m}^{3}\right)$. The region's total water consumption in 2010 was 175.8 billion $\mathrm{m}^{3}$, including agriculture irrigation water to $70.2 \%\left(123.4\right.$ billion $\left.\mathrm{m}^{3}\right)$; next was industrial water consumption and urban domestic water consumption, which were $11.7 \%$ (20.5 billion $\left.\mathrm{m}^{3}\right)$ and $4.8 \%\left(8.5\right.$ billion $\left.\mathrm{m}^{3}\right)$; the ecological water consumption (water used directly for physiological processes of the ecosystem) was only $3.7 \%\left(6.5\right.$ billion $\left.\mathrm{m}^{3}\right)$. Compared to the level in 1995 , water consumption for agriculture increased significantly, three times higher (43.1 billion $\mathrm{m}^{3}$ in 1995) in 2010. Three typical sub-regions were selected from southwest to northeast in IMAR to capture gradient discrepancies in water resource consumption, including Dongsheng District and Ejin Horo Banner (in Ordos), located in the south-west of IMAR and mainly characterized by semi-desert steppe, Zhangxiangbai Banner (in Xilin Gol) located in the central IMAR and characterized by typical steppe, and Evenk Banner (in Hulun Buir) located northeast of IMAR and characterized by meadow steppe (Figure 3.1). The spatial distribution of water resources is different. In Hulun Buir has abundant water resources, but utilization is extremely low and about $60 \%-80 \%$ of total annual precipitation falls between June and September; Ordos has serious problems with water shortages due to the dry climate. In Xilin Gol, the proportion of agricultural water (agriculture water includes three parts: (1) irrigation water (rainfall, artificial watering); (2) water use for animal husbandry (animal drinking water, animal and manure cleaning); and (3) cleaning water for agricultural product processing.) is large, in which leads to issues from excessive extraction of groundwater for most cities and rural areas (Xiao et al. 2014). Therefore, water resource stress is serious, especially in the central and western areas of IMAR.

Major land-use types include grassland, arable land, forest and others (including unban area, water body and wetland) (Figure 3.1 and Table 3.1). The percentages of land-use in the three sub-regions are distributed differently and statistical data of invested banners or districts were explored to distinguish the differences between land uses. In Evenk Banner, the grassland and forest are the majority of land-use and occupied $56.8 \%$ and $34.6 \%$ of total land. The arable land only accounts $0.9 \%$ of total land. Evenk Banner is a traditional pastoral area and is famous for livestock and poultry cultivation. The Hulun Buir has become the largest milk and meat export centre in China. In Zhengxiangbai Banner, the grassland dominates 94\% of total land, and the percentage of arable land is larger than Evenk Banner (accounts 2.2\%); more than half of them grow grains. The forest area in Zhengxiangbai Banner has a lowest percentage, only $1.5 \%$. Half of Zhengxingbai Banner is a traditional pastoral area and half is a farming area. In recent years, the scale of cultivation has been greatly increased, from livestock husbandry from traditional farming to modern cultivation. Dongsheng District and Ejin Horo Banner in Ordos were investigated; grassland was still the dominant land-use, $67.4 \%$ and $60.7 \%$, respectively. The second largest area was forest, $27.1 \%$ in Dongsheng District and 33.1\% in Ejin Horo Banner. Dongsheng District and Ejin Horo Banner take the leading role for booming economic development with the rapid development of mining. The general trend in livestock husbandry and crop farming activities is moving away from individual participation to larger-scale operations, and the population engaged in husbandry and farming has decreased greatly over the last 15 years. 
Table 3.1 Land-use patterns in the study sites

\begin{tabular}{lllll}
\hline Land use & Hulun Buir (ha) & Xilin Gol (ha) & \multicolumn{2}{c}{ Ordos (ha) } \\
\cline { 2 - 5 } & Evenk Banner & $\begin{array}{l}\text { Zhengxiangbai } \\
\text { Banner }\end{array}$ & $\begin{array}{l}\text { Dongsheng } \\
\text { District }\end{array}$ & $\begin{array}{l}\text { Ejin Horo } \\
\text { Banner }\end{array}$ \\
\hline $\begin{array}{l}\text { Grassland } \\
\text { Arable land }\end{array}$ & $1063013(56.8 \%)$ & $585700(94.0 \%)$ & $203000(67.4 \%)$ & $435593(60.7 \%)$ \\
Of which: & $16436(0.9 \%)$ & $13867(2.2 \%)$ & $7865(2.6 \%)$ & $31891(4.4 \%)$ \\
$\quad$ grain & $9245(0.5 \%)$ & $7066(1.1 \%)$ & $5735(1.9 \%)$ & $21621(3.0 \%)$ \\
$\quad \begin{array}{l}\text { fruit-vegetable } \\
\text { Forest }\end{array}$ & $269(0.0 \%)$ & $2667(0.4 \%)$ & $103(0.0 \%)$ & $3841(0.5 \%)$ \\
Others & $647160(34.6 \%)$ & $9087(1.5 \%)$ & $81670(27.1 \%)$ & $238000(33.1 \%)$ \\
Total & $143386(7.7 \%)$ & $14246(2.3 \%)$ & $8654(2.9 \%)$ & $12471(1.7 \%)$ \\
\hline
\end{tabular}

Source: Statistics of 2010 yearbook in Evenk Banner, Zhengxiangbai Banner, Dongsheng District and Ejin Horo Banner; A banner is a county (rural area in China) or administratively equivalent district (city or suburbs area) in China, and is specially used for IMAR.

${ }^{\mathrm{A}}$ Others are including water body, wetland and urban areas.

In the past two decades, IMAR's human population and its GDP grew significantly. According to the Chinese sixth census, the total population of IMAR was 24.71 million people in 2010, compared with the fourth census of 21.46 million people in 1990, a total increase of 3.25 million people, with a growth rate of $13.15 \%$. However, the rural population has decreased, especially in Ordos. According to the report of Chinese National Statistics Bureau (2015), the total immigrated population in the IMAR from rural to city increased by 0.48 million from 1997 to 2006 . In 2013 the IMAR's GDP totalled $2.71 \times 10^{12} \mathrm{US} \$$, an enormous increase from the estimated 2.56 $\times 10^{9}$ US\$ in 1987 (Inner Mongolia Statistics Bureau 1997; Inner Mongolia Statistics Bureau 2014). Farming and animal husbandry, particularly sheep and goat herding, are the traditional approaches for subsistence. However, emphasis on industrial and economic growth during the last two decades has greatly transformed in IMAR, and caused increasing pressure on natural ecosystems. The ability to maintain a balance between economic growth and ecosystem stability, and thus foster long term societal sustainability, has become a serious challenge facing the people of IMAR.

\subsubsection{Research design, questionnaire and data collection}

A survey of 209 households ( $\mathrm{n} \approx 70$ per site) was conducted by questionnaire surveys (Appendix 5) to assess their direct water and food consumption. In addition, information on household characteristics and major production activities were collected to assess the total water consumption per household. We used a stratified random sampling method (Weber and Tiwari 1992) to select the villages in the study. We selected three villages in Hulun Buir (Evenk Banner), two villages in Xilin Gol (Zhengxiangbai Banner) and four villages in Ordos (Dongsheng District and Ejin Horo Banner). The survey was conducted from June to July 2010; simple random sampling was adopted for the household survey. For each household we visited, we asked the head of each household or a family member who was familiar with the household to answer the questions. We interviewed over $65 \%$ of total households and $70 \%$ of total population of each village with appropriate sample sizes based on the suggestion of Tabachnick and Fidell (2007) that a sample should be over 50\% when the total households of the survey unit group are lower than 100. Because the survey was carried out using face-to-face interviewing of the respondents or having the 
respondents complete the questionnaires under the research group members' guidance, a high response rate of $90.5 \%$ was obtained.

Prior to the formal surveys, we conducted test surveys using individual interviews and family group discussions with herders and other key informants, and the information collected in the test surveys guided the development of the formal questionnaire. Closed-ended questions were primarily applied for a formal survey, which included questions in the following areas: (a) demographics, land characteristics, financial conditions and the socioeconomic characteristics of the households related to household composition, levels of education, livestock owned, the area cultivated and crops grown; (b) their consumption of domestic water and food in 2010; (c) their consumption of domestic water and food around the year 1995 (as recalled by the respondents). Because a series of policies and counter-measures of grassland restoration have been put forward and enforced around 1998, this intervention may cause great changes in the use of natural recourses and its subsequent issues. In China, many data are updated every 5 years. This is why 1995 (before restoration policy) and 2010 (recent, after restoration policy) have been chosen to make comparisons. In the survey, we asked the households to categorize and quantify the foods they had consumed in the year prior to the survey (2010) and 15 years ago (1995). In this case, 15 foods as basic food types for consumption have identified according quantities of household food consumption for the analysis, namely wheat, rice, glutinous millet, potatoes, vegetables, fruit, cooking oil, bean products, mutton, beef, pork, chicken, fish, milk products and eggs. The respondents reported the variety and quantity of the consumed foods. These 15 foods were further grouped into seven categories based on clarification of Chinese dietary guidelines (2007), namely staple foods (wheat, rice and glutinous millet), potatoes, vegetable-fruit, mutton-beef, other meats (pork, chicken and fish), oil-bean products and milk-eggs. Quantities of consumed food include home grown food and purchased. The survey revealed that households could accurately recall their consumptions in the year prior to the survey and the main consumption patterns in 1995.

\subsubsection{Calculation of water consumption}

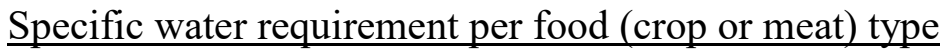

The direct water consumption of a household is defined by the domestic water required for drinking, flushing, washing and cooking. The indirect water consumption of a household is defined by the water required to produce all the food products included in this study. To calculate the cumulative indirect water consumption per capita ( $\mathrm{W}_{\text {indirect }}$ ), we used data generated from the VWC method (Zimmer and Renault 2003) and measured data of Specific Water Demand (SWD) per food (crop) item consumed by taking into consideration variations in the elevation, precipitation, temperature and economic development level from east to west of the study sites, and by using site-specific SWD for each of the sites under study (Xiao et al. 2007; Li and Wu 2008; Xu et al. 2003). The total water consumption is the sum of the direct and indirect water consumption.

In our study, we first determined the direct water consumption according to the results from the questionnaire survey, which was provided by household respondents in unite of tons per capita per year. Next, we determined the indirect water consumption for producing the specific food items that consumed by the households. The 15 basic food types are collected to estimate the indirect water consumption ( $\left.\mathrm{W}_{\text {indirect }}\right)$ in the household survey by using the following Equation (3.1): 


$$
W_{\text {indirect }}=\sum_{i=1}^{15}\left(S W D_{i} \bullet S_{i}\right)
$$

Where $S W D_{i}$ is specific water demand $\left(\mathrm{m}^{3} \mathrm{~kg}^{-1}\right)$ of a specific type of food (i); and $S_{i}$ is the quantities of food consumption in categories (i) $\left(\mathrm{kg} \mathrm{capita}^{-1}\right.$ year $\left.^{-1}\right)$. For indirect water consumption derived from meat consumption, we defined it as total amount of water consumed from the beginning of life to the end of its life period, including the daily drinking water and water contained within the feed (fodder) for livestock. The indirect water consumption of feed (fodder) includes water consumption during the period per specific fodder (grass fodder and crop fodder) growing processing. Indirect water consumption of different animal products (e.g. meat, milk and eggs) is based on the distribution ratio containing the water consumption in the animal products. The calculation method of fodder water requirement (in $\mathrm{m}^{3} \mathrm{ha}^{-1}$ ) is same as the crop water requirement.

Pressure of total water consumption on their land

For this purpose, I hypothesize that all the water consumed is from the local ecosystems, and the pressure index of total water consumption on their unit land is express by water consumption per capita.

$$
P_{\text {index }}=W_{\text {total }} / A_{\text {land }}
$$

Where $\mathrm{W}_{\text {total }}$ is the reference the total consumption of domestic water consumption and indirect water consumption from food production items, $A_{\text {land }}$ is the area of total land ownership (farmland, grass and forest) per capita (ha capita ${ }^{-1}$ ).

\subsection{Results and discussion}

\subsubsection{Background information of the respondents}

The average household size of three adult equivalents (AE) is consistent with the national average in China reported by the National Bureau of Statistics, China (NBSC) (NBSC 2006). Table 3.2 indicates that the average age of all respondents was approximately at 51, in which herders in Hulun Buir, Xilin Gol and Ordos had average ages of 43.2, 55.8 and 54.6 respectively. The average age of farmers and herders in Xilin Gol were the oldest with an average age of 55.8; 57\% of the respondents were older than fifty. This can probably be explained by the fact that since the grassland in Xilin Gol was seriously degraded, the basic daily consumption needs cannot be relied upon from the land only, and the sub-regions do not have industries like mining that herders and farmers can work for, so more young people immigrated to the city to find jobs while older people without special work abilities had to stay at home. Another reason accelerated the immigration: the government established a policy of converting most farmland to grassland and forest, and nomadic grazing was strictly forbidden in Xilin Gol.

Herders in Hulun Buir own the use-right of farmland and grassland, with per capita ownership of 0.03 and 24.4 ha, respectively. Most of their land is covered by meadow steppe; only small pieces of land in their back yards are used to grow potatoes and vegetables during the spring and summer. However, in Xilin Gol, the total amount of land owned is less than Hulun Buir, only 9.9ha per capita in overall, including 9.4ha (94\%) grassland, 0.4ha (4\%) forest and 0.1 ha (1\%) farmland. The inhabitants of Xilin Gol rural area are a combination of one-half herders and one-half farmers settled in different villages. In Ordos, the inhabitants have more diverse land-use of grassland, forest and farmland, with per capita ownership of 2.6ha (63\%), 1.1ha (28\%) and 0.4 ha $(9 \%)$, respectively. 
Table 3.2 The Characteristics of the households that participated in the survey

\begin{tabular}{|c|c|c|c|c|c|}
\hline & Study Area & $\begin{array}{l}\text { Hulun Buir } \\
\qquad(N=66)\end{array}$ & $\begin{array}{l}\text { Xilin Gol } \\
(N=71)\end{array}$ & $\begin{array}{c}\text { Ordos } \\
(N=72)\end{array}$ & $\begin{array}{c}\text { Total } \\
(N=\mathbf{2 0 9})\end{array}$ \\
\hline & Family size & 3.2 & 3.2 & 3.4 & 3.3 \\
\hline & Average age & 43.2 & 54.6 & 55.3 & 51.4 \\
\hline Ave & age education level & 7.8 & 6.3 & 4.7 & 6.3 \\
\hline \multirow{5}{*}{ 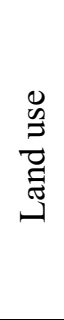 } & & A1 (\%) & A1 (\%) & A1 (\%) & A1 (\%) \\
\hline & Farmland & $0.0(0)$ & $0.1(1)$ & $0.4(9)$ & $0.2(1)$ \\
\hline & Grassland & $24.4(100)$ & $9.4(94)$ & $2.6(63)$ & $11.5(94)$ \\
\hline & Forest & $0(0)$ & $0.4(4)$ & $1.1(28)$ & $0.5(4)$ \\
\hline & Total land area & $24.4(100)$ & $9.9(100)$ & $4.1(100)$ & $12.2(100)$ \\
\hline \multirow{5}{*}{$\begin{array}{l}\dddot{\Xi} \\
\Xi \\
\Xi\end{array}$} & & A2 (\%) & A2 (\%) & A2 (\%) & A2 (\%) \\
\hline & Crop production & $97(1)$ & $2656(14)$ & $500(1)$ & $1082(6)$ \\
\hline & Livestock & $13,438(72)$ & $7188(38)$ & $1765(3)$ & $7109(38)$ \\
\hline & Non-agriculture $^{1}$ & $5250(28)$ & $8844(47)$ & $17,425(96)$ & $10,705(57)$ \\
\hline & Total income & $18,784(100)$ & $18,688(100)$ & $19,690(100)$ & $18,896(100)$ \\
\hline
\end{tabular}

${ }^{\mathrm{T}}$ Non-agriculture includes income from migrant job, subsidies and land expropriation;

A1: Average area of land per capita in unite of ha;

A2: Average amount of income per capita in unite of CNY.

Total annual income per capita in the research area is $18896 \mathrm{CNY}$ (approximately 3000 US\$) per capita over all income sources, including $6 \%$ from crop production, $38 \%$ from livestock herding, 33\% from migrant jobs, $7 \%$ from subsidies and $17 \%$ from land expropriation for mining and forest planting (ecological corridor construction project). Results show that per capita income in Ordos is highest with average per capita of $19690 \mathrm{CNY}$ (approximately 3126 US\$); followed by Hulun Buir (18 784 CNY, approximately 2983 US\$); the lowest is Xilin Gol with 18688 CNY (approximately 2967 US\$). In our samples, livestock herding still is the most important source of income in Hulun Buir, accounting for $72 \%$ of total income. Comparing to Hunlun Buir, the most significant difference in Xilin Gol is the income from livestock has decreased to $38 \%$ of total, but the income from crop products, nonagriculture works has increased to $14 \%$ and $47 \%$, respectively. The income from migrant labour increased greatly, occupying $37 \%$ of total income. This may indicate that the inhabitants in Xilin Gol do not strongly rely on their grassland due to the degradation and herders and farmers are beginning to find new sources of income, such as the income from employment. In Ordos, off-farm income accounts for $96 \%$ of this total. A significant component of income is land expropriation, which makes up almost $79 \%$ of total income.

\subsubsection{Spatial and temporal variation of food consumption}

Results have shown significant spatial variations in consumption. In Hulun Buir, the households consume more meat products, especially mutton and beef which represent over $76 \%$ of total meat consumption, accounting for an annual average per capita of $53.9 \mathrm{~kg}$ and $43.3 \mathrm{~kg}$, respectively in 2010 (Table 3.3). This is due to the fact that Hulun Buir dominated with a high cover of meadow steppe and that average size of 
grassland per household in Hulun Buir is the highest (24.4ha in 2010), which greatly exceeds the average level of 11.5 ha of the three sub-regions. In addition, in Hulun Buir, herders rear significantly more sheep and goats than herders in Xilin Gol, and hence consume more mutton (43.3kg capita ${ }^{-1}$ year $^{-1}$ ) than the rest in 2010. Although Hulun Buir herders raise significantly more cattle (18vs. 4.2) than those in Xilin Gol, they use the cattle primarily to earn income from selling milk rather than for meat production and consumption; as a result, their consumption of beef did not differ significantly from that in Xilin Gol in 2010 (per capita totals of 53.9 and $46.4 \mathrm{~kg}$ year 1 , respectively). Compared to Hunlun Buir and Ordos, herders and farmers in Xilin Gol consumed more staple foods, especially flour in $2010\left(102.7 \mathrm{~kg} \mathrm{capita}^{-1}\right.$ year $^{-1}$ in Hulun Buir; $108.1 \mathrm{~kg}$ capita $^{-1}$ year $^{-1}$ in Xilin Gol and $62.1 \mathrm{~kg}$ capita $^{-1}$ year $^{-1}$ in Ordos). Ordos shows a significant difference in food consumption from Hulun Buir and Xilin Gol. The inhabitants in Ordos consume more potatoes $\left(70.9 \mathrm{~kg}_{\text {capita }}{ }^{-1}\right.$ year $^{-1}$ in Hulun Buir; 50.6kg capita ${ }^{-1}$ year $^{-1}$ in Xilin Gol and $168.4 \mathrm{~kg}_{\text {capita }}{ }^{-1}$ year $^{-1}$ in Ordos), vegetables $\left(66.7 \mathrm{~kg}\right.$ capita $^{-1}$ year $^{-1}$ in Hulun Buir; $50.2 \mathrm{~kg}$ capita $^{-1}$ year $^{-1}$ in Xilin Gol and $119 \mathrm{~kg}_{\text {capita }}{ }^{-1}$ year $^{-1}$ in Ordos) and fruits $\left(19.8 \mathrm{~kg}_{\text {capita }}{ }^{-1}\right.$ year $^{-1}$ in Hulun Buir; $25.5 \mathrm{~kg} \mathrm{capita}^{-1}$ year $^{-1}$ in Xilin Gol and $40.6 \mathrm{~kg}$ capita $^{-1}$ year $^{-1}$ in Ordos) instead of staple foods $\left(183.2 \mathrm{~kg} \mathrm{capita}^{-1}\right.$ year $^{-1}$ in Hulun Buir; $184.4 \mathrm{~kg} \mathrm{capita}^{-1}$ year $^{-1}$ in Xilin Gol and $111.8 \mathrm{~kg} \mathrm{capita}^{-1}$ year $^{-1}$ in Ordos) and milk products in $2010\left(96.9 \mathrm{~kg} \mathrm{capita}^{-1}\right.$ year $^{-1}$ in Hulun Buir; $88.8 \mathrm{~kg}_{\text {capita }}^{-1}$ year $^{-1}$ in Xilin Gol and $27.2 \mathrm{~kg}_{\text {capita }}{ }^{-1}$ year $^{-1}$ in Ordos). This discrepancy towards the consumption of foods is associated with what they produced or cultivated locally. However, in Ordos, most of the farmers and herders were liberated from their land due to degrading ecosystems and the restoration policy for returning the farmland to forest and grassland (implementation of grazing prohibition). Their livelihood is not to rely on the land, and their consumption depends more on market trading.

We found that the consumption patterns of foods have changed in Hulun Buir, Xilin Gol and Ordos from 1995 to 2010. The diet of Hulun Buir still involves high meat consumption, with an amount of $127.2 \mathrm{~kg}_{\text {capita }}$ year $^{-1}$ in 2010 compared to $96.1 \mathrm{~kg}$ capita $^{-1}$ year $^{-1}$ in 1995. Although the pastoralists turn to settlement away from nomadic grazing, the livelihoods of herders still relies on livestock products and large numbers of livestock. However, in Xilin Gol, consumption of mutton and beef decreased from $82.8 \mathrm{~kg} \mathrm{capita}^{-1}$ year $^{-1}$ in 1995 to $65.6 \mathrm{~kg} \mathrm{capita}^{-1} \mathrm{year}^{-1}$ in 2010 ; whilst vegetable and fruit consumption increased greatly from $95.3 \mathrm{~kg} \mathrm{capita}^{-1} \mathrm{year}^{-1}$ in 1995 to $126.3 \mathrm{~kg}$ capita $^{-1}$ year $^{-1}$ in 2010; and staple foods remained similar. This is caused by a great reduction in livestock grazing due to implementation of a restoration policy measures of limiting the number of livestock based on the land carrying capacity (one sheep unite per $40 \mathrm{mu}$, equal 2.7 sheep unite per hector); a household in Xilin Gol on average consumes approximately 25 sheep (equal to five cattle). In Ordos, the consumption for each item of food changed dramatically (Table 3.3). By 2010, the consumption of staple food in Ordos dropped significantly, especially flour and rice from $90.6 \mathrm{~kg}_{\text {capita }}$ year $^{-1}$ in 1995 to $62.1 \mathrm{~kg} \mathrm{capita}^{-1}$ year $^{-1}$ in 2010 and from $56 \mathrm{~kg}$ capita $^{-1}$ year $^{-1}$ in 1995 to $36.8 \mathrm{~kg}_{\text {capita }}$ year $^{-1}$ in 2010, respectively; Meanwhile, vegetables, fruits, eggs and milk maintained an increasing trend, in which from $40.1 \mathrm{~kg} \mathrm{capita}^{-1}$ year $^{-1}$ in 1995 to $119 \mathrm{~kg} \mathrm{capita}^{-1}$ year $^{-1}$ in 2010 , from $16.6 \mathrm{~kg} \mathrm{capita}^{-1}$ year $^{-1}$ in 1995 to $40.6 \mathrm{~kg}_{\text {capita }}{ }^{-1}$ year $^{-1}$ in 2010 , from $8.1 \mathrm{~kg}$ capita $^{-1}$ year $^{-1}$ in 1995 to $11 \mathrm{~kg}$ capita $^{-1}$ year $^{-1}$ in 2010 , from $14 \mathrm{~kg}_{\text {capita }}{ }^{-1}$ year $^{-1}$ in 1995 to $27.2 \mathrm{~kg} \mathrm{capita}^{-1}$ year $^{-1}$ in 2010, respectively; Within the category of meat, consumption of pork (from $36.6 \mathrm{~kg}$ capita $^{-1}$ year $^{-1}$ in 1995 to $41.2 \mathrm{~kg}_{\text {capita }}{ }^{-1}$ year $^{-1}$ in 2010 ), chicken (from $7.8 \mathrm{~kg}$ capita $^{-}$ ${ }^{1}$ year $^{-1}$ in 1995 to $8.1 \mathrm{~kg} \mathrm{capita}^{-1}$ year $^{-1}$ in 2010) and fish (from $1.2 \mathrm{~kg} \mathrm{capita}^{-1}$ year $^{-1}$ in 
1995 to $5.4 \mathrm{~kg}$ capita $^{-1}$ year $^{-1}$ in 2010) rose slightly in Ordos, but the consumption of beef and mutton has decreased from $35.7 \mathrm{~kg}$ capita $^{-1}$ year $^{-1}$ in 1995 to $23.2 \mathrm{~kg}$ capita $^{-1}$ year ${ }^{-1}$ in 2010 , and from $15.9 \mathrm{~kg} \mathrm{capita}^{-1}$ year $^{-1}$ in 1995 to $12.5 \mathrm{~kg}_{\text {capita }}$ year $^{-1}$ in 2010 , respectively. This may be due to more people engage in off-farming activities in Ordos, such as milling, transportation and urban construction that improved the economic purchasing power of the herders and market development. As a consequence, their consumption is less reliant upon their land and more affected by market trading. The herders and farmers have to buy meat from markets, and pork, chicken and fish are cheaper than mutton and beef.

Table 3.3 The variation of food consumption per capita per year (unit: $\mathrm{kg} \mathrm{capita}^{-1}$ year $^{-1}$ )

\begin{tabular}{lllllll}
\hline $\begin{array}{l}\text { Research Area } \\
\text { Year }\end{array}$ & $\begin{array}{l}\text { Hulun Buir } \\
\mathbf{1 9 9 5 / 2 0 1 0}\end{array}$ & t-test & $\begin{array}{l}\text { Xinlin Gol } \\
\mathbf{1 9 9 5 / 2 0 1 0}\end{array}$ & t-test & $\begin{array}{l}\text { 1995/2010 } \\
\text { t-test }\end{array}$ \\
\hline Staple food & $152.2 / 183.2$ & $*$ & $188.8 / 184.4$ & $*$ & $161.2 / 111.8$ & $* * *$ \\
Oil and Beans & $16.9 / 25.1$ & $* *$ & $20.4 / 26.6$ & $*$ & $19.2 / 22.5$ & $*$ \\
Potato & $55.9 / 70.9$ & $* *$ & $50.9 / 50.6$ & $*$ & $202.2 / 168.4$ & $* *$ \\
Vegetable-Fruit & $45.8 / 86.5$ & $* * *$ & $44.4 / 75.7$ & $* *$ & $56.7 / 159.6$ & $* * *$ \\
Egg-milk & $90.2 / 108.5$ & $*$ & $119.5 / 107.6$ & $* *$ & $22.1 / 38.2$ & $* * *$ \\
Mutton-Beef & $75.7 / 97.2$ & $* *$ & $82.8 / 65.5$ & $* *$ & $51.6 / 35.7$ & $* * *$ \\
Other meat ${ }^{2}$ & $20.4 / 30.1$ & $* *$ & $11.8 / 13.9$ & $*$ & $45.6 / 54.7$ & $* *$ \\
Total $\left(\mathrm{kg} \mathrm{year}^{-1}\right)$ & $457.1 / 601.4$ & $* *$ & $518.6 / 524.4$ & $*$ & $558.6 / 590.9$ & $* *$ \\
\hline
\end{tabular}

${ }^{\mathrm{T}}$ Staple food is including flour, rice and glutinous millet;

${ }^{2}$ Other meat is including pork, chicken and fish;

$* \mathrm{p} \geq 0.05$ (No significant changes);

$* * 0.01>\mathrm{p}<0.05$ (Significant changes);

$* * * \mathrm{p} \leq 0.01$ (High significant changes).

\subsubsection{Water consumption per household}

\section{Direct (Domestic) Water Consumption pattern}

In 2010, average annual amount of water consumed per capita were $13.1 \mathrm{~m}^{3}$ year $^{-1}$, and total daily domestic water intake ranged from 49.3 to $17.9 \mathrm{~m}^{3}$ capita $^{-1}$ year ${ }^{-1}$ in surveyed households. In Hulun Buir, all respondents used ground water from private wells, and the water use is free of charge. They consumed higher amounts of water (in average of $14.0 \mathrm{~m}^{3}$ capita $^{-1}$ year $^{-1}$ ) in 2010 than those in Xilin Gol and Ordos due to relatively more rain for ground water recharge compared to other areas of IMAR (Chen et al. 2007). After 2005, a national tap water construction project in rural areas was implemented by the government in some parts of IMAR, and about $37 \%$ and $42 \%$ of surveyed households in Xilin Gol and Ordos respectively able to use tap water. The project did not cover the area of Hulun Buir. Decreasing trends in the amounts of water consumed were exhibited in all survey sites. In Xilin Gol this trend was more apparent, where water consumption decreased from $15.3 \mathrm{~m}^{3}$ capita $^{-1}$ year $^{-1}$ in 1995 to $12.5 \mathrm{~m}^{3}$ capita $^{-1}$ year $^{-1}$ in 2010 . While in Ordos, water consumption was stable and reduced slightly from $13.7 \mathrm{~m}^{3}$ capita $^{-1}$ year ${ }^{-1}$ in 1995 to $13.2 \mathrm{~m}^{3}$ capita $^{-1}$ year ${ }^{-1}$ in 2010. Although there were no significant changes for the direct domestic water consumption, the water consumption shows a little slight decreasing trend in Hulun Buir, Xilin Gol and Ordos, mainly due to severe drought in 1995. This discrepancy 
may also be caused by the water payment mechanism for using the tap water. In 2010, water from privately-owned wells was totally free in all three sub-regions, but tap water must be paid for according to the actual quantity of water they consume (water

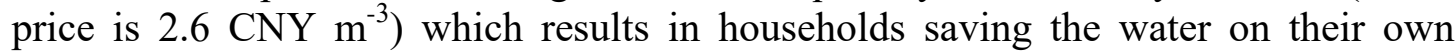
initiative. This phenomenon suggests that the market price of water can reduce water consumption.

\section{Indirect Water Consumption from food (crop) consumption}

The calculation results show that the discrepancy of indirect water consumption for specific food consumption was large. The spatial variations of SWD in three subregions of Hulun Buir, Xilin Gol and Ordos have been identified according to previous research (Xiao et al. 2007; Li and Wu 2008; Xu et al. 2003). The top five foods for SWD are beef, mutton, oil produce, marine products and pork, and the bottom five foods for water demand are vegetables, potatoes, flour, fruit and rice (Table 3.4). With accumulation of indirect water consumption for annual total food consumption, the results show that the herders in Hulun Buir consumed the highest amount of indirect water for food production, $2307.3 \mathrm{~m}^{3}$ capita $^{-1}$ year $^{-1}$ in 2010 . The Ordos consumed the lowest indirect water with amount of $1553.8 \mathrm{~m}^{3}$ capita $^{-1}$ year $^{-1}$ in 2010. Compared to the level of 1995 , the indirect water consumption shows a decreasing trend in both Xilin Gol $\left(2377.7 \mathrm{~m}^{3}\right.$ capita $^{-1}$ year $^{-1}$ in 1995 and $2054.3 \mathrm{~m}^{3}$ capita $^{-1}$ year $^{-1}$ in 2010) and Ordos $\left(1838.5 \mathrm{~m}^{3}\right.$ capita $^{-1}$ year $^{-1}$ in 1995 and $1553.8 \mathrm{~m}^{3}$ capita $^{-1}$ year $^{-1}$ in 2010) (Table 3.4). The main reason is the changes in food patterns from 1995 to 2010 leading to more vegetable and fruit consumption instead of meat consumption, and meat consumption switching from a combination of mutton and beef to more diverse meat consumption including fish, chicken and pork.

Although the amount of vegetable and fruit consumption in all three sub-regions shows a high significant increasing trend when comparing the food consumption in 1995 and 2010, due to the SWD of vegetable and fruit being relative low (in average 0.1 for vegetable and 1.2 for fruit), the indirect water from agri-food production item remains at a relatively low level. The changes in indirect water consumption driven by mutton and beef are significant in all three sub-regions in large proportion (Table 3.4). In Hulun Buir, the total indirect water consumption increased $31.2 \%$ from $1758.8 \mathrm{~m}^{3}$ capita $^{-1}$ year $^{-1}$ in 1995 to $2307.3 \mathrm{~m}^{3}$ capita $^{-1}$ year $^{-1}$ in 2010 , for which the contribution from beef is the highest $\left(469.6 \mathrm{~m}^{3}\right.$ capita $^{-1}$ year $\left.^{-1}\right)$ among total variations, and indirect water from mutton contributed negatively $\left(-87.6 \mathrm{~m}^{3}\right.$ capita $^{-1}$ year $\left.^{-1}\right)$ to total changes

In Xilin Gol, the indirect water consumption from beef and mutton products has decreased $446.6 \mathrm{~m}^{3}$ capita $^{-1}$ year $^{-1}$ (21.5\% of the level of 1995) from 1995 to 2010 . In Ordos, the mutton and beef consumption both declined comparing to 1995, which contributed $-225.0 \mathrm{~m}^{3}$ capita $^{-1}$ year $^{-1}$ and $-68 \mathrm{~m}^{3}$ capita $^{-1}$ year $^{-1}$ of total indirect water consumption changes. Therefore, changing diet behaviour and reducing the population can be considered an option for sustainable use of water. 
Table 3.4 Indirect water consumption from major food consumption items

\begin{tabular}{|c|c|c|c|c|c|c|c|c|c|}
\hline \multirow[t]{3}{*}{ Type of foods } & \multicolumn{3}{|c|}{ SWD $\left(\mathrm{m}^{3} \mathrm{~kg}^{-1}\right)$} & \multicolumn{6}{|c|}{$W_{\text {indirect }}\left(m^{3}\right.$ capita $^{-1}$ year $\left.^{-1}\right)$} \\
\hline & \multirow[t]{2}{*}{ Hulun Buir ${ }^{1}$} & \multirow[t]{2}{*}{ Xilin $\mathrm{Gol}^{2}$} & \multirow[t]{2}{*}{$\operatorname{Ordos}^{3}$} & \multicolumn{2}{|l|}{ Hulun Buir } & \multicolumn{2}{|l|}{ Xilin Gol } & \multicolumn{2}{|l|}{ Ordos } \\
\hline & & & & $1995 / 2010$ & $\begin{array}{l}\text { Changes } \\
\text { in } \%{ }^{6}\end{array}$ & $1995 / 2010$ & $\begin{array}{l}\text { Changes } \\
\text { in } \%{ }^{6}\end{array}$ & $1995 / 2010$ & $\begin{array}{l}\text { Changes } \\
\text { in } \%{ }^{6}\end{array}$ \\
\hline Staple food ${ }^{1}$ & $1.0-3.2$ & $1.4-3.2$ & $1.5-3.6$ & $213.1 / 256.5$ & 20.4 & $339.8 / 331.9$ & -2.3 & $322.4 / 223.6$ & -30.6 \\
\hline Oil and Beans & $1.7-4.2$ & $3.2-6.2$ & $1.0-5.8$ & $60.8 / 90.4$ & 48.5 & $77.5 / 101.1$ & 30.5 & $74.9 / 87.8$ & 17.2 \\
\hline Potato & 0.8 & 0.2 & 1.1 & $44.7 / 56.7$ & 26.8 & $10.2 / 10.1$ & -1.0 & $222.4 / 185.24$ & -16.7 \\
\hline Vegetable-Fruit & $0.1-0.8$ & $0.1 / 1.4$ & $0.3-1.3$ & $9 / 20.5$ & 127.8 & $16.1 / 40.7$ & 152.8 & $33.6 / 88.5$ & 163.4 \\
\hline Egg-milk & $1.8-3.8$ & $2.2-2.7$ & $2.2-2.9$ & $177.8 / 218.5$ & 22.9 & $268 / 246.2$ & -8.1 & $54.3 / 91.7$ & 68.9 \\
\hline Mutton-Beef & $15.1-17.2$ & $18-20$ & $18-20$ & $1198.9 / 1580.9$ & 31.9 & $1623 / 1273.6$ & -21.5 & $960.6 / 667.6$ & -30.4 \\
\hline Other meats $^{5}$ & $1.9-3.8$ & $3.1-5$ & $3.7-5$ & $54.4 / 83.8$ & 54.0 & $43 / 50.7$ & 17.9 & $170.3 / 209.4$ & 23.0 \\
\hline \multicolumn{4}{|c|}{ Total indirect water consumption from food production item } & $1758.8 / 2307.3$ & 31.2 & $2377.6 / 2054.3$ & -13.6 & $1838.5 / 1553.8$ & -15.5 \\
\hline
\end{tabular}

${ }^{1}$ the data of SWD is from Xiao et al. (2007);

${ }^{2}$ the data of SWD is from Li and Wu (2008);

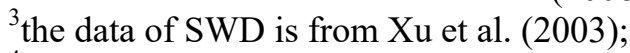

${ }^{4}$ Staple food includes flour, rice and glutinous millet;

${ }^{5}$ Other meat includes pork, chicken and fish;

6 "Changes in \%" was calculated based on level in 1995. 


\subsubsection{Water consumption pressure for grassland ecosystems}

In IMAR, grassland is the dominant ecosystem; it is one of the most important terrestrial ecosystems on the earth, provides fundamental ecosystem services for humans such as internal nutrient cycling, soil protection, biodiversity conservation, climatic regulation and water supply (König et al. 2014b; Xiao et al. 2013). Many studies have pointed out that water is treated as a service provided by ecosystems as well as a system (inland waters) (Li et al. 2015; Dudley and Stolton 2003). Therefore, the sustainable use of water can be critical issue for grassland. Overuse of water resources can be one of the main drivers for grassland degradation, because of water expressed as a comprehensive regulation through various hydrological processes of the grassland ecosystem, including canopy interception, stem flow, litter interception, water storage in soil and permeability, runoff and vaporization (Zhang et al. 2010). The water conserved in the local ecosystem is the main source for the human's direct and indirect water consumption. The pressure index of grassland can be estimated by accounting total water consumption per hector in ecosystems to identify areas that are critical to human well-being as well as those that require particular attention in designing strategies for sustainable grassland management.

In this research, the degree of intensive consumption of water resources can be measured by the amount of water intake from local grassland ecosystems in the land unit to indicate the pressure for local grassland. Figure 3.2 shows the results for water consumption intake from grassland ecosystems per hectare. In Hulun Buir, humans took in $95.1 \mathrm{~m}^{3} \mathrm{ha}^{-1}$ year $^{-1}$ of water in 2010 and $72.7 \mathrm{~m}^{3} \mathrm{ha}^{-1}$ year $^{-1}$ in 1995 from local grassland ecosystems, which was the lowest comparing to Xilin Gol and Ordos. Although Hulun Buir has the highest total water consumption per capita, the herder has abundant grassland resources, which results in low pressure from water consumption on their grassland. On the contrary, Xilin Gol and Ordos have higher degrees of water consumption per land unit which creates high pressure on their grassland. Such high water consumption pressure may affect water conservation services and productivity of grassland ecosystems and the grassland will be exposed to degradation.

Due to the changes of food consumption patterns recently, the water consumption per unit area shows a decreasing trend in 1995-2010 in Xilin Gol and Ordos from $241.7 \mathrm{~m}^{3} \mathrm{ha}^{-1}$ year $^{-1}$ to $208.8 \mathrm{~m}^{3} \mathrm{ha}^{-1}$ year $^{-1}$, and $451.8 \mathrm{~m}^{3} \mathrm{ha}^{-1}$ year ${ }^{-1}$ to $382.2 \mathrm{~m}^{3} \mathrm{ha}^{-1}$ year ${ }^{1}$, respectively. Since the $1980 \mathrm{~s}$, the economic development of IMAR was so fast that the total water requirement increased greatly due to increased meat consumption (Dai et al. 2009). With the subsequent issue of overuse of grassland, ecosystems degraded seriously in IMAR in the 1990s. In 2010, the water shortage issue limited their farming and grazing, and the grassland ecosystems in IMAR could not support the needs of inhabitants, which meant people started to purchase food from outside of the ecosystem to reduce dependency on local ecosystems (Du et al. 2014; Renault and Wallender 2000). The purchase activities resulted in diversified consumption, especially increased vegetable and fruit consumption, but purchased food highly depended on economic levels. Better economic income improved purchase power of herders and market development, such as in Ordos, and high income level causes diversified food consumption patterns. Beside the influences of different natural environment conditions and economic development, the grassland restoration policy measures have deeply changed pastoral tradition and basic household consumption patterns. Grazing activity was less affected by policy measures of seasonal grazing and rotational grazing than the other policy measures, thus more herders preferred to 
maintain most of their food/water consumption patterns (e.g. in Hulun Buir). However, in the context of grazing prohibitions and limited number of livestockrearing policy measures (e.g. in Xilin Gol and Ordos), the food/water consumption patterns changed greatly. Therefore, the implementations of grassland ecosystem restoration policy aggravated the herders and farmers in IMAR, who changed their diet by reducing their meat consumption and starting to purchase food to reduce indirect water consumption for conservation of the local grassland.

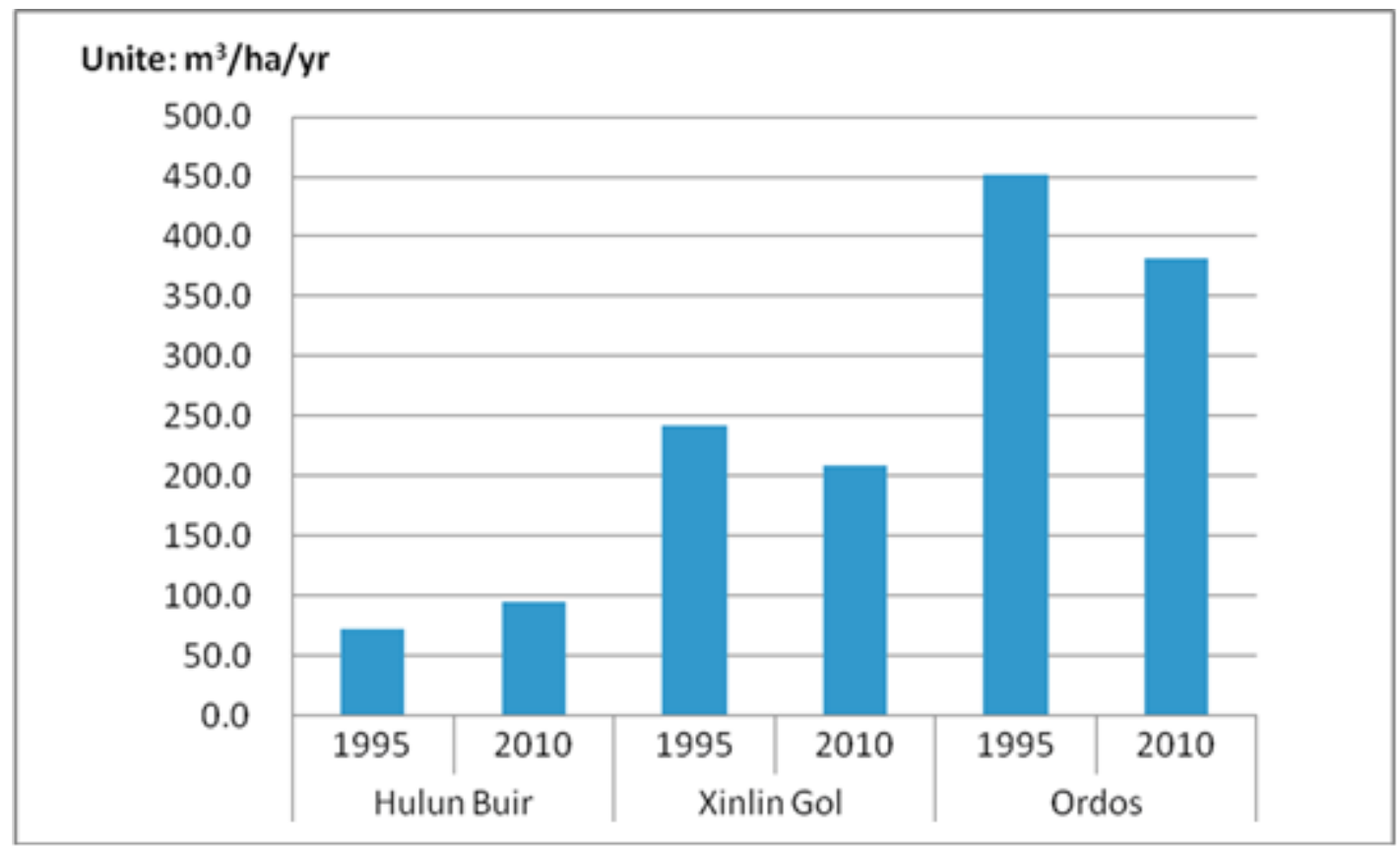

Figure 3.2 Water requirement per unit of land area for producing consumable items

\subsubsection{Advantage, uncertainties and future improvements}

The method for estimating the total water consumption in direct and indirect ways according to quantities and types of household food consumption can be widely applied for many cases, which is useful in explaining the effects of household consumption and livelihoods on grassland's water conservation services, improving herder awareness of the environmental effects from their daily consumption activities, and in providing guidelines for sustainable grassland management, and it provides a viewpoint on ecosystem adaptive management at a household level, especially in linking micro-level livelihood (alternative diets) responses to macro-level environmental/policy procedures, which facilitates the further review of policies and enables policy adjustment and amendment through feedback from livelihood outcomes.

The realistic total water consumption is difficult to estimate, due to the complexity of ecological processes in our world. This approach tries to show the actually total water use of humans, but it is still a partial estimate; the water use for fuel consumption is not included. Many steps of the calculation are general estimates, for instance of (1) selection of data of SWD per food (crop); it still needs more field experiment data to establish accurate results; (2) the data on direct water consumption and indirect water consumption for 1995 and 2010 was gathered in one survey of 2011 (recalled by the respondents); although the herders were able to recall the situation in 1995 and 
answered the questions properly, there are is still the possibility of overestimates or underestimates because of consumed foods did not actually weighed.

Most areas of the world show economic development results increased purchasing power, causing increased demand for meat products (FAO 2009; Grigg 1995; Popkin 2002), especially in developing countries like Brazil and China; populations continue to increase, and combined with economic growth, demand for animal products is predicted to increase and would require more water consumption. These show different trend with our results, which may be because most food consumption research is on the national or global scale, based on statistics or trading data, while the results of this chapter are based on the household level of consumption in a specific pastoral area under different circumstances. Making real comparisons, however, is hard. Moreover, understanding the likely structure and trends of the water consumption from food consumption can give policymakers a better picture of sustainable water management. Therefore, future research is highly encouraged to assess how diet composition will change with household level under different cultural backgrounds and constraint conditions.

\subsection{Conclusion and suggestions to management}

Because at least $99 \%$ of the total water consumption of households consists of indirect water consumption behind food production, the large differences between the specific water requirements of the various foods (crop) types for consumption indicate that the total water consumption can be reduced if we change our food consumption patterns. The results show that beside the influences of different natural environment conditions and economic development, the grassland restoration policy measures deeply changed pastoral tradition and food consumption patterns. When comparing the food and water consumption in 2010 to 1995, although the amount of vegetables and fruits in all three sub-regions show a highly significant increasing trend when compared to food consumption in 1995 and 2010, the water consumption behind the food production displays a decreasing trend in Xilin Gol and Ordos due to the decrease of meat consumption and increase in fruit and vegetable consumption.

The changes for mutton and beef are significant in all three sub-regions, which contribute the large proportion of variation in indirect water consumption. In Hulun Buir, total indirect water consumption has increased over $31.2 \%$ by comparing the level 1995, in which beef-mutton contributes the highest proportion. In Xilin Gol, the indirect water consumption from beef-mutton has decreased $21.5 \%$ of the level of 1995. In Ordos, the mutton-beef consumption all declined greatly (30.4\%) comparing to 1995 , which beef and mutton contributed $79 \%$ and $23.9 \%$ of total decreased indirect water consumption. In Hulun Buir, the pressure of local grassland was lowest comparing to Xilin Gol and Ordos. Although Hulun Buir has highest total water consumption per capita, the herder has abundant land resources which mean a low amount of water intake from local ecosystems. On the contrary, Xilin Gol and Ordos have high pressure on grassland due to a higher degree of water consumption per land unit. However, due to the changes in food consumption patterns recently, the water consumption per unit area shows a decreasing trend in Xilin Gol and Ordos from 1995 to 2010 .

Compared to direct water consumption, indirect water consumption from food production made up the major part of total water consumption, which is affected by (1) geographic location (grassland types), (2) economic development level and (3) grassland-use policy measures. The grassland ecosystem degradation in IMAR leads 
to a shortage of meat production that result in people starting to purchase food from outside of the ecosystem to reduce dependency on local ecosystems. These purchase activities resulted in diversified consumption, especially increased vegetable and fruit consumption, but purchased food highly depends on the economic level. In Ordos, high income level causes a reduction in direct water consumption through adoption of diversified food consumption patterns. In addition, the grassland restoration policy measures deeply changed pastoral tradition and basic household consumption patterns. In the context of grazing prohibitions and limited number livestock-rearing policy measures (e.g. in Xilin Gol and Ordos), the food/water consumption patterns changed greatly from meat-dominated consumption to more diverse staple and vegetable consumption patterns.

The reductions in indirect water consumption can reduce the pressure on local grassland, and grassland conservation can be achieved by changing food consumption patterns. Under the current scale of restoration policy, subsequent policy measures need to increase livelihood diversity and mitigate livelihood dependence on grassland ecosystems. A variety of strategies need to be employed, such as provided off-farm works, skill training, establishment of food trading market and education on healthy diets. Therefore, accounting for direct and indirect water consumption is critical to human well-being and requires particular attention in designing strategies for sustainable development of natural resources. 


\section{CHAPTER 4}

Effects of Grassland Conservation Policy on Household Livelihoods and Dependence on Grasslands

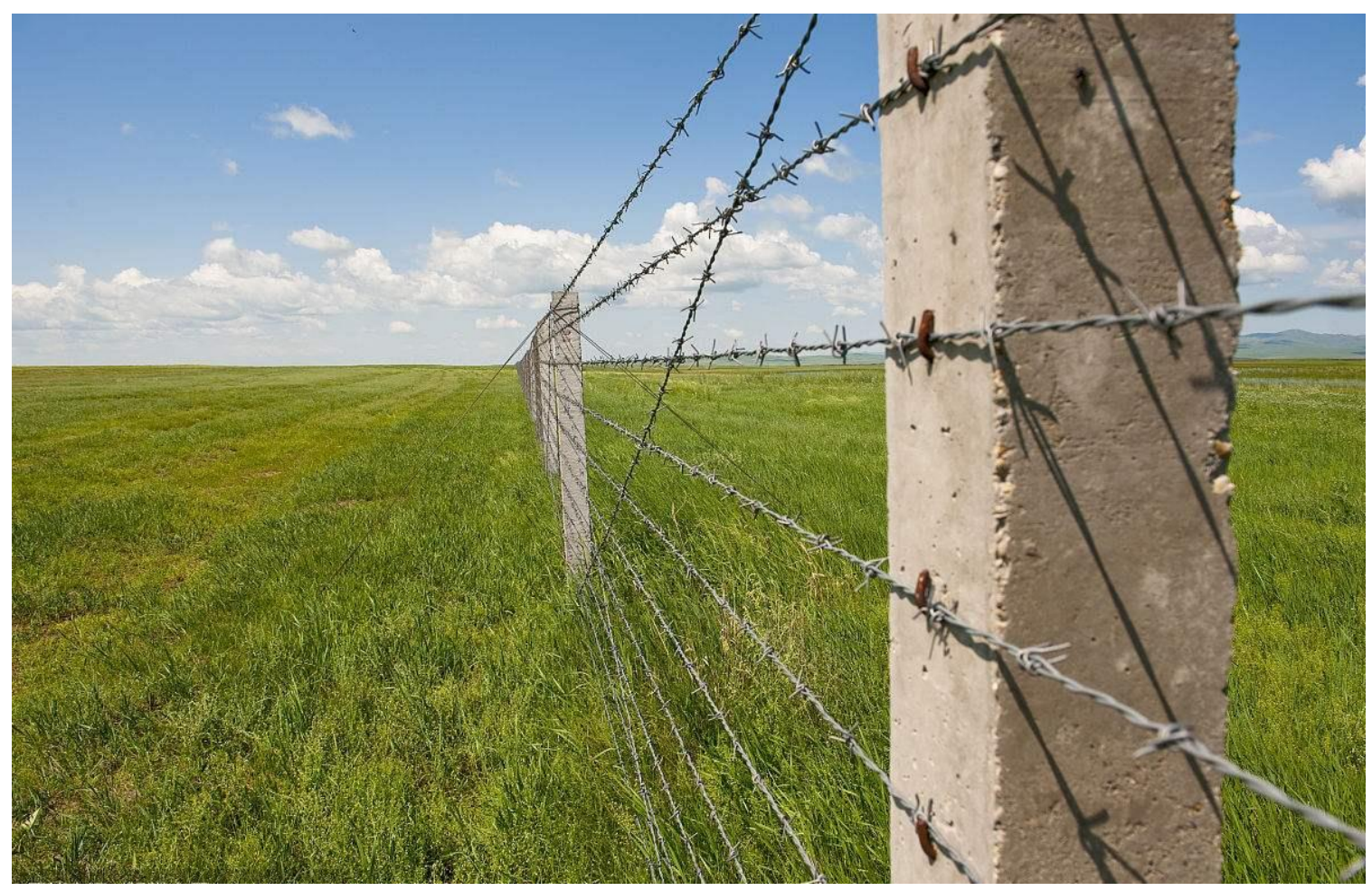

\section{Based on:}

Du B., Zhen L., Yan H., de Groot R. 2016. Effects of government grassland conservation policy on household livelihoods and dependence on local grasslands: evidence from Inner Mongolia, China. Sustainability 8(12): 1314. 


\begin{abstract}
:
Grassland degradation intensifies human-environment conflicts and adversely affects local residents' livelihoods. To reduce grassland degradation in Inner Mongolia, China, the government has enforced (since 1998) a series of grassland conservation and management policies that restrict the use of grasslands. To ease the impact on the residents' livelihoods, the national and regional governments have offered a series of top-down arrangements to stimulate sustainable use of the grasslands. Simultaneously, local households spontaneously developed bottom-up countermeasures. To determine the effects of these processes, the members of 135 households were interviewed by using a mix of qualitative and quantitative methods. We analysed the effects on household dependence on local grasslands and on perceptions of the future of grassland use. Our findings show that the implementation of the grassland conservation policies significantly affected household livelihoods, which in turn affected household use of natural assets (primarily the land), their agricultural assets (farming and grazing activities) and their financial assets (income and consumption), resulting in fundamental transformation of their lifestyles. The households developed adaptation measures to account for the dependence of their livelihood on local ecosystems by initializing strategies, such as seeking off-farm work, leasing pasture land, increasing purchases of fodder for stall-fed animals and altering their diet and fuel consumption to compensate for their changing livelihoods.
\end{abstract}

Keywords: Livelihood Analysis; Dependence; Conservation Policy; Grassland Management 


\subsection{Introduction}

Grasslands are among the largest and most important ecosystems in the world, and human populations derive a variety of crucial benefits from the ecosystem services that grasslands provide. The livelihoods of pastoral communities are strongly linked to the health of the grasslands on which the majority of these communities rely (Pricope et al. 2013). However, grasslands in many regions of the world are showing alarming signs of degradation (Xie et al. 2010; Werger and van Staalduinen 2010). Increasing demand on pasture resources, especially in arid and semi-arid regions, has led to extensive and sometimes irreversible damage to the grassland environment, while simultaneously compromising the livelihoods of residents (Dong et al. 2007; Schiborra et al. 2009).

For the purposes of this chapter, livelihood refers to a person's "means of securing the basic necessities - food, water, shelter, fuel and clothing - of life" (Carney 1998). This definition comprises the set of activities required to obtain these necessities by working either individually or in groups to sustainably meet individual and household requirements. In practice, the definition of "livelihood" differs among countries based on differences in their economic levels, social relationships and environmental conditions (Ellis 1998; Dai et al. 2009). In China, there is no standard definition, but for rural residents, the term generally refers to income-generating activities both on and off their farm (Liu and Lan 2015). The concept of livelihood has gained wide acceptance as a valuable means to analyse the factors that influence human living, well-being and impacts on the ecosystems that sustain them, particularly in the most impoverished and ecologically fragile areas in the developing world (Ellis 2000), such as Inner Mongolia, in northern China.

The analysis of livelihoods normally links the micro-level of individual livelihoods with macro-level policy development and implementation and thereby provides support for policy development and poverty alleviation (Cinner and Bodin 2010; Sievanen et al. 2005). This is especially useful when policies are examined from the perspective of the sustainable use of human, natural, financial, social and physical capital to reveal the influence of the policy on these important aspects of livelihoods (Qu et al. 2011). Most current research has focused on the construction of a conceptual framework for livelihood and the application of the framework in different contexts, as well as on identifying policy intervention mechanisms in natural resource management to reveal the effects of local ecosystems (Lim et al. 2005; Allison and Horemans 2006; Pahl-Wostl 2009). Several studies for adaptive management have investigated the vulnerability of ecosystems and of communities and nations that depend on the exploitation of natural resources against the background of global climatic change (Dai et al. 2009; Lim et al. 2005). In previous research, the analysis of the household dependence on natural resources simply referred to the economic aspect, such as the actual household income or its proportional change over time. However, until recently, the implications of interventions (e.g. government policy, urbanization) on the livelihoods of resource users and changes in household dependence on natural resources at local scales have been less well explored (Xu et al. 2012; König et al. 2014a). In addition, there has been insufficient attention to the changing background of ecological management and the adoption of new livelihoods in response to changes in government policy, especially in regions with a vulnerable environment (e.g. Inner Mongolia), where policies to balance regional socio-economic development with ecological conservation have had important effects on household livelihoods (Jiang et al. 2006). 
The grasslands of Inner Mongolia have been experiencing degradation for decades, resulting in decreased primary production and frequent forage shortages, especially in the spring ( $\mathrm{Li}$ et al. 2008). The degradation appears to have been caused by unsustainable use of the natural resources provided by these grasslands (Zhang et al. 2013). However, Inner Mongolia is inherently an ecologically-vulnerable area, and this degradation directly threatens both the environment and the sustainability of regional socioeconomic development. To solve the problem, national and local governments have implemented a series of grassland management policies. The implementation of these policies began in limited parts of Inner Mongolia in 1998, and the policies were expanded to all of Inner Mongolia after several years' experience. The overall policy included five main measures (NDRC 2014):

(1) Seasonal grazing, in which pastures could only be grazed throughout the period of grass growth from April to November, was broadly implemented in the slightly degraded grassland, and pastoralists received an annual compensation payment of $22.5 \mathrm{CNY} \mathrm{ha}^{-1}$ (US\$ $3.46 \mathrm{ha}^{-1}$ based on the exchange rate of $6.50 \mathrm{CNY} / \mathrm{US} \$$ on 10 January 2016).

(2) Rotational grazing, in which the grassland was divided into paddocks that could only be used at 25- to 50-day intervals, depending on the type of grassland: 25 to 30 days for meadow, 30 to 35 days for steppes and 40 to 45 days for desert steppes. This policy was implemented in slightly to moderately degraded grasslands, and pastoralists received an annual compensation payment of 22.5 CNY ha ${ }^{-1}$ (US\$3.46 ha-1).

(3) Grazing prohibition, which was mainly carried out in severely-degraded grassland, eliminated all grazing in an area until it recovered to near its original condition, and pastoralists received an annual compensation of $90 \mathrm{CNY} \mathrm{ha}{ }^{-1}$ (US\$13.85 ha ${ }^{-1}$ ).

(4) Control of livestock rearing, in which the number of livestock was limited according to the carrying capacity of the local grassland, and nomadism was prohibited and replaced by indoor rearing. To implement this measure, fences were constructed throughout the grassland, and pastoralists received a single compensation payment of $300 \mathrm{CNY} \mathrm{ha}{ }^{-1}$ (US\$46.15 ha-1).

(5) Offering jobs in the cities let residents change their employment from animal husbandry or farming to urban employment, thereby reducing household dependence on local grasslands. This policy was mainly implemented in severelydegraded grassland. The government provided assistance for job training, employment opportunities and social benefits, such as medical insurance and education for their children.

Unfortunately, these policies created great stresses on households by fundamentally changing their lifestyles (Zhen et al. 2010a; Li and Huntsinger 2011) and drastically reshaping the patterns of grassland use that had existed for millennia in Inner Mongolia (Du et al. 2014). In recent years, rural livelihoods in Inner Mongolia have increasingly shifted from subsistence agriculture and animal husbandry to include non-agricultural, off-farm work for wages and government subsidies (König et al. 2014a; Li et al. 2011). Adapting to these changes has required households to take risks and look for new opportunities, leading to continuous transformation of rural landscapes, land uses and livelihoods by changing the dependence of these households on local grasslands.

In the chapter, I had the following main goals: to identify indicators of changes in the livelihoods of residents of the study area in Inner Mongolia; to reveal the dynamics of 
household livelihoods in response to changes in access to natural assets and in their agricultural activities; to quantify the financial adjustments of households to changes in their dependence on local grasslands; and to investigate their perceptions of careers for the next generation of their family. This chapter also aims to provide a better understanding of the grassland use policy changes and the process of policy influencing livelihoods and household adoptive strategies and to contribute to the sustainable use of natural resources.

\subsection{Description of the study area}

We selected China's Inner Mongolia Autonomous Region for the case study. This region has an arid to semi-arid continental climate ( $\mathrm{Yu}$ et al. 2003) with strong climatic gradients and grassland as the dominant land-use (Figure 4.1). Inner Mongolia is China's third-largest province, covering an area of approximately $1.18 \times$ $10^{6} \mathrm{~km}^{2}$ (National Statistics Bureau 2015). The population amounted to $25.05 \times 10^{6}$ people in 2014 (National Statistics Bureau 2015). Typical steppes, meadows and semi-desert and desert steppes are the major grassland types (Zhou et al. 2006). Grasslands were traditionally used for grazing and animal production before 1995 (König et al. 2015). Frequent drought was the major natural disaster, although severe winter weather was also a frequent problem (Xiao et al. 2013); Inner Mongolia has suffered from decades of climate fluctuation that have exacerbated the effects of human disturbance (e.g. over-grazing, excessive reclamation of grasslands for agriculture), so grassland degradation is a widely-observed problem. Zhang et al. (2013) found that both degradation and improvement of the grasslands have occurred since the 1980s, but that grassland degradation was the major trend. The area of degraded grassland increased from $18.08 \times 10^{4} \mathrm{~km}^{2}$ in the $1980 \mathrm{~s}$ to $22.47 \times 10^{4} \mathrm{~km}^{2}$ in the 2010s, and its distribution shifted from the central-eastern to the western parts of Inner Mongolia, from mainly in the Hulun Buir and Xilin Gol grasslands in the 1980s to mainly in the Ordos and Alxa grasslands in the 2010s.

We chose three regions of Inner Mongolia as county-level study sites: The West Ujimqin Banner, the Zhengxiangbai Banner and the Alxa Right Banner. These areas are representative of three typical and fragile grassland areas. The West Ujimqin Banner has a continental temperate semi-arid climate; the mean monthly temperatures range from a minimum of $-19.5^{\circ} \mathrm{C}$ in January to a maximum of $19.5^{\circ} \mathrm{C}$ in July, and the growing season is from April to September. The annual precipitation decreases from $400 \mathrm{~mm}$ in the northeast to less than $300 \mathrm{~mm}$ in the southwest and occurs mostly (68\%) during the summer (from June to August). The main vegetation type is a typical steppe, and over $96 \%$ of the total area is grassland, which has high drought tolerance. The rural residents live mainly by grazing their animals in grasslands and by livestock rearing. The West Ujimqin Banner is one of the most important animal husbandry regions in China. The area of cultivated land accounts for only $0.2 \%$ of the total area (WURBSB 2010).

The Zhengxiangbai Banner is located in north-central Inner Mongolia and is dominated by semi-desert steppe, with annual rainfall ranging from $100 \mathrm{~mm}$ to $350 \mathrm{~mm}$, of which $67 \%$ falls between June and August. The pan mean annual temperature averages $1.9^{\circ} \mathrm{C}$, but mean monthly temperatures range from a minimum of $-19.1^{\circ} \mathrm{C}$ in January to a maximum of $17.6^{\circ} \mathrm{C}$ in July. The area of cultivated land $(2.2 \%)$ is proportionally larger than in the West Ujimqin Banner, and more than half of the land is used to grow grains; most of the other half grows oil plants, fruits, vegetables and other crops (ZBSB 2010). The trend for animal husbandry and agriculture has been 
from personal use (i.e. subsistence agriculture) to professional use (i.e. selling animals and crops to earn income) and then to a large-scale industry.

The Alxa Right Banner of north-western Inner Mongolia, which is bounded by the Baba Jilin Desert to the north, is covered by desert steppe or desert and has an arid climate, with only $100 \mathrm{~mm}$ of annual precipitation and $3000 \mathrm{~mm}$ of annual pan evapotranspiration. The average annual temperature is $7^{\circ} \mathrm{C}$, but mean monthly temperatures range from a minimum of $-13^{\circ} \mathrm{C}$ in January to a maximum of $27^{\circ} \mathrm{C}$ in July. Traditionally, local herders were described as "the people who live on the backs of camels", but most of them no longer raise camels and instead raise cattle, goats and sheep. There is no significant agriculture, other than small gardens for household use (ARBSB 2010).

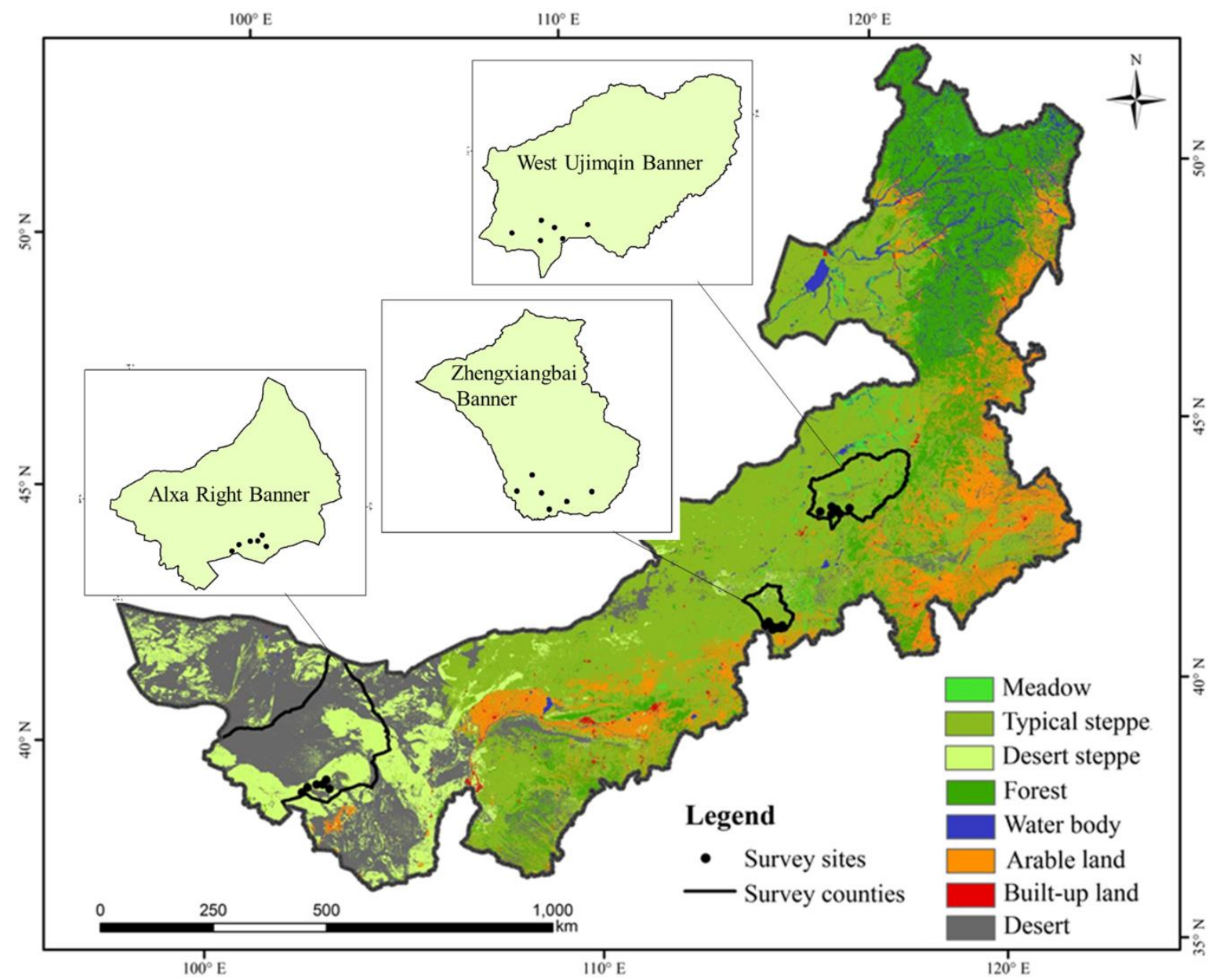

Figure 4.1 Maps of the land-cover types and locations of the survey sites in the Inner Mongolia

Autonomous Region

\subsection{Materials and methods}

\subsubsection{Research Design, Questionnaires and Data Collection}

To investigate the changes in household livelihood (Figure 4.2) that have occurred in response to the stresses created by government policy interventions, grassland degradation and urbanization, We conducted a household survey (using guided interviews structured by a questionnaire, Appendix 5) by visiting households in the three regions of Inner Mongolia in June 2011 (Zhengxiangbai Banner) and July 2012 (West Ujimqin Banner and Alxa Right Banner). We asked households to report 
changes in their circumstances between 1995 (before the government ecological policies were implemented) and 2010. A total of 135 households was interviewed, at a total of 18 survey sites (each of survey site represents a smaller community) in 6 villages, with the survey frequency proportional to the population size of each village. In selecting villages, we specifically included two or three villages in each banner that differed in characteristics, such as the proportions of various economic activities and ecological characteristics. We surveyed a total of 35 respondents in the West Ujimqin Banner, 71 in the Zhengxiangbai Banner and 29 in the Alxa Right Banner. Based on our survey, most respondents performed both animal husbandry and farming rather than only one of these activities. Prior to the formal surveys, we conducted a re-visit in July 2014 to monitor the changes of their animal husbandry activities and household income and employment situations.

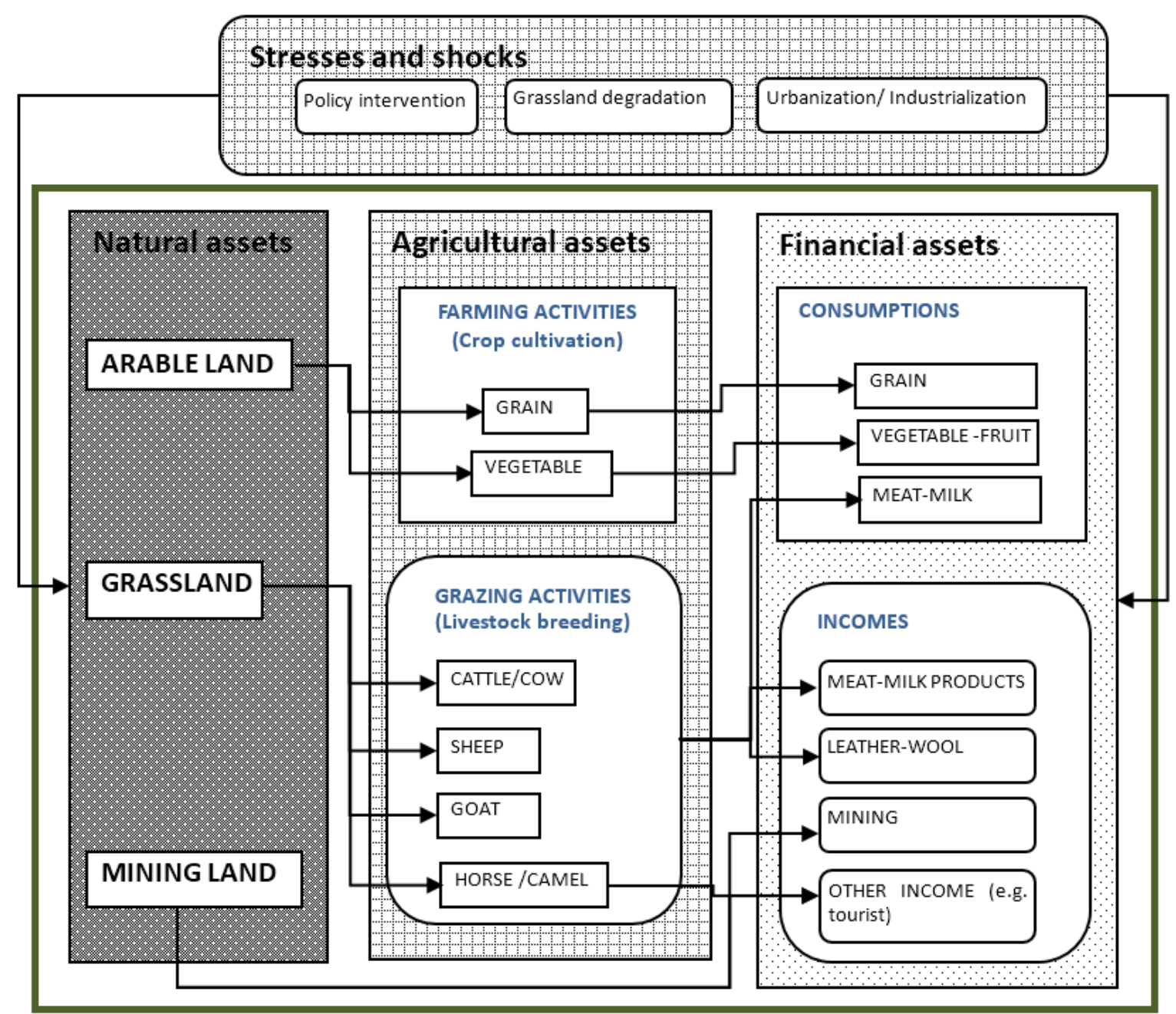

Figure 4.2 Main components of herders' livelihood in the study area

We selected the three banners beforehand and then used stratified random sampling to select the villages within each category (i.e. dominant activity or environment) in each banner. We used simple random sampling to select households for the survey in each village. We considered a sample size that included more than $70 \%$ of the total households in each village to be appropriate based on the recommendation of Tabachnick and Fidell (2007) that a sample should account for more than 50\% of the households when the total number of households is less than 100 . Because the survey was carried out in person by interviews or by having the respondents complete the 
questionnaire under guidance from a member of the research group, a high response rate $(94.5 \%)$ was obtained. For respondents who did not speak Mandarin Chinese, local interpreters help the communication clearly.

For each household, we asked the head of the household or a family member who was familiar with the household's characteristics to answer the questions. The interviewees were asked to provide: (1) personal and household information, including the age, education and technical and skill training of all members of the household, their land-use assets, the number and species of livestock and their perceptions of the ecological context; (2) a description of livelihood changes in terms of their agricultural and animal husbandry activities, including cultivation patterns, investments and annual return on these investments; and (3) the household income and employment situation, consumption patterns (foods and fuels) and their perceptions of the next generation's potential career choices.

\subsubsection{Selection of Indicators for the Livelihood Analysis}

Because of the ecological changes (land degradation), government policy changes (grassland conservation) and urbanization in the study region, this livelihood analysis provides important data on changes in the use of local natural resources and on livelihood strategies (particularly changes) in response to the stresses facing the households (Figure 4.2). The results of this analysis reveal the elements that make a household more or less sensitive to the effects of environmental and government factors.

Table 4.1 Selection of indicators for livelihood assessment

\begin{tabular}{cll}
\hline $\begin{array}{c}\text { Components of } \\
\text { Livelihood }\end{array}$ & Selected Indicators & \multicolumn{1}{c}{ Rationale } \\
\hline $\begin{array}{c}\text { Natural assets } \\
\text { (land use) }\end{array}$ & $\begin{array}{l}\text { Changes in percentage } \\
\text { of grasslands }\end{array}$ & $\begin{array}{l}\text { Comparison the changing percentage of land-use, } \\
\text { especially the grassland changes. }\end{array}$ \\
\cline { 2 - 3 } & $\begin{array}{l}\text { Perception on } \\
\text { Changing Grassland } \\
\text { context }\end{array}$ & $\begin{array}{l}\text { Households' perspective on the general quality of } \\
\text { grasslands, which includes grass diversity level, } \\
\text { biomass, soil quality and vegetation cover ratio. }\end{array}$ \\
\hline $\begin{array}{c}\text { Agricultural } \\
\text { assets (farming } \\
\text { and grazing } \\
\text { activities) }\end{array}$ & New social relations & $\begin{array}{l}\text { Pasture leasehold relation; closer economic ties by } \\
\text { building cooperative associations. }\end{array}$ \\
\cline { 2 - 4 } & $\begin{array}{l}\text { Controlled animal } \\
\text { breeding mode }\end{array}$ & $\begin{array}{l}\text { Including activities of decrease of livestock holding } \\
\text { numbers, stall-fed livestock, etc. }\end{array}$ \\
\hline species in livestock & $\begin{array}{l}\text { Switching from conditional goat/sheep grazing to } \\
\text { modern daily cattle breeding. }\end{array}$ \\
\hline $\begin{array}{c}\text { Financial assets } \\
\text { (incomes and } \\
\text { consumption) }\end{array}$ & $\begin{array}{l}\text { Net annual per capital } \\
\text { income }\end{array}$ & $\begin{array}{l}\text { Sum of farm income from sale and trade of crop and } \\
\text { livestock products, from livestock services; off-farm } \\
\text { income; and the diversity of income sources. }\end{array}$ \\
\cline { 2 - 4 } based employment & $\begin{array}{l}\text { Number of the population participating in grazing or } \\
\text { crop cultivation. }\end{array}$ \\
\cline { 2 - 4 } & $\begin{array}{l}\text { Food and fuel } \\
\text { consumption }\end{array}$ & \begin{tabular}{l} 
Change of food and fuel consumption. \\
\hline
\end{tabular}
\end{tabular}

For the selected indicators (Table 4.1), we collected data to describe the change that occurred between 1995 and 2010. To quantify changes in the use of natural assets, we estimated the change in the percentage of total land-use accounted for by grasslands. 
To investigate the change in agricultural assets, we obtained data on the number and type of livestock and how they were fed, as well as the extent to which households formed cooperative associations. We then determined the dependence of household income on agriculture, and the food (locally produced and purchased) and fuel consumption (based on the quantity of each major fuel that was consumed).

\subsubsection{Calculation of Household Dependence on Local Grasslands Based on Income and Employment}

To determine changes in household dependence on grassland, we divided all sources of income into income derived from agriculture and income derived from other sources (non-farm income). We then calculated a dependence ratio as follows:

$$
\text { Income dependence ratio }=\text { Farm income/Total household income }
$$

Where the value of this ratio ranged between 0 and 1 , with greater values representing greater dependence on farming and raising of livestock.

We also assessed the dependence of households on off-farm labour by calculating an employment dependence ratio, as follows:

Employment dependence ratio $=$ On-farm employment/Total labour force

Where the total labour force excluded children in school or those who could not work (the disabled, the elderly and very young children). In this calculation, household survey data for on- and off-farm employment were obtained and reported by herders or farmers from each household. These data accounted for the number of hours of each form of employment by an individual as a proportion of their total number of hours of work.

\subsection{Results and discussion}

\subsubsection{Use of Natural Assets and Changing Ecological Context}

Inner Mongolia has a low economic development level, and household livelihoods rely heavily on the exploitation of the local natural resources. The use of natural resources reflects the changing land-use patterns. Table 4.2 summarizes the changes in these uses from 1995 to 2010 . Grassland occupied the largest proportion of the total area in 2010, with areas of $1.97 \times 10^{6}, 0.59 \times 10^{6}$ and $4.23 \times 10^{6}$ ha in the West Ujimqin Banner, the Zhengxiangbai Banner and the Alxa Right Banner, respectively (WURBSB 2010; ZBSB 2010; ARBSB 2010). The changes in land-use were consistent among the three banners: the forest and grassland area increased significantly (by an average of $9.4 \%$ and $2.5 \%$, respectively), and the area of cultivated land decreased greatly (by an average of $21 \%$ ) from 1995 to 2010 (Table 4.2). The main reason for this trend was the implementation of the government conservation policy. Our survey suggested that grazing prohibition and control of livestock rearing were most responsible for the increasing area of grassland. The analysis showed that herders increasingly (23\% of respondents in 1995 and $78 \%$ in 2010) grew vegetables in a home garden. This may have resulted from the implementation of the controlled livestock rearing policy to limit the number of animals raised annually; about $82 \%$ of the herders and farmers reported reduced meat consumption and increased vegetable consumption. Table 4.2 shows that the area of land cultivated for fruit and vegetable consumption increased greatly, which supports the self-reported data. 


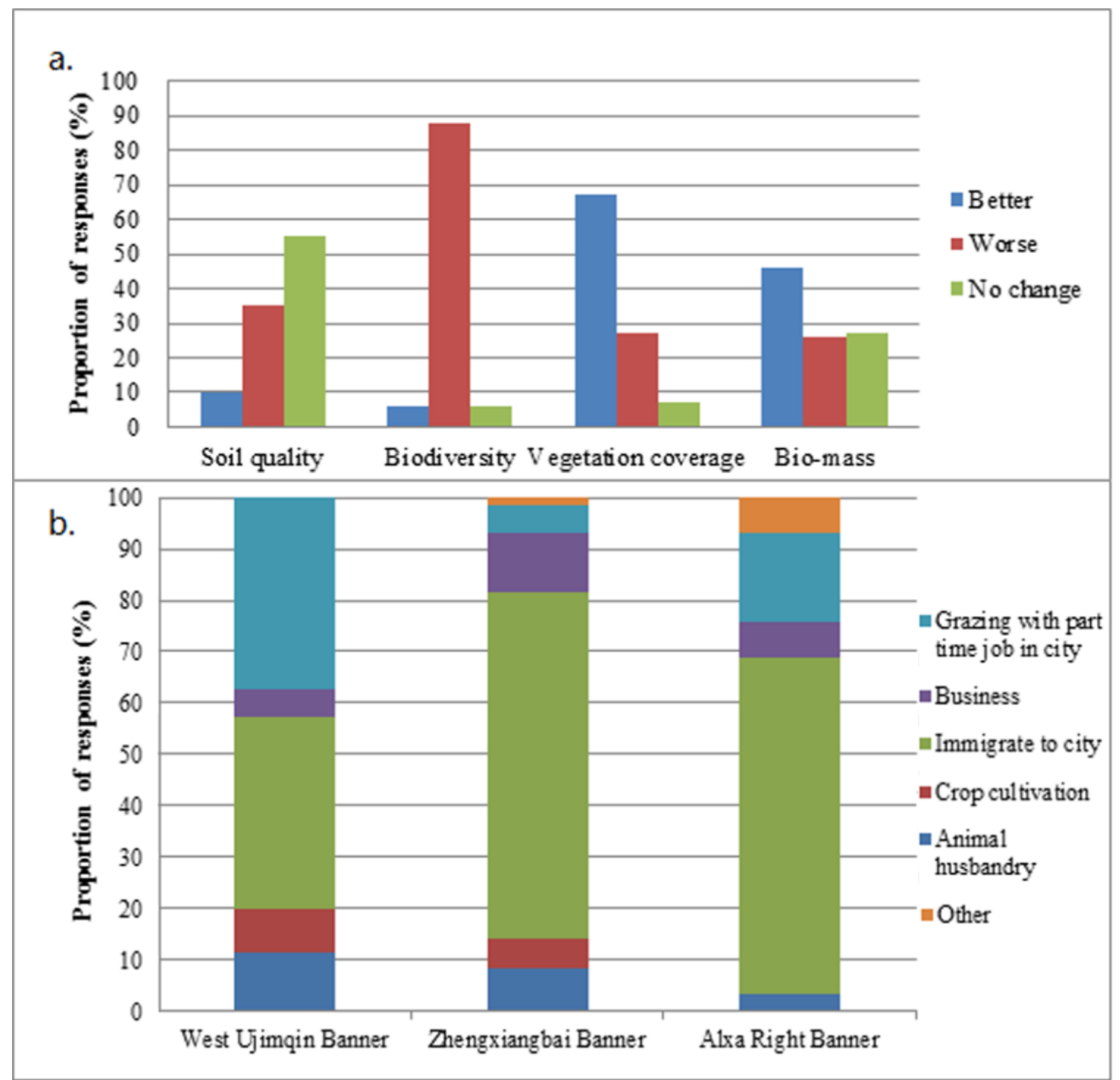

Figure 4.3 Household perceptions (a: Changes in household perceptions of grassland conditions compared with conditions in the 1980s, before grassland degradation became increasingly serious; b: Perception of the next generation's probable career choices).

Many previous studies reported that grassland degradation was a widely-observed problem in the 1990s (especially in north-western and north-central areas, e.g. the Alxa Right Banner and Zhengxiangbai Banner), but that the grasslands were recovering in the 2000s as a result of the implementation of the RGLGP (Zhang et al. 2013; Kawamura et al. 2005). The present results, based on household interviews, confirm this trend. More than $84 \%$ of respondents believed that their pasture had improved compared to its condition in the 1990s. In addition, $66.7 \%$ reported that the vegetation cover had improved, and $45.9 \%$ believed that biomass had improved (Figure 4.3). However, they believed that the grassland was still degraded compared with its quality during the 1980s (before the most serious degradation began). The most significant changes were in the biodiversity of grass species; $88.1 \%$ of respondents believed that biodiversity was declining (not only for plant diversity, but also for forage grasses). The original grass species in the West Ujimqin Banner were dominated by an important fodder species (guinea grass, Leymus chinensis Tzvel.), which reached an overall height of 40 to $50 \mathrm{~cm}$ (Zheng et al. 2015). However, possibly as a result of climate change combined with overgrazing, the abundance of guinea grass decreased, and the abundance of Stipa capillata L. increased to replace it 
(Bai et al. 2004). Stipa capillata reaches an overall height of 60 to $70 \mathrm{~cm}$. This height difference explains the biomass increase (Figure 4.3), but this increase may be deceptive. A serious problem resulting from this species change is that the mature seeds of Stipa capillata are sharp and hurt the mouths and skin of the livestock, potentially leading to lost production or even mortality of the animals. In addition, 54.8\% of respondents reported no improvements in soil quality (Figure 4.3) and believed that such changes would require a long time.

Despite the severity of grassland degradation and the changes in their lifestyle, more than $80 \%$ of the herders and farmers did not want to move to the city, for three main reasons: lack of suitable skills, low education and a desire to preserve their culture. Even herders and farmers with high levels of education and skills training felt strong ties to their local social network and culture. However, herder and farmer perceptions of the next generation's career choices (Figure 4.2) showed different results, and these can be used to predict the degree of the next generation's dependence on the local grasslands. Of the six career choices they identified (animal husbandry, crop cultivation, immigrate to city, establish a business, grazing combined with obtaining a part-time job in the city and "other"), the most likely career for the next generation was moving to the city to obtain a stable job (37.1\% in the West Ujimqin Banner, $67.6 \%$ the Zhengxiangbai Banner and $65.5 \%$ in the Alxa Right Banner). The next most common choice was grazing combined with obtaining part-time work in a city in the West Ujimqin Banner (37.1\%), starting a business in the Zhengxiangbai Banner $(11.3 \%)$ and grazing with part-time work in a city in the Alxa Right Banner (17.2\%). Respondents in all three banners believed that crop cultivation $(<3 \%)$ and animal husbandry $(<10 \%)$ were the least likely careers. Because the respondents believed that the natural conditions greatly influenced crop planting and animal husbandry, they felt that the basic needs of these careers could not be guaranteed under the current poor environmental conditions and unstable climate. They reported a high willingness to help their children free themselves from the grasslands: about $84 \%$ of the respondents thought it would be good to send their children to a big city to improve their education and employment options.

\subsubsection{Changes in Agricultural Production Activities}

Controlled Animal Husbandry: From Traditional Grazing of Goats and Sheep to Modern Raising of Dairy Cattle

To comply with the grassland conservation policy, households decreased the total number of livestock per household from an average of 261.6 in 1995 to 88 in 2010 (Table 4.2), a $66.7 \%$ decrease. More than $60.0 \%$ of respondents reported that their number of livestock had decreased by more than half from the 1995 level. Because of the continually implementing of the grassland conservation policy, the result of a revisit in 2014 shows the number of livestock per household kept the same level of 2010 The number of animals varied among the three banners in 2010, with the highest mean being 197 in the West Ujimqin Banner, followed by 34 in the Zhengxiangbai Banner and 32 in the Alxa Right Banner. These results were strongly related to the natural conditions in each banner and particularly the per capita land ownership: 17.6, 9.9 and 9.2ha, respectively, in the West Ujimqin Banner, the Zhengxiangbai Banner and the Alxa Right Banner. 
Table 4.2 Results of the livelihood analysis for the three banners in the Inner Mongolia Autonomous Region. All households were asked to provide data from 2010, even though the surveys were conducted in different years.

\begin{tabular}{|c|c|c|c|c|c|c|c|c|c|c|c|c|c|}
\hline & \multirow[b]{2}{*}{ Year } & \multicolumn{3}{|c|}{ West Ujimqin Banner } & \multicolumn{3}{|c|}{ Zhengxiangbai Banner } & \multicolumn{3}{|c|}{ Alxa Right Banner } & \multicolumn{3}{|c|}{ Average } \\
\hline & & 1995 & 2010 & $\begin{array}{c}\text { Change } \\
(\%)\end{array}$ & 1995 & 2010 & $\begin{array}{c}\text { Change } \\
(\%)\end{array}$ & 1995 & 2010 & $\begin{array}{c}\text { Change } \\
(\%)\end{array}$ & 1995 & 2010 & $\begin{array}{c}\text { Change } \\
(\%)\end{array}$ \\
\hline \multirow{5}{*}{$\begin{array}{l}\text { Land use a } \\
\text { (ha) }\end{array}$} & Grassland & 1896600 & 1968700 & 3.8 & 567774 & 585700 & 3.2 & 4210450 & 4231133 & 0.5 & 2224941 & 2261844 & 2.5 \\
\hline & Cultivated land & 4150 & 3267 & -21.3 & 21,432 & 13,867 & -35.3 & 2140 & 2000 & -6.5 & 9241 & 6378 & -21.0 \\
\hline & Grain production & 3670 & 2280 & -37.9 & 18,664 & 9066 & -51.4 & 1700 & 1016 & -40.2 & 8011 & 4121 & -43.2 \\
\hline & Fruit and vegetable & 480 & 987 & 105.6 & 2768 & 4801 & 73.5 & 440 & 984 & 123.6 & 1229 & 2257 & 100.9 \\
\hline & Forest & 74500 & 81540 & 9.5 & 8125 & 9087 & 11.8 & 302340 & 323133 & 6.9 & 128,322 & 137920 & 9.4 \\
\hline \multirow{5}{*}{$\begin{array}{l}\text { Livestock } \\
\text { number }^{\mathrm{b}}\end{array}$} & Sheep & 325 & 162 & -50.2 & 139 & 21 & -84.9 & 88 & 18 & -79.6 & 184 & 67 & -71.5 \\
\hline & Goats & 50 & 21 & -58.0 & 125 & 4 & -96.8 & 20 & 6 & -70.0 & 65 & 10 & -74.9 \\
\hline & Cattle & 7 & 13 & 85.7 & 10 & 8 & -20.0 & 5 & 7 & 40.0 & 7.3 & 9 & 35.2 \\
\hline & Horses and camels & 3 & 1 & -66.7 & 9 & 1 & -88.9 & 4 & 1 & -75.0 & 5.3 & 1 & -76.9 \\
\hline & Total livestock & 385 & 197 & -48.8 & 283 & 34 & -88.00 & 117 & 32 & -72.7 & 261.6 & 87 & -69.8 \\
\hline \multirow{4}{*}{ Employment $^{\mathrm{c}}$} & Land-based & 1.3 & 1.2 & -11.4 & 1.8 & 1.6 & -11.4 & 1.1 & 0.6 & -47.8 & 1.4 & 1.1 & -23.5 \\
\hline & Non-land-based & 0.9 & 0.9 & 4.6 & 0.5 & 0.6 & 23.1 & 1.2 & 1.6 & 30.6 & 0.9 & 1.1 & 19.4 \\
\hline & Total workforce & 2.2 & 2.1 & -5.0 & 2.4 & 2.3 & -3.8 & 2.3 & 2.2 & -6.9 & 2.3 & 2.2 & -5.2 \\
\hline & $\begin{array}{l}\text { Employment-based } \\
\text { dependence ratio }\end{array}$ & 0.6 & 0.6 & -6.7 & 0.8 & 0.7 & -7.7 & 0.5 & 0.3 & -43.8 & 0.6 & 0.5 & -19.4 \\
\hline \multirow{4}{*}{$\begin{array}{l}\text { Per capita net } \\
\text { income }(\mathrm{CNY} \\
\left.\text { year }^{-1}\right)^{\mathrm{d}}\end{array}$} & Land-based & 3759 & 8000 & 112.8 & 3275 & 5046 & 54.1 & 3086 & 4681 & 51.7 & 3373 & 5909 & 72.9 \\
\hline & Non-land-based & 1061 & 6695 & 531.0 & 1134 & 7054 & 522.1 & 1662 & 6736 & 305.3 & 1286 & 6828 & 452.8 \\
\hline & Total income & 4820 & 14695 & 204.9 & 4409 & 12100 & 174.4 & 4748 & 11417 & 140.5 & 4659 & 12737 & 173.3 \\
\hline & $\begin{array}{l}\text { Income-based } \\
\text { dependence ratio }\end{array}$ & 0.8 & 0.5 & -30.8 & 0.7 & 0.4 & -43.2 & 0.7 & 0.4 & -36.9 & 0.7 & 0.5 & -37.0 \\
\hline
\end{tabular}

${ }^{\mathrm{a}}$ The area of cultivated land is including the areas of Grain production and Fruit and vegetable, source: WURBSB 2010, ZBSB 2010, ARBSB 2010; ${ }^{\mathrm{b}}$ source: field survey data from the present study, in units of No. per household on average; ${ }^{\mathrm{c}}$ land-based-employment is the number of people who participated in grazing or crop cultivation on average per household; non-land-based employment includes all work outside the household's farming activities; source: field survey data from the present study; ${ }^{\mathrm{d}}$ land-based net income includes all agricultural activities. Non-land-based net income comes from non-agricultural activities, such as non-land-based employment, subsidies and government fees paid as compensation for land expropriation; source: field survey data from the present study. 
The livestock most commonly domesticated in the surveyed villages was dairy and beef cattle, sheep, goats, horses, camels, donkeys and poultry. Most respondents increased cattle rearing to compensate for decreased grazing of goats and sheep and replacement of this grazing by stall rearing of cattle. The herders usually chose the livestock species most appropriate for their local environment and raised the species that produced the most income to compensate for their loss of income caused by the grazing restrictions. Herders traditionally raised cattle, goats and sheep to produce meat and milk; horses, camels and donkeys were retained as traditional "vehicles" or to support domestic needs, such as the production of skins and blankets (e.g. camel wool, leather) and ploughing the land. However, horses, camels and donkeys were increasingly replaced by cars, motorbikes and tractors, so most households retained only one or two horses and camels, mostly for tourist purposes. Goats and sheep produce less profit than cattle, because the cattle provide larger amounts of meat and produce milk. Therefore, replacing goats and sheep by cattle mitigates the loss of agricultural income caused by the government policies. In addition, raising cattle both increased and symbolizes wealth.

For the household-level variables, we used the proportion of stall-fed livestock and the proportion of seasonally-grazed livestock as indicators of the livestock strategies of the herders. About $60 \%$ of the households used only stall feeding, and the others adopted a combination of stall feeding in winter (November to March) and local grazing in summer (April to October). When grazing is restricted in the local grasslands, herders must purchase fodder from outside their area to feed their animals. In traditional animal husbandry, daily fodder was obtained from each household's grassland. However, at present, the major components of livestock fodder are crop residues, leaves from fodder plants and herbaceous plants from adjacent forests, and this indicates that grasslands are no longer the only sources of fodder. This change increased costs for the purchase and storage of forage, which is one of the frequently-reported adaptation strategies in Inner Mongolia. More than $74.8 \%$ of respondents reported a need to purchase or store forage.

Since the implementation of the conservation polices, the household dependence on local grasslands has decreased based on both the employment and income dependence ratios: the employment ratio decreased by an average of $19.4 \%$ and the income ratio by $37.0 \%$ (Table 4.2). This has resulted from replacement of traditional animal husbandry (grazing of goats and sheep) by intensive modern animal husbandry (raising dairy and beef cattle), especially for emigrants from severely-degraded grassland areas. These emigrants were resettled in dairy cattle villages in peri-urban areas, where they adopted modern dairy cattle production techniques to raise income from the sales of meat, milk and leather. In addition to using grassland as their basic capital goods, the emigrants received technical and financial assistance from the local government to support dairy production. The government offers loan guarantees so households can access low-interest loans from local banks to alleviate the financial burden and invest in the establishment of dairy cattle facilities, such as milking centres. The combined business plus household system provides ongoing income for the emigrants. Modern raising of dairy cattle permits more sustainable use of the grasslands and has also reduced the grassland damage caused by overgrazing, including the loss of ground flora, depletion of soil nutrients and impaired regeneration of the dominant grass species. On the other hand, this new mode of animal husbandry has increased the household resilience in terms of their ability to adapt to and mitigate the impacts of climatic disasters, such as drought, freezing rain and snow, which historically led to serious consequences for households, including famine. 
Improved Socio-Economic Relations: Leasing of Land and Development of Cooperative Associations

To lower the ecological risk of grazing and stabilize income sources, about $23.7 \%$ of the respondents ceased grazing and leased their grassland to others who wanted to expand their access to pasture. In this way, leaseholders could earn greater profits because they could support larger herds with the extra pasture. Additionally, the leasers could engage in nonfarm businesses, such as working outside the community or running a home business, and even some households moved to peri-urban or urban areas to find other opportunities (Jun et al. 2007). Thus, as we noted earlier, grasslands were no longer the only basic capital goods used to guarantee their livelihood; their degree of dependence on the grasslands has decreased. On the other hand, about $34.3 \%$ of the households in the West Ujimqin Banner, versus $23.9 \%$ in the Zhengxiangbai Banner and 17.2\% in the Alxa Right Banner, leased pasture from others. Those who leased pastures became more dependent on the local grasslands; animal husbandry both provided their livelihood and provided income to pay for the leasing of grassland. In theory, decreasing the number of households who live in grasslands can reduce the pressure on this land, allowing ecological improvement, but we lack the data to support this hypothesis because leasing of pasture is too recent for clear trends to have emerged.

To mitigate the effects of the government policy, climate hazards and fluctuations in the prices of livestock products, many herders in all three banners have created or joined a cooperative association: this accounted for $45.7 \%$ of households in the West Ujimqin Banner, 28.2\% of households in the Zhengxiangbai Banner and $69.0 \%$ of households in the Alxa Right Banner. The goals of these cooperatives were to support market-oriented activities, such as pooling pastures for grazing, unified management of livestock and selling production together to establish a "brand" reputation for quality. The cooperatives appear to have increased the income and efficiency of rangeland utilization and have accelerated the adoption of technologies, such as communal storage of fodder to prevent food shortages during certain times of the year that decrease the risk of starvation and disease. The government has provided skill training and technology transfer to promote the adoption of more efficient methods. The formation of cooperatives has somewhat restored the traditional cooperation among nomadic households that was lost when they were forced to relocate to permanent villages (Du et al. 2015).

\subsubsection{Household Dependence on Grasslands Based on Income and Consumption Behaviours}

\section{Diversification of Income Sources and Reduction of Land-Based Employment}

The proportion of total income accounted for by non-agricultural income increased greatly between 1995 and 2010: by 531.0\%, 522.1\% and 305.3\%, respectively, in the West Ujimqin Banner, the Zhengxiangbai Banner and the Alxa Right Banner (Table 4.2). In contrast, agricultural income increased only slightly. As a result of these changes, the proportions of total income accounted for by agriculture decreased from $78.0 \%, 74.3 \%$ and 65.0\%, respectively, in the West Ujimqin Banner, the Zhengxiangbai Banner and the Alxa Right Banner in 1995 to $54.4 \%, 41.7 \%$ and $41.0 \%$, respectively, in 2010. These changes resulted mainly from the reduction in the number of livestock and the increased cost for grazing and purchases of fodder. Based on the results of the re-visit in 2014, the nonagricultural income still kept the increasing trend, and the agricultural income maintained the same level of 2010 .

Employment showed similar trends. In 1995, land-based employment was the dominant form, especially Zhengxiangbai Banner, employing two- to three-times the number of 
people who were employed in non-land-based employment. With the increase of the urban process and controlled use of grasslands (grassland management policies) at all research sites from 1995 to 2010, the total workforce decreased slightly in the West Ujimqin Banner, the Zhengxiangbai Banner and the Alxa Right Banner (by $-5.0 \%,-3.8 \%$ and $-6.9 \%$, respectively). However, the non-land-based employment increased more dramatically, by 4.6\%, 23.1\% and 30.6\%, respectively, in the West Ujimqin Banner, the Zhengxiangbai Banner and the Alxa Right Banner. This can be explained by the combined effects of the grassland conservation policy and an urbanization process that encouraged herders and farmers, and especially young adults, to move to towns and cities to seek employment in off-farm businesses, thereby decreasing the human pressure on the grasslands.

Between 1995 and 2010, the mean income-based dependence ratio decreased from 0.7 to 0.5 , and the employment-based dependence ratio decreased from 0.6 to 0.5 . This indicated that although the land remained the main source of capital for daily life, the dependence on grasslands has gradually decreased. The main reason for these decreases is that the area of grassland used for animal husbandry has decreased. The macro-level policy changes and micro-level livelihood adjustments by the affected households have caused large changes in the land-use asset structure. For instance, herders who lost the right to access grassland were more severely affected than those who retained access to pastures under the grassland conservation policy. Because these changes were implemented rapidly, herders who lost access to pasture were forced to sell most or all of their livestock, although the government provided partial compensation for this loss. On the plus side, this decreased their dependence on grasslands and increased the rate of business operation and employment in non-agricultural economic activities.

Simultaneous with the process of urbanization, the herders and farmers acquired new skills and new opportunities to earn money, so their income and employment were less constrained by their former dependence on the land. Comparing the income and employment situations among the three banners provides insights into the dependence of livelihoods on the local grassland. The Zhengxiangbai Banner had the largest proportional decrease in the income-based dependence ratios $(-43.2 \%)$, followed by the Alxa Right Banner $(-36.9 \%)$ and the West Ujimqin Banner $(-30.8 \%)$. One of the most important reasons for this difference is that the Zhengxiangbai Banner is close to many megacities, including Beijing, Hohhot and Tianjin, so residents have more opportunities to seek high income with urban employment. Alxa Right Banner had the largest proportional decrease in the employment-based dependence ratios $(-43.2 \%)$, followed by the Zhengxiangbai Banner $(-7.7 \%)$ and West Ujimqin Banner $(-6.7 \%)$. This is because Alxa Right Banner has the most venerable grassland type (desert steppe or semi-desert steppe), which has been severely influenced by ecosystem degradation (Zhang et al. 2013). The herders in Alax Right Banner have to give up their land and are engaged in non-land-based employment. Our survey revealed that about $77.1 \%$ of respondents in the West Ujimqin Banner, $91.5 \%$ of respondents in the Zhengxiangbai Banner and $89.7 \%$ of respondents in the Alxa Right Banner believed that finding urban employment was the best way to increase their income and that diversification of income sources would play a crucial role in securing their household livelihood. Especially in poorly-developed areas, off-farm employment and activities could increase cash income and improve household risk resilience by increasing their capacity to cope with shocks. 
Table 4.3 The per capita fuel and food consumption in the three banners of the Inner Mongolia Autonomous Region.

\begin{tabular}{|c|c|c|c|c|c|c|c|c|}
\hline \multirow[b]{2}{*}{ Year } & \multicolumn{2}{|c|}{ West Ujimqin Banner } & \multicolumn{2}{|c|}{ Zhengxiangbai Banner } & \multicolumn{2}{|c|}{ Alxa Right Banner } & \multicolumn{2}{|c|}{ Average } \\
\hline & $1995 / 2010$ & Change (\%) & $1995 / 2010$ & Change (\%) & $1995 / 2010$ & Change (\%) & $1995 / 2010$ & Change (\%) \\
\hline \multicolumn{9}{|c|}{ Total fuel consumption (unit: $t \cdot$ year $^{-1}$ for biofuel and coal; CNY $\cdot$ year $^{-1}$ for electricity and gas) } \\
\hline Biofuel $^{\text {a }}$ & $3.1 / 2.4$ & -23 & $2.7 / 1.0$ & -63 & $1.2 / 0.5$ & -58 & $2.3 / 1.3$ & -48.0 \\
\hline Coal $^{b}$ & $0.5 / 0.8$ & 60 & $0.7 / 1.1$ & 57 & $0.6 / 0.9$ & 50 & $0.6 / 0.9$ & 55.7 \\
\hline Electricity and gas ${ }^{b}$ & $53 / 175$ & 230 & $54 / 174$ & 222 & $57 / 245$ & 330 & $55 / 198$ & 260 \\
\hline \multicolumn{9}{|c|}{ Total Food consumption (unit: $\mathrm{kg} \cdot \mathrm{year}^{-1}$ ) } \\
\hline Grains & $170 / 160$ & -6 & $175 / 156$ & -11 & $196 / 180$ & -8 & $180.3 / 165.3$ & -8.3 \\
\hline Fruits and vegetables & $50 / 110$ & 120 & $195 / 206$ & 6 & $110 / 160$ & 45 & $118.3 / 158.7$ & 57.0 \\
\hline Milk & $86 / 64$ & -26 & $50 / 60$ & 20 & $54 / 76$ & 41 & $63.3 / 66.7$ & 11.7 \\
\hline Meat & $170 / 124$ & -27 & $84 / 77$ & -8 & $66 / 73$ & 11 & $106.7 / 91.3$ & -8.0 \\
\hline \multicolumn{9}{|c|}{ Self-produced rates of food consumption (unit: \%) } \\
\hline Grains & $6.3 / 5.1$ & -1.20 & $32.8 / 16.1$ & -16.7 & $18.6 / 7.6$ & -11.0 & $19.2 / 9.6$ & -9.6 \\
\hline Fruits and vegetables & $19.5 / 23.4$ & 3.90 & $50.2 / 49.7$ & -0.5 & $21.8 / 30.5$ & 8.7 & $30.5 / 34.5$ & 4.0 \\
\hline Milk & $100 / 96.7$ & -3.30 & $57.0 / 49.3$ & -7.7 & $77.2 / 43.1$ & -34.1 & $78.1 / 63.0$ & -15.0 \\
\hline Meat & $87.4 / 72.7$ & -14.70 & $66.2 / 46.3$ & -19.9 & $65.4 / 37.7$ & -27.7 & $73.0 / 52.2$ & -20.8 \\
\hline \multicolumn{9}{|c|}{ Purchased rates of food consumption (unit: \%) } \\
\hline Grains & $93.7 / 94.9$ & 1.2 & $67.2 / 83.9$ & 16.7 & $81.4 / 92.4$ & 11.0 & $80.8 / 90.4$ & 9.6 \\
\hline Fruits \& vegetables & $80.5 / 76.6$ & -3.9 & $49.8 / 50.3$ & 0.5 & $78.2 / 69.5$ & -8.7 & $69.5 / 65.5$ & -4.0 \\
\hline Milk & $0.0 / 3.3$ & 3.3 & $43.0 / 50.7$ & 7.7 & $22.8 / 56.9$ & 34.1 & $21.9 / 37.0$ & 15.0 \\
\hline Meat & $12.6 / 27.3$ & 14.7 & $33.8 / 53.7$ & 19.9 & $34.6 / 62.3$ & 27.7 & $27.0 / 47.8$ & 20.8 \\
\hline
\end{tabular}

Source: field survey data from the present study. ${ }^{\mathrm{a}}$ Self-produced fuel; ${ }^{\mathrm{b}}$ purchased fuel. Biofuel: firewood, dry dung and crop residues; grains: flour and rice; meat: mutton, beef, pork, chicken and fish. 


\section{Household Food and Fuel Consumption}

In the three banners, most of the pasture area (95\%) was fenced; 37\% of the pasture area was totally protected from grazing in the past five or 10 years. Thus, the former livelihoods of herders changed fundamentally, causing them to shift their activities to raising dairy cattle in stalls, cooperative activities, such as the sales and transportation of livestock, or milling of grains. Moreover, as household income changed, this directly affected consumption patterns, especially in terms of the dietary structure and fuel consumption. We defined the food (including grains, fruits, vegetables, milk and meat) and fuel (biofuels, such as firewood, dry dung and crop residues) as the main household biological products, which are consumed by the local population. Additionally, household consumption into self-produced and purchased food and fuel has been separated (Table 4.3).

Based on the results of the food and fuel analysis, the total annual per capita bio-fuel and meat consumption decreased during the study period, from $2.3 \mathrm{t} \cdot \mathrm{year}^{-1}$ and $180.3 \mathrm{~kg} \cdot$ year $^{-1}$ in 1995 to $1.3 \mathrm{ton} \mathrm{year}^{-1}$ and $165.3 \mathrm{~kg} \cdot$ year $^{-1}$ in 2010 and mainly comprised consumption from grasslands (Table 4.2). The main reason for the decreases was the grassland conservation policy, which substantially decreased the number of livestock (Table 4.2). Dried dung from livestock and firewood collected from forests and bush vegetation communities were traditionally important biofuels and were widely used in Inner Mongolia. The types and amounts of fuel consumed changed significantly during our study period. Usage of coal, gas and electricity increased in all three banners and increased particularly rapidly for electricity and gas (Table 4.3).

The government statistics of Inner Mongolia reported that annual electricity consumption in the rural area kept an increasing rate (by $14.5 \%$ in average) during 2010 to 2015 (Inner Mongolia Statistics Bureau 2015a). This may have resulted from rapid economic development and government initiatives to provide cleaner sources of power to residents of the study area. Although cleaner energy, such as gas and electricity, is more costly, people prefer it because it is more convenient and efficient. The amount of biofuel consumed decreased because livestock numbers decreased (providing insufficient amounts of dry dung), the protection of forests increased (thereby decreasing the availability of firewood) and the availability of alternative fuels increased. Our survey revealed that up to $74.8 \%$ of the respondents sharply decreased their consumption of meat from cattle, sheep and goats and consumed more fruits and vegetables (Table 4.3). This represents a large change from their traditional nomadic diet; when the number of livestock was constrained under the government policy, more of the animals were kept to sell rather than for eating. The decreased consumption of meat from cattle, sheep and goats was compensated for by increased consumption of pork, poultry, fruits and vegetables from the market.

In additional, the meat and milk consumption from self-produced products decreased from $73.0 \%$ in 1995 to $52.2 \%$ in 2010 and $78.1 \%$ in 1995 to $63.0 \%$ in 2010, respectively (Table 4.3). Most of the consumed grain foods came from for purchased products, and this proportion increased from an average of $80.8 \%$ in 1995 to $90.4 \%$ in 2010. The total self-produced meat consumption decreased significantly (by 20.8\%) between 1995 and 2010, especially in the Alxa Right Banner, because grassland in this banner is vulnerable and had sustained the most serious degradation, followed by grasslands in the Zhengxiangbai Banner and the West Ujimqin Banner. The West Ujimqin Banner maintained the highest self-produced rates of milk and meat 
consumption in 2010 , at $96.7 \%$ and $72.7 \%$, because this banner has high quality grassland and still maintains the traditional animal husbandry with the largest number of livestock (Table 4.3). The ecological conditions were also better than those in the Zhengxiangbai Banner and Alxa Right Banner. In contrast, the West Ujimqin Banner had the lowest self-produced rate of gain and fruits and vegetables consumption in 2010 , at only $5.1 \%$ and $23.4 \%$, respectively (Table 4.3 ). The decreased self-produced rate from meat and milk consumption indicated that the local herders and farmers relied less on their grasslands for food consumption, but this was achieved by placing some of the pressure of their food consumption on other areas that supplied imports of food and other materials. Therefore, household food consumption began to depend less on the available land and more on market factors. From a nutritional perspective, residents of Inner Mongolia are generally well nourished, even for low-income families (Xie et al. 2006). The food being consumed is also becoming more diverse, and this can encourage both grassland conservation and human health.

\subsection{Conclusions}

Ecosystem degradation, urbanization and the enforcement of the restoration policy have greatly impacted rural life and the use of grasslands. Three main conclusions can be drawn from the results of the survey:

(1) The analysis of household livelihoods and dependence on grasslands revealed that the implementation of grassland conservation policies had a strong impact on the livelihoods and security of households in three banners of Inner Mongolia. Both household-initiated adaptation and government-guided adaptation helped households to cope with the changes they were forced to endure. The main responses involved leasing of pasture, decreasing the number of livestock, adopting seasonal grazing supplemented by fodder purchases, increasing the intensity of livestock production, forming cooperative associations, seeking non-farming income sources and changing food and fuel consumption patterns. Table 4.4 summarizes the changes and household responses.

(2) This chapter analysed the dependence of household livelihoods on local grasslands and found that grasslands still provide vital functions. The annual household income and employment based on agricultural land still depended heavily on local grasslands, and most households owned some livestock, which they raised to sell for income or for personal consumption, especially in the West Ujimqin Banner and the Zhengxiangbai Banner. However, from 1995 to 2010 (before and after the implementation of the grassland conservation policy), the household dependence on local grasslands generally decreased, indicating a transition from traditional pastoral grazing to controlled grazing, modern raising of dairy cattle (intensive animal husbandry), diversification of income sources and decreases in land-based employment and in the household food and fuel consumption from grasslands. These changes increased the diversity of livelihoods and increased both household resilience and environmental sustainability.

(3) Despite this diversification, neither the government-stimulated adjustments nor household-initiated adaptations have liberated households from their dependence on the grasslands. However, most respondents reported a strong willingness for their family's next generation to move to a city to improve their education and employment opportunities. 
Table 4.4 Changes in household dependence on local grasslands from 1995 to 2010

\begin{tabular}{|c|c|c|c|}
\hline Indicators & Sub-Indicators & $\begin{array}{l}\text { Change } \\
\text { from } 1995 \\
\text { to } 2010\end{array}$ & Explanations \\
\hline \multirow{2}{*}{$\begin{array}{l}\text { Improved } \\
\text { social } \\
\text { relations }\end{array}$} & $\begin{array}{l}\text { Leasing of } \\
\text { pasture }\end{array}$ & $\uparrow \downarrow$ & $\begin{array}{l}\text { Leasing allows the owners of the grassland to } \\
\text { decrease their dependence on the land, while } \\
\text { increasing the leaseholder's dependence on the } \\
\text { land. }\end{array}$ \\
\hline & $\begin{array}{l}\text { Formation of } \\
\text { cooperative } \\
\text { associations }\end{array}$ & $\uparrow$ & $\begin{array}{l}\text { Social connections were enhanced by the } \\
\text { formation of cooperative associations. }\end{array}$ \\
\hline \multirow{3}{*}{$\begin{array}{l}\text { Controlled } \\
\text { animal } \\
\text { husbandry }\end{array}$} & $\begin{array}{l}\text { Number of } \\
\text { livestock }\end{array}$ & $\downarrow$ & $\begin{array}{l}\text { The decreased number of livestock per } \\
\text { household led to decreased pressure on the } \\
\text { grasslands to provide forage or fodder. }\end{array}$ \\
\hline & $\begin{array}{l}\text { Changes in } \\
\text { species }\end{array}$ & $\downarrow$ & $\begin{array}{l}\text { Herders and farmers decreased the number of } \\
\text { goats and sheep and increased the number of } \\
\text { cattle. Because modern raising of dairy cattle } \\
\text { can produce a more diverse and stable income } \\
\text { by making both meat and milk products } \\
\text { available, it represents a more cost-effective } \\
\text { use of the grasslands. }\end{array}$ \\
\hline & $\begin{array}{l}\text { Stall-fed } \\
\text { livestock }\end{array}$ & $\downarrow$ & $\begin{array}{l}\text { Stall feeding increased fodder purchases and } \\
\text { the utilization of crop residues to replace grass } \\
\text { fodder. }\end{array}$ \\
\hline \multirow{2}{*}{$\begin{array}{l}\text { Income- and } \\
\text { employment- } \\
\text { based } \\
\text { dependence } \\
\text { ratios }\end{array}$} & $\begin{array}{l}\text { Income (farm } \\
\text { vs. non-farm } \\
\quad \text { income) }\end{array}$ & $\downarrow$ & $\begin{array}{l}\text { Diversified income sources indicated the } \\
\text { increased flexibility of livelihoods, and } \\
\text { grasslands were no longer the only resources } \\
\text { that provided income. }\end{array}$ \\
\hline & $\begin{array}{l}\text { Employment } \\
\text { (land-based vs. } \\
\text { non-land based) }\end{array}$ & $\downarrow$ & $\begin{array}{l}\text { Increased labour engaged in non-land-based } \\
\text { employment decreased the dependence on the } \\
\text { grasslands. }\end{array}$ \\
\hline \multirow{2}{*}{$\begin{array}{l}\text { Food and } \\
\quad \text { fuel } \\
\text { consumption }\end{array}$} & $\begin{array}{c}\text { Food } \\
\text { consumption }\end{array}$ & $\downarrow$ & $\begin{array}{l}\text { The transition from a diet dominated by meat } \\
\text { to a more diverse diet was accompanied by } \\
\text { purchasing more food from markets, thereby } \\
\text { decreasing the meat consumption with less } \\
\text { intensive use of the grasslands, but shifted } \\
\text { some of this ecological footprint to other areas. }\end{array}$ \\
\hline & $\begin{array}{l}\text { Fuel } \\
\text { consumption }\end{array}$ & $\downarrow$ & $\begin{array}{l}\text { Fuel consumption patterns changed, with } \\
\text { decreased use of biofuels (dried dung, } \\
\text { firewood) and increased use of coal, electricity } \\
\text { and gas; thus, the fuel consumption was mostly } \\
\text { placed on mining or wind power generation } \\
\text { plants that provided these resources. }\end{array}$ \\
\hline
\end{tabular}

Our findings raise new concerns. For example, as increasing numbers of residents abandon the grasslands, there may come a time when nobody remains to use or manage the grasslands. Since the grasslands have coevolved with nomadic herders for millennia, this could lead to significant negative ecological effects; although vegetation communities are likely to recover in response to reduced human pressure, they may not recover to something that resembles their original state. Thus, future grassland management will need to emphasize sustainable use of grasslands. 
Within Inner Mongolia, basic management of most natural resources is weak and needs to be improved before sustainable management will be possible at the village or household level. Our results show how livelihood analysis provides a new perspective on resource and ecosystem management, especially in terms of linking micro-level household livelihood responses to macro-level policies. This approach provides insight into how new resource management strategies may differentially affect households. Further research will be required to fully understand the impacts of the policy-induced changes, with special attention to expanding livelihood diversity, enhancing resilience against environmental and economic stresses and advancing the urbanization process to improve the quality of life of grassland residents and reverse grassland degradation. 


\section{CHAPTER 5}

\section{Comparison of ecosystem services provided by grasslands with different utilization patterns}

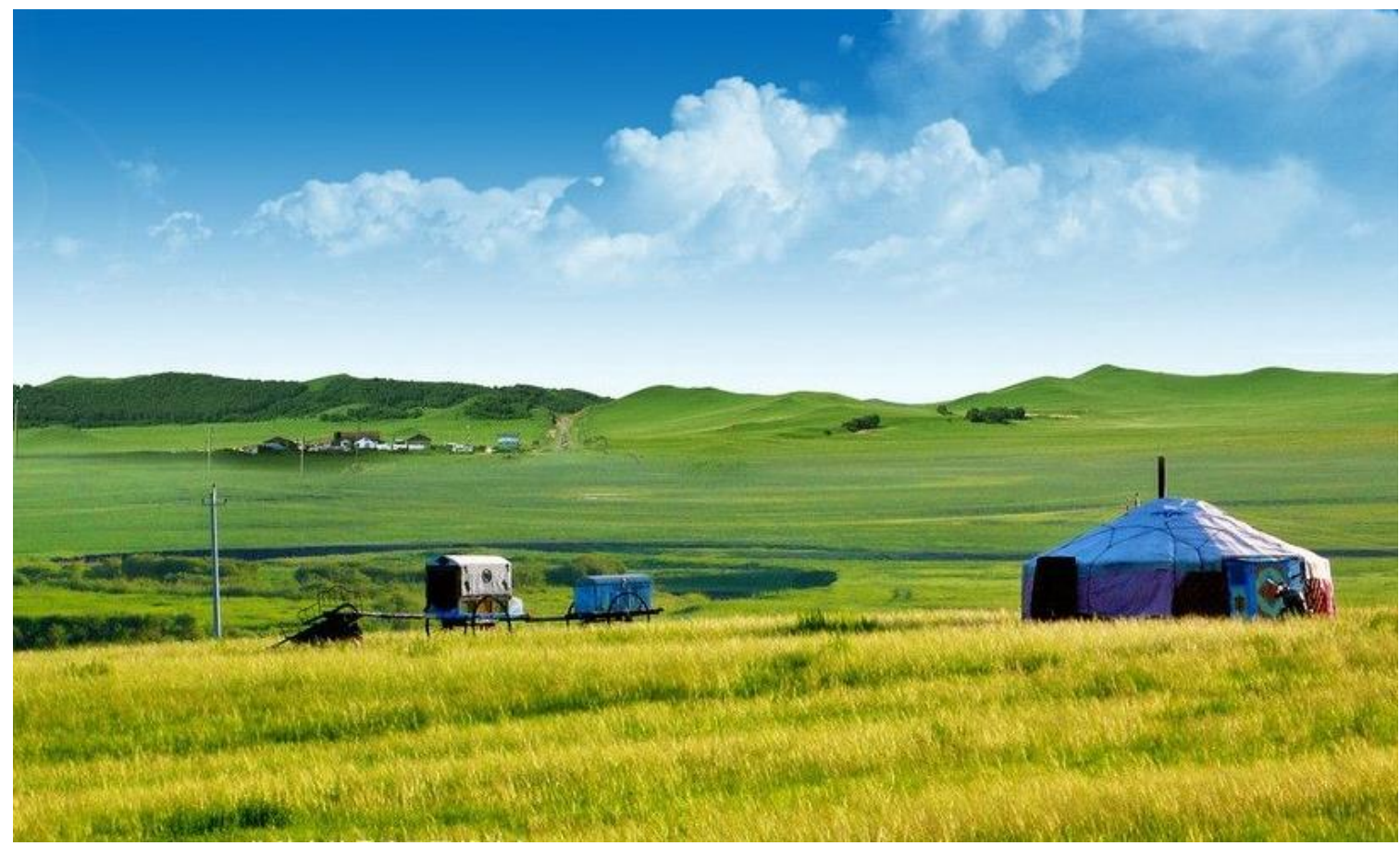

\section{Based on:}

Du B., Zhen L., Hu Y., Yan H., De Groot R., Leemans R. Comparison of ecosystem services provided by grasslands with different utilization patterns in China's Inner Mongolia Autonomous Region. Journal of Geographical Sciences 28(10): 1398-1414 


\begin{abstract}
:
Although several previous studies in Inner Mongolia Autonomous Region (IMAR) examined the effects of ecological conservation on the delivery of ecosystem services, they were often limited in scope (few ecosystem services were assessed) and often suffered from confounding by spatial variation. In this chapter, the impact of conservation measures (changes in grassland utilization patterns) on the provision of selected ecosystem services was examined at three study sites in IMAR (Hulun Buir, Xilin Gol and Ordos). Five utilization patterns were examined in this chapter: no use (natural grasslands), light use, moderate use, intensive use, and recovery sites (degraded sites protected from further use). Through household surveys and vegetation and soil surveys, the differences in ecosystem services among the different grassland utilization patterns were measured. We also identified spatial factors that confounded the quantification of ecosystem services in the different types of grasslands (meadow steppe, typical steppe and semi-desert steppe). The results of this chapter show light use generally provided higher levels of ecosystem services than intensive use and no use, with the main differences in the supporting ecosystem services. Surprisingly, we found no consistently positive impacts of strict conservation activities across the sites, since the results varied spatially and with respect to differences in the land-use patterns. Our result suggests that appropriate grassland utilization patterns can enhance the supply of ecosystem services and reduce negative effects on both household livelihoods and the environment.
\end{abstract}

Keywords: Ecosystem Services, Grasslands Utilization Pattern, Natural Resource Management, Soil, Vegetation, Household Livelihoods 


\subsection{Introduction}

Ecosystem services are the benefits that people derive from ecosystems, and represent the conditions and processes through which ecosystems and the species they contain sustain and satisfy the needs of human life (Daily 1997; Deng et al. 2016). The rapid economic growth that has occurred since the 1950s has led to serious environmental threats caused by humans, as we have consumed the services provided by natural ecosystems more rapidly and extensively than in any comparable period of human history. As a result of this unsustainable use, the Millennium Ecosystem Assessment (2003) reported that 15 of the world's 24 ecosystem services are declining. As these services are essential for human well-being, understanding the interactions between humans and their ecological environment is increasingly urgent. (Du et al. 2014; Liu et al. 2007). Such interactions result from the consumption and utilization of ecosystem services.

The analysis of ecosystem services has become an important source of data that support policy development and the management of natural resources (Crossman et al. 2013). The analysis of ecosystem services commonly focuses on the supply of immediate, direct benefits to humans, such as provisioning services (Millennium Ecosystem Assessment 2005), and decision-making therefore ignores the regulating and supporting services that permit these provisioning sources to exist (Abson \& Termansen 2011). However, shifts in management philosophy towards maintaining the regulating and supporting services are increasingly advocated given the threats these services pose to the continued supply of provisioning services as a result of climate change and human interventions. This increasing understanding of the interdependencies among services have led managers to understand the need to seek compromises for the trade-offs among the different services (Prober et al. 2012).

A key element for the maintenance of multiple ecosystem services is to identify and account for changes in the intensity of land-use patterns (e.g. plant cultivation, forestry, livestock activities) in the policy development process. Indeed, these patterns depend on several services (Power 2010). However, the changes associated with the development of these patterns often have important negative impacts on ecosystem services in the medium and long term that impair the land's ability to continue sustaining such activities (Kareiva et al. 2011; Raudsepp-Hearne et al. 2010; Swinton et al. 2007). To maintain multiple ecosystem services, it's necessary to seek an optimal spatial allocation of human activities that will minimize their negative environmental impacts. Growing recognition of the need for such analyses has led to the incorporation of ecosystem analysis as a mandatory component of ecosystem management in many countries (Pan et al. 2013). In addition, there is also a critical need for new studies that reveal the simultaneous changes in provision of multiple services so that managers can better understand the trade-offs involved in the delivery of ecosystem services and look for solutions and synergies (Bennett et al. 2009).

Unfortunately, analyses of multiple ecosystem services are problematic. For instance, researchers are typically constrained in the number and range of services they can analyse due to a lack of available datasets at relevant scales. Focusing on only two or three indicators (such as remote-sensing data for net primary productivity) runs the risk of creating an incomplete or distorted picture of the full range of services that different ecosystems or land-use types provide. Most research has been theoretical, which results in excessive reliance on imperfect proxies for ecosystem services; for example, soil carbon stocks are often used as a proxy for climate regulation services. 
This approach limits and constrains the findings (Castro et al. 2015). In current research, a lack of focus on supporting services has made it especially difficult to compare different utilization patterns due to a mismatch of the scales of analysis for different services.

To solve some of these problems and improve the support for developing resourcemanagement policy in the grasslands of Inner Mongolia Autonomous Region (IMAR), this chapter aimed to reduce the bias that results from focusing on too few services. To do so, we analysed these grasslands, which are highly vulnerable to human activities, to provide a more comprehensive understanding of the relationships between natural resource conservation actions (which result in different land utilization patterns) and the resulting impacts on ecosystem services. a household survey was performed to understand the context for residents of this region, performed vegetation and soil surveys, and obtained expert opinions to (1) identify the major ecosystem services provided by IMAR's grassland ecosystem; (2) classify the grassland utilization patterns; and (3) assess the ecosystem services and their variations among grasslands in different geographic locations and with different utilization patterns. The analysis of this chapter included both sites that are managed for nature conservation and sites with a range of utilization intensities in three parts of IMAR with different geographic characteristics. The results of our research will improve grassland management in the study area by accounting for both ecological conservation and the livelihoods of residents of the region.

\subsection{Study area}

Typical steppe and meadow steppe are the major types of grassland ecosystem in IMAR, and are most commonly used for grazing and animal production (Kang et al. 2007). The local people depend mainly on animal husbandry, and the grassland ecosystems supply almost all of the forage needed for their livestock's consumption; thus, these vegetation types support the dominant livelihood of the region's residents (Zhen et al. 2010a). However, the grasslands of IMAR have been experiencing degradation for decades that is directly threatening both the environment and the sustainability of regional socioeconomic development. To reverse the increasing tendency toward grassland degradation, national and local governments have implemented a series of ecosystem conservation policies and countermeasures to alleviate the anthropogenic stresses on the ecosystems.

The most important of these measures, which has been implemented in heavily degraded areas, aims to return pastures to grassland. The policy was implemented in 1998 and extended throughout the region after several years' experience. The policy included four measures (NDRC 2014):

1. Seasonal grazing allows grazing of pastures only during a certain season (e.g. summer), typically throughout the period of grass growth from April to November. During the winter, herders feed livestock indoors using conserved forage. This approach has been broadly implemented, but especially in slightly degraded grassland, such as that in Hulun Buir.

2. Rotational grazing has been implemented in slightly and moderately degraded grassland, mostly in Xilin Gol but also on a small scale in Hulun Buir. In this measure, the grassland is fenced and divided into paddocks that are then used in rotation, with the goal of leaving time for vegetation recovery. 
3. Grazing prohibition is mainly carried out in intensely degraded grassland, especially in Ordos, to encourage grassland recovery. Because grazing prohibition could cause high economic losses by reducing the number of livestock a resident can support and can lead to a requirement for high economic inputs due to the need to purchase fodder, a fourth measure was implemented.

4. Livestock-rearing control has the objective of lowering the impact on pastures by limiting the number of livestock allowed to graze in an area. Xilin Gol has been strongly influenced by this last measure. The number of livestock is defined based on the carrying capacity of local grasslands, and nomadic grazing is prohibited and replaced by indoor rearing. To implement this measure, grassland fencing has been widely performed.

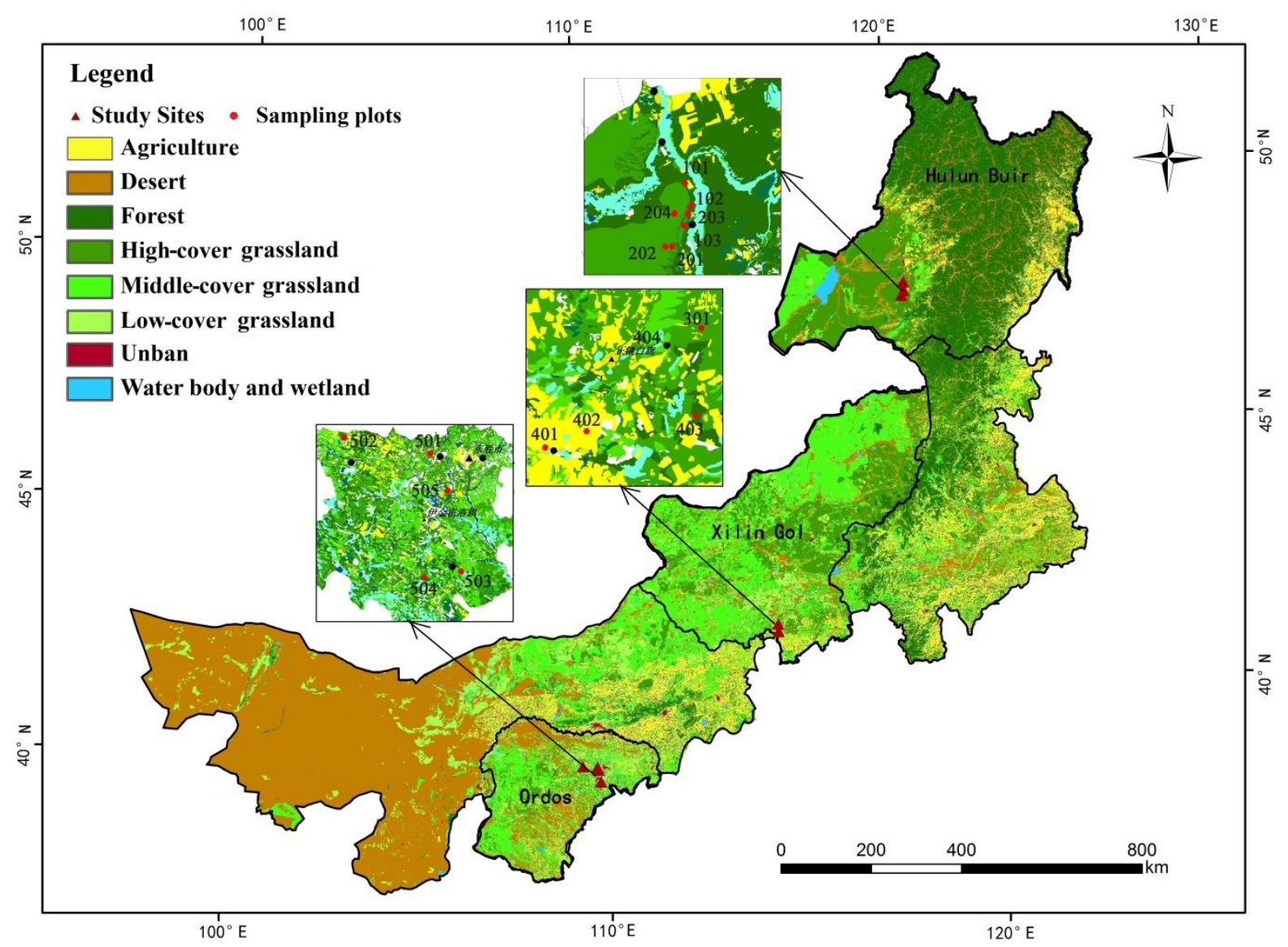

Figure 5.1 Location of the study area and map of the study sites. (Grassland types: high-cover, vegetation cover $>50 \%$; medium-cover, vegetation cover between $25 \%$ and $50 \%$; low-cover, vegetation cover $<25 \%$. Numbers in the inset maps refer to the study plot numbers.)

\subsection{Materials and methods}

\subsubsection{Identifying grassland utilization patterns}

Ecosystems may change their state in response to geographic variation, the degree of grassland utilization, and indirect impacts via management responses such as changed grazing regimes. By considering these factors, five grassland utilization patterns have been defined: no use, light use, moderate use, intensive use and recovery. Multiple methods were used to identify the grassland utilization patterns (Table 5.1): 
1. Before we travelled to the field, the five utilization patterns were identified based on an intensive literature review, analysis of remote-sensing data, and interviews with experts.

2. During the field surveys, we used the density of dung and traces of grazing as an indicator of grazing intensity.

3. We also invited local herders to provide information on their number of livestock, grazing locations and grazing practices (e.g. seasonal grazing, rotational grazing).

Table 5.1 Characteristics of the five grassland utilization patterns in the Inner Mongolia Autonomous Region

\begin{tabular}{|c|c|c|c|}
\hline $\begin{array}{l}\text { Utilization } \\
\text { pattern }\end{array}$ & Features & $\begin{array}{l}\text { Degree } \\
\text { of use }\end{array}$ & Source \\
\hline \multirow[t]{3}{*}{ No use } & - natural grassland & \multirow[t]{3}{*}{ none } & Literature reviews \\
\hline & - no degradation & & Expert interviews \\
\hline & - no grazing (no sign of trampling or livestock dung) & & Remote sensing \\
\hline \multirow[t]{3}{*}{ Light use } & $\begin{array}{l}\text { - occasional use }(<4 \text { months from April to } \\
\text { November })\end{array}$ & \multirow[t]{3}{*}{+} & $\begin{array}{l}\text { data (comparison } \\
\text { of images from }\end{array}$ \\
\hline & - seasonal grazing or rotational grazing & & $\begin{array}{l}1995,2000,2005 \\
\text { and 2010) }\end{array}$ \\
\hline & - livestock number controlled & & Field observations \\
\hline \multirow[t]{2}{*}{ Moderate use } & $\begin{array}{l}\text { - continuous use from April to November } \\
\text { - seasonal grazing }\end{array}$ & \multirow[t]{2}{*}{++} & $\begin{array}{l}\text { (density of dung, } \\
\text { traces of grazing) }\end{array}$ \\
\hline & - livestock number controlled & & Household surveys \\
\hline Intensive use & $\begin{array}{l}\text { - continuous use from April to November } \\
\text { - mowing for winter fodder } \\
\text { - no grazing control measures }\end{array}$ & +++ & $\begin{array}{l}\text { (no. of livestock in } \\
\text { their pasture, } \\
\text { grazing locations, } \\
\text { activities) }\end{array}$ \\
\hline \multirow[t]{4}{*}{ Recovery } & $\begin{array}{l}\text { - fencing used to exclude livestock and protect the } \\
\text { grassland }\end{array}$ & \multirow[t]{4}{*}{ none } & \\
\hline & - grazing prohibition & & \\
\hline & - used to be a seriously degraded area & & \\
\hline & - recovering from degradation & & \\
\hline
\end{tabular}

\subsubsection{Selection of ecosystem services indicators}

The local grassland ecosystem provides multiple ecosystem services, and it was not possible to assess all of them. Thus, three steps were used to identify the most important indicators:

1. Identifying ecosystem services through a literature review. Based on the classification schemes that have been devised, such as those of De Groot et al. (2002) and the Millennium Ecosystem Assessment (2005), we selected a list of potential ecosystem services for consideration (Appendix 6).

2. Identifying vital ecosystem services for grasslands. We conducted a stakeholder workshop on local grassland use perspectives in the summer of 2012 in Xilin Gol. The workshop's aim was to obtain information on the relative importance of ecosystem services from the local perspective. Based on the invitation of local stakeholders to the workshop on the concept of multi-level governance (Suškevics 2012). On a county (regional) level, we selected participants from among local stakeholders following the recommendations of the vice-governor of Xilin Gol, who was responsible for land use and grassland management issues. 
On a village (local) level, we asked the village headmen if they were interested in joining the workshop during a household survey in Xilin Gol that occurred shortly before the workshop. The final group of invitees included a mixed group of 10 participants (three village headmen and seven county officers). Based on the list of ecosystem services identified in step 1, we asked the stakeholders to assign weights that represented the perceived importance of each ecosystem service (very important, important and less important). Based on the results of this workshop, seven key ecosystem services were identified: three provisioning services (food, raw materials including fodder and fuel), two regulating services (soil retention and soil nutrients), and two supporting services (primary production and habitat). These were selected based on their high importance to sustain rural socioeconomic activities and to prevent negative environmental impacts on the local grasslands.

3. Selecting indices for assessing the ecosystem services identified in step 2. Meat is the major food provisioning service provided by the grassland ecosystem, and can be represented based on the number of livestock per household. Beef and mutton were the two major types of meat produced in the study area. The raw material provisioning service can be quantified as the amount of fodder consumed by local livestock. The fuel provisioning service was based on the fact that the livestock produced dung, which was dried and used as a traditional local fuel source. Regulating services represent benefits obtained from regulation of the environment and ecosystem processes. In this category, soils are considered the primary element (Millennium Ecosystem Assessment 2005). Many studies have indicated that extensive degradation of IMAR's grasslands has been accompanied by decreased regulating services, such as loss of soil nutrients and increased soil erosion and desertification (e.g. Zhang et al. 2013). We chose soil bulk density, soil water content and soil nutrient contents as the site-specific indicators of the regulating services. Supporting services were defined as services necessary for the production of ecosystem functions. The most important product of IMAR's grasslands in is livestock, and two main factors control the number of livestock: primary production and habitat. To avoid the bias that can result from using a single indicator, we divided primary production into aboveground biomass and the proportion of this biomass that is edible. Similarly, because grasses are the dominant vegetation type in the grasslands, we used three biodiversity indicators to quantify the habitat characteristics: the Margalef, Shannon-Wiener and Pielou indices, which represent species richness, diversity and evenness, respectively. These indices are detailed in Section 5.3.3 and Table 5.2 summarizes the results of this selection process. 
Table 5.2 Proposed indicators for assessing ecosystem services under the different grassland utilization patterns

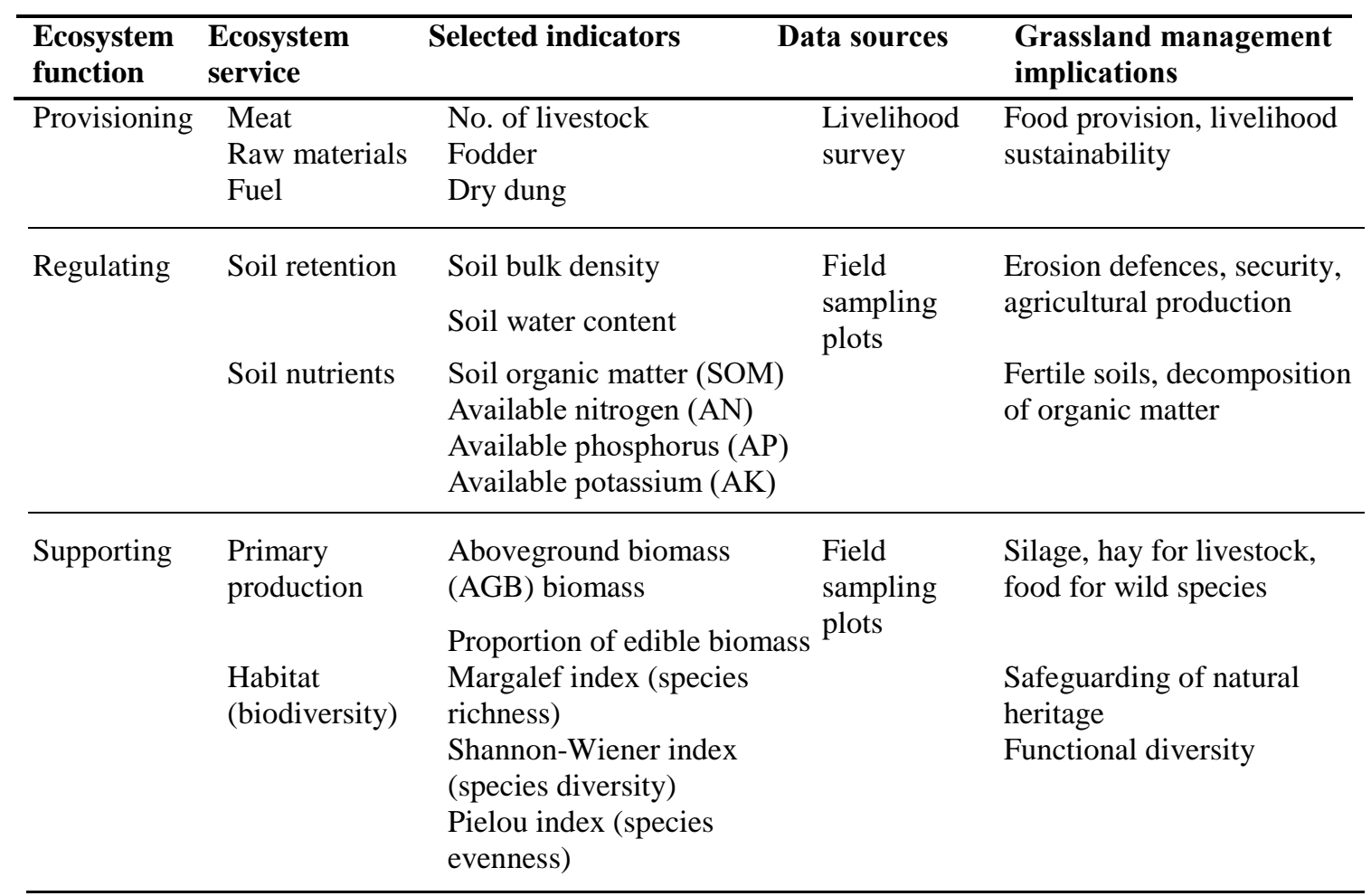

\subsubsection{Quantification of ecosystem services}

\section{Accounting for provisioning services by household surveys}

To quantify the actual provisioning services derived from the grassland to sustain household needs, we used a questionnaire survey from June to July 2011 that was administered to 230 households, with an average of 23 households per village in 10 villages (three in Hulun Buir, three in Xilin Gol and four in Ordos), and received 209 valid responses $(90.9 \%)$. To explore and quantify how ecosystem conservation (the different land-use patterns) affected the delivery of ecosystem services, we chose three study regions (Hulun Buir, Xilin Gol and Ordos; Figure 5.1) for the household survey. To quantify spatial variation, we included the abovementioned 10 villages, which differed in terms of characteristics such as geographical and ecological characteristics and economic activities. In each village, stratified random sampling were used to select households for the interviews; households were only included in the survey if they comprised at least two people (typically a married couple). We investigated more than $65 \%$ of the total households in each village, which agrees with the suggestion of Tabachnick and Fidell (2007) that the sample should include more than $50 \%$ of the total households for populations smaller than 100 households. A high valid response rate $(90.9 \%)$ was achieved because the questionnaire was applied through face to face interviews in which the respondents filled out the questionnaires with guidance from the research group. The questionnaire asked for information on the household's demographic characteristics and economic activities; quantification of household consumption of meat, fuel and fodder and their sources derived from grassland provisioning services; and information to help validate the preliminary classification of the grassland utilization patterns. 


\section{Assessing regulating services by investigating soil properties}

We quantified regulating and supporting services by means of a vegetation and soil survey in June and July 2011, at the same time as the household survey. We established sampling plots at 16 sampling sites (Table 5.3) to provide an estimate of the spatial variation in soil and vegetation characteristics; these included plots in semi-desert steppe (at 5 locations in Ordos), typical steppe (at 4 locations in Xilin Gol) and meadow steppe (at 7 locations in Hulun Buir). The vegetation surveys in June and July were conducted during the key growth period for the local vegetation. There were five no use sites, three light use sites, two moderate use sites, two intensive use sites (due to regional policy, only in Hulun Buir) and four recovery sites.

At each site, soil samples were collected from three soil profiles to determine soil properties to a depth of $30 \mathrm{~cm}$. Soil samples were carefully cleaned to remove plant materials and organic matter, then were air-dried and sieved through a 2-mm mesh to extract coarse materials. The three replicates were then carefully mixed to produce a single bulked sample. Analysis of soil properties was then conducted at the Chinese Academy of Sciences physics and chemistry laboratory in Beijing. Each mixed soil sample was divided into two parts. One sub-sample was oven-dried at $105^{\circ} \mathrm{C}$ to constant weight to measure the bulk density and gravimetric soil water content. The other sub-sample was ground to a final size of $1 \mathrm{~mm}$ in a ball mill before analysis of the soil organic matter (SOM), available phosphorus (AP), available potassium (AK) and available nitrogen (AN) contents. Soil properties were determined following standard protocols (Bao 2000; Brown 1993).

Table 5.3 Basic characteristic of the study plots

\begin{tabular}{|c|c|c|c|c|c|c|c|c|c|}
\hline Location & $\begin{array}{l}\text { Plot }^{\mathrm{a}} \\
\text { number }\end{array}$ & $\begin{array}{l}\text { Longitud } \\
\text { e }\left({ }^{\circ} \mathrm{N}\right)\end{array}$ & $\begin{array}{l}\text { Latitud } \\
\text { e }\left({ }^{\circ} \mathrm{E}\right)\end{array}$ & $\mathrm{T}^{\mathrm{b}}\left({ }^{\circ} \mathrm{C}\right)$ & $\mathrm{P}^{\mathrm{c}}(\mathrm{mm})$ & $\begin{array}{l}\text { No. of } \\
\text { species }\end{array}$ & Type of grassland & Soil type & $\begin{array}{l}\text { Utilization } \\
\text { intensity }\end{array}$ \\
\hline \multirow[t]{7}{*}{ Hulun Buir } & 101 & 119.8 & 48.89 & -1 & 329.5 & 22 & Meadow steppe & medium /light loam & None \\
\hline & 102 & 119.81 & 48.82 & -0.9 & 334.0 & 17 & Meadow steppe & medium /light loam & Intensive \\
\hline & 103 & 119.77 & 48.77 & -0.8 & 336.5 & 44 & Meadow steppe & medium/light loam & Moderate \\
\hline & 201 & 119.71 & 48.72 & -0.7 & 338.3 & 32 & Meadow steppe & medium/heavy loam & None \\
\hline & 202 & 119.68 & 48.72 & -0.7 & 337.5 & 33 & Meadow steppe & heavy/medium loam & None \\
\hline & 203 & 119.79 & 48.8 & -0.8 & 334.9 & 16 & Meadow steppe & light/sandy loam & Intensive \\
\hline & 204 & 119.74 & 48.81 & -0.9 & 333.3 & 42 & Meadow steppe & medium/light loam & Light \\
\hline \multirow[t]{4}{*}{ Xilin Gol } & 301 & 115.14 & 42.33 & 3.3 & 217.0 & 23 & Typical steppe & sandy loam & Light \\
\hline & 401 & 114.88 & 42.21 & 3.4 & 210.2 & 10 & Typical steppe & light/sandy loam & Recovery \\
\hline & 402 & 114.95 & 42.22 & 3.4 & 210.9 & 15 & Typical steppe & light/sandy loam, & Moderate \\
\hline & 403 & 115.12 & 42.23 & 3.3 & 217.6 & 24 & Typical steppe & light loam & None \\
\hline \multirow[t]{5}{*}{ Ordos } & 501 & 109.79 & 39.84 & 7.1 & 248.1 & 20 & Semi-desert steppe & light loam & None \\
\hline & 502 & 109.32 & 39.92 & 7.2 & 219.8 & 19 & Semi-desert steppe & sandy loam & Recovery \\
\hline & 503 & 109.92 & 39.36 & 7.1 & 230.1 & 20 & Semi-desert steppe & dense sand, sandy loam & Recovery \\
\hline & 504 & 109.72 & 39.34 & 7.1 & 225.6 & 26 & Semi-desert steppe & sandy loam, dense sand & Light \\
\hline & 505 & 109.87 & 39.69 & 7.1 & 247.5 & 17 & Semi-desert steppe & light loam, sandy loam & Recovery \\
\hline
\end{tabular}

${ }^{\mathrm{a}}$ Locations of the plots are shown in Figure 5.1.

${ }^{\mathrm{b}} \mathrm{T}$ is the annual average temperature $\left({ }^{\circ} \mathrm{C}\right)$, were obtained from meteorological stations in IMAR in 2011

${ }^{\mathrm{c}} \mathrm{P}$ is the annual average precipitation $(\mathrm{mm})$, were obtained from meteorological stations in IMAR in 2011 


\section{Assessing supporting services based on vegetation traits}

To quantify the vegetation characteristics, the aboveground biomass (AGB) was harvested in three sub-plots (each $1 \times 1 \mathrm{~m}$ ) at each plot, with similar topography and exposure to sunlight and with the sub-plots separated by every $10 \mathrm{~m}$. All living vascular plants in each quadrat were sorted according to species. Subsequently, the plant height, vegetation cover, number of individuals and density (no. individuals per $\mathrm{m}^{2}$ ) were determined. AGB was determined by clipping the plants at ground level, and was measured after oven-drying at $65 \pm 5^{\circ} \mathrm{C}$ for $48 \mathrm{~h}$. The proportion of edible biomass was determined based on knowledge of the local species that could be consumed by the local livestock; this proportion equalled AGB for all edible species divided by total AGB.

The grassland production data (AGB and the proportion of edible biomass) were used directly to indicate supporting services for primary production. In addition, three diversity indices were calculated to represent the habitat ecosystem service:

The Shannon-Wiener index $(H)$ was calculated as follows (Bakelaar and Odum 1978):

$$
H=-\sum_{i=1}^{S}\left(P_{i} \ln P_{i}\right)
$$

Where $S$ is the number of species and $P_{i}$ is the relative importance of species $i$ (its proportion of the total number of species). The relative importance of species is calculated as follows:

$$
P_{i}=N_{i} / N
$$

Where $N_{i}$ is the number of individuals of species $i$, and $N$ is the total number of individuals of all species in the quadrat.

The Margalef index $(D)$ was calculated as follows:

$$
D=(S-1) / \ln N
$$

The Pielou index $(E)$ was calculated as follows:

$$
E=\frac{H}{\ln (S)}
$$

\subsection{Results and discussion}

\subsubsection{Provisioning services that support herder livelihoods}

Grasslands produce three main products that sustain the livelihood of herders: meat (mutton and beef), fodder (grass) and biofuel (dry dung). All three goods are directly related to the number of livestock, and the results therefore differed greatly among the three areas due to the different numbers of livestock per household (Table 5.4). In Hulun Buir, herding of sheep (an average of 52 per household) and cattle (18 per household) was the major economic activity. A smaller number of cattle (an average of 4.2 per household) and sheep (2.4 per household) dominated economic activity in Xilin Gol. The productivity for livestock production per household in Xinlin Gol was only around $10 \%$ of Hunlun Buir (76.3 per household vs. 8.8 per household). In Ordos, a few cattle (an average of 0.8 per household) and sheep (2.4 per household) are raised, primarily for breeding. In Ordos, households chose to raise many smaller animals than in the other areas, such as goats (an average of 6.0 per household) and 
chickens (16.9 per household). This seems to be a pragmatic response to government initiatives that greatly reduce the consumption of fodder from ecosystems to prevent further degradation of the semi-desert steppe.

Table 5.4 Household consumption of provisioning services

\begin{tabular}{|c|c|c|c|c|}
\hline \multirow[t]{2}{*}{ Consumptions } & \multicolumn{3}{|c|}{ Study site $^{a}$} & \multirow[b]{2}{*}{$\begin{array}{l}\text { Overall } \\
(n=209)\end{array}$} \\
\hline & $\begin{array}{l}\text { Hulun Buir } \\
(n=66)\end{array}$ & $\begin{array}{l}\text { Xilin Gol } \\
(n=71)\end{array}$ & $\begin{array}{l}\text { Ordos } \\
(n=72)\end{array}$ & \\
\hline \multicolumn{5}{|c|}{ Livestock (no. per household, \% of total) } \\
\hline Sheep & $52.0(68.2)$ & $2.4(27.0)$ & $2.4(8.9)$ & $18.0(49.5)$ \\
\hline Goats & $3.2(4.2)$ & $0.2(2.2)$ & $6.0(22.3)$ & $3.2(8.8)$ \\
\hline Cattle & $18.0(23.6)$ & $4.2(47.2)$ & $0.8(3.0)$ & $7.3(20.1)$ \\
\hline Chickens & $3.0(3.9)$ & $2.0(22.5)$ & $16.9(62.8)$ & $7.5(20.6)$ \\
\hline Pigs & $0.1(0.1)$ & $0.1(1.1)$ & $0.8(3.0)$ & $0.4(1.1)$ \\
\hline Total livestock & $76.3(100)$ & $8.8(100)$ & $26.9(100)$ & $37.3(100)$ \\
\hline \multicolumn{5}{|c|}{ Meat (kg per capita per year, $\%$ of total) } \\
\hline Mutton-Beef & $97.2(76.3)$ & $65.6(82.5)$ & $35.7(39.5)$ & $65.3(66.4)$ \\
\hline Other Meat ${ }^{b}$ & $30.1(23.6)$ & $13.9(17.5)$ & $54.7(60.5)$ & $33.1(33.6)$ \\
\hline Total meat & $127.3(100)$ & $79.5(100)$ & $90.4(100)$ & $98.4(100)$ \\
\hline \multicolumn{5}{|l|}{ Fuel (per capita per year) } \\
\hline Dry dung (kg) & 2878.6 & 265.2 & 199.4 & 1407.5 \\
\hline Coal (kg) & 2063.6 & 690.6 & 922.4 & 1203.9 \\
\hline Electricity (CNY) & 84.4 & 135.9 & 215.0 & 146.9 \\
\hline
\end{tabular}

The results of household survey show that dry dung from livestock was an important biofuel; it was widely used in all three areas, but especially in Hulun Buir, where the annual per capita consumption was $2878.6 \mathrm{~kg}$. The high consumption of dried dung can be attributed to the higher numbers of sheep and cattle. Herders used biofuel to support the needs of daily life, including cooking, heating and heating bath water. Due to the great reduction in the number of livestock in response to government policies to reduce grazing pressure on the ecosystem, with especially severe reductions in Xilin Gol and Ordos, dry dung cannot satisfy the household demand so households use more new forms of energy (e.g. coal, electricity) instead of dung. Table 5.5 shows how the ecosystem services differed among the three regions and changed as a function of the intensity of grassland use. Due to the government's conservation policies, the no use and recovery grassland utilization patterns have totally lost their provisioning services to herders. The intensive use pattern has the highest value of provisioning services, followed by the moderate use and light use patterns. 
Table 5.5 Scores for ranking ecosystem services in the three parts of the study area as a function of the grassland utilization patterns (intensities)

\begin{tabular}{|c|c|c|c|c|c|c|c|c|c|c|c|c|c|}
\hline \multirow{2}{*}{\multicolumn{2}{|c|}{$\begin{array}{l}\text { Ecological service Ecosystem service } \\
\text { function }\end{array}$}} & \multirow[t]{2}{*}{ Selected indicator } & \multicolumn{4}{|c|}{ Utilization patterns in Hulun Buir } & \multicolumn{4}{|c|}{ Utilization patterns in Xilin Gol } & \multicolumn{3}{|c|}{ Utilization patterns in Ordos } \\
\hline & & & No use & Light use & Moderate use & Intensive use & No use & Light use & Moderate use & Recovery & No use & Light use & Recovery \\
\hline \multirow[t]{4}{*}{ Provisioning } & Food & No. of livestock & NA (0) & $+(1)$ & $++(2)$ & $+++(3)$ & NA $(0)$ & $+(1)$ & $++(2)$ & NA $(0)$ & NA $(0)$ & $+(1)$ & NA $(0)$ \\
\hline & Fuel & Fuel & NA (0) & $+(1)$ & $++(2)$ & $+++(3)$ & NA (0) & $+(1)$ & $++(2)$ & NA $(0)$ & NA $(0)$ & $+(1)$ & NA $(0)$ \\
\hline & Raw materials & Fodder & NA (0) & $+(1)$ & $++(2)$ & $+++(3)$ & NA $(0)$ & $+(1)$ & $++(2)$ & NA $(0)$ & NA $(0)$ & $+(1)$ & NA $(0)$ \\
\hline & \multicolumn{2}{|c|}{ Average score for provisioning services } & 0 & 1 & 2 & 3 & 0 & 1 & 2 & 0 & 0 & 1 & 0 \\
\hline \multirow[t]{7}{*}{ Supporting } & \multirow[t]{2}{*}{ Primary production } & $\operatorname{AGB}\left(\mathrm{g} / \mathrm{m}^{2}\right)$ & $164.4(3)$ & $130.7(2)$ & $178.0(4)$ & $61.8(1)$ & $129.3(3)$ & $210.9(4)$ & $101.4(2)$ & $81.8(1)$ & $95.0(3)$ & $81.0(2)$ & $129.4(1)$ \\
\hline & & Edible biomass (\%) & $100.0(4)$ & $99.5(3)$ & $83.1(2)$ & $37.2(1)$ & $99.7(4)$ & $65.1(3)$ & $42.4(2)$ & $23.0(1)$ & $96.8(3)$ & $76.5(2)$ & $44.4(1)$ \\
\hline & \multicolumn{2}{|c|}{ Average score for primary production services } & 3.5 & 2.5 & 3 & 1 & 3.5 & 3.5 & 2 & 1 & 3 & 2 & 1 \\
\hline & \multirow[t]{3}{*}{ Habitat (biodiversity) } & Margalef index & $2.14(2)$ & $6.18(4)$ & $5.88(3)$ & $1.81(1)$ & $2.49(2)$ & $2.82(3)$ & $3.16(4)$ & $1.83(1)$ & $1.97(2)$ & $1.95(1)$ & $2.03(3)$ \\
\hline & & Shannon-Wiener index & $1.37(2)$ & $2.73(3)$ & $2.76(4)$ & $0.52(1)$ & $1.12(1)$ & $1.49(3)$ & $1.41(2)$ & $1.59(4)$ & $1.16(2)$ & $1.21(3)$ & $1.10(1)$ \\
\hline & & Pielou index & $0.51(2)$ & $0.79(3)$ & $0.80(4)$ & $0.20(1)$ & $0.41(1)$ & $0.54(3)$ & $0.50(2)$ & $0.69(4)$ & $0.48(1)$ & $0.52(2)$ & $0.62(3)$ \\
\hline & \multicolumn{2}{|c|}{ Average score for habitat services } & 2 & 3.33 & 3.67 & 1 & 1.33 & 3 & 2.67 & 3 & 1.67 & 2 & 2.33 \\
\hline \multirow[t]{8}{*}{ Regulating } & \multirow{2}{*}{ Soil retention } & Soil bulk density $(\mathrm{g} / \mathrm{kg})$ & $3.1(4)$ & $3.9(1)$ & $3.5(3)$ & $3.8(2)$ & $3.9(4)$ & $4.0(3)$ & $4.5(1)$ & $4.9(2)$ & $4.4(3)$ & $4.7(2)$ & $4.9(1)$ \\
\hline & & Soil water content (\%) & $12.4(4)$ & $9.1(2)$ & $9.9(3)$ & $7.0(1)$ & $7.8(4)$ & $5.0(2)$ & $3.1(1)$ & $5.1(3)$ & $5.8(3)$ & $3.6(1)$ & $4.4(2)$ \\
\hline & \multicolumn{2}{|c|}{ Average score for soil retention services } & 4 & 1.5 & 3 & 1.5 & 4 & 2.5 & 1 & 2.5 & 3 & 1.5 & 1.5 \\
\hline & \multirow[t]{4}{*}{ Soil nutrients } & $\mathrm{SOM}(\mathrm{g} / \mathrm{kg})$ & $40.2(4)$ & $20.3(3)$ & $15.7(2)$ & $9.0(1)$ & $38.4(4)$ & $27.9(3)$ & $26.8(2)$ & $12.9(1)$ & $13.7(2)$ & $8.8(1)$ & $14.3(3)$ \\
\hline & & $\mathrm{AN}(\mathrm{mg} / \mathrm{kg})$ & $136.6(4)$ & $114.0(2)$ & $98.1(3)$ & $92.3(1)$ & $103.0(4)$ & $57.7(1)$ & $60.1(2)$ & $76.7(3)$ & $19.6(2)$ & $14.4(1)$ & $31.5(3)$ \\
\hline & & $\mathrm{AP}(\mathrm{mg} / \mathrm{kg})$ & $4.8(4)$ & $3.6(3)$ & $3.04(2)$ & $2.9(1)$ & $3.7(4)$ & $2.5(1)$ & $2.6(2)$ & $3.1(3)$ & $3.6(3)$ & $2.5(1)$ & $3.4(2)$ \\
\hline & & $\mathrm{AK}(\mathrm{mg} / \mathrm{kg})$ & $162.4(4)$ & $128.0(3)$ & $101.6(2)$ & $97.5(1)$ & $21.1(1)$ & $78.0(3)$ & $74.6(2)$ & $87.7(4)$ & $41.3(2)$ & $8.5(1)$ & $57.8(3)$ \\
\hline & \multicolumn{2}{|c|}{ Average score for soil nutrient services } & 4 & 2.75 & 2.25 & 1 & 3.25 & 2 & 2 & 2.75 & 2.25 & 1 & 2.75 \\
\hline \multicolumn{3}{|c|}{ Sum of rank scores for all services * } & 13.5 & 11.08 & 13.92 & 7.5 & 12.08 & 12 & 9.67 & 9.25 & 9.92 & 7.5 & 7.58 \\
\hline
\end{tabular}

${ }^{a} \mathrm{NA}$ means that the grassland is not used to provide the specified ecosystem services due to policy interventions or limitations of accessibility (Du et al. 2014). Values in brackets represent the rank score for each service for the amount of ecosystem services provided: + low, ++ medium, +++ high. The scores are based on the ranking of ecosystem services, and higher scores represent higher provision of services. 


\subsubsection{Regulating services in the different grassland utilization patterns}

\section{Soil retention}

Along the transect from northeast to southwest, soil bulk density increased (representing greater compaction), and SOM and the soil water content decreased (Table 5.6), indicating a decreasing ecological service for soil retention. Soil bulk density was lowest in Hulun Buir and highest in Ordos. Soil water content was highest in Hulun Buir (meadow steppe) and lowest in Ordos (semi-desert steppe), with a significant decreasing trend $(\mathrm{P} \leq 0.05)$ along with decrease of precipitation and incease of temperature (Table 5.3). In Hulun Buir, the no use pattern had the highest soil water content $(12 \%)$, and the intensive use pattern had the lowest soil water content $(7 \%)$. As in the case of Hulun Buir, soil water content decreased with increasing intensity of grassland use. The soil water content also increased at the recovery sites compared with the used sites (Table 5.5, Appendix 7).

Previous research in Xilin Gol (Yu et al. 2003) indicated that soil retention services were and correlated with decreased desertification and ecosystem degradation, and that increased soil retention services may have been responsible for a higher soil water content. IMAR is characterized by an arid to semi-arid continental climate and strongly imfluenced by tempreture and precipitaition. Thus, water shortages are widely observed. From 2014 statistics, the region's total water resources were $412.1 \times 10^{9} \mathrm{~m}^{3}$, and have decreased at an average rate of $5 \%$ per year since the $1990 \mathrm{~s}$ (Inner Mongolia Statistics Bureau 2015b). Chinese statistics suggest that desertification caused by drought is the most frequent meteorological disaster in the study area (Inner Mongolia Statistics Bureau 2013). The drought mainly occurs between May and September, the most inportant period for grass growth.

\section{$\underline{\text { Soil nutrients }}$}

Soil nutrient contents (SOM, AN, AP and $\mathrm{AK}$ ) represented nutrient regulation services. AK and AN were highest in Hulun Buir and lowest in Ordos, and showed a significant decreasing trend $(\mathrm{P} \leq 0.05)$ along this transect (Table 5.6). SOM and AP also decreased along this transect, but the trend was not significant $(\mathrm{P} \geq 0.05)$. As was the case for soil retention services, the soil nutrient regulating service decreased in strength with increasing intensity of grassland use (Table 5.5). SOM, AN, AP and AK were highest with no use in all three regions, but showed little difference between the light and moderate use patterns in Xilin Gol. Ordos had fewer grassland use patterns, and the highest SOM, AN, AP and AK values were achieved under the no use or recovery patterns. This may be because Ordos is one of earliest demonstration sites for the grassland restoration project in IMAR, which started around 2000.

Grazing intensity is one of the factors that most strongly influences the regulating services as a result of the changes it causes in soil properties. Trampling by grazing animals increases soil bulk density and the mechanical resistance to penetration, and therefore decreases porosity, water infiltration, and aggregate stability (Evans et al. 2012). Zhou et al. (2010) reported that grazing and trampling by livestock caused deterioration of soil physical properties (e.g. soil bulk density) and increased soil vulnerability to erosion. The results for regulating services show that soil properties (water content, SOM and available nutrients) improve with decreasing intensity of grassland use. These results confirm that maintaining grazer densities at or below the 
grassland's carrying capacity will improve soil-related ecosystem services in the grassland of northern China, as has been suggested by Eastwood et al. (2013).

Table 5.6 Differences in soil properties and habitant qualities among the study area

\begin{tabular}{|c|c|c|c|c|c|c|}
\hline \multirow[t]{2}{*}{ Site } & \multicolumn{2}{|c|}{$\begin{array}{l}\text { Soil bulk density } \\
\qquad(\mathrm{g} / \mathrm{kg})\end{array}$} & \multicolumn{2}{|c|}{$\mathrm{SOM}(\mathrm{g} / \mathrm{kg})$} & \multicolumn{2}{|c|}{ Soil water content $(\%)$} \\
\hline & Average & S.E. & Average & S.E. & Average & S.E. \\
\hline $\begin{array}{l}\text { Hulun Buir } \\
\text { (meadow steppe) }\end{array}$ & 3.40 & 0.35 & 24.98 & 17.23 & 10.04 & 4.47 \\
\hline $\begin{array}{l}\text { Xilin Gol } \\
\text { (typical steppe) }\end{array}$ & 4.50 & 0.59 & 23.4 & 12.68 & 5.22 & 4.65 \\
\hline $\begin{array}{l}\text { Ordos } \\
\text { (semi-desert steppe) }\end{array}$ & 4.60 & 0.26 & 13 & 3.24 & 4.52 & 2.12 \\
\hline \multirow{2}{*}{ Site } & \multicolumn{2}{|c|}{$\mathrm{AN}(\mathrm{mg} / \mathrm{kg})$} & \multicolumn{2}{|c|}{$\mathrm{AP}(\mathrm{mg} / \mathrm{kg})$} & \multicolumn{2}{|c|}{$\mathrm{AK}(\mathrm{mg} / \mathrm{kg})$} \\
\hline & Average & S.E. & Average & S.E. & Average & S.E. \\
\hline Hulun Buir & 114.18 & 31.63 & 4.1 & 1.17 & 130.29 & 9.14 \\
\hline Xilin Gol & 64.94 & 33.94 & 3.11 & 0.54 & 93.50 & 20.11 \\
\hline Ordos & 24.10 & 15.31 & 3.24 & 0.46 & 44.4 & 30.88 \\
\hline \multirow[t]{2}{*}{ Site } & \multicolumn{2}{|c|}{$\begin{array}{c}\text { Margalef index } \\
\text { (species richness) }\end{array}$} & \multicolumn{2}{|c|}{$\begin{array}{l}\text { Shannon-Wiener index } \\
\text { (species diversity) }\end{array}$} & \multicolumn{2}{|c|}{$\begin{array}{c}\text { Pielou index } \\
\text { (species evenness) }\end{array}$} \\
\hline & Average & S.E. & Average & S.E. & Average & S.E. \\
\hline Hulun Buir & 3.83 & 1.87 & 1.87 & 0.82 & 0.61 & 0.21 \\
\hline Xilin Gol & 2.20 & 0.55 & 1.29 & 0.30 & 0.51 & 0.14 \\
\hline Ordos & 2.00 & 0.89 & 1.92 & 1.31 & 0.58 & 0.27 \\
\hline
\end{tabular}

$\mathrm{AK}$, available potassium; AN, available nitrogen; AP, available phosphorus, SOM, soil organic matter.

S.E: standard error

\subsubsection{Supporting services in different utilization patterns}

\section{Primary production (AGB)}

Primary production is a fundamental ecosystem service for the whole ecosystem, and is closely related to other ecosystem services such as provisioning services. Hulun Buir, Xilin Gol and Ordos produced different amounts of AGB due to differences in their geographic characteristics (such as temperature, precipitation and soil type, and shows gradient decreasing tend from Hulun Buir to Ordos); AGB was highest in Hulun Buir (meadow steppe) and lowest in Ordos (semi-desert steppe) (Table 5.6). In general, the proportion of edible biomass decreased with decreasing of precipitation and increasing intensity of grassland use (Rook et al. 2004; Yan et al. 2012). The highest values of AGB were found in the moderate use pattern in Hulun Buir and the light use pattern in Xilin Gol. The lowest AGB was found in the intensive use pattern. Our results therefore support previous research of Rook et al. (2004) and Yan et al. (2012) in which grazing does not inevitably degrade an ecosystem, and may actually increase its supporting ecosystem services if it occurs at an intensity below the carrying capacity. The proportion of edible biomass was low in the recovery pattern, at only 23\% in Xilin Gol and 44\% in Ordos (Table 5.5, Appendix 8). 


\section{Habitat}

Table 5.6 shows that habitat services were greater in the meadow steppe (Hulun Buir) than in the typical steppe (Xilin Gol) and semi-desert steppe (Ordos). One of the most important restrict factor is the geographic condition (e.g. Temperature and precipitation) beside of the utilization patterns of grasslands.

Under the different grassland utilization patterns, diversity in Hulun Buir was highest under light use, followed by moderate use, and then decreased sharply with increasingly intensive use (Table 5.5, Appendix 8). However, the species richness (Margalef index) and evenness (Pielou index) in Hulun Buir were both highest in the moderate use pattern, with values slightly higher than those in the light use pattern. Unlike in Hulun Buir, the species diversity and evenness of grassland in Xilin Gol decreased with utilization intensity increasing from light to moderate use. This means that the typical steppe (Xilin Gol) is more vulnerable than the meadow steppe to intensive use of the grassland. In Ordos, grazing was restricted more than in the other areas, so there was little difference in diversity among the different intensities of grassland use.

In summary, the supporting services in Hulun Buir decreased with increasing utilization intensity, which agrees with the results of Medina-Roldan et al. (2012), who found that grassland biomass production and biodiversity decreased in grazing areas because of overgrazing. In the present study, the proportion of edible biomass was relatively low at the recovery sites, although the diversity and evenness of the grassland were enhanced by conservation activities. Our results show that AGB and the three diversity indicators did not always follow a gradient of increasing intensity of grassland use in IMAR. For instance, the highest values of AGB and the Shannon index were observed in the moderate use pattern in Hulun Buir and the light use pattern in Xilin Gol. Xu et al. (2013) found that moderate grazing had positive effects on seedling recruitment and vegetation diversity, but that heavy gazing may alter community succession by affecting recruitment patterns.

\subsubsection{Ranking of ecosystem services under different grassland utilization patterns}

The results of ranking of ecosystem services under different grassland utilization patterns (Table 5.5) show large spatial variation among the three areas. In Hulun Buir, the moderate use pattern had the highest total score (i.e. the highest sum of the scores for provisioning, regulating and supporting services), followed by the no use pattern; these use patterns therefore provided the highest overall ecosystem services values. The lowest values were for intensive use. In Xilin Gol, the no use pattern had the highest total score, followed by the light use pattern, and these patterns therefore provided the highest overall service values; the recovery pattern produced the lowest rank score, and thus the lowest services. In contrast, the rank score in Ordos was highest for no use, followed by recovery, but the scores did not differ greatly among the three patterns.

Our data suggests that natural conservation (non-use) of grasslands should be encouraged because it helps to deliver the greatest quantity of ecosystem services. However, the evidence for this argument is weaker than might be expected, and is sometimes equivocal. For example, the agricultural provisioning services (food, fuel and fodder) tended to decrease with decreasing intensity of grassland use in IMAR. Eigenbrod et al. (2010) also found that protected areas in England have high levels of biodiversity and carbon storage, but low levels of recreation and agriculture services. 
At a European scale, Burkhard et al. (2012) looked at the association between the demand for ecosystem services and different CORINE land cover classes (http://ec.europa.eu/agriculture/publi/landscape/about.htm), and found that habitat classes that were important for conservation, such as peat bogs and natural grassland, ranked highly for their supply of regulating services, but ranked low in terms of their provisioning services. Our results also indicate that suitable use of grasslands can be achieved by considering differences in the resilience and capacities of the different grassland types, thereby offering more effective ways to protect the grassland ecosystems. For instance, the meadow steppe has high resilience and tolerance of human activities, so the moderate use pattern can be applied in this region. In contrast, fragile ecosystems such as the semi-desert steppe in Ordos should be protected against anything more than light use.

\subsection{Conclusions}

For sustainable management of ecosystems to provide services, analysing both the ecological and socioeconomic elements of the ecosystem is necessary, since complex interdependencies between humans and ecosystems strongly affect the provision of ecosystem services. The analysis of this chapter shows how quantitatively accounting for a greater number of ecosystem services than in many previous studies provided important insights into differences among ecosystems in their ability (such as precipitation, temperature and soil type) to tolerate human disturbance (different degree of grassland utilization patterns) and still provide ecosystem services.

The results of this chapter demonstrate the value of a more holistic approach to the management of grasslands such as those of IMAR. Specifically, they reveal that the optimal utilization intensity differs among the regions, with the Hulun Buir grasslands being able to tolerate a higher level of disturbance from human activities (moderate use of grassland) than the other grasslands (light use or no use) and the Ordos grasslands being able to tolerate the least disturbance (no use or recovery). Our results also show how grassland utilization for livestock grazing had significant ecological consequences (decrease of ecosystem services), but that there was an important interaction between the geographic condition, grassland type and utilization intensity. There were also trade-offs that must be carefully considered. For example, in the Hulun Buir grassland, the ability (e.g. highest precipitation of over $300 \mathrm{~mm}^{\text {year }}{ }^{-1}$ comparing with other areas of around $200 \mathrm{~mm} \mathrm{year}^{-1}$ ) to tolerate a higher grazing intensity before ecosystem services decreased allows the grassland to provide a greater quantity of provisioning services but at the cost of decreased regulating and supporting services. In future research, it will be necessary to find ways to identify the key factors that determine these trade-offs so that managers can focus on optimizing those factors. 


\section{CHAPTER 6}

Herders' willingness to accept versus the public sector's willingness to pay for grassland restoration

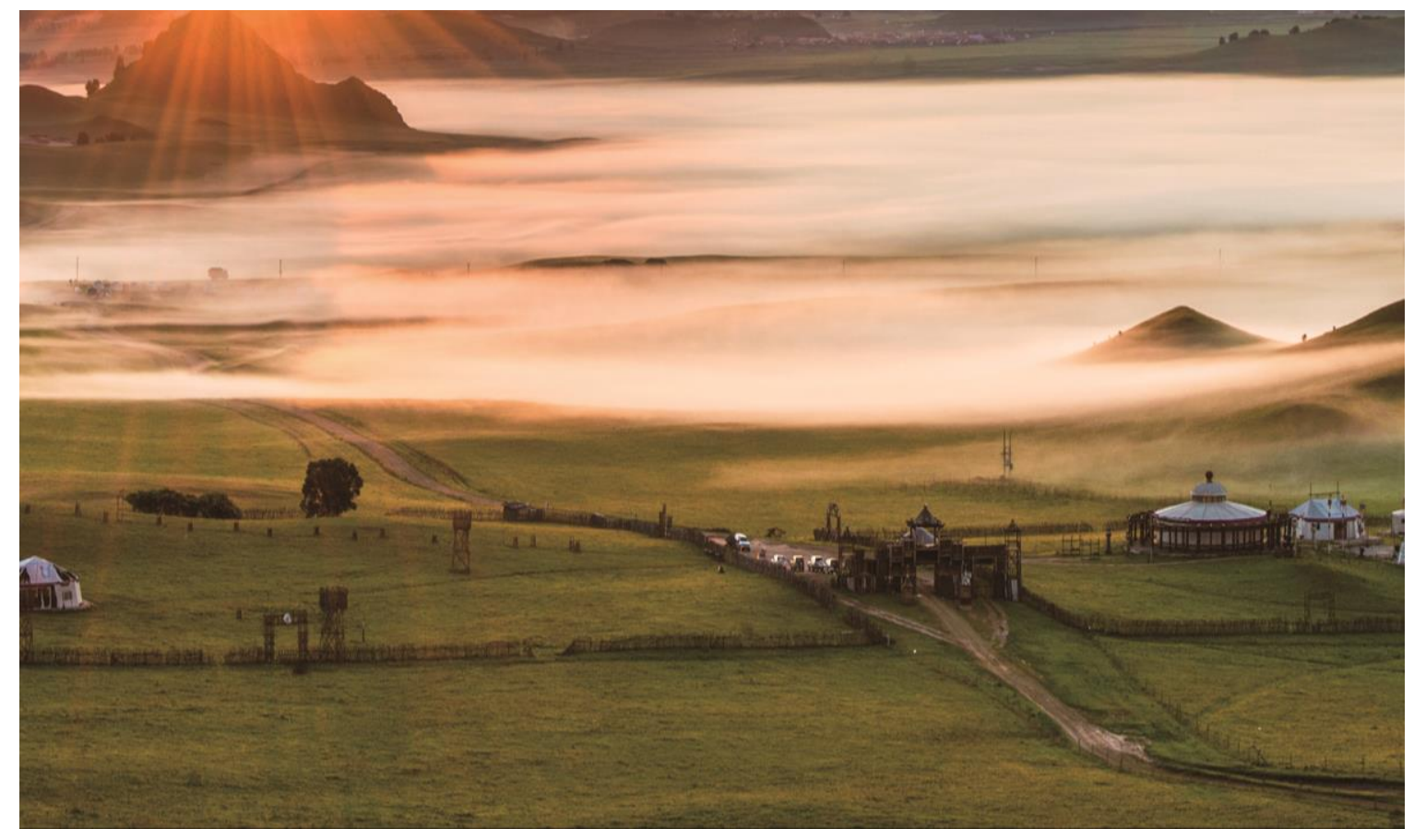

\section{Based on:}

Zhen L., Li F., Yan H., Liu G., Liu J., Zhang H., Du B., Wu R., Sun C., Wang C. 2014. Herders' willingness to accept versus the public sector's willingness to pay for grassland restoration. Environmental research letters 9(4): 045003 


\begin{abstract}
:
This chapter describes two payments for ecosystem services (PES) programs to restore grassland ecosystems in Inner Mongolia in Northern China. A key challenge is to sustain the livelihood of local residents, who earn most of their income from traditional animal husbandry. Total of 240 herders and 36 government representatives was surveyed in 2 years. Contingent valuation and logistic regression were used to analyse the resulting data. Since the PES implementation, income from cultivation and animal grazing decreased, whereas income from compensation and off-farm activities increased. The herders preferred an annual payment of 625 Chinese Yuan (CNY) $\mathrm{ha}^{-1}$ for participating in conservation activities, but the government prefers to provide $528 \mathrm{CNY} \mathrm{ha}^{-1}$, resulting in an annual gap of $97 \mathrm{CNY} \mathrm{ha}{ }^{-1}$. The current too low payments may lead some herders to expand their grazing into restricted grassland or increase their number of animals, particularly if either payment program ends. The herders were most concerned about their economic loss, whereas the government considered both grassland restoration and income protection to be important. To create an improved and sustainable PES scheme, this chapter recommend solutions that will let the herders sustain their livelihood while conserving the grasslands. The findings of this chapter will help to establish more effective PES schemes for the grasslands of Inner Mongolia and similar regions.
\end{abstract}

Keywords: Eco-Compensation, Willingness To Accept, Willingness To Pay, Contingent Valuation 


\subsection{Introduction}

Grasslands located in arid and semi-arid areas are often characterized by high ecological fragility and thus, high vulnerability to disturbance. There is growing agreement that many ecosystem services in such grasslands are undergoing rapid degradation due to overuse and misuse, and as a result of this trend, grassland degradation and desertification are increasing (MEA 2005). In China, about 54\% of the natural grasslands in the arid north are experiencing at least moderate levels of degradation due to the rapid socioeconomic development and population growth that began in the 1980s, and the area of degraded or decertified land has expanded at an annual rate of $2 \times 10^{6}$ ha (Zhao et al. 2006). Because of the resulting decrease in ecosystem services, this has also hindered regional economic development, jeopardized the livelihoods of residents of the region, and endangered regional ecosystems.

China's Inner Mongolia Autonomous Region (IMAR) is an important base for animal husbandry and an important ecological barrier that conserves water and soil, stabilizes the region's sandy soils against wind erosion, and preserves biodiversity (Yao et al. 2007). Between 1980 and 2000, IMAR's population increased by $26 \%$, from $18.76 \times$ $10^{6}$ to $23.72 \times 10^{6}$ (Table 6.1), while the number of livestock almost doubled, from 12.6 million to 24.2 million animals, mainly sheep. (Unless otherwise noted, all statistics presented in this chapter were provided by the Statistical Bureau of the IMAR) The available area of grassland per sheep unit decreased from 6.80 ha in 1950 to 1.27 ha in 2000, and the proportion of degraded grassland now ranges from 19 to $79 \%$. The worst of the degraded grassland areas can be found in the region's Xilin Gol League, where the population increased by 19\%, from 764000 in 1980 to 909000 in 2000 (Table 6.1); during the same period, the number of livestock increased by $177 \%$, but the grassland productivity decreased by $30 \%$, and the percentage of degraded grassland increased from $48.6 \%$ in 1984 to $64 \%$ in 2000 , of which about $27.5 \%$ is severely degraded grasslands (Li et al. 2008; Bao 2009). In addition, natural disasters such as heavy snowfall, drought, wind erosion, and insects damaged the already vulnerable grasslands.

Table 6.1 Demographic information for the study region

\begin{tabular}{lllllllll}
\hline & \multicolumn{7}{c}{ Population $\left(\times \mathbf{1 0}^{\mathbf{4}}\right)$} \\
\cline { 2 - 8 } & 1980 & 1985 & 1990 & 1995 & 2000 & 2005 & 2010 & 2012 \\
\hline Xilin Gol & 76.4 & 82.5 & 88.9 & 90.6 & 90.9 & 100.6 & 102.9 & 103.6 \\
Inner Mongolia & 1876.5 & 2015.9 & 2162.6 & 2284.4 & 2372 & 2403 & 2472.2 & 2481.7 \\
\hline
\end{tabular}

This worsening situation has significantly affected the livelihood of local peoples, who have started to look for alternative means to support their living. Damage to the production of economic value and hence material welfare in the form of ecosystem services is widely believed to results from a lack of institutions to guide the supply and demand for ecosystem services (Costanza et al. 1997; Balmford et al. 2002). In addition, institutional settings play a key role in shaping land cover and land use (Prishchepov et al. 2012), which can also influence the provision of ecosystem services. Payment for ecosystem services (PES) has been widely considered to be one useful measure to deal with this problem (CCICED 2007). 
To solve these problems and conserve the vast grasslands in its northern territory, the Chinese government has adopted several measures, including PES. This form of ecocompensation payment can be defined as 'a type of institutional arrangement to protect and sustainably use ecosystem services, and to adjust the distribution of costs and benefits between different actors and stakeholders, mainly through economic measures' (CCICED 2007). PES programs internalize the benefits associated with enhancing or maintaining ecosystem services to ensure that land managers and other providers of ecosystem services have incentives that agree with the interests of the users of these ecosystem services (Arrow et al. 2000; Pagiola et al. 2005; van Noordwijk and Leimona 2010). There has been an increasing number of publications that describe China's PES program, but most of them focus on the sloping land conversion program (SLCP) - the largest land retirement and reforestation program in the world (e.g. Bennett 2008; König et al. 2014a; Zhen et al. 2013) SLCP uses a public payment scheme that directly engages millions of rural households as core agents of the project's implementation. Although PES schemes assume that participation is voluntary, and that participants can negotiate a price that is acceptable to them, this is not how the program has been implemented in practice; participation is mandatory. Thus, as Bennett (2008) reported, some participants are likely to be undercompensated (i.e. paid less than they would request if they had freedom to negotiate the bid price). Any gap between the actual payments and what participants would bid if they were free to choose would reveal an important problem with the current approach, since voluntary participation requires what the participants consider to be a fair payment. Xu et al. (2010) revealed that the program could have significant implications for China's forests and remaining natural ecosystems, potentially representing a $10-20 \%$ increase in the current national forest area, a roughly $10 \%$ decrease in China's cultivated area, and a significantly positive impact on participant income due to the program's payments. However, it seems likely that the program's cost-effectiveness could be improved by targeting sites with the highest environmental benefits and allowing payments to reflect the heterogeneous opportunity costs faced by residents of the region, while also preventing farmers from reconverting their land to cultivation.

The PES approach has been applied increasingly in both developed and developing countries. Increasing attention has been paid to (1) the concepts, theory and framework of PES (e.g. Wunder 2005, 2008; CCICED 2007; Engel et al. 2008; Zhen and Zhang 2011); (2) assessments of the environmental impacts of PES programs (Thornley 1998; Xu et al. 2006b; Munkhtsetseg et al. 2007; Wu et al. 2012); (3) institutional and policy aspects that affect how to determine compensation schemes (Ren et al. 2006; Wang et al. 2006); and (4) the stakeholders' willingness to pay (WTP) for the PES scheme. In the latter case, examples include WTP for pollution reduction (e.g. Zhen et al. 2011a); for protection of the Tapanti National Park and forestry ecosystems in Costa Rica based on surveys of local residents, tourists and companies (Bernard et al. 2009); and for environmental management while developing the economy of China's Tianjin City (Zhai and Suzuki 2008). In addition, researchers have studied (5) the impact of the conservation programs on local peoples, such as the impacts of the presence of working land programs on land retirement in an important agricultural region of the United States (e.g. Kling et al. 2005), on biodiversity and conservation programs in Europe (e.g. Hawksworth and Bull 2008), on urbanization and agricultural land-use in the Netherlands (Vermaat et al. 2008), and on sedentarization and nomadic culture in China's Xinjiang Uyghur Autonomous Region (Fan et al. 2013) and IMAR (Bao 2009). However, little attention has been 
given to the people who are most likely to be affected by a policy's implementation in China in terms of their preferences, perceptions and willingness to accept (WTA) a PES scheme for protecting grasslands, as well as the public sector's WTP to compensate those affected by PES projects based on the actual changes in their livelihood caused by the project (e.g. Li and Li 2010; Wu et al. 2012).

In this chapter, the impacts of a top-down PES program designed by China's central government on the livelihood of herders in IMAR, and examined their preferences for key elements of the PES program design, including the payment type, amount and means. The WTA of the herders and WTP of the relevant government agencies for two local PES programs were also estimated. First, this chapter describes the PES programs that have been implemented in the region. Next, the impact of these programs on the income structure of the herders was assessed based on a survey of households in the regions affected by the program, and the factors that influence this structure and the WTP of local officials. Finally, this chapter discusses the main conclusions that arise from the results and propose recommendations for an improved PES design.

Once the Chinese government has designated land for protection under a PES program, participation in the program became notably mandatory. Thus, analysis in this chapter does not consider a hypothetical situation in which residents of the study region have the option of not participating. Instead, the goals of WTA and WTP analysis in this chapter were to compare WTA with the actual payments to learn whether these payments are satisfactory, and to compare WTA with WTP to learn whether the government recognizes dissatisfaction among program participants and is willing (budget permitting) to improve their situation. These factors will have important consequences for the long-term effectiveness of the programs.

\subsection{PES programs implemented in the Xilin Gol League grassland of the Inner Mongolia Autonomous Region}

For this chapter, IMAR's Xilin Gol League was selected for a case study (Figure 6.1). IMAR's population amounted to 24.871 million people in 2012. Agriculture, which is currently the main land-use in the Xilin Gol League, is characterized by small scale mixed subsistence farming systems with livestock production as an integral part (Zhang et al. 2007; Zhen et al. 2010a). Grassland is the main land cover type in this region, accounting for $86 \%$ of the total land area. In addition to agriculture, mining and related industries are gaining in economic importance. In terms of land ownership, China's land reform began in 1987 and the grasslands in Xilin Gol were allocated under contract to collectives (haote in the local language) that consisted of three to eight families, who shared the contracted grasslands for their grazing. In 1997, the grasslands were contracted to individual families based on the nearness of the land to their settlements, and each family received usage rights for the lands that were defined in a contract signed with the local government. To increase their income and make best use of the grasslands, each family then increased the number of animals they owned; during this period, the total number of sheep increased by $41.4 \%$ in Xilin Gol, from 1727 in 1989 to 2442 in 1999 (Bao 2009). To prevent the animals of other families from entering the contracted grasslands, each individual family built fences around their land, leading to segmentation of the grasslands and sedentarization of the herder families. As a result of the increased pressure on the grassland ecosystem, degradation of the grasslands has been increasing seriously since then (Bao 2009). 
Facing increasingly severe grassland degradation, both China's central government and local governments have begun taking a series of countermeasures since 2000 to control this negative trend. These include the Wind and Sand Source Control Around Beijing and Tianjin Project, which focuses on afforestation, grassland maintenance and water conservation as countermeasures; the Ecological Migration Project, in which nomadic herders are encouraged to leave ecologically vulnerable areas and settle in stationary settlements where the land has a higher carrying capacity; the SLCP; and the Returning Grazing Land to Grassland Program (RGLGP). This chapter focus on the two latter programs in the rest of this section. The common targets of these projects are to restore the ecological condition of the grasslands and to improve the quality of life of the herders. To successfully implement these environmental protection policies, sustaining the livelihood of the herders, who depend so strongly on grazing their livestock in these grasslands, is necessary (Chen and $\mathrm{Su} 2008$ ), especially under the SLCP and RGLGP, which are important components of PES in the grasslands.

SLCP: Since 2002, the government of the Xilin Gol League has implemented the SLCP in the agricultural and pastoral zone. The project involves converting cultivated land on slopes $>5$ to forests or grasslands, thereby protecting the vulnerable soil throughout the year. The project covers the whole agricultural region, including 75 890 households and 278806 persons. By 2008, the total area converted under this program amounted to 170000 ha. The central government budgeted $2 \times 10^{8}$ Chinese Yuan (CNY) annually for the project, representing an annual compensation of about $2100 \mathrm{CNY}$ ha $^{-1}$ or $717 \mathrm{CNY}$ per capita (Xilin Gol Ecological Monitoring Station 2008).

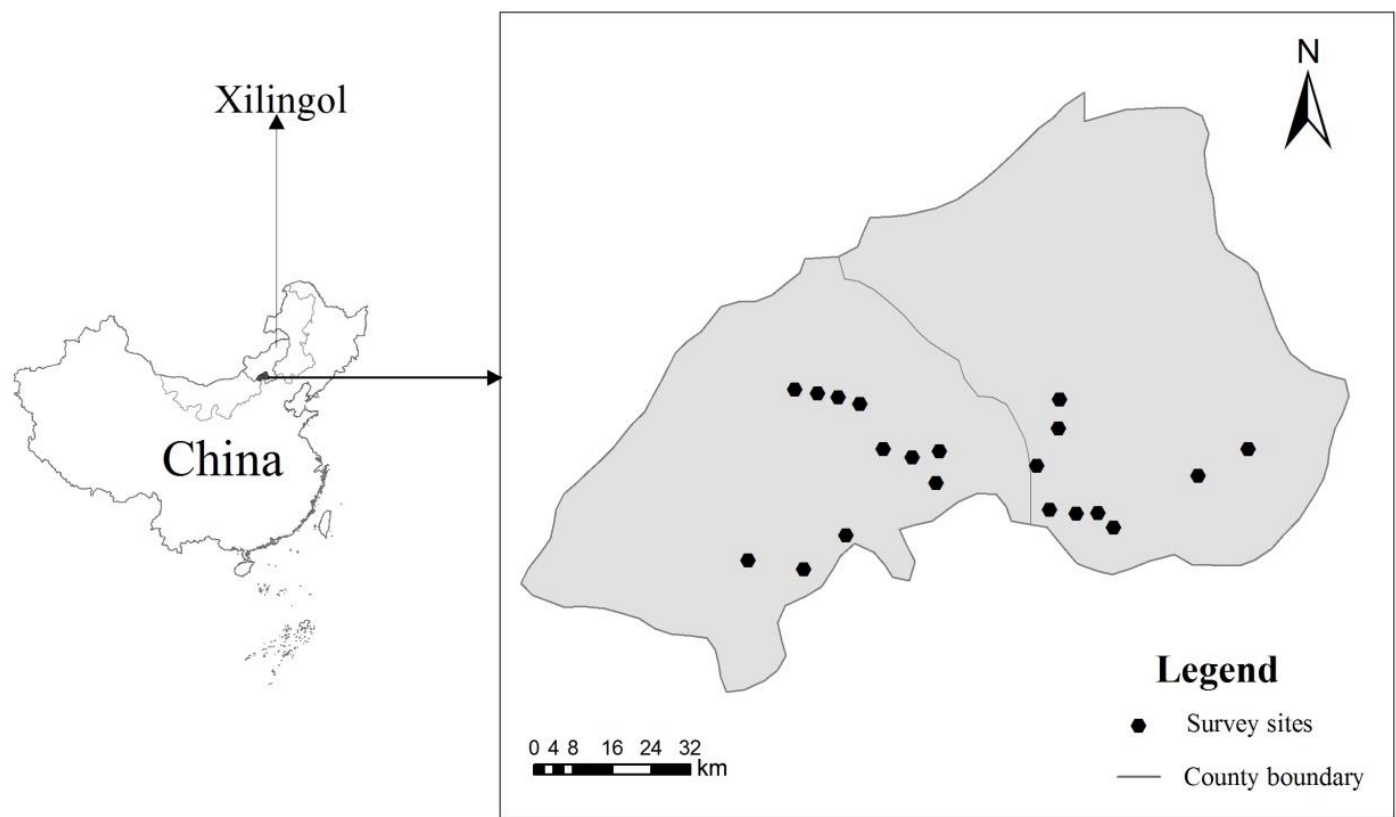

Figure 6.1 Location of $\mathrm{t}$ the survey sites in Xilin Gol of the Inner Mongolia Autonomous Region

Common vegetation such as Caragana korshinskii Kom. (a shrub species) and Salix alba var. tristis (a fast-growing willow) were planted on the converted land, with survival rates of about 85 and $81 \%$, respectively, after 8 years. The cover by forests and converted grassland increased from $45 \%$ in 2000 to $70 \%$ in 2008 . The total area 
converted to forests amounted to 160000 ha, of which $75 \%$ were ecological restoration forests.

RGLGP: China's central government launched this project to optimize the utilization of grassland resources. The project area covered $10.351 \times 10^{6}$ ha, which amounts to $54 \%$ of the total grassland in the Xilin Gol League. The project had a budget of 1.59 $\times 10^{8} \mathrm{CNY}$ from 2002 to 2007 , and covered 56 towns and 582 villages, with a total of 56228 households. The project includes three sub-measures: grazing prohibition, seasonal grazing and rotational grazing. Grazing prohibition requires the installation of livestock fencing and bans livestock from badly degraded areas for long periods to allow recovery of the vegetation. Resting of the grazing land means breeding the livestock indoors or in a fenced pasture for at least 40-60 days during the spring season to prevent grazing of the grass plumules, thereby allowing them to recover. Rotational grazing is a livestock production system in which livestock graze in one portion of a pasture that has been divided into several paddocks. Livestock are systematically moved from one paddock to another based on the growth of the forage. By integrated both central and local government payment, the current annual compensation awarded to herders is about 90-95 $\mathrm{CNY}$ ha $^{-1}$ under grazing prohibition, about 22.5 $\mathrm{CNY} \mathrm{ha}{ }^{-1}$ for seasonal grazing and rotational grazing, about $25 \mathrm{CNY} \mathrm{ha}^{-1}$ for having fewer animals per ha than the amount defined locally (i.e. 1.7 ha for one sheep unit) to avoid overgrazing, and $150 \mathrm{CNY} \mathrm{ha}{ }^{-1}$ for using improved grass species to improve local fodder production. Thus, the current maximum amount paid to the RGLGP herders is about $270 \mathrm{CNY} \mathrm{ha}{ }^{-1}$ (because the $22.5 \mathrm{CNY}$ ha-1 for seasonal grazing and rotational grazing cannot be received simultaneously with the 90-95 CNY $\mathrm{ha}^{-1}$ for grazing prohibition). This is far lower than the standard SLCP payment, in part because the area of grassland is much larger than the area of sloping land that is owned by the herders (Table 6.2).

Table 6.2 Proportion of total land resources accounted for by converted sloping land and the area in which grazing is prohibited

\begin{tabular}{|c|c|c|c|c|c|c|c|}
\hline \multirow{3}{*}{ Programs } & \multirow{3}{*}{$\begin{array}{l}\text { No. of } \\
\text { households }\end{array}$} & \multicolumn{6}{|c|}{ Area (ha/household) } \\
\hline & & \multicolumn{2}{|c|}{ Before project } & \multicolumn{2}{|c|}{ After project } & \multicolumn{2}{|c|}{ Land area affected } \\
\hline & & $\begin{array}{l}\text { Cultivated } \\
\text { land }\end{array}$ & Grassland & $\begin{array}{l}\text { Cultivated } \\
\text { land }\end{array}$ & Grassland & Converted & Grassland \\
\hline $\begin{array}{l}\text { Returning } \\
\text { Grazing Land } \\
\text { to Grassland } \\
\text { Program }\end{array}$ & 79 & 0.20 & 89.3 & 0.20 & 53.6 & 0 & 35.7 \\
\hline $\begin{array}{l}\text { Sloping land } \\
\text { conversion } \\
\text { program }\end{array}$ & 105 & 1.18 & 17.1 & 0.47 & 17.1 & 0.71 & 0 \\
\hline Both projects & 56 & 1.08 & 98.3 & 0.73 & 78.2 & 0.35 & 20.1 \\
\hline
\end{tabular}

\subsection{Data and methodology}

The information from both secondary and primary sources was obtained. Secondary information was derived from national and local statistical yearbooks and documents provided by various government agencies such as the Statistics Bureau, Bureau of Agriculture and Animal Husbandry, Bureau of Land Resources, Bureau of Forestry and Monitoring Station of Grassland Ecosystem. Primary information was collected through household surveys at the sites shown in figure 6.1. Selection criteria for these 
sites included the dominance of livestock and agriculture production in local economic development, location in a potential sandstorm source area that affects Beijing (China's capital), and location in a region where both the SLCP and the RGLGP have been implemented.

\subsubsection{Surveys}

\section{Household survey}

Based on these criteria, stratified random sampling (Weber and Tiwari 1992) was used to select the villages in this study. In this process, villages that differed in terms of characteristics such as income levels, number of animals raised (primarily sheep and cows), and the distances to the nearest main road and to the capital city of the county were specifically included. Total of 20 survey sites in 10 villages from 7 townships (Figure 6.1) were selected. Then, simple random sampling (Weber and Tiwari 1992) was used to select 240 households (ranging from 21 to 35 per village) to answer the questionnaire, which amounted to a total of 135 herding households and 105 farming households. These families represented $68-82 \%$ of the households in the selected villages. The surveys were conducted from October to November 2008, and from July to August 2012. The visited villages were loose collections of households, scattered through a large area of pasture. The head of each household or a family member who was familiar with the household were asked to answer the questions. To ensure correct understanding of the questions, two to three local people (from the Mongolian ethnic group) were hired to help us translate during the interviews. Completion of a questionnaire required 1.0 to $1.5 \mathrm{~h}$.

Prior to the formal surveys, an informal preliminary survey was conducted by using individual interviews and group discussions with herders and key informants to test the designed questions and increase the validity of the results. The interviews included questions in the following areas: (a) the socioeconomic characteristics of the households, which related to the household composition, levels of education, land and livestock owned, and income structure. (b) Their WTA compensation for grassland conservation, and the preferences for key elements of the PES programs such as how to determine the standard payment, the source of the payment funds and the means of payment. Closed-ended questions were primarily used, but added open-ended questions where there was an opportunity to expand on certain topics during the interview.

\section{Government survey}

In China, PES projects are initiated by the government. The representatives of local government agencies involved in grassland conservation were interviewed by using pre-prepared questionnaires to learn about their WTP for grassland protection. The questions were designed to determine how much they believed that households should be paid for protection of grassland resources through grazing prohibition and rotational grazing, with the goal of maintaining the household's livelihood. In addition, the surveys gathered information about the standard payment rate, source of the payment funds, means of payment and their perceptions of the current payment schemes.

All relevant local government agencies were selected for the survey: the Xilin Gol Development and Reform Commission, Xilin Gol County Council, Statistics Bureau, Bureau of Agriculture and Animal Husbandry, Bureau of Land Resources, Bureau of Forestry, Xilin Gol Grassland Monitoring Station, Ecological Management Office, 
Station of Forest Management, Bureau of Environmental Protection, Bureau of Water Resources, Inner Mongolian Grassland Monitoring Station and Inner Mongolian Normal University. Altogether, total of 36 officials from 13 government departments was interviewed. Each questionnaire took about $40 \mathrm{~min}$ to complete.

\section{$\underline{\text { Statistical analysis }}$}

The impact of PES on the income structure of the households affected by the projects, and their knowledge, perceptions and WTA were analysed, using version 16.0 of the SPSS software (SPSS Inc., Chicago, IL). Specifically, descriptive statistics (mean values, standard deviations and percentages for land-use and perceptions) were calculated and independent-sample t-tests was used to identify significant differences between groups. The multinomial logistic regression was also used to analyse the relationships between WTA and household characteristics. Similar analyses were performed for the WTP of government officials.

\subsubsection{Calculation of WTA and WTP}

Willingness to accept (WTA) represents the minimum amount that a person is willing to accept to abandon a good or to tolerate something negative, such as pollution. In this study, WTA represented the amount a respondent was willing to accept to limit grazing and in exchange for an improvement in environmental quality (e.g. conservation of grasslands, water and soil, and reduced grassland degradation) through the PES programs. Willingness to pay (WTP) represents the maximum amount that an individual is willing to sacrifice to procure a good or avoid something undesirable. A government official's WTP represents the amount they believe would represent a fair payment, which may differ from the amount they are actually able to pay based on the budget they have available. Combining WTA with WTP is particularly useful when the goal of a study is to determine whether those who pay and those who accept the payments have reached a satisfactory compromise that meets both of their needs.

The contingent valuation method (CVM) was used to quantify each household's WTA and each government official's WTP for grassland conservation. CVM is a kind of stated reference approach that employs a hypothetical market system to extract WTA or WTP values for environmental goods (Hadker et al. 1997; Carson 2000). CVM has become one of the most widely used valuation techniques due to its flexibility and its ability to estimate total values (e.g. Hanemann 1984, 1989, 1994; Spash and Hanley 1995; Bjornstad and Kahn 1996; Liu and Zhen 2007; Spash et al. 2009). Existing methods for estimating WTA or WTP include continuous CVM (represented by openended questions) and discrete CVM (represented by dichotomous-choice questions). In continuous CVM, the interviewees are free to answer the open-ended questions by defining the maximum amount they are willing to pay. This also facilitates analysis of the data. The disadvantage is that giving the appropriate answer to the interviewees is sometimes difficult when they don't have enough background information about the research subject or when they are actually not sure of the maximum amount they are able to offer or the minimum amount they are willing to accept when they have to do so Loomis and Walsh 1997. In contrast, discrete CV lets the interviewees express their WTP or WTA by choosing either 'yes' or 'no'; thus, they don't need to indicate the specific amount, and this can avoid the problem of inconsistency between the stated and actual values (Hoehn and Randall 1987). 
The most persistently troubling empirical result in the CVM literature is hypothetical bias, the tendency for the hypothetical WTP to overestimate the real WTP (Cummings et al. 1995, 1997; Blumenschein et al. 1997). Critics of CVM often claim that responses about WTP or WTA will be different for hypothetical versus real choices, and that, for instance, respondents will actually pay less (Whitehead and Cherry 2007). A meta-analysis by Murphy et al. (2005) found a median difference of $35 \%$ between the hypothetical and actual WTA or WTP, and this difference may relate to how respondents define the value of the good or service (Murphy et al. 2010). Many studies have addressed ways of overcoming the biases created by this phenomenon. For example, the dissonance-minimization techniques proposed by Blamey et al. (1999) and Loomis et al. (1999) allow the respondent to choose an option such as 'I support the [program]... but it is not worth [value] to me'. This is likely to be effective if the bias is predominantly caused by management of the impressions of the respondents. On the other hand, the popular cheap-talk and budget-reminder technique (Whitehead and Cherry 2007) may encourage the respondent to think twice, which may be more effective in alleviating the bias than dissonance-minimization approaches, which proved to be more effective than dissonance-minimization approaches in alleviating the bias for a reforestation program (Krawczyk 2012).

Whitehead and Cherry (2007) found that both ex-ante and ex-post approaches can successfully mitigate and even eliminate hypothetical bias because they addressed the bias in the survey using one or more follow-up questions. In a recent study, Kim et al. (2012) examined how accounting for the hypothetical bias affects the WTP for preservation of an endangered species from two different samples of respondents who were separated by distance (and costs) from the species' location. Mjelde et al. (2012) noted that four factors may be related to the bias: income, environmental awareness, age and familiarity with a good. Increasing any of these factors will reduce the potential bias.

To gain the data required for WTA and WTP, a single-bounded dichotomous CVM method was used. To mitigate the hypothetical bias, preliminary surveys and followup questions were used to determine the potential WTA and WTP for grassland conservation for the herders and the government officials respectively. The ranges for WTA and WTP were obtained from the preliminary surveys, and the questionnaire to mitigate this bias was revised during the formal survey. The formal survey started with a description of the purpose of the survey to participants, continued with gathering of basic demographic data, and concluded with questions intended to reveal the participant's WTA for not overgrazing or not grazing in specific plots, based on the expected annual bid values $\left(75,150,300,450,750,1050,1350\right.$ and $1500 \mathrm{CNY} \mathrm{ha}^{-}$ ${ }^{1}$; 1 US $\$=6.3417 \mathrm{CNY}$ in April 2013). The expected bids were determined based on a preliminary survey of the income losses that resulted from land conservation and based on pre-interviews with local people and government officials. In each questionnaire, the respondent was asked a follow-up question such as the following: 'If grazing activities are restricted to conserve grasslands and your financial losses should be compensated, would you be willing to accept/pay [amount] for the economic loss/conservation to meet this end? (yes/no)'. Respondents who answered 'yes' to the question were then asked to indicate their willingness by choosing either yes or no in response to the corresponding bid value. Because the bid values were based on the direct income loss from grazing restrictions and estimates by government officials, the hypothetical responses would be close to the real choices. However, this hypothesis should be tested in future research. 
For analysis of WTA in this chapter, a logit model (Hanemann 1984) was applied to reveal the relationship between the respondent's willingness to accept a bid ('yes' or 'no') and the corresponding bid value (based on data from the preliminary surveys). The standard form of the model is as follows:

$$
\text { Prob }=1-\left\{1+\exp \left[B_{0}-B_{1} x\right]\right\}^{-1}
$$

Where Prob represents the probability of accepting a bid, $\mathrm{B}_{0}$ and $\mathrm{B}_{1}$ are regression coefficients, and $\mathrm{x}$ is the bid value. The relationship between the bid values and the consensus rate (i.e. the proportion of the households who were willing to accept the corresponding bid value) is shown by the following function:

$$
\mathrm{p}=1 /\left(1+b_{0} \cdot b_{1}^{x}\right)
$$

Where $\mathrm{P}$ is the consensus rate, which represents the percentage of the households who are willing to accept the corresponding bid value, $\mathrm{x}$ is the bid value, and $\mathrm{b}_{0}$ and $b_{1}$ are regression coefficients, where $b_{0}=e^{-B 0}$ and $b_{1}=e^{B 1}$.

The probability density of WTA is expressed as follows:

$$
\rho=P^{\prime}(x)
$$

Where $\rho$ is the probability density of WTA, and $P^{\prime}(x)$ represents the probability of a WTA value less than $\mathrm{x}$.

To gain the necessary data for WTP, the same method was used for WTA, with the same bid values, which were also determined based on preliminary survey data from pre-interviews with local officials. The interviewees indicated no in response to the corresponding bid value, which can help to avoid the problem of inconsistency between the stated WTP and the actual amount they are able to pay (Hoehn and Randall 1987). The equations (6.1)-(6.3) were also used to calculate WTP, but with WTA replaced by WTP and with the household replaced by the government department in each equation.

The possible factors that influenced the herders' willingness to accept PES schemes (equation (6.4)) were analysed by using multinomial logistic regression, with significance at $\mathrm{P}<0.05$, and the Wald test was used to determine whether the partial regression coefficients of the independent variables equalled zero. The resulting equation was:

$$
\begin{aligned}
\mathrm{y}= & -0.475+0.126 x_{1}+0.226 x_{2}+0.231 x_{3}-0.025 x_{4}-0.069 x_{5}-0.406 x_{6}+ \\
& 0.107 x_{7}+0.151 x_{8}+0.876 x_{9}-0.049 x_{10}
\end{aligned}
$$

Where $\mathrm{y}$ is the WTA for the PES scheme, and $x_{a}-x_{10}$ are the independent variables listed in Table 6.3.

\subsection{Results and discussion}

\subsubsection{Characteristics of the respondents}

The proportion of male respondents $(67 \%)$ was higher than that of female respondents (33\%), as men are the dominant partner in most of the local families. About $41 \%$ of the respondents belonged to the Mongolian ethnic group, and the remaining 59\% belonged to the Han ethnic group. Most of the respondents $(62.1 \%)$ were middle-aged (35-45), and only $6.3 \%$ were older than 65 years. The family size averaged about three persons, generally representing two parents and a child. More than half of the respondents $(61.3 \%)$ were illiterate or had only attended primary school due to 
difficulty of access to the nearest school and low family income, and only $8 \%$ of respondents had a high school education. The average household owned 0.20, 0.47, and 0.73 ha of cultivated land for the households that participated in the RGLGP, the SLCP, and both programs, respectively, versus 53.6, 17.1 and 78.2ha of grassland, respectively.

Among the interviewed 240 respondents, 79 were involved in the RGLGP, 105 were involved in the SLCP, and 56 were involved in both programs simultaneously (Table 6.2). For each group, the change in land resources was analysed as a result of the RGLGP and the SLCP. In the RGLGP group, RGLGP affected 39.9\% of the original grassland area (an average of 35. ha per household), as the available grassland decreased from 89.3 to $53.6 \mathrm{ha}$. In the SLCP group, about $60 \%$ of the cultivated land was returned to natural grassland or artificial forest, with an average area affected of about 0.71 ha per household; that is, the area changed from 1.18ha per household before the project to 0.47 ha after the project; this made farming difficult, as the land's productivity is very low due to poor soil conditions. The grassland resource of about 17ha per household that remained after implementation of the PES programs is able to support 10 sheep or 1 cow according to the local standard of 1.7 ha of grassland per sheep unit. In the group that participated in both programs, the available grassland decreased from 98.3 to 78.2 ha, and the area in which grazing was prohibited totalled 20.1 ha $(20.4 \%$ of the original grassland area); thus, about 0.35 ha of cultivated land per household was converted into natural grassland, and the area of cultivated land per household decreased by $32.4 \%$, from 1.08 to 0.73 ha.

In terms of income, the implementation of the SLCP and of the RGLGP has changed how the respondents earn their living, which is reflected in the local income structure. Comparing the income structure before and after implementation of the two projects (Table 6.4), the results of this chapter found that the SLCP group depended on traditional crop cultivation, with a relatively low productivity due to the dry weather and impoverished soils. The income from cultivation before implementation of the SLCP was 1025 CNY annually, accounting for $31.4 \%$ of the total income. 
Table 6.3 Responses to questions designed to reveal the awareness and attitudes of the interviewees. Variables x1 to x10 represent the parameters in equation (6.4).

\begin{tabular}{|c|c|c|c|c|c|c|c|c|c|c|}
\hline Parameters & Responses & Mean & SD & $\boldsymbol{B}$ & S.E. & Wald & df & $\mathbf{P}$ & $\operatorname{Exp}(B)$ & $\beta^{a}$ \\
\hline Education & $\begin{array}{l}\text { (1) illiterate, (2) primary, (3) secondary, (4) } \\
\text { high school, (5) college and above }\end{array}$ & 1.92 & 0.91 & 0.126 & 0.443 & 0.081 & 1 & 0.077 & 1.134 & 0.031 \\
\hline Employment & $\begin{array}{l}\text { (1) grazing, (2) farming, (3) off-farm, (4) } \\
\text { house, (5) student }\end{array}$ & 1.78 & 0.64 & 0.226 & 0.683 & 0.109 & 1 & 0.047 & 1.253 & 0.085 \\
\hline Land area & Land area (66.7 ha) & 0.14 & 0.12 & -0.231 & 2.244 & 2.074 & 1 & 0.000 & 5.306 & -0.285 \\
\hline Land renting & $\begin{array}{l}\text { (1) none, (2) rent to someone else, (3) rent from } \\
\text { someone else }\end{array}$ & 1.68 & 0.93 & -0.025 & 0.244 & 0.01 & 1 & 0.091 & 0.976 & -0.003 \\
\hline Income & Total annual family income $\left(10^{4} \mathrm{CNY}\right)$ & 1.68 & 1.64 & 0.069 & 0.138 & 0.249 & 1 & 0.160 & 1.071 & 0.005 \\
\hline Subsidy & Total annual government subsidy $\left(10^{4} \mathrm{CNY}\right)$ & 0.27 & 0.32 & -0.406 & 0.749 & 3.524 & 1 & 0.005 & 0.245 & -0.167 \\
\hline $\begin{array}{l}\text { Awareness of } \\
\text { payments for } \\
\text { ecological services }\end{array}$ & (1) Yes, (2) No & 1.58 & 0.49 & 0.107 & 0.476 & 0.051 & 1 & 0.082 & 1.113 & 0.028 \\
\hline Conservation policy & (1) Satisfied, (2) Not satisfied, (3) No opinion & 1.19 & 0.39 & 0.151 & 0.506 & 5.174 & 1 & 0.052 & 3.163 & 0.042 \\
\hline $\begin{array}{l}\text { Willingness to } \\
\text { participate in } \\
\text { conservation }\end{array}$ & (1) Willing, (2) Not willing & 1.32 & 0.46 & 0.876 & 0.475 & 3.404 & 1 & 0.006 & 2.401 & 0.229 \\
\hline Accessibility & $\begin{array}{l}\text { Distance from } \\
\text { homestead to county seat }(\mathrm{m})\end{array}$ & 1620 & 2940 & -0.049 & 0.035 & 2.044 & 1 & 0.26 & 0.952 & -0.001 \\
\hline
\end{tabular}

${ }^{\mathrm{a}} \beta$ is the standardized coefficient (SC) of the independent variable: $\beta_{I}=\frac{b_{I} \times s d_{i}}{\pi / \sqrt{3}} \approx \frac{b_{i} \times s d_{i}}{1.8138}$ where $\beta_{i}$ is the SC for independent variable $i$; $b_{i}$ is the nonstandardized coefficient for independent variable $i$; and $s d_{i}$ is the standard deviation of independent variable $i$. 
Table 6.4 Comparison of the income structure of respondents before and after the payment for ecosystem services programs

\begin{tabular}{|c|c|c|c|c|c|c|c|c|c|c|}
\hline \multirow{2}{*}{ Program $^{a}$} & \multirow{2}{*}{ Period } & \multirow{2}{*}{$\begin{array}{l}\text { Living } \\
\text { cost }\end{array}$} & \multicolumn{5}{|c|}{ Income per household (CNY year $\left.{ }^{-1}\right)$} & \multirow[b]{2}{*}{ Off-farm jobs } & \multirow[b]{2}{*}{ Remittance } & \multirow[b]{2}{*}{ Total } \\
\hline & & & Cultivation & Sheep & Cattle & Compensation & Allowance & & & \\
\hline \multirow{4}{*}{$\begin{array}{l}\text { Sloping land } \\
\text { conversion } \\
\text { project }\end{array}$} & Before & 20042 & 1024.5 & 1413.6 & 428.0 & 0.0 & 0.0 & 393.5 & 0.0 & 3259.6 \\
\hline & Before & 2904.2 & $(31.4)$ & $(43.4)$ & $(13.1)$ & $(0.0)$ & $(0.0)$ & $(12.1)$ & $(0.0)$ & $(100.0)$ \\
\hline & & & 631.2 & 2998.0 & 328.0 & 1845.7 & 0.0 & 2378.9 & 1820.5 & 10002.3 \\
\hline & Atter & 5350.5 & $(6.3)$ & $(30.0)$ & $(3.3)$ & $(18.5)$ & $(0.0)$ & $(23.8)$ & $(18.2)$ & $(100.0)$ \\
\hline \multirow{4}{*}{$\begin{array}{l}\text { Grazing } \\
\text { prohibition } \\
\text { project }\end{array}$} & Before & 49123 & 0.0 & 9983.6 & 4038.6 & 0.0 & 0.0 & 189.5 & 0.0 & $\begin{array}{ll}14 & 211.7\end{array}$ \\
\hline & & 4912.3 & $(0.0)$ & $(70.2)$ & $(28.4)$ & $(0.0)$ & $(0.0)$ & $(1.4)$ & $(0.0)$ & $(100.0)$ \\
\hline & & & 0.0 & 12543.4 & 3825.9 & 2648.0 & 308.5 & 3428.6 & $623.1^{\mathrm{b}}$ & $23 \quad 377.5$ \\
\hline & Atter & 7882.5 & $(0.0)$ & $(53.7)$ & $(16.4)$ & (11.3) & $(1.3)$ & $(14.7)$ & $(2.7)$ & $(100.0)$ \\
\hline \multirow{4}{*}{ Both projects } & Before & 38001 & 8956.7 & 2135.5 & 0.0 & 0.0 & 0.0 & 0.0 & 0.0 & $\begin{array}{ll}11 & 092.2\end{array}$ \\
\hline & & 3800.1 & $(80.7)$ & (19.3) & $(0.0)$ & $(0.0)$ & $(0.0)$ & $(0.0)$ & $(0.0)$ & $(100.0)$ \\
\hline & After & 64048 & 9948.0 & 1923.4 & 0.0 & 2424.0 & 353.3 & 0.0 & 0.0 & $\begin{array}{ll}14 & 648.7\end{array}$ \\
\hline & Alter & 0404.8 & $(67.9)$ & $(13.1)$ & $(0.0)$ & $(16.5)$ & $(2.4)$ & $(0.0)$ & $(0.0)$ & $(100.0)$ \\
\hline
\end{tabular}

\footnotetext{
${ }^{a}$ Average data from household surveys in 2008 and 2012. Because the 2008 and 2012 data did not differ significantly, we used their average for our analysis.

${ }^{\mathrm{b}}$ Including 80.6 CNY (0.3\%) from rental of mowing machines to produce fodder. 'Remittance' represents money received from migrant workers (family members working and living in the cities). 'Allowance' represents government funds provided to purchase mowing equipment, buy fodder and veterinary medicine, and construct storage facilities for hay or fodder.
} 
The most important income source was small scale animal husbandry, including 3040 sheep per household and 1-2 cows; these animals accounted for $56.5 \%$ of the farm income (1842 CNY annually). After the SLCP, the available cultivated land decreased, and the income from cultivation decreased by nearly half, to $631 \mathrm{CNY}$ in 2012, which accounted for only $6.3 \%$ of annual income; income from animal husbandry nearly doubled, but decreased to $33.3 \%$ of the total annual income. Compensation provided by the government accounted for $18.5 \%$ of the total income, and was intended to compensate farmers for their losses caused by limitations on farming and grazing. Many farmers found off-farm jobs in construction, processing of agricultural products, and services in nearby cities or towns, and income from these off-farm jobs accounted for $23.8 \%$ of the total; money received from migrant workers (family members working and living in the cities) who sent money back to their parents or relatives at the end of the year or to celebrate a festival ('remittance') also reached $18.2 \%$ of the total income.

Total annual income of herders who participated in the RGLGP (Table 6.4) increased by $65 \%$, from $14212 \mathrm{CNY}$ to $23378 \mathrm{CNY}$, as they have been receiving $2648 \mathrm{CNY}$ annually from the government, which is equivalent to $11.3 \%$ of their total income, in the form of compensation payments and an allowance of $309 \mathrm{CNY}$ to purchase production equipment (e.g. mowing equipment), buy fodder and veterinary medicine, build storage rooms for hay or fodder, and so on. This can be seen by the decreased share of total income accounted for by animal husbandry, which decreased from $98.6 \%$ of the total to $70.1 \%$, representing a decrease of $28.5 \%$ points. Labourers released from grazing work (an average of about 0.75 persons per household) could find off-farm jobs, so the share of off-farm income contributed by these jobs increased to about 10 times its original proportion (from $1.4 \%$ to $14.7 \%$ of total income).

Those who participated in both programs were mostly involved in cultivation activities, although their total income has increased by $32 \%$ since the implementation of the two programs; however, the proportion of total income contributed by farming and grazing of sheep decreased from $80.7 \%$ to $67.9 \%$ and from $19.3 \%$ to $13.1 \%$, respectively, and compensation payments $(16.5 \%$ of total income) and a production allowance ( $2.4 \%$ of total income) have become important and stable income sources for the farmers.

This analysis shows that the household income rose compared with their income before the programs. Especially for RGLGP households, the income (23 $377 \mathrm{CNY}$ ) was higher than that of the average household (farmers and herders) in Xilin Gol (18 459 CNY; XLGLDRC 2011) because the compensation payment was higher and the grassland area was larger than was the case for households that participated in the SLCP or in both programs. In contrast, the annual incomes of households that participated in the SLCP (10 $002 \mathrm{CNY})$ and in both programs (14 $648 \mathrm{CNY}$ ) were both lower than the region's average. Although this is an imperfect comparison (i.e. the mean Xilin Gol income statistics available from the government include families that participated in the two PES programs), it was not possible to obtain separate income statistics for households that did not participate in either program.

Since the implementation of the programs, the grassland conditions have improved and net primary production increased by $20 \%$ (Yang 2007), which had positive effects for the households in terms of better grazing and farming conditions; in addition, the price of agricultural and livestock products has increased in recent years, therefore the income per household from farming and grazing has increased by about 1091, 2347 
and 799 CNY, respectively, for households that participated in the SLCP, the RGLGP, and both programs. These amounts were less than the payments provided by the programs, which amounted to 1846, 2648 and 2424 CNY, respectively (Table 6.4). Due to the restrictions on grazing and farming, some workers have been released from agricultural work and have moved to the cities to earn off-farm wages, especially for the SLCP and RGLGP households. The income increases from these off-farm jobs were 1985 and $3239 \mathrm{CNY}$, respectively, which were higher than the respective income increases from farming and grazing.

Unfortunately, the cost of living (the cost for food, medicine, clothing and other domestic expenses, but excluding farming and animal costs) has also increased since implementation of the programs. Table 6.4 shows that the average annual cost of living for families that participated in the SLCP, the RGLGP and both projects increased by 2446, 2970 and $2608 \mathrm{CNY}$ per household, whereas their incomes increased by 6742,9165 and $3556 \mathrm{CNY}$ per household, respectively. Therefore, the net income has increased for all three household types.

\subsubsection{Herder WTA}

To calculate the expected household WTA for protecting the grasslands, multinomial logistic regression analysis was used, and the regression was both strong and significant $(\mathrm{F}=81.207, \mathrm{P}=0.002, \mathrm{R} 2=0.931)$. Based on the bid-response data (Table 6.5 and figure 6.2), the results show the relationship between the bid amount and the proportion of households who were willing to accept that amount $(\mathrm{P})$, and the probability density as a function of the bid amount.

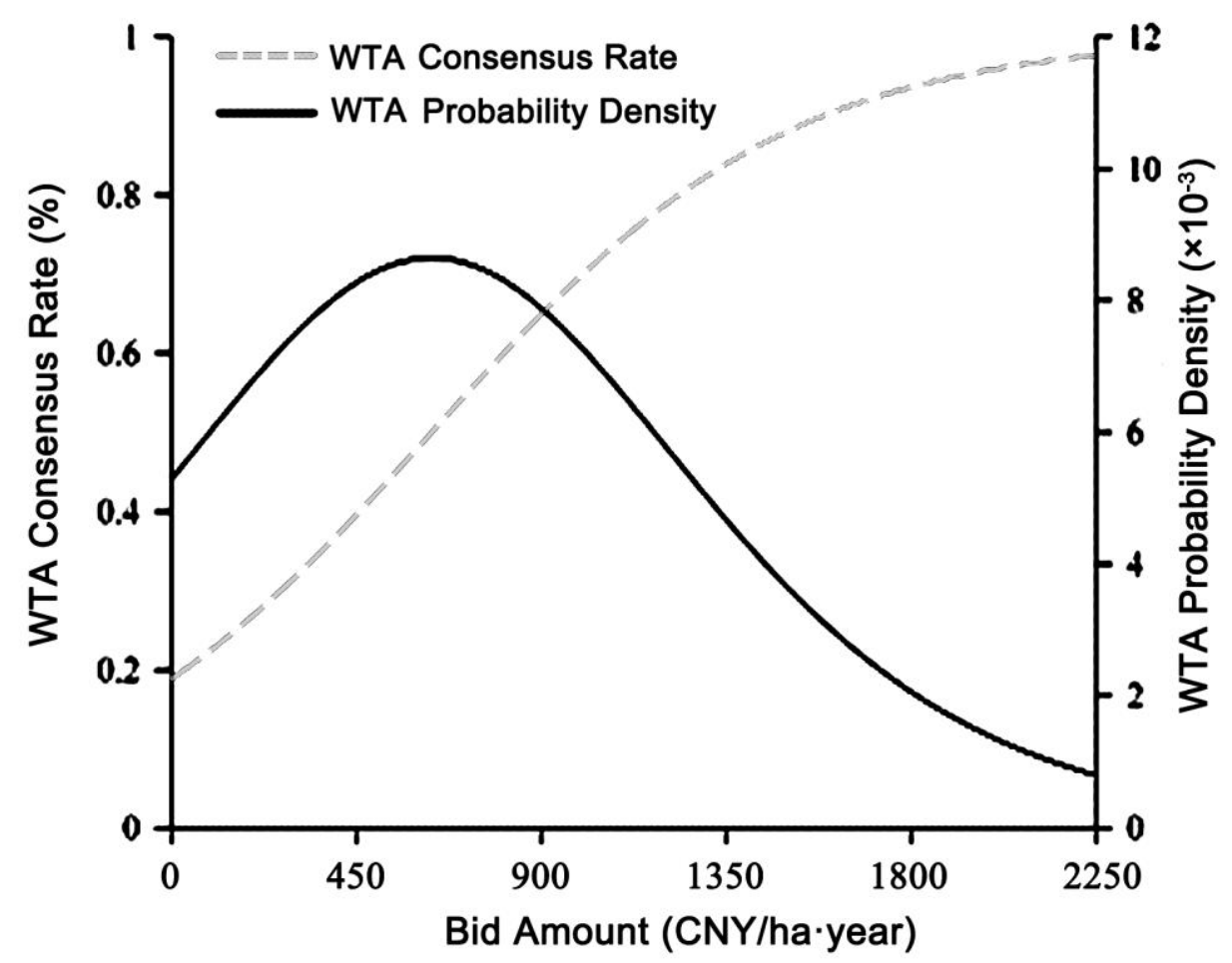

Figure 6.2 Functional relationships between the bid amount and the associated WTA consensus rate and probability density

Figure 6.2 shows that the consensus rate increased steadily with increasing bid amount. Most of the farmers were willing to receive an amount between 450 and 645 CNY ha ${ }^{-1}$ annually (with a maximum probability density of nearly $9 \cdot 10^{-3}$ for this 
range of values), and the average annual WTA per household was $625 \mathrm{CNY} \mathrm{ha}^{-1}$ (versus a current maximum payment of about $270 \mathrm{CNY} \mathrm{ha}^{-1}$ ). In the Xilin Gol League, the total area of grassland affected by RGLGP was $9.84 \cdot 10^{5}$ ha in 2012 , thus the total WTA for the study area ranged between $443 \times 10^{6}$ and $635 \cdot 10^{6} \mathrm{CNY}$ year ${ }^{-1}$. This result can be used as a reference value to design a PES scheme and determine the total funding required to promote conservation measures in IMAR's grasslands.

Most of the herders (about 86\%) determined their WTA based on the economic loss that resulted RGLGP and the average cost required to maintain their basic standard of living (e.g. the costs for food and fuel). About $78 \%$ of the herders would like to use the compensation provided for grassland protection to build fences to keep their animals in a field and to purchase fodder; about $25 \%$ would like to hire local herders to graze their animals in grasslands where grazing is still permitted and prevent animals from damaging the degrading grasslands, about $14 \%$ would purchase equipment needed to produce fodder (e.g. water tanks, fodder silos, grass mowers), and about $13 \%$ would like to invest in supporting tourism activities. The following additional information was found, that provides insights into how to modify the PES schemes:

- Employment activities: About $83 \%$ of farmers had a high willingness to implement PES because they were aware of the benefits of the resulting environmental improvement, and the production and benefits from their small area of farmland were too little to sustain their livelihood. About $76.1 \%$ of the herders who performed off-farm work as migrant workers also had strong willingness to participate in PES, because by so doing, they could earn more income from their grasslands that they no longer used for grazing due to a shortage of workers. This result is similar to what has been found previously in a forestry PES program, where the decreased reliance on forest resources and the high proportion of off-farm income (about 32\%) led to high WTA (4950 CNY ha 1 annually) for forest protection ( $\mathrm{Li}$ and $\mathrm{Li} 2010$ ).

- Area of grassland: The total grassland area owned by a family significantly affected WTA. Among those who owned more than 200 ha of grassland, only $36 \%$ were willing to accept the payment scheme. However, those who owned less grassland were more interested in the payment scheme; for instance, $68 \%$ of those who owned less than 67 ha of grassland agreed to accept the payment scheme. This result suggests that the willingness to participate in the payment scheme was strongly determined by the herders' reliance on the grassland for grazing; those who owned the most grassland normally depended more on their livestock for their income and livelihood, and did not wish to reduce their number of animals. However, owners of a small area of land could normally choose either grazing or off-farm activities to supplement their income, and were therefore more willing to accept some payment to limit their grazing and to support other activities.

- Willingness of the herders to participate in conservation: Among those herders $(89.7 \%)$ who were willing to participate in grassland conservation, $65.6 \%$ wanted to continue the PES scheme because they have realized the significance of grassland degradation and reduced production for grazing; for example, grassland productivity decreased from $2.26 \mathrm{~kg} \mathrm{ha}^{-1}$ in 2000 to $1.39 \mathrm{~kg} \mathrm{ha}^{-1}$ in 2007 in unprotected grassland in the study area (Yang 2007). The herders were willing to continue their participation because they could obtain subsidies from the government's PES program, and they could use this money to support their 
grassland protection activities, while also supporting their family despite the income loss caused by limited grazing.

Table 6.5 The relationship between the bid amount and the proportion of the households that were willing to accept (WTA) that amount for the conservation of grassland in Inner Mongolia.

\begin{tabular}{lllllllll}
\hline Annual bid amount $\left(\mathrm{CNY} \mathrm{ha}^{-1}\right)$ & 75 & 150 & 300 & 450 & 750 & 1050 & 1350 & 1500 \\
\hline $\begin{array}{l}\text { Proportion of households } \\
\text { willing to accept }(\%)\end{array}$ & 10.0 & 24.0 & 46.0 & 52.0 & 63.0 & 69.0 & 78.0 & 89.0 \\
\hline
\end{tabular}

Table 6.6 The relationship between the bid amount and the proportion of the government officials willing to pay (WTP) that amount for the conservation of grassland in Inner Mongolia.

\begin{tabular}{lllllllll}
\hline Annual bid amount $\left(\mathrm{CNY} \mathrm{ha}^{-1}\right)$ & 75 & 150 & 300 & 450 & 750 & 1050 & 1350 & 1500 \\
\hline $\begin{array}{l}\text { Proportion of households } \\
\text { willing to accept (\%) }\end{array}$ & 91.0 & 72.0 & 69.0 & 40.0 & 32.0 & 26.0 & 18 & 11.0 \\
\hline
\end{tabular}

\subsubsection{Government WTP}

We calculated the expected amount the government respondents were willing to pay to the herders to protect the grasslands (Table 6.6) using logistic regression analysis, and the regression was both strong and significant $(\mathrm{F}=67.317, \mathrm{P}=0.003, \mathrm{R} 2=$ 0.943). Figure 6.3 shows the relationship between the bid amount and the proportion of the officials who were willing to pay that amount (PWTP), as well as the probability density for WTP.

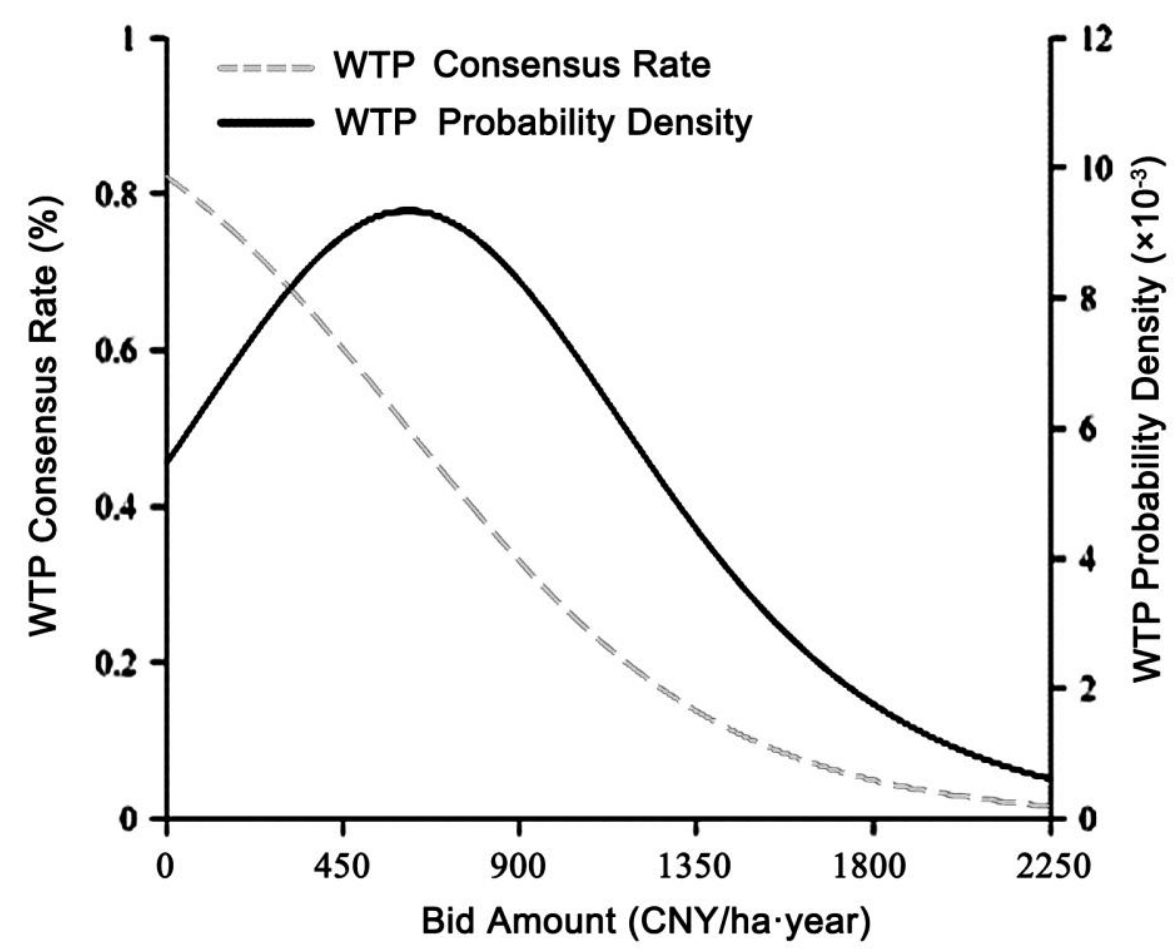

Figure 6.3 Functional relationships between the bid amount and the associated WTP consensus rate and probability density

Most of the officials were willing to pay between 375 and $600 \mathrm{CNY} \mathrm{ha}{ }^{-1}$ annually, with a high probability density of nearly $9.6 \times 10^{-3}$ for this range of values. The expected WTP can be estimated using equations (6.3) and (6.4), which predict an 
average annual WTP of $528 \mathrm{CNY} \mathrm{ha}{ }^{-1}$. The total area of grassland in which grazing is prohibited was $9.84 \times 10^{5}$ ha in 2012, thus the total payment would be between $369 \times$ $10^{6}$ and $590 \times 10^{6} \mathrm{CNY}$ year $^{-1}$. The current maximum payment standard is $270 \mathrm{CNY}$ $\mathrm{ha}^{-1}$ annually, which is less than the WTP of the local governments but far below the herder WTA for conserving the grassland.

\subsubsection{Stakeholder awareness and considerations for PES: herders versus officials}

The herders and the representatives from relevant local government agencies told us about their awareness of the impact of the RGLGP and SLCP on the livelihood of herders, and this provided important background information for designing a locally acceptable and practical payment scheme that would fairly compensate the herders for their income losses caused by grassland conservation activities. The results (Table 6.7 ) show that most of the respondents ( $56 \%$ of herders and $52 \%$ of officials) believe that the grassland conservation and restoration programs have affected the herders' livelihood by decreasing their net income and increasing the difficulty of their lives. Some $(33 \%$ of herders and $26 \%$ of officials) nonetheless thought that the programs had a positive impact on the herders because of the improved grassland conditions and reduced sandstorm frequency compared to the time before the programs were implemented. However, the proportions who thought there was no impact from the programs differed between the two groups $(11 \%$ of the herders and $22 \%$ of the officials), and the difference was marginally significant $(P=0.0627)$ because these officials thought the herders were adequately compensated for their losses and therefore were not forced to change their standard of living.

In general, the respondents welcomed the programs and considered them good because they received payments from the programs, because some of the workers released from the hard work of cultivation and grazing were able to earn wages from off-farm jobs in the cities (which also exposed them to new ideas from the outside world), and because the grassland conditions improved. They were also willing to participate in the program as long as the program payments continued, or if the program encouraged farmers to shift into activities that could provide income even if the program payments ended. All of the respondents were concerned about whether the programs would continue and for how long, and they noted that if the government ended the payments in the future, they would return to grazing in their grasslands. The other most important concerns were the growing conditions for grass $(50 \%$ of the respondents), water availability (50\%), vegetation cover $(36 \%)$ and the number of animals they could own (11\%).

Some also raised concerns about grass species (7.1\% of the respondents), biomass (3.6\%), and soil conditions (3.6\%). The agricultural and pastoral families perceived the programs as affecting their livelihoods through a direct impact on their way of life, including by increased income from the program payments and wages, reduced grazing area (nearly half of the pastoral areas had grazing prohibited), the reduced number of animals (the number of goats was especially decreased, by $17 \%$ ), the reduced percentage share of their total income from sheep (by 16.5\%) and cattle (by $12.0 \%$ ) for RGLGP families, and the $25.1 \%$ reduction in the proportion of total income from cultivation for SLCP families due to restrictions on grazing and cultivation (Table 6.4), the increased cost for purchasing animal fodder and feed (from $8636 \mathrm{CNY}$ in 1995 to $23339 \mathrm{CNY}$ in 2010), less dependence on biofuels (e.g. animal dung, dried grass, shrubs) but more dependence on coal, gas and electricity, and increasing reliance on food imported from other regions. 
Table 6.7 shows that most of the herders $(58 \%)$ wanted to have the compensation amount calculated based on their general loss of income from grazing and farming, followed by compensation based on their cost of living (13.6\%) and the cost of the grassland protection activities $(10.0 \%)$. Although the government officials also prioritized the loss of income $(22.1 \%)$ and cost of living $(23.3 \%)$, they placed a much lower priority on income losses (by $36 \%$ points), and the difference was significant; they also placed a much higher priority on the cost of environmental protection $(17.4 \%)$, although the difference between the two groups was not significant. The government officials also placed a much higher importance on the cost of managing the RGLGP and SLCP lands (16.3\%, which was $12 \%$ points higher than for the herders, and the difference was significant). These results suggest that the government officials considered the compensation from several angles, and tried to balance the economic and ecological aspects.

Table 6.7 Responses to questions designed to reveal the perceptions of payment for ecological services (PES): herders versus officials. (Note: Percentages represent the proportion of the respondents who agreed with the statement.)

\begin{tabular}{|c|c|c|c|}
\hline PES perceptions & $\begin{array}{l}\text { Herders } \\
(\%)\end{array}$ & Officials (\%) & $\begin{array}{l}\mathrm{t} \text {-test (P level) for the } \\
\text { difference }\end{array}$ \\
\hline \multicolumn{4}{|c|}{ Impact of the Grazing Prohibition Project on herders' livelihood } \\
\hline Loss & 56.4 & 51.9 & 0.5627 \\
\hline Gain & 32.6 & 25.9 & 0.1376 \\
\hline No impact & 11.0 & 22.2 & $0.0627^{\mathrm{a}}$ \\
\hline \multicolumn{4}{|c|}{ PES standard payment should be set based on: } \\
\hline Income from grazing and farming & 58.0 & 22.1 & $<0.001 \mathrm{c}$ \\
\hline Loss from natural disasters & 5.0 & 10.5 & 0.5307 \\
\hline Cost for environmental protection & 10.0 & 17.4 & 0.2304 \\
\hline $\begin{array}{l}\text { Cost for managing lands under the } \\
\text { Returning Grazing Land to } \\
\text { Grassland Program and the Sloping } \\
\text { Land Conversion program }\end{array}$ & 4.0 & 16.3 & $0.0019^{\mathrm{b}}$ \\
\hline Living cost & 13.6 & 23.3 & 0.1730 \\
\hline Other & 6.4 & 10.5 & 0.3017 \\
\hline \multicolumn{4}{|l|}{ Source of PES funds } \\
\hline Central government & 62.6 & 56.6 & 0.1045 \\
\hline Provincial government & 22.8 & 28.3 & 0.5114 \\
\hline County government & 9.3 & 7.5 & 0.8663 \\
\hline Levies from herders & 1.2 & 3.8 & 0.4528 \\
\hline Others (e.g. mining companies) & 0.041 & 0.038 & 0.7226 \\
\hline \multicolumn{4}{|l|}{ Means of compensation } \\
\hline Cash & 74.2 & 62.8 & $0.0850^{\mathrm{a}}$ \\
\hline Grain & 10.0 & 12.3 & 0.8371 \\
\hline $\begin{array}{l}\text { Employment opportunities } \quad \text { and } \\
\text { skills training }\end{array}$ & 15.8 & 24.9 & 0.1815 \\
\hline
\end{tabular}

Table 6.7 shows considerable agreement between the two groups about who should pay for the programs. Most of the respondents $(62.6 \%$ of herders and $56.6 \%$ of officials) believed that China's central government should pay the costs, and lower but 
similar proportions believed that the provincial government should pay (22.8 and $28.3 \%$, respectively). Very few of the respondents $(1.2 \%$ of herders and $3.8 \%$ of officials) believed that the herders should bear the cost. Table 6.7 also shows considerable agreement about the form of the payment. Most of the herders (74.2\%) and most of the officials $(62.8 \%)$ believed that the payments should be in cash. Relatively few $(<13 \%)$ believed that payment in grain, as has been done under China's SLCP, was a good option. More government officials (24.9\%) than herders $(15.8 \%)$ considered that job and related training to increase employment opportunities was a good option, but the difference was not significant.

During the survey, both the households and the officials were able to choose their WTA or WTP according to their real willingness, because they have been involved in the program implementation for many years, have experienced the improvement of the grasslands, and want to have better grassland conditions. The households also realized their economic loss from limited grazing, and the amount they wanted to receive from the government (their WTA) was comparable to their loss from the limitations on their activities. This agrees with the findings in other studies (Li 2010; Zhen et al. 2011a), in which the WTA of farmers was determined by their direct income loss from decreased production. The WTP of officials was also based to at least some extent on the income loss of the households that resulted from grazing limitations. The households are receiving compensation from the government for their participation in the two programs, and they can use this amount to support their family, but workers released from working on the land could also find off-farm jobs in the nearby cities, which is becoming an important income source for the households.

The average household annual income in Xilin Gol was 5186 CNY in 1995, before the RGLGP and SLCP programs were implemented, but increased to $19635 \mathrm{CNY}$ in 2012, after the programs had been implemented. The SLCP group's income before the programs (3260 CNY) was lower than the regional average income level in Xilin Gol, but its income after the programs $(10002 \mathrm{CNY})$ was higher than the regional average because the decrease in the income from cultivation activities (mostly grains and potatoes) was much lower than the increase in the income from sheep and from the SLCP compensation payments, which amounted to $18.5 \%$ of total income (Table 6.4). For the RGLGP group, average household income was $14212 \mathrm{CNY}$ before the program and $23378 \mathrm{CNY}$ after the program, and both were higher than the region's respective averages; this was because the RGLGP households depended on animal grazing for income, and this activity accounted for 98.6 and $70.1 \%$ of total income before and after the program, respectively. This difference is because the prices of meat, milk, and other animal products are much higher than those for the region's crops. For the households that participated in both programs, their average annual income was $11092 \mathrm{CNY}$ (higher than the region's average) and $14649 \mathrm{CNY}$ (lower than the region's average) before and after the programs, respectively. The mixture of cultivation (mostly greenhouse vegetables with higher prices than grains) and grazing activities contributed to the income changes for these households.

China's PES schemes have brought mostly positive effects to the participants. A typical example that was reported recently (Zheng et al. 2013), suggested that participation in a program to convert paddy land to dry land in Beijing, with the goal of improving the availability of water for other purposes and the quality of the available water, changed the distribution of household livelihoods and their production and consumption activities. Incomes doubled for both participants and nonparticipants, even though the income that participants earned from agriculture 
decreased, because they relied more on off-farm income. The income gap between participants and nonparticipants was $3554 \mathrm{CNY}$ in favour of the participants, which was similar to the mean payment; this suggests that the payment standard was determined by the direct income loss from land conversion. The participants changed their production and consumption behaviours by increasing spending on production inputs, material assets and education, which improved the livelihood effects of the program.

However, despite the overall promising results of this chapter, an alarming number of herders $(88 \%)$ and farmers $(90 \%)$ may return their retired land to grazing or farming activities if the program payments end. If the program encourages herders and farmers to shift into activities that can provide income even after the program payments end, there will likely be less pressure to return the retired land to grazing or cultivation. Because this is a common concern in other parts of the country (Uchida et al. 2005; Zhen and Zhang 2011), governments must not end payments under these programs without providing participants with alternative ways to earn a living.

\subsection{Conclusions}

This chapter combined government statistics with the results of interviews of households and government officials to quantify each household's WTA and the government officials' WTP for grassland conservation, and to reveal the factors that influenced these choices. The land-use and income changes that resulted from the government's PES projects, were also analysed. The following main conclusions were obtained from the analysis:

(1) Major PES projects implemented in the Xilin Gol League included the SLCP and the RGLGP. After implementation of these projects, the areas of cultivated land and grazing land both decreased. As a result, herder income from cultivation and animal husbandry decreased, although income from sheep increased under the RGLGP because the high compensation payments allowed herders to purchase enough fodder to maintain large herds. In contrast, income from government compensation payments and off-farm activities increased, and became an important and stable income source for the herders.

(2) Most of the herders want to continue the PES projects to improve grassland conditions, and they were willing to accept PES to mitigate their economic losses. The average WTA of the herders was about $625 \mathrm{CNY} \mathrm{ha}^{-1}$, which is much higher than the current maximum amount they receive (about $270 \mathrm{CNY} \mathrm{ha}^{-1}$ ). On the other hand, government officials had a WTP of about $528 \mathrm{CNY} \mathrm{ha}^{-1}$ annually to the herders. Although this amount is much higher than the current annual payment of $270 \mathrm{CNY} \mathrm{ha}{ }^{-1}$, it is still less than the herder WTA. The gap between the herder WTA and government WTP is about $97 \mathrm{CNY} \mathrm{ha}^{-1}$.

Hypothetical bias is likely to exist for the specific levels of WTA and WTP that we determined because the answers to the questions had no real consequences; respondents who stated that they would accept compensation for grazing restrictions or who stated that they would pay for grassland conservation were not required to actually do so. Some respondents may have stated that they would agree with some amount of money, but they could actually accept an amount less than their expressed WTA; similarly, some government officials may have stated that they would pay a certain amount, when, in fact, they would pay less (e.g. due to constraints on their budget) if placed in the real situation. 
However, because the respondents were familiar with the subject of the questions after more than ten years of involvement in the PES programs and because the hypothetical choices (bids) were based on the preliminary surveys, and thus closely mirrored the potential real choices for the residents of IMAR's grasslands, the results are likely to be realistic. Thus, the results could reflect the gap between WTA and WTP to some extent. Perhaps most importantly, the WTA values were very similar to the economic losses of participants, which suggests that any hypothetical bias was relatively small. However, more research will be necessary to quantify the bias and its causes.

The government officials considered the PES from both economic and ecological perspectives, whereas the herders emphasized their income losses and basic cost of living; thus, they related their compensation standard to their reliance on grasslands and their willingness to continue PES projects. Most of the herders and officials believed that China's central government and provinces should take responsibility for the compensation payments, and believed that the payments should be paid in cash rather than in grain or training to obtain skills that would enhance their off-farm income or permit additional farm activities such as the production of greenhouse vegetables. The findings have significant implications for designing an operational PES scheme for study area. The herders have clearly been experiencing economic losses from conservation activities, but although they wanted to participate in conservation activities, they also expected sufficient compensation payments to mitigate their losses. Unfortunately, they want more money than the government is willing to provide, and the gap between WTA and WTP, as well as the current very low payments, may lead some herders to expand grazing into restricted grassland or increase their number of animals. The result of chapter confirms Bennett's (2008) results: some participants may resist the RGLGP and SLCP because they feel they are not compensated enough to participate, and will have no incentive to continue participating if the payments end. This potentially jeopardizes the success of the RGLGP and SLCP. 


\section{CHAPTER 7}

Synthesis, discussion and conclusions

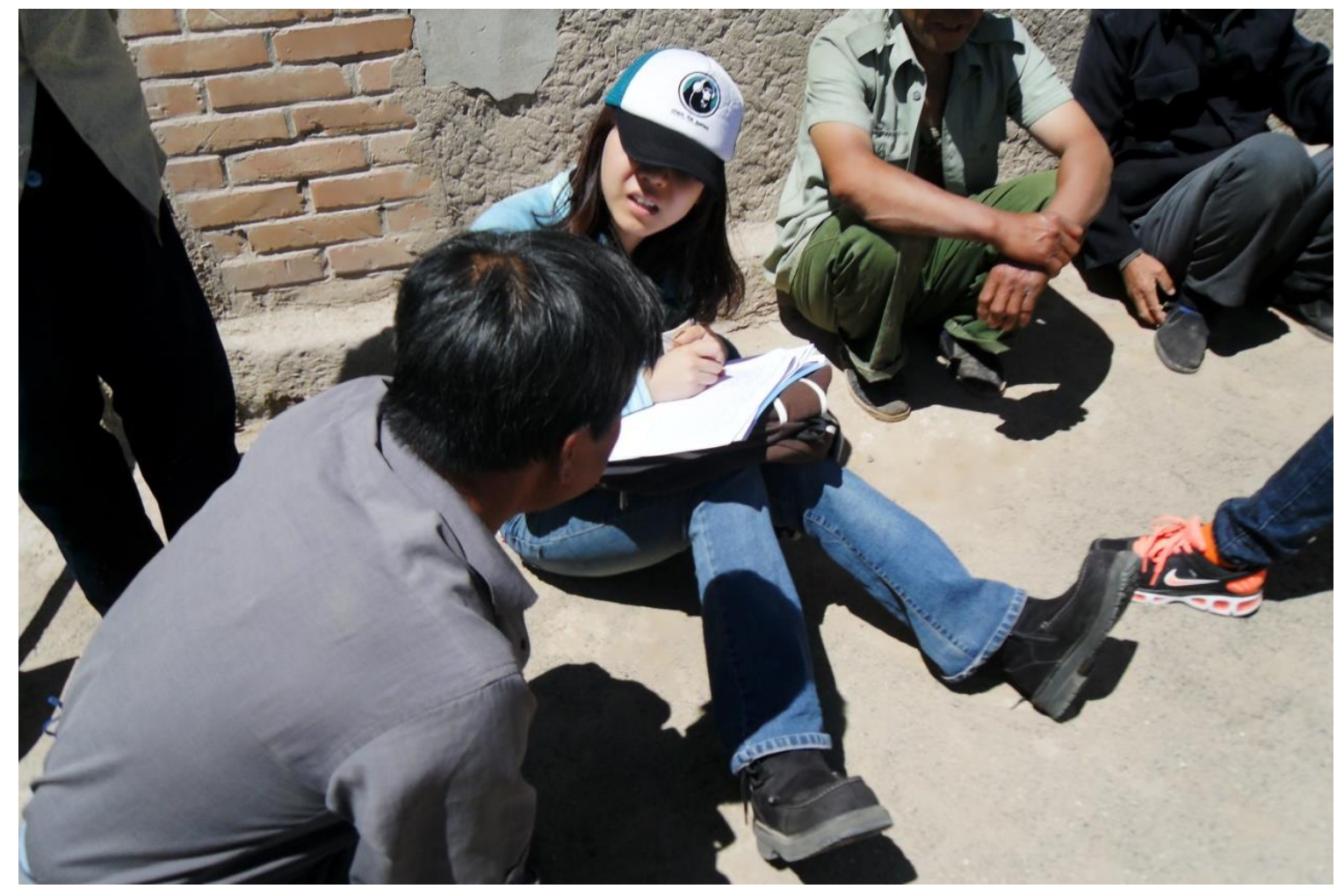




\subsection{Introduction}

For my thesis, I made an integrated assessment of the interactions between people and ecosystems in the Inner Mongolian Autonomous Region to analyse the effects of landuse change on people's livelihood and ecosystem services (ESs). This should help decision makers and land managers to better understand the effects of their management choices and activities. I analysed the effects of changing livelihood dependence and grassland-utilization patterns on ESs and explored the possible grassland management strategies in selected study sites (i.e. Hulun Buir, Xilin Gol and Ordos; Box 1). Six research questions guided my analysis:

RQ1 What are the spatial and temporal variations of land-cover changes since 1998, when the restoration program started, and what are the effects on habitat quality?

RQ2 a) How have basic household consumption patterns changed under different management regimes in the selected study sites?

b) What are the main factors affecting current household consumption?

RQ3 What are impacts of changing food consumption patterns on water resources conservation?

RQ4 How has people's livelihood dependence on local ecosystems and their utilization patterns changed in the last 15 years?

RQ5 What are the trade-offs between selected ecosystems services as a consequence of the changing grassland utilization patterns?

RQ6 What recommendation can be given to design feasible strategies and incentives for sustainable management of IMAR's grassland ecosystems?

My study mainly collected empirical data at the household scale. To analyse historical land-use change effects on the regional habitat quality in IMAR, I also used an integrative modelling approach (i.e. InVEST). Section 7.2 discusses and concludes the main findings of my thesis by addressing each research question. Section 7.3 presents discussion of research methods on both strengths and weaknesses aspects with comparison of literatures. Section 7.4 provides a brief synthesis and recommendations.

\subsection{Discussion and conclusions of main findings}

\subsubsection{What are the spatial and temporal variations of land-cover changes since 1998, when the restoration program started, and what are the effects on habitat quality?}

Major land-cover types in the study area include grassland (high, middle and low cover ratio), arable land, forest and other land uses, including urban areas, water bodies and wetlands (Appendix 9). The distribution of land cover in the three study sites is different and statistical data of investigated 'banners' (county level in China) or districts were explored to analyse the differences in land-cover changes between the three study sites (Box 7.1)

The previous research of Bao (2009) showed that grassland was mainly transferred to farmland in the period 1975 to 1990 . My results indicated that forest, grassland and farmland were the main land-use types in my research area with obvious reciprocal transformations in the period 2000 to 2010. Farmland was primarily converted to grassland and forest, and grassland tended to increase in between 1995 and 2010. 
Deserts decreased with the rapid increase of low cover grasslands during 2000 and 2010. The change of human intensification played an important role on the variation of land cover. Land-use intensity was mainly affected by the changes in population and national land-use policies (e.g. SLCP and RGLGP). Since 2000, agricultural land and grassland areas tend to decrease, the desert area was slightly reduced and forests and grasslands notably increased. A basic approach to ecological restoration is to implement rational land-use policies and utilise ecosystem self-repair functions (Yin and Yin 2010; König et al. 2015).

\section{Box 7.1 Land-cover in the three study sites}

In Hulun Buir, grassland and forest are the main land covers and occupy $57 \%$ and $35 \%$ respectively of the total land area, whereas arable land only accounts for $1 \%$. Hulun Buir is a traditional pastoral area and is famous for its livestock and poultry cultivation. The region has now become the largest milk and meat export centre in China.

In Xilin Gol, the grassland dominates $94.0 \%$ of the total land area and the percentage of arable land is larger than in Hulun Buir (i.e. 2.2\%). More than half of this land produces grains. The forest area in Xillin Gol has the lowest percentage; only $1.5 \%$. Half of Xilin Gol is a traditional pastoral area and half is a farming area. In recent years, cultivation greatly increased and changed from traditional livestock husbandry to modern cultivation.

Grasslands in Ordos are still the dominant land-use: 67.4\%. The second largest land use is forest $27.1 \%$ and Ordos (especially the Dongsheng District and Ejin Horo Banne) takes the leading role in economic development with the rapid development of mining. The general trend in livestock-husbandry and crop-farming activities is moving away from individual farms to larger-scale operations. This decreases the population that is engaged in husbandry and farming over the last fifteen years.

Although the grasslands have increased in general, the high and middle cover grasslands have decreased in between 2000 and 2010 (Appendix 8). In economic and ecological terms, low cover grassland has a low productivity compared to high and middle cover grasslands (Yan et al. 2012). Thus, I used the InVEST model to quantify their overall habitat quality based on land-cover types and land-use magnitude for the period from 1995 to 2010 . This model considers three major parameters: intensity of threat, distance between habitats and the stressor and habitat sensitivity. All the parameters to run the InVEST model (Box 7.2) are based on Tallis et al. (2013), but I have modified them according to my own field surveys and workshops results (for details on the workshops, see Section 1.9).

The habitat quality in all three sites decreased between 1995 and 2000 (Figure 7.1). This is caused by the region's rapid economic development. Its people require more food, fuel and water to satisfy their needs. Especially meat consumption in China increased strongly (FAO 2003) and IMAR traditionally exports meat. Therefore it suffers from overgrazing-induced degradation caused by the fast decreasing habitat quality of local ecosystems. After implementing the ecological restoration projects, this trend was stopped and stabilised, especially in Xilin Gol and Ordos with only moderate variations between 2000 and 2010 (Figure 7.1 and Appendix 9). 


\section{Box 7.2 Identifying the parameters of the InVEST model to assess habitat quality}

Intensity of relative threat: Human activities are classified in the InVEST model as activities related to roads, residential activities and agricultural production. In the land-use maps that I modified during the field surveys, I classified human activities as transportation activities (on both paved and unpaved roads), residential activities (on residential land) and cultivation activities (both crop production on cultivated land and vegetable gardening). Each type of threat affected an activity's habitat quality with a different (threat intensity). In the InVEST model, these were defined on a scale of 0-1 with higher scores representing more intense stress. Based on field surveys, I quantified the threat intensity scores as 0.8 for residential land, 0.6 for transportation land and 0.4 for cultivated land.

Influence of distance between habitat and the threat source: The influence of the distance between threat source and habitat was obtained from literature, the InVEST model database and my own observations on Inner Mongolia grasslands. I chose a maximum impact distance of 200m (Carney and Sydeman 1999) for paved roads and a maximum impact distance of $100 \mathrm{~m}$ for unpaved rural roads because most transportation occurred on paved roads, whereas unpaved roads served as branch roads and had much less traffic. The InVEST model assumes that residential areas have at least twice or triple as much impact on habitat quality than traffic (Tallis et al. 2013). Thus, I set a $600 \mathrm{~m}$ impact range for the rural residents and used this as a buffer for the maximum distance of the threats to the habitats. Agricultural land had an impact range that was similar to road traffic (Tallis et al. 2013). I therefore defined the impact range for agricultural land (including cultivated land and aquaculture) as $200 \mathrm{~m}$.

Habitat sensitivity to the threat sources: In the InVEST model, habitat sensitivity is defined for each combination of habitat and threat source. Its values are defined between 0 and 1 . Higher scores represent greater sensitivity. From my survey, habitats were more sensitive to cover ratio of grassland activities and paved roads. Low cover grasslands therefore are given a sensitivity value greater than 0.6. The habitats were less sensitive to high cover grasslands with a sensitivity value less than 0.2 . The middle covere grasslands have on average a sensitivity value of 0.4 .

Hulun Buir's habitat quality, however, sharply dropped after 2005 (from 0.82 to 0.75 ; Figure 7.1). This is caused by the increases of urban and residential areas and road construction, and continued intensive grazing activities in Hulun Buir. Its livestock rearing was also less affected by the grassland restoration policy. Because high-quality (high cover) meadow steppes are the dominant vegetation in Hulun Buir, many animal husbandry enterprises and milk processing enterprises moved here and invested in Hunlun Buir (Gao 2013). This rapid development of agriculture mainly caused the reduction of local habitat quality. 


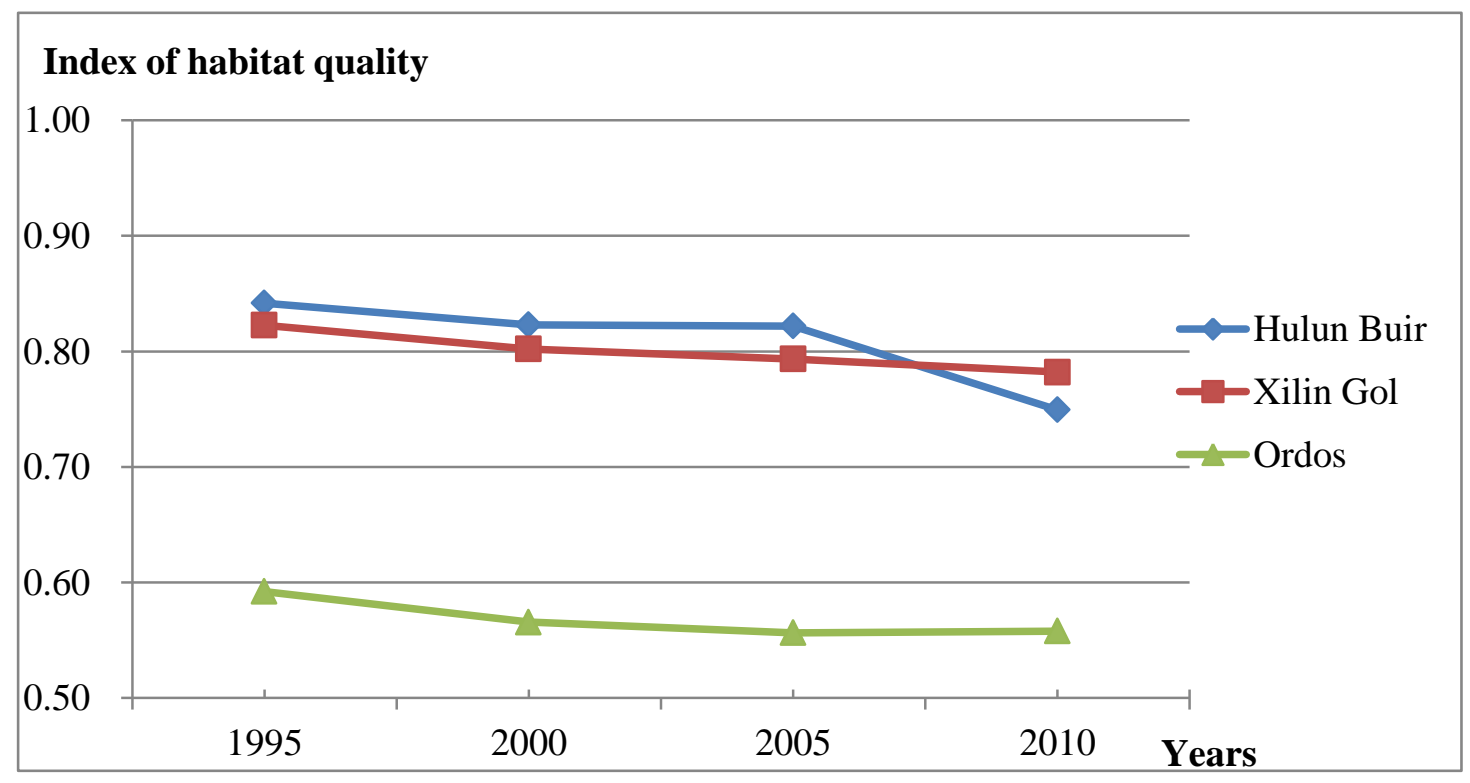

Figure 7.1 Change of habitat quality in Inner Mongolian grasslands

7.2.2 How have basic household consumption patterns changed under different management regimes in the selected study sites and what are the main factors affecting current household consumption? (RQ2)

(a) How have basic household consumption patterns changed?

To reverse grassland deterioration in Inner Mongolia, a basket of grassland restoration policy measures have been enforced in the last decade (Li et al. 2007; Yin and Yin 2010; Li and Huntsinger 2011). These measures include rotational grazing, seasonal grazing, grazing prohibition, livestock movement and control of livestock rearing. However, these grassland management policies exert great stress on local households' livelihood by fundamentally changing their lifestyles (Xie et al. 2006; Dong et al. 2007; König et al. 2014) and reshaping the basic household consumption patterns.

I used a household survey by using face-to-face interviewing of the 209 respondents to acquire first-hand data to estimate actual daily consumption. The consumption patterns were constructed using statistics based on a field-level survey of the three study areas. From the responses, large differences could be seen in food, fuel and domestic water consumption patterns between the three study sites.

Food consumption: IMAR's historic food-consumption consists of few agricultural crops and high meat consumption. This is mainly due to the lagging effects of the traditional nomadic grazing culture. There is, however, considerable spatial variation between the three study sites due to different economic developments, restorationpolicy measures, ecosystem types and variations in ESs provided by the meadow steppe (Hulun Buir), typical steppe (Xilin Gol) and semi-desert steppe (Ordos) areas. Hulun Buir retained the low agricultural crops with high meat-consumption pattern. Approximately half of the households in Xilin Gol and Ordos shifted their dietary patterns and now follow a high consumption of agricultural crops with lower meat consumption. 
Fuel consumption: Dried dung from livestock and firewood collected from forests and scrublands were traditionally important fuels and were widely used in IMAR. The types and amounts of fuel consumed changed significantly during my study period. Fuel consumption patterns changed from using mainly bio-fuels in 1995 to mainly electricity or gas in 2010. However, dried dung is still a major energy source for daily life in Hulun Buir with coal being the second most important fuel. Trends of coal and electricity or gas consumption showed increases at all three study sites, especially in Xilin Gol and Ordos, where livestock rearing is not as prevalent as in Hulun Buir.

Domestic water consumption: Groundwater was and still is the sole domestic water source in all three study sites. Some households have begun to use public water supply (tap water) instead of privately owned wells as their water source.

\section{(b) What are main factors affecting current household consumption?}

Economic development stimulated more diverse food-consumption patterns and established trading markets and changed consumption consciousness. My survey results also showed that the market supply of food also affects food-consumption patterns. When the food accessibility increased through improved transport (Zhang et al. 2014) because a comprehensive transportation system was developed in Inner Mongolia. This has supported the rapid economic development in the past 22 years, especially after 2003. Staple foods, fruit and vegetables became less expensive than mutton and beef. Consequently, the consumption of these crops increased substantially.

Another important factor that affects current household-consumption patterns is changes in land-use type or land assets. My results show that herders in Hulun Buir own abundant grasslands and most herders no longer follow a nomadic lifestyle. Instead, they settle near their land and cultivate small parcels of farm land to grow potatoes and vegetables in the spring and the summer. In Xilin Gol, the total land owned in 2010 was less than half than that in Hulun Buir. The grassland degradation in Xilin Gol led to a shortage of meat production and this resulted in people starting to purchase food from outside the region. This reduced their dependency on local ecosystems. In Ordos, the inhabitants have the lowest land ownership. In the past, some Ordos' farmers and herders also owned severely degraded grasslands and mineral lands, but these lands have been expropriated by the government for protection or released to individual companies for mining ( $\mathrm{Li}$ et al. 2014; Zhao et al. 2014). Fast economic development caused by mining stimulated these changes in food consumption structure from simplified to diversified food consumption patterns.

In addition to influences of economic development and different environmental conditions, the grassland-restoration policies deeply changed pastoral tradition and basic household-consumption patterns. In the past twenty years, Inner Mongolia was not perceived as an economic priority area focusing, for example, on agricultural production or mining. It was rather classified as a 'priority-ecological zone' aiming at sand-storm prevention and soil-erosion mitigation to rehabilitate grassland ecosystems (National Development and Reform Commission 2014). The implementation of grassland-conservation policies (i.e. seasonal grazing and rotational grazing) affected grazing activities less of than other measures. Thus, more herders preferred to maintain most of their basic consumption patterns (e.g. in Hulun Buir). However, in the context of grazing prohibition, emigration and livestock rearing control-policy measures (e.g. in Xilin Gol and Ordos), the consumption of agricultural crops has increased and meat and bio-fuel consumption has decreased substantially. 
Similar to my survey, the socio-economic statistics for rural areas in IMAR also indicated that meat consumption in the period from 1995 to 2010 decreased by $21 \%$ and vegetable consumption increased by 45\% (Inner Mongolia Statistics Bureau 1996, 2011). Feng and Shi (2006) showed that the initial preference for human food consumption is home-produced food from family owned land or local ecosystems (i.e. self-sufficiency). However, when the changing conditions result in insufficient homeproduced food, the people start to alter their food acquisition, including purchasing. For instance, in Xilin Gol, the number of livestock is controlled by the carrying capacity of local grasslands (1 sheep unit per 1.67 ha grassland). To confront this livestock-rearing control policy measure, the herders and farmers increase cattle rearing to compensate for the loss of goat/sheep grazing due to the control policy. Cattle can produce milk products. This produces higher incomes than just selling their meat. This change requires herders and farmers to buy food from external markets and they tend to buy vegetables and fruit, as these are less expensive than mutton and beef.

From a nutritional perspective, IMAR had a 2.2 times higher meat consumption than the Chinese average and 1.9 times China's average vegetable consumption (Feng and Shi 2006, Liu et al. 2012). And in IMAR, the meat consumption per household in pastoral areas was the $230 \%$ of arable farming areas in 2010 . Consumer preferences in my research areas were still meat-based. This satisfied daily protein and energyconsumption requirements (Chinese Nutrition Society 2010). Therefore, a decrease of meat consumption does not cause undernourishment.

\subsubsection{What are the implications of changing food consumption patterns on water resources conservation (RQ 3$)$ ?}

Based on the literature review, household questionnaires and stakeholder workshops, the limited clean fresh water availability strongly constrains further social and economic development in IMAR (Dai et al. 2009, Hu et al. 2012). A burgeoning population, pressing development needs and increasing household consumption are rapidly increasing the amount of water used. Increasing water consumption is leading to water stress and grassland degradation. Household-water use is a combination of both direct water consumption (e.g. domestic water consumption for drinking, washing, flushing and cooking) and the indirect water consumption to produce food. The specific water requirement per unit food (crop or meat) in my study sites was identified from the Virtual Water Content (VWC) method (Bessembinder et al. 2005; Xiao et al. 2007).

\section{(a) Changes in the amount of indirect water use}

My results show that indirect water use from food consumption represents $99 \%$ of the total household-water consumption in the study sites. The herders in Hulun Buir consumed the highest amount of indirect water for food production in 2010 and Ordos the lowest amount. Compared to 1995, the indirect water consumption increased in Hulun Buir and decreased in both Xilin Gol and Ordos. The main reason for these trends is the changes in food patterns from 1995 to 2010 that shift away from meat consumption towards more vegetable and fruit consumption. Meat consumption also switched from a combination of mutton and beef to more diverse meat consumption 
including fish, chicken and pork. Changing diet behaviour and reducing the population pressure therefore likely influence the sustainable use of water.

Although the amount of vegetable and fruit consumption in all three study sites increased substantially between 1995 and 2010 because the Specific Water Demands (SWD) of vegetables and fruits are relative low (on average $0.1 \mathrm{~m}^{3} \mathrm{~kg}^{-1}$ for vegetables and $1.2 \mathrm{~m}^{3} \mathrm{~kg}^{-1}$ for fruits), the indirect water use from agricultural food production remains relatively low. The changes in indirect water consumption, which are driven by mutton and beef, are substantial in all three sites. In Hulun Buir, the total indirect annual water consumption increased by $30 \%$ between 1995 and 2010. The annual indirect water use from beef is the highest $\left(470 \mathrm{~m}^{3}\right.$ per capita) and annual indirect water use from mutton decreased (i.e. $-88 \mathrm{~m}^{3}$ per capita). In Xilin Gol and Ordos, the indirect water consumption from beef and mutton products decreased $(22 \%$ and $30 \%$ of the level of 1995 respectively) between 1995 and 2010.

\section{(b) Implications for water resource conservation}

My results confirmed that the livelihoods of pastoral communities are strongly linked to the health of the grasslands that the majority of these communities rely on (Pricope et al. 2013). The reductions in indirect water consumption can reduce the pressure on local grassland and grassland conservation can probably be achieved by changing food-consumption patterns. The large differences between the SWD of the various food (or crop) types for consumption indicate that the total water consumption can be reduced if food-consumption patterns change.

Economic development (e.g. purchasing ability) and grassland-use policy measures are identified by my researches as the most efficient ways to switch food-consumption patterns with lower indirect water consumption in IMAR. Most developing countries of the world that economically develop, show increased purchasing power, which increase demand for meat products (FAO 2009; Grigg 1995; Popkin 2002). Their populations grow and, combined with economic growth, meat demand increases. This requires more water. Interestingly, my results for the study areas in Inner Mongolia show a different trend. The increasing purchasing power, which differed in the three sites (c.f. Figure 7.2), reduced indirect water consumption through adaption of diversified food-consumption patterns (especially increased vegetable and fruit consumption). The reason of this difference with other developing countries is my focus on household consumption in specific pastoral areas with under different economic and environmental circumstances.

The results from RQ2 (Section 7.2.2) showed that the implementations of grasslandrestoration policies in IMAR aggravated the situation for the herders and farmers. They changed their diets by reducing their meat consumption and started to purchase food. This reduced indirect water consumption and conserved the local grasslands. Moreover, studies on structure and trends of water and food-consumption patterns (e.g. Hu et al. 2015) likely allow policymakers to better manage water and land sustainably by implementing grassland ecosystem-restoration policies. The current restoration policies need additional policy measures to increase livelihood diversity and mitigate the livelihood dependence on grassland ecosystems. Various strategies, such as provided off-farm works, skill training, establishment of food trading market and education on healthy diets, need to be employed. Therefore, quantifying direct and indirect water consumption is critical to design strategies for water conservation and, consequently, sustainable grassland management. 


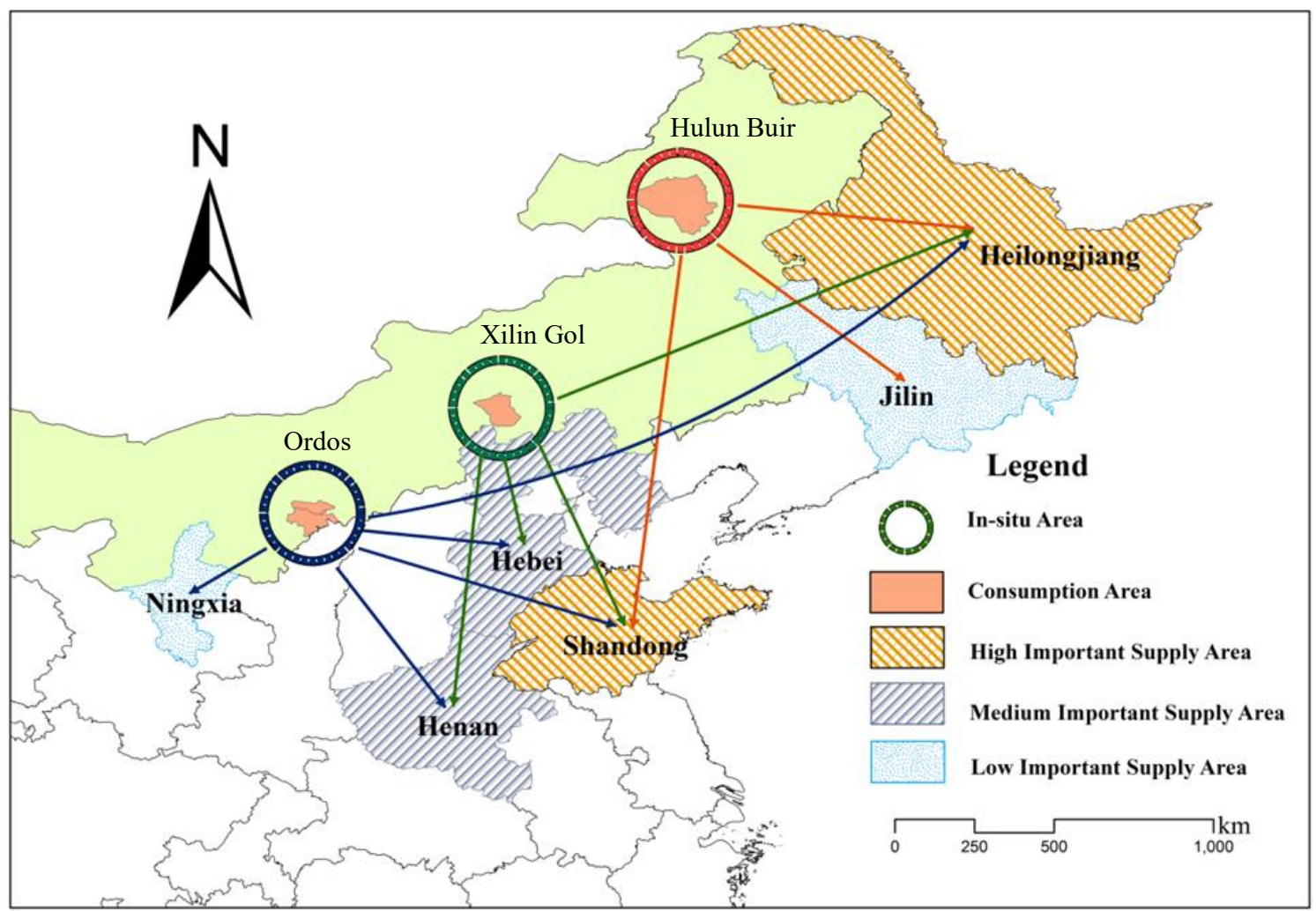

Figure 7.2 The producing places for purchasing food products

\subsubsection{How has people's livelihood dependence on local ecosystems and their utilization patterns changed in the last 15 years?}

Inner Mongolia is not fully developed economically, and household livelihoods rely heavily on exploiting the local resources. The implementation of the government's conservation policies considerably changed the use of local ecosystem. To lower the ecological risk of over-grazing and stabilize income sources, a quarter of the respondents ceased grazing and leased their grassland to others, who wanted to expand their pasture area. In this way, leaseholders could earn greater profits because they could support larger herds. And the leasers could engage in non-farm activities and move to peri-urban or urban areas to pursue other opportunities. Thus, grasslands are no longer the only basic assets used to guarantee herders' livelihoods. This reduced their dependence on the grasslands. The main effects of these trends are briefly presented and discussed below.

\section{(a) Effects of Grassland Conservation Policy on Household Livelihoods}

To comply with the grassland conservation policies, households decreased the total number of livestock per household from an average of 262 in 1995 to 88 in 2010 (a decrease by two-thirds). More than $60 \%$ of the respondents reported that their livestock has halved since 1995. The decreasing trend of total number of livestock has been confirmed by statistic data of Inner Mongolia Statistics Bureau (1996, 2011 and 2015). However, my research shows the number of animals varied among the three study sites in 2010. The highest mean is 197 in the West Ujimqin Banner, 34 in the Zhengxiangbai Banner and 32 in the Alxa Right Banner. These results are strongly related to the natural conditions in each banner, and particularly the per capita land ownership: 17.6, 9.9 and 9.2 ha in the West Ujimqin Banner, the Zhengxiangbai and the Alxa Right Banner respectively. About $60 \%$ of the households used only stall 
feeding, and the others combined stall feeding in winter (November to March) and local grazing in summer (April to October). More than $75 \%$ of respondents reported a need to purchase or store forage.

The proportions of total income accounted for by agriculture decreased from $78 \%$, $74 \%$ and $65 \%$ in these Banners respectively in 1995 to $54 \%, 42 \%$ and $41 \%$ respectively in 2010. These changes resulted mainly from the reduced numbers of livestock and the increased cost for grazing and fodder purchases. Between 1995 and 2010 , the mean shares of agriculture-based income in the three banners decreased from $72 \%$ to $46 \%$ and the share of employment-based income decreased from $65 \%$ to $60 \%$.

\section{(b) Effects of decrease in household dependence on local grasslands}

From 1995 to 2010 (before and after implementation of the grassland conservation policies), the household dependence on local grasslands generally decreased. This indicates (1) a transition from traditional pastoral grazing to controlled grazing and intensive animal husbandry; (2) diversification of income sources and decreases in land-based employment; and (3) reductions of household food and bio-fuel consumption, which is derived from local grasslands. These changes increased the diversity of livelihoods and increased environmental sustainability. For instance, when grazing is restricted to the local grasslands, herders must purchase fodder from outside their area to feed their animals. In traditional animal husbandry, daily fodder was obtained from each household's grassland. The traditional adaptation to fodder shortage is to move to other pastures and is called 'Otor' in Mongolian (Wang 2009). However, at present the major components of livestock fodder are crop residues, leaves from fodder plants and herbaceous plants from adjacent forests. The research of Zhang and Wang (2012) also reported that many herders could not find pastures to rent and had to buy forage or use crop residues directly in 2010. This indicates that grasslands are no longer the only fodder sources. This change increased costs to purchase and store forage, but it probably also avoids or alleviates the fodder crisis caused by climate extremes (e.g. droughts and snow storms) and ecosystem degradation (Dong et al. 2007; Wang and Zhang 2012).

Another aspect of increasing of household resilience is the diversification of income sources. Similar to the results of Wan et al. (2008), rural livelihoods in Inner Mongolia have increasingly shifted from subsistence agriculture and animal husbandry to include non-agricultural, off-farm work for wages and government subsidies in recent years. The proportion of total income accounted for by nonagricultural income increased greatly. This is likely explained by the decreasing area of grassland used for animal husbandry. The macro-level policy changes and microlevel livelihood adjustments largely changed the land-use asset structure. For instance, herders, who lost the right to access grassland, were more severely affected than those who retained access to pastures under the grassland-conservation policy. Because these changes were implemented rapidly, herders, who lost access to pasture, were forced to sell most or all their livestock, although the government partially compensated for this loss. On the positive side, this decreased their dependence on grasslands and increased the rate of business operation and employment in nonagricultural economic activities. Over $80 \%$ of the respondents in the three Banners believed that finding urban employment was the best way to increase their income and that diversification of income sources is crucial in securing their household livelihoods. Especially in poorly-developed areas, off-farm employment and activities 
could increase cash income and improve household resilience by increasing their capacity (including acquired new skills and new opportunities) to earn money to cope with possible shocks.

(c) Effects of changed livelihood dependence on perceptions of the future of grassland use

Despite the severity of grassland degradation and the changes in their lifestyle, more than $80 \%$ of the herders and farmers did not want to move to the city, for three main reasons: lack of suitable skills, low education and a desire to preserve their culture. Even herders and farmers with high levels of education and skills training felt strong ties to their local social network and culture. However, herder and farmer perceptions of the next generation's career choices showed different results and these differences can be used to predict the next generation's dependence on the local grasslands. Of the six career choices that they identified (animal husbandry, crop cultivation, migrate to cities, establish a business, combine grazing with a part-time city job and other opportunities), the most likely career choice for the next generation is moving to the city to obtain a secure job. A common choice was also to start a business or combine grazing with a part-time city job. Respondents in all three banners believed that crop cultivation $(<3 \%)$ and animal husbandry $(<10 \%)$ were the least likely careers. Because the respondents believed that the natural conditions greatly influenced crop planting and animal husbandry, they felt that these careers could not guaranteed their basic needs under the current poor environmental conditions and unstable climate. They reported a high willingness to help their children free themselves from the grasslands as $84 \%$ of the respondents thought sending their children to a big city to improve their education and employment options would be good.

This raises new concerns. For example, as more people abandon the grasslands, eventually too few remain to use or manage the grasslands. Since the grasslands have coevolved with nomadic herders for millennia, this could lead to considerable negative ecological effects. Although ecosystems are likely to recover in response to reduced human pressure (Hoffmann et al. 2011), they may not recover to their original state (König et al. 2015). Thus, grassland management needs to emphasize sustainable use of grasslands.

\subsubsection{What are the trade-offs between selected ecosystem services as a consequence of the changing grassland utilization patterns? (RQ 5)}

In order to analyse trade-offs between provisioning services (livelihoods based consumption) with other ESs (vegetation and soil-trait based), a household questionnaire survey and a quadrats-sampling plot survey were used to assess soil and vegetation at sixteen sampling sites (including semi- desert steppe (five in Ordos), typical steppe (four in Xilin Gol) and meadow steppe (seven in Hulun Buir)) to trace the trade-offs between ecosystem state (i.e. functioning) and ESs under different utilization patterns (i.e. non-use, light use, moderate use, intensive use and recovery) of the IMAR grasslands.

(a) Effects of changes in grassland utilization on individual ecosystem services in the three study sites

Provisioning services: the main production of grasslands for the herders' livelihoods can be distinguished into three main commodities, which are meat (mutton and beef), fodder (grass fodder) and bio-fuel (dry dung). All these commodities directly related to the number of livestock and the results showed significantly different numbers of 
livestock per household in the three areas. In Hulun Buir, herding of sheep (average of 52 sheep per household) and cattle (18) was the major breeding activity, whereas herding of a smaller numbers of cattle (average of 4.2 per household) and sheep (2.4) dominated household activity in Xilin Gol. In Ordos a few cattle (average of 0.8 per household) and sheep (2.4) are raised for breeding activities. On the contrary, the decision to raise more small animals, such as goats (average of 6 per household) and chicken (16) in Ordos is clearly a pragmatic response to government initiatives that stimulate less fodder consumption to prevent the continued degradation of the local semi-desert steppe. Dry dung from livestock was an important biofuel and was widely used in all three areas, but especially in Hulun Buir, where the annual per capita use was 2878.kg. The high consumption of dried dung can be attributed to the higher numbers of sheep and cattle. Herders used biofuel to support the needs of daily life, including cooking, heating and heating bath water. Due to the great reduction in the number of livestock in response to government policies to reduce grazing pressure on the ecosystem, with especially severe reductions in Xilin Gol and Ordos, dry dung cannot satisfy the household demand anymore so households use more new forms of energy (e.g. coal, electricity) instead of dung.

Soil water retention services: In Hulun Buir, non-use grasslands shows the highest value of soil water content $(12 \%)$, the intensively used grasslands received the lowest value of soil water content $(7 \%)$. Similar to Hulun Buir, with the increase of intensively used grasslands, soil-water content gradually reduced in Xilin Gol and Ordos. The soil-water contents will likely be recover grasslands use is stopped, initially in the recovery sites.

Soil nutrition regulating services: I measured soil nutrition contents (organic matter, available $\mathrm{N}$, available $\mathrm{P}$ and available $\mathrm{K}$ ) to trace nutrition regulation services. The results show a decreasing trend of soil nutrients along a gradient with increasing intensification of grasslands. Organic matter and available N, P \& K contents are highest in Xilin Gol with non-used grasslands and did not show much difference between light used and moderate used grasslands. Ordos has little used grassland with the highest value of organic matter and available $\mathrm{N}$ and $\mathrm{K}$ contents after the earliest demonstration site of grassland restoration in IMAR started two decades ago.

Primary production (Biomass) services: In general, total above-ground biomass decreases with the intensity of grassland utilization. The ratio of edible grass and above-ground biomass increases with the increasing intensity of grassland utilization. The highest values of total above ground biomass were found in moderately used grasslands in Hulun Buir and lightly used grasslands in Xilin Gol. The lowest total above-ground biomass is found in the intensively used grasslands. The edible grass ratio in the recovery projects is rather low, only 34\% in Xilin Gol and 43\% in Ordos.

Habitat services: Under the different utilization patterns, grasslands in Hulun Buir shows the highest Shannon-Index value in lightly used grasslands, followed by moderately used grasslands and a sharp reduction in the more intensively used grasslands. However, the Margalef index and the Pielou index in Hulun Buir are both the highest in moderately used grasslands. This is even slightly higher than in lightly used grasslands. Unlike in Hulun Buir, the Shannon and Pielou index in Xilin Gol clearly decease when lightly used grasslands are changed into moderately used grasslands. This means that the typical steppe (Xilin Gol) is more vulnerable than the meadow steppe with lower tolerance for intensive grassland utilization. In Ordos, the grazing activities in most areas are restricted and prohibited. The results only show 
small differences among non-used grasslands, lightly used grasslands and recovered grasslands.

\section{(b) Trade-offs between ecosystem services under different utilization patterns}

The results of trade-offs between ESs under different utilization patterns show the large spatial variation among the three study areas (Figure 7.1). In Hulun Buir, moderately used grasslands have the highest rank score. This indicates that the sum of total selected provision, regulating and supporting services is the highest. These grasslands are followed by non-use, lightly used and intensively used grasslands. In Xinlin Gol, lightly used and non-use grasslands also received the highest rank score, followed by the moderately use used grasslands and recovery sites. In Ordos, however, recovery sites have a higher rank score than lightly used grasslands. This differs from Xinlin Gol's scores.

Thus, aggregated results for ESs are analysed with reference to the five different utilization patterns of grazing (i.e. non-use, light use, moderate use, intensive use and recovery). My data suggests that conservation of grasslands (i.e. non-use and light use) should be encouraged because it delivers most ESs. Eigenbrod et al. (2010) also found that protected areas in England have high levels of biodiversity and carbon storage but only few recreation and agriculture services. Burkhard et al. (2012) correlated the European demand for ESs and different CORINE land-cover classes (http://ec.europa.eu/agriculture/publi/landscape/ about.htm) and found that habitat classes that were important for conservation (e.g. such as peat bogs and natural grassland), ranked high for their regulating services supply, but ranked low in their provisioning services supply.

Increasing herd densities have increased grassland utilization beyond its threshold of natural resilience, resulting in grassland degradation, the appearance of uncovered land surface, and a respective increase in soil erosion (Feng \& Zhao 2011, Li et al. 2011). To alleviate grassland degradation, my results also indicate that suitable grassland utilisation can be achieved by considering the different grassland types (e.g. meadow steppe, typical steppe and semi-desert steppe), thereby offering more effective ways to protect the grassland ecosystems. For instance, the meadow steppe has high resilience and tolerance to human activities, so a moderately use of these grasslands is appropriate in this region. In contrast, fragile ecosystems, such as the semi-desert steppe in Ordos, should be protected against anything more than light use.

I therefore conclude that light utilization of grasslands for exclusively livestock grazing had several positive effects on vegetation. This also includes improved environmental conditions by increasing primary production and supporting habitats. Soil-retention and nutrient-regulating services were improved after the recovery following prohibiting the use of grasslands by establishing fences. Nevertheless, longterm intensively used grasslands (over grazing) showed negative effects on all selected supporting and regulation services. 
Table 7.1 Scores for ranking ecosystem services in the study areas as a function of the grassland utilization patterns

\begin{tabular}{|c|c|c|c|c|c|c|c|c|c|c|c|c|}
\hline \multirow[b]{2}{*}{ ESs } & & \multicolumn{4}{|c|}{ Utilization patterns in Hulun Buir } & \multicolumn{4}{|c|}{ Utilization patterns in Xilin Gol } & \multicolumn{3}{|c|}{ Utilization patterns in Ordos } \\
\hline & & No use & Light use & $\begin{array}{l}\text { Moderate } \\
\text { use }\end{array}$ & $\begin{array}{l}\text { Intensive } \\
\text { use }\end{array}$ & No use & Light use & $\begin{array}{l}\text { Moderate } \\
\text { use }\end{array}$ & Recovery & No use & Light use & Recovery \\
\hline Provisioning & & 0 & 1.0 & 2.0 & 3.0 & 0 & 1.0 & 2.0 & 0 & 0 & 1.0 & 0 \\
\hline \multirow[t]{2}{*}{ Supporting } & Primary production & 3.5 & 2.5 & 3.0 & 1.0 & 3.5 & 3.5 & 2.0 & 1.0 & 3.0 & 2.0 & 1.0 \\
\hline & Habitat & 2 & 3.3 & 3.7 & 1.0 & 1.3 & 3.0 & 2.7 & 3.0 & 1.7 & 2.0 & 2.3 \\
\hline \multirow[t]{2}{*}{ Regulating } & Soil retention & 4.0 & 1.5 & 3.0 & 1.5 & 4.0 & 2.5 & 1.0 & 2.5 & 3.0 & 1.5 & 1.5 \\
\hline & Soil nutrients & 4 & 2.8 & 2.3 & 1.0 & 3.3 & 2.0 & 2.0 & 2.8 & 2.3 & 1.0 & 2.8 \\
\hline \multicolumn{2}{|c|}{ Sum of rank scores for all services } & 13.5 & 11.1 & 14.0 & 7.5 & 12.1 & 12.0 & 9.7 & 9.3 & 10 & 7.5 & 7.6 \\
\hline
\end{tabular}

Note: Values represent the rank score for each service for the amount of ecosystem services provided. The scores are based on the ranking of ecosystem services, and higher scores represent higher provision of services. The detail of the score refers to Chapter 5. 
7.2.6 What recommendations can be given to design feasible strategies and incentives for sustainable management of IMAR's grassland ecosystems (RQ 6)?

By combining household analysis (RQs 2, 3 and 4) and ecosystem-services analysis (RQ5), China's ecological restoration projects have brought mostly positive effects to the environment (e.g. water conservation and restoring ESs) and local participants (changed production and consumption activities). However, the current too-low payments will likely lead some herders to expand their grazing into restricted grassland or increase their number of animals (over grazing), particularly if the payment program ends (Box 7.3).

\section{Box 7.3 Herders' willingness to accept versus the public sector's willingness to pay for grassland restoration}

Based on results of interviews of households and government officials, household's income, willingness to accept (WTA) and the government officials' willingness to pay (WTP) for grassland conservation was quantified. Such quantification aims to reveal the factors that influenced their WTA or WTP preferences. The main ecological conservation projects that are implemented in IMAR, included the Sloping Land Conversion Project (SLCP) and the Grazing Prohibition Project (GPP). After implementing these projects, the areas of cultivated land and grazing land both decreased. As a result, herders' income from cultivation and animal husbandry decreased, although income from sheep increased under the GPP because the high compensation payment allowed herders to purchase enough fodder to maintain large herds. In contrast, income from government compensation payments and off-farm activities increased and became an important and stable income source for the herders.

Most of the herders want to continue the related payment for ecosystem services (PES) projects to improve grassland conditions and they were willing to accept PES to mitigate their economic losses. The average annual WTA of the herders was $625 \mathrm{CNY}$ $\mathrm{ha}^{-1}$, which is much higher than the maximum amount that they receive now (270 CNY ha ${ }^{-1}$ ). On the other hand, government officials acceptable an annual WTP of 528 $\mathrm{CNY}$ ha $^{-1}$ to the herders. Although this amount is much higher than the current annual payment of $270 \mathrm{CNY} \mathrm{ha}{ }^{-1}$, it is still less than the herders' desired WTA. The gap between the herders' desired WTA and the government's acceptable WTP is about 97 CNY ha ${ }^{-1}$ year $^{-1}$.

The results of my study reflect a gap between herders' desired WTA and government's acceptable WTP of $97 \mathrm{CNY}$ ha $^{-1}$ year $^{-1}$ (Box 7.3). This indicates the conflicting perspectives between government officials and herders. The government officials considered the PES from both economic and ecological perspectives, whereas the herders emphasized their income losses and basic cost of living. Thus, they related their compensation standard to their reliance on grasslands and their willingness to continue PES projects. Most of the herders and officials believed that China's central and provincial governments should take responsibility for the compensation payments and these payments should be paid in cash rather than in grain or training to obtain skills that would enhance their off-farm income or permit additional farm activities (e.g. the production of greenhouse vegetables). My findings have large implications for designing an operational PES scheme for my study area. The herders have clearly been experiencing economic losses from conservation activities, but, although they wanted to participate in conservation activities, they also expected sufficient compensation payments to mitigate their losses. Unfortunately, they want more 
money than the government is willing to provide and the gap between WTA and WTP, and the currently very low payments, likely lead some herders to expand grazing into restricted grasslands or increase their number of animals.

My study confirms Bennett's (2008) results that some participants probably resist the GPP and SLCP because they feel that they are not appropriately compensated to participate and have no incentives to continue participating if the payments end. This potentially jeopardizes the success of the GPP and SLCP. My results show that a suitable design of compensation mechanisms for ecological restoration is essential to encourage more sustainable use of grasslands. The PES approach has been applied increasingly in both developed and developing countries (Engel et al 2008; Zhen and Zhang 2011; Ren et al 2006; Wu et al 2012). However, little attention has been given to the people to compensate those affected by PES projects based on the actual changes in their livelihood caused by the project (in terms of their preferences, perceptions and WTA, a PES scheme for protecting grasslands and the public sector's WTP), to compensate those affected by PES projects based on the actual changes in their livelihood caused by the project. Further research on these PES complexities need to be encouraged.

\subsection{Discussion of research methods and comparison with literature}

My thesis most importantly aimed to integrative analyse the effects of conservation policies on the livelihood of the people in IMAR and the interactions with the grassland ecosystems. I especially focused on the different utilization patterns of ESs and the dependence of the livelihood of local herders and other stakeholders on these services. My thesis demonstrates a grassland management analysis that can be used to bridge the gap between ecological and socio-economic analysis.

\section{Integration of ecological and socio-economic research}

In previous research in IMAR, the use of ESs was primarily analysed from the perspective of engineering (management) science or natural science focusing on interactions with geophysical processes (Lichtfouse et al. 2010). My research has also integrated the socio-economic and ecological aspects of an ESs analysis to better restore grasslands because only such multidisciplinary research fully addresses the complexities of the land-use challenges and the human-nature interactions behind these complexities.

\section{Combination of field measurements and surveys}

To analyse trade-offs between different grassland ESs, I focused on the mechanisms of soil formation and vegetation dynamics that drive these trade-offs. In previous studies, most investigators used remotely sensed data, such as Net Primary Productivity (NPP) or NPP-based calculations of Soil Organic Carbon (SOC) (e.g. Erb et al. 2009; Haberl et al. 2007) to approximate these processes. 'Imperfect' proxies to estimate and quantify ESs (e.g. soil carbon stocks for climate regulation) are thus often relied upon and it limits the findings and their applicability. I used fieldsurvey data that are more realistic and closer to the actual 'on the ground' situation.

\section{Stakeholder participation}

I also emphasise the importance of stakeholder participation. I aimed to identify research gaps by contrasting local sustainability issues (i.e. needs and constraints). The primary focus was on the decision makers' side and mainly considered the administrative level to gather information from 'key players', who were responsible 
for decisions and its implementation (Xu 2004). I regarded the framework of my $\mathrm{PhD}$ research as specifically relevant for China since the state -and thus political decisionsstrongly affects land properties and land management even today. When including participatory aspects in a research approach, understanding the strengths and limitations of the stakeholder participation is essential (Reed et al. 2009). The role of stakeholders in Inner-Mongolian-grassland management has thus far been poorly discussed in international studies. Taylor (2006) indicated that the need to concentrate on the role of humans in grassland management. In his words: "grassland science should be partnered with sound local pastoral knowledge." Therefore, my research approach specifically addressed the nexus of regional to local in the household questionnaire and stakeholder workshops. I thus involved stakeholders at multiple levels (e.g. grassland management officials and village headmen) and reflected on the local interests and needs. Based on my transdisciplinary methodology the selected stakeholders group enabled me to obtain a 'good picture' of specific regions in IMAR. This picture helped to identify the relevant social-ecological problems and to better understand important regional sustainability constraints. My results are a starting point to better understand the science-policy-interface between local needs and internationally relevant results. My research framework can probably be transferred to other regions in Inner Mongolia and to other grassland regions in the world.

\section{Limitations and weaknesses}

Due to my limited time and financial budget, my research also has some limitations and weaknesses. For instance, 1) my ESs analysis excluded cultural services. However, some studies show that, for example, ecotourism can have positive effects on local livelihoods (e.g. König et al. 2015; Dou et al. 2016). Inner Mongolia probably has high potential for ecotourism or cultural tourism. This will most likely increase in the future as the result of growing Chinese incomes; 2) Primary information on food consumption was collected through my household survey. Although to increase the sampling's randomness and reduce the selection bias, I interviewed key informants, who were familiar with the situation in each village and who had conducted annual socioeconomic surveys to identify the criteria for the village selection within each county. Household sampling is difficult to do without introducing some form of selection bias when the sampling is not strictly random (Jill et al. 1996, Hashimoto et al. 2005); 3). My field survey was conducted from 2011 to 2015 and provided ample data. However, greater accuracy and confidence in the evidence could be achieved by including more field-survey data (from different areas) and involving more stakeholders in the assessment. To quote de Groot et al. (2010) "Empirical information on the quantitative relationship between land use and ecosystem management and the provision of ESs at local and regional scales, however, is still scarce." My study partly fills this gap for IMAR.

\subsection{Synthesis and management recommendations}

\section{(a) Changes in land-covers due to the Restoration program}

Approximately half of IMAR's grassland area has suffered degradation due to overgrazing during the past three decades (Zhang et al. 2013). Comparing remote sensing data (from 1995, 2000, 2005 and 2010) and statistical data (Inner Mongolia Statistics Bureau 2015b), I estimate that $70 \%$ of the grasslands in Inner Mongolia suffers from overgrazing to varying degrees. This strongly alters the local social-economic structure (livelihood of indigenous communities) and grassland ecosystem functioning. My results show that grassland ecosystems are the basic natural resource 
in the Inner Mongolia Autonomous Region, but are becoming increasingly sensitive to human intervention. Suitable use of grasslands is an effective way to reduce deterioration of these fragile ecosystems.

\section{(b) Effects on livelihoods}

The present grassland-conservation policy has led to adaptive changes in basic household-consumption patterns of food, fuel and water, and their spatial distribution by grassland types (i.e. meadow steppe, typical steppe and semi-desert steppe) in IMAR. From 1995 to 2010, people increasingly switched diet from high meat consumption to agricultural crops (e.g. staple foods, vegetables and fruits) in all three surveyed grassland types. Fuel consumption patterns changed from being dominated by bio-fuels (dung) to being dominated mainly by electricity and gas. However, biofuel remains a major energy source for daily life in the meadow-steppe ecosystems. Due to its geographic location in arid and semi-arid areas, IMAR faces growing pressures on limited water resources. Fortunately, the changed household food consumption pattern helped to decrease water consumption, both direct water use and indirect water use.

The grassland conservation policy also affected the household dependence on local grasslands. My findings show that affected households changed the use of their land and this resulted in a fundamental transformation of their lifestyles: their farming and grazing activities and consumption behaviours have changed. Most households developed adaptation measures (e.g. seeking off-farm work, leasing pasture land, increasing purchases of fodder for stall-fed animals and altering their diet and fuel consumption) to compensate for the lower dependence on local grasslands.

\section{(c) Effects on ecosystem services}

My thesis research revealed that, as increasing numbers of residents abandon the grasslands, few remain to use or manage the grasslands in the future. Since the grasslands have coevolved with nomadic herders for millennia, this could lead to considerable negative ecological effects. Although grasslands are likely to recover in response to reduced human pressure, I found that light use generally provided higher levels of ESs than intensive use and no-use in the meadow steppe and typical steppe, with the main differences in habitat and supporting ESs. Surprisingly, I found no consistently positive effects of strict conservation activities across the sites because the results varied spatially and with respect to differences in the land-use patterns.

\section{(d) Management recommendations}

To improve grassland management, my study suggests that appropriate grasslandutilization patterns can enhance the supply of ESs and reduce negative effects on both people's livelihoods and the environment. Appropriate grassland-utilization patterns depend on many factors, such as geographic location (grassland types, access ability), economic development (purchasing ability) and traditional culture. To encourage community-based grassland management, implementing agencies need to be more aware of these alternative options and have the willingness and capacity to adopt a flexible and participatory approach to grassland policy implementation.

The design of suitable financial compensation mechanisms could encourage more efficient use of grasslands. My results show that the present grassland conservation policy has decreased the trend of grasslands degradation but a key challenge now is to sustain the livelihood of local residents, who earn most of their income from traditional animal husbandry. The herders were most concerned about their economic 
loss, whereas the government considered both grassland restoration and income protection to be important. To create an improved and sustainable PES scheme, I recommend to increase the amount of PES that will let the herders sustain their livelihoods, while conserving the grasslands.

The focus of land management should shift from solely agricultural production to include a broader range of ecological and environmental objectives. Beneficial changes in integrated grassland management resulted thus far from more extensive management, but at the cost of reduction in total animal output and, in some cases, a reduction in individual animal performance.

To achieve many of these changes is clearly a long-term process and this must be recognized by policy makers. Future grassland management should focus more on policy instruments (e.g. PES, grassland laws and legislation), other livestock systems and technologies (grassland utilization patterns by changing feed and breeding systems), new institutional arrangements (tenure and administration), new production and marketing structures, better prices and marketing, and social aspects (education and poverty alleviation), rather than single purpose measures of grazing prohibition, migration and resettlement.

\subsection{Future research directions}

Firstly, future research should address how to manage potential conflicts that arise from intensified use of IMAR's grasslands and related household sustainability, while simultaneously protecting grassland biodiversity and ESs. Appropriate grasslandutilization patterns and suitable design of ecological and financial compensation mechanisms can enhance the supply of ESs and reduce environmental and livelihood impacts. Thus, more integrated research at household level is needed to develop and implement appropriate ecological compensation mechanisms.

Secondly, future studies should focus on longer-term in-situ observations to better understand ecological restoration processes. To develop better science-based grassland restoration strategies, ecological research on the policy effects on grassland plant diversity, soil seed banks and other ecological processes should be strengthened, by means of combined method of plot survey and remote sensing monitoring. The timing of excluding grazing under different degrees of grassland degradation and grassland adaptability or resilience to climate change, including extreme weather and climate events, should be studied. Finding ways to scientifically assess the necessary key factors (e.g. soil, climate, management and their interactions) that determine the dynamics of ecosystems and their ESs, help the development of better management plans.

Thirdly, I only included five ESs in my study. Although my conclusions are robust for these ESs and they can probably extrapolated to other services, more complete or robust conclusions on the overall effects of different land-utilization patterns on ES trade-offs and synergies, future studies should include the full suite of cultural, provisioning, regulation and supporting services.

Finally, methods, such as difference in indicator selection for an ESs assessment or household analysis and their sensitivity tests should be applied to identify or account for possible hidden biases that are caused by currently ignored factors. An example is the sampling bias on household consumption and ES use, which can be reduced by adding more surveys at the village level (e.g. to select all households in a village or obtain a more robust random sample). 
My research demonstrates that an integrated approach, combining field measurements and household surveys can assess ESs trade-offs and synergies in a practical way across a diverse range of ecosystem types, management regimes and grasslandutilization patterns. This is of particular benefit to evaluate national or regional conservation policies and provide evidence to support policy decisions. My research identified several relevant social-ecological problems in IMAR and helped to better understand important regional sustainability constraints. My results could serve as a model to better understand the effects of policies on local communities' livelihoods and the interactions with their environment in grassland ecosystems. 
APPENDIXES 
Appendix 1: Implementation Measures of the Returning Grazing Land to Grassland Program

\begin{tabular}{|c|c|c|}
\hline Year & Major Measures & Details \\
\hline \multirow[t]{4}{*}{2003} & $\begin{array}{l}\text { Improve the household } \\
\text { responsibility system. }\end{array}$ & $\begin{array}{l}\text { Divide grazing land with individual household as the basic } \\
\text { unit of grazing land management, issue grassland use right } \\
\text { licenses to herders who participate in the program and } \\
\text { define their rights and obligations. }\end{array}$ \\
\hline & $\begin{array}{l}\text { Determine livestock numbers } \\
\text { based on the area of grassland } \\
\text { and control stocking rates. }\end{array}$ & $\begin{array}{l}\text { Control the No. of livestock grazing on areas where grazing } \\
\text { is banned temporarily or rotational according pasture's } \\
\text { carrying capacity, to prevent overgrazing and achieve the } \\
\text { grassland-livestock balance. }\end{array}$ \\
\hline & $\begin{array}{l}\text { The program is a joint effort of } \\
\text { the central government, local } \\
\text { governments and individual } \\
\text { farmers and herders, and } \\
\text { government subsidies for the } \\
\text { program include a cash } \\
\text { subsidy and a subsidy in the } \\
\text { form of forage. Provincial } \\
\text { governments may adjust the } \\
\text { amount of subsidies according } \\
\text { to the actual situation as long } \\
\text { as it is within the specified } \\
\text { total amount of government } \\
\text { subsidies. }\end{array}$ & 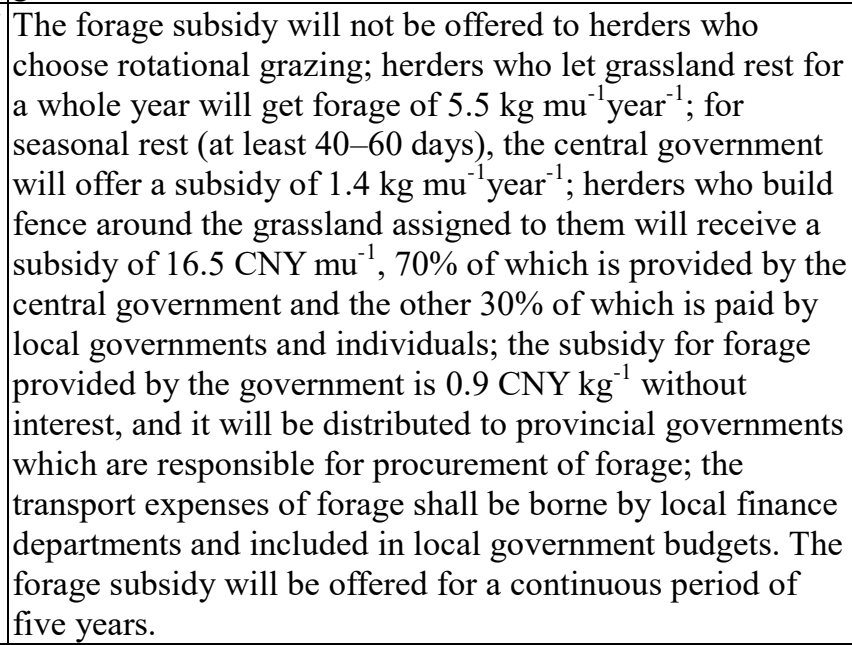 \\
\hline & $\begin{array}{l}\text { Provincial governments have } \\
\text { the full responsibility for } \\
\text { management of the grassland } \\
\text { restoration program. }\end{array}$ & $\begin{array}{l}\text { The central government will assign tasks, allocate funds and } \\
\text { distribute forage to provincial governments. Provinces } \\
\text { (IMAR) shall then assign tasks and allocate funds to } \\
\text { governments at municipal, county (banner) and township } \\
\text { levels and build accountability in local governments. }\end{array}$ \\
\hline \multirow[t]{3}{*}{2011} & $\begin{array}{l}\text { Rationally plan the layout of } \\
\text { grassland fence. }\end{array}$ & $\begin{array}{l}\text { Put the construction of fence for rotational grazing and } \\
\text { seasonal rest at top of the program agenda. Expand the } \\
\text { scope of grassland management in Karst areas. }\end{array}$ \\
\hline & $\begin{array}{l}\text { Build covered livestock pens } \\
\text { and stables and cultivate } \\
\text { artificial grassland. }\end{array}$ & $\begin{array}{l}\text { Build an } 80 \mathrm{~m}^{2} \text { livestock pen for each participating } \\
\text { household that does not have one. Plant grass in areas } \\
\text { (within the implementation scope of the program) which } \\
\text { have stable surface water sources to solve feed shortages. }\end{array}$ \\
\hline & $\begin{array}{l}\text { Increase the proportion of } \\
\text { investment and subsidy } \\
\text { standards of the central } \\
\text { government. }\end{array}$ & $\begin{array}{l}\text { The proportion of the central investment subsidy for fence } \\
\text { construction is raised from } 70 \% \text { to } 80 \% \text { and accordingly the } \\
\text { proportion of the fence construction subsidy from local } \\
\text { governments is lowered from } 30 \% \text { to } 20 \% \text {. For fence } \\
\text { constructions in IMAR, the subsidy that is offered by the } \\
\text { central government, is raised from } 14 \text { to } 16 \mathrm{CNY} \mathrm{mu}^{-1} \text {. The } \\
\text { seedling subsidy for grassland restoration from the central } \\
\text { government is raised from } 10 \text { to } 20 \mathrm{CNY} \mathrm{mu}{ }^{-1} \text {. The subsidy } \\
\text { for artificial grassland construction from the central } \\
\text { government is } 160 \mathrm{CNY} \mathrm{mu}^{-1} \text { and the central government } \\
\text { subsidy for livestock pen construction is } 3000 \mathrm{CNY} \text { per } \\
\text { household. }\end{array}$ \\
\hline
\end{tabular}


Appendix 2: Coupled human-ecosystem interaction: a conceptual framework (Based on Zhen et al. 2011b)

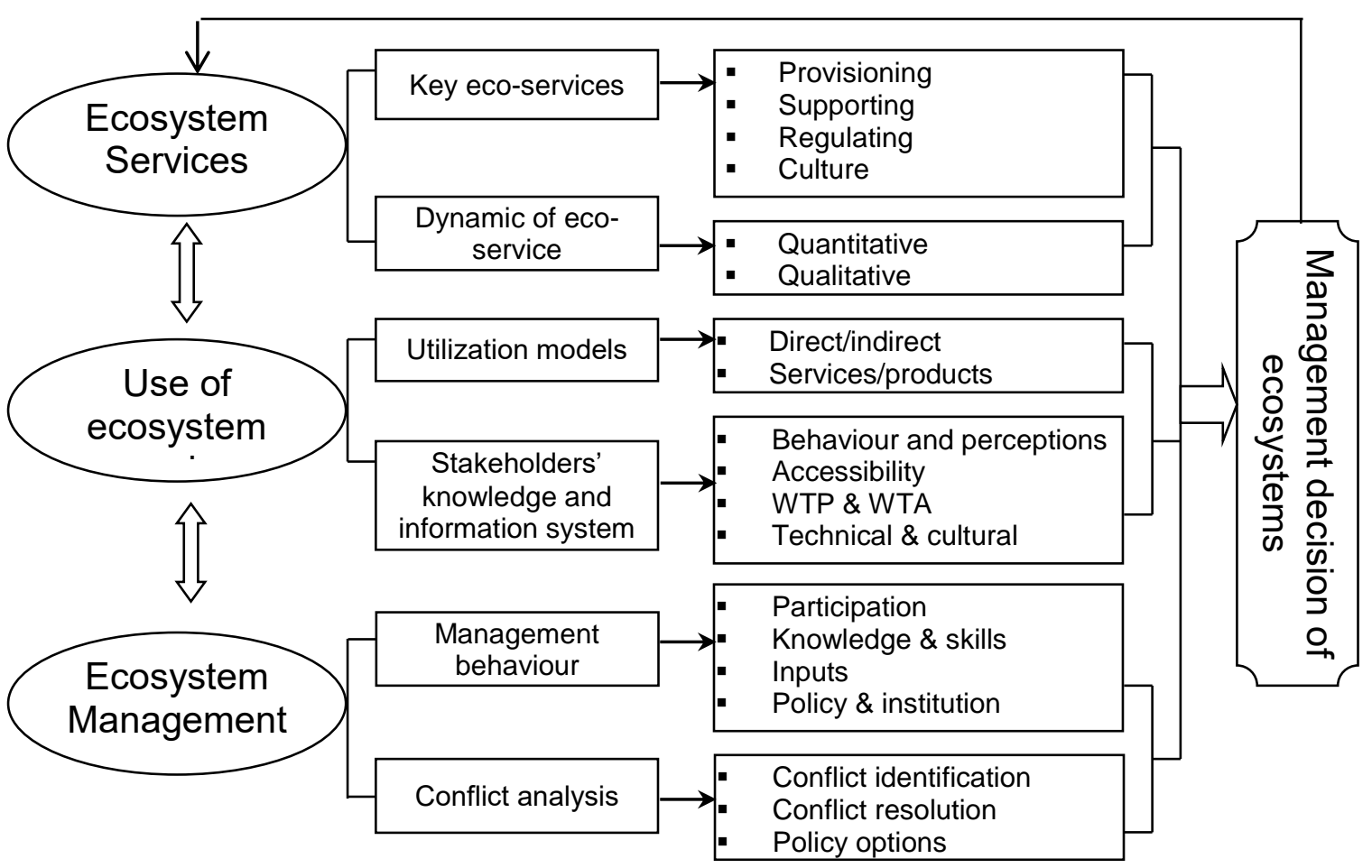


Appendix 3a: The human-ecological system in the Inner Mongolia Autonomous Region in 1950s

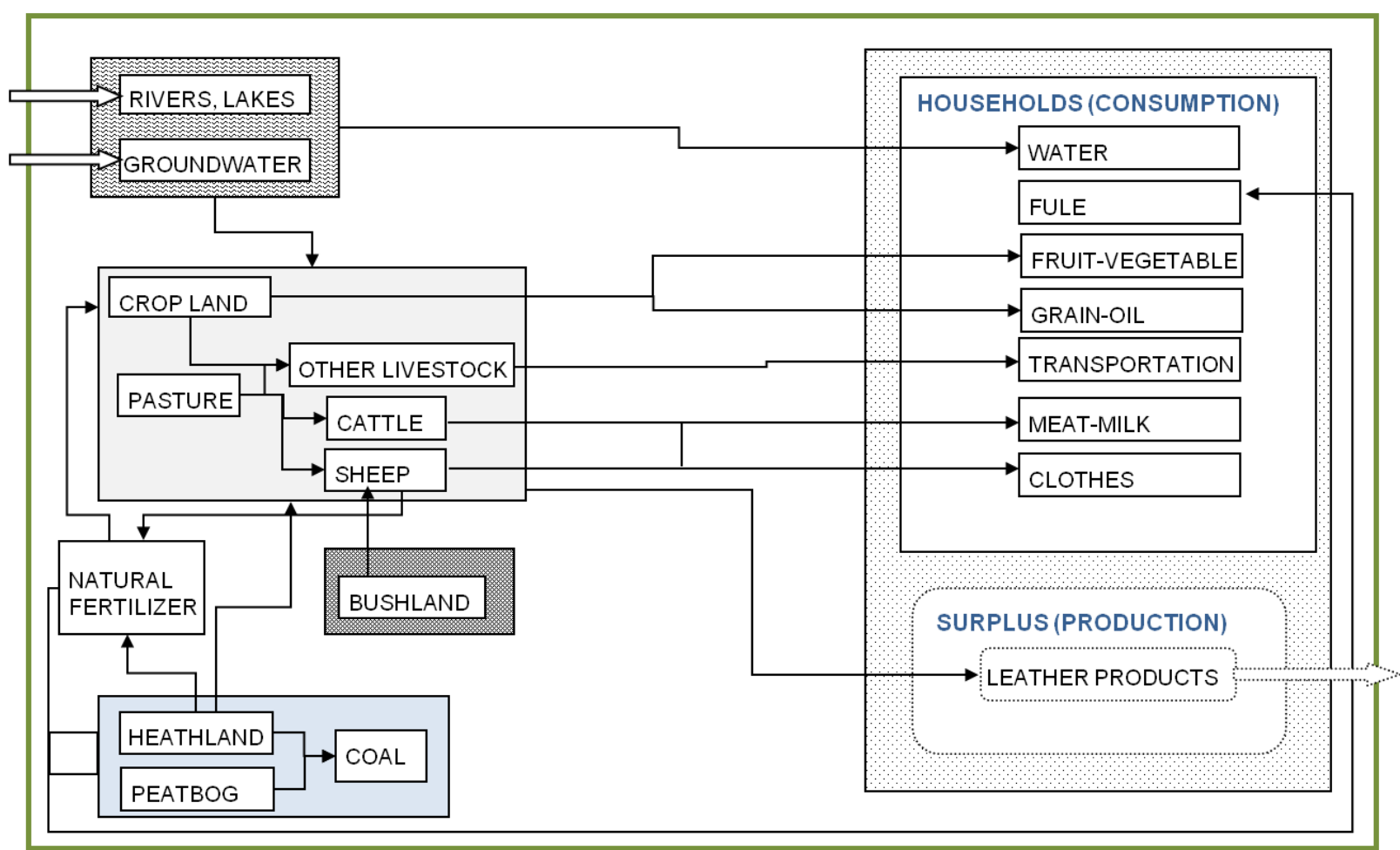

Note: Green line is the boundary line of local social-ecological system. 
Appendix 3b: The human-ecological system of the Inner Mongolia Autonomous Region in 1995

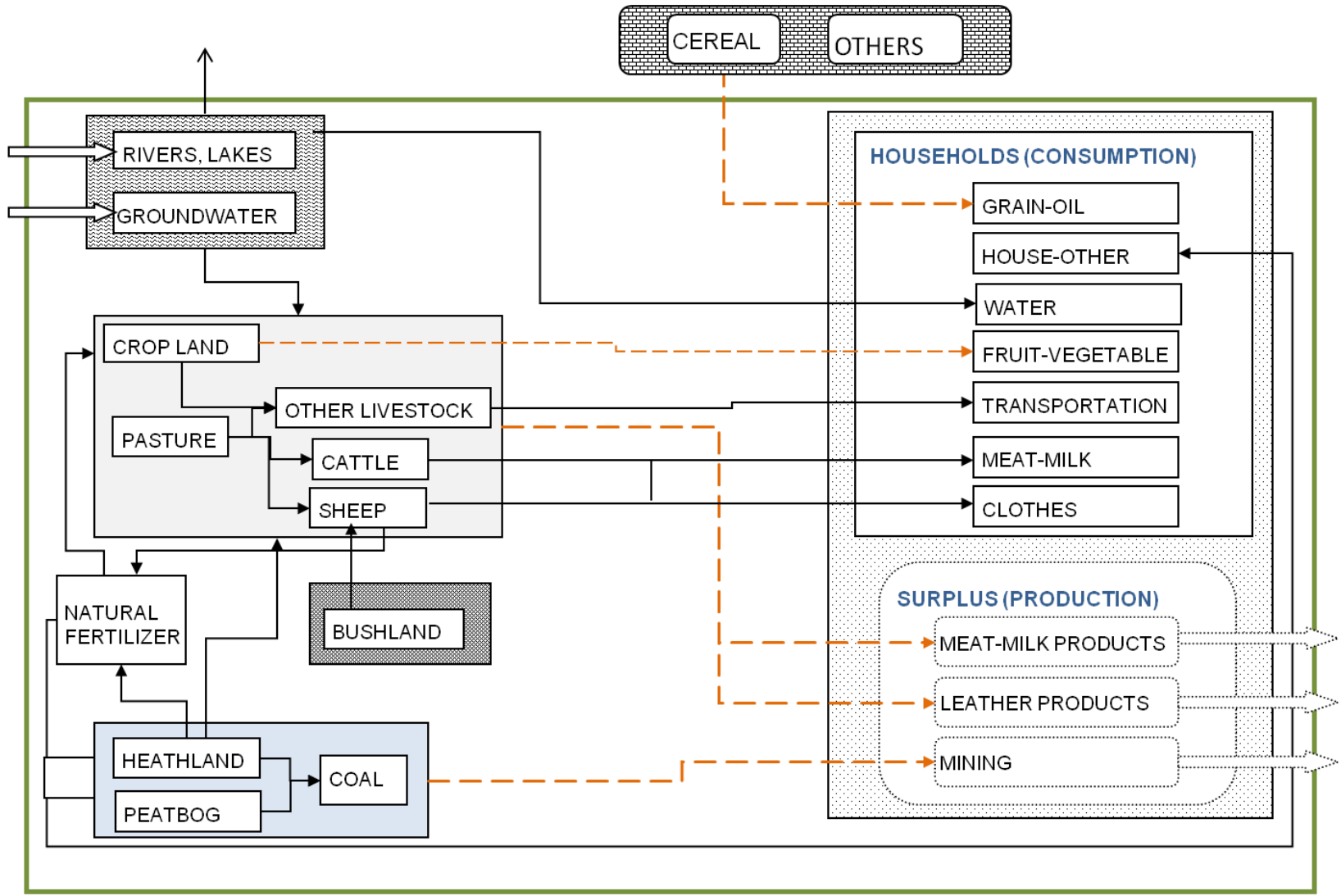

Note: Green line is the boundary line of local social-ecological system; The orange dashed line means the amount of each item has increased comparing to $1950 \mathrm{~s}$. 
Appendix 3c: The human-ecological system of the Inner Mongolia Autonomous Region in 2010

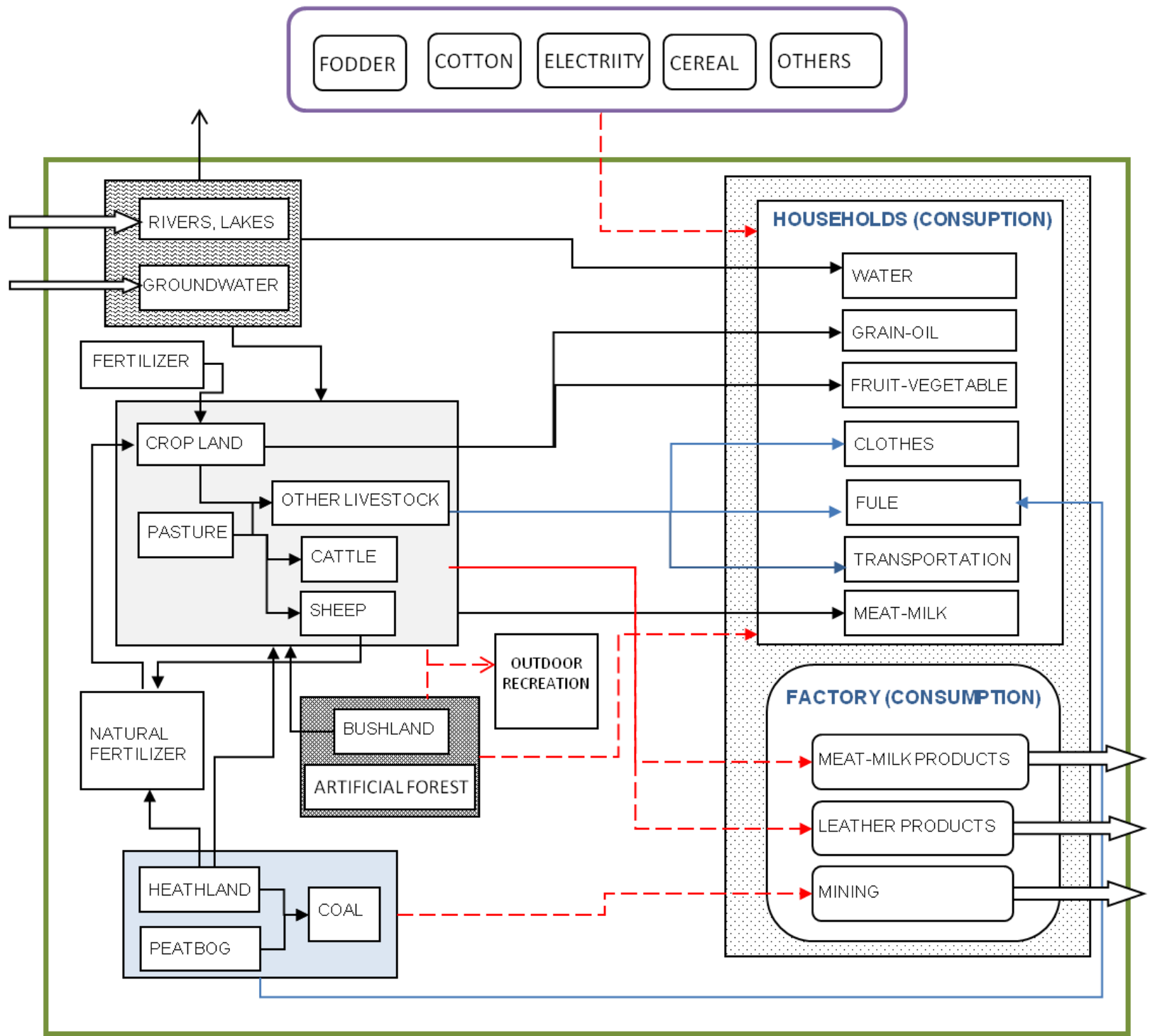

Note: Green line is the boundary line of local social-ecological system;

The red dashed line means the amount of each item has greatly increased; and The blue line means $s$ the amount of each item has sharply decreased comparing to 1995. 


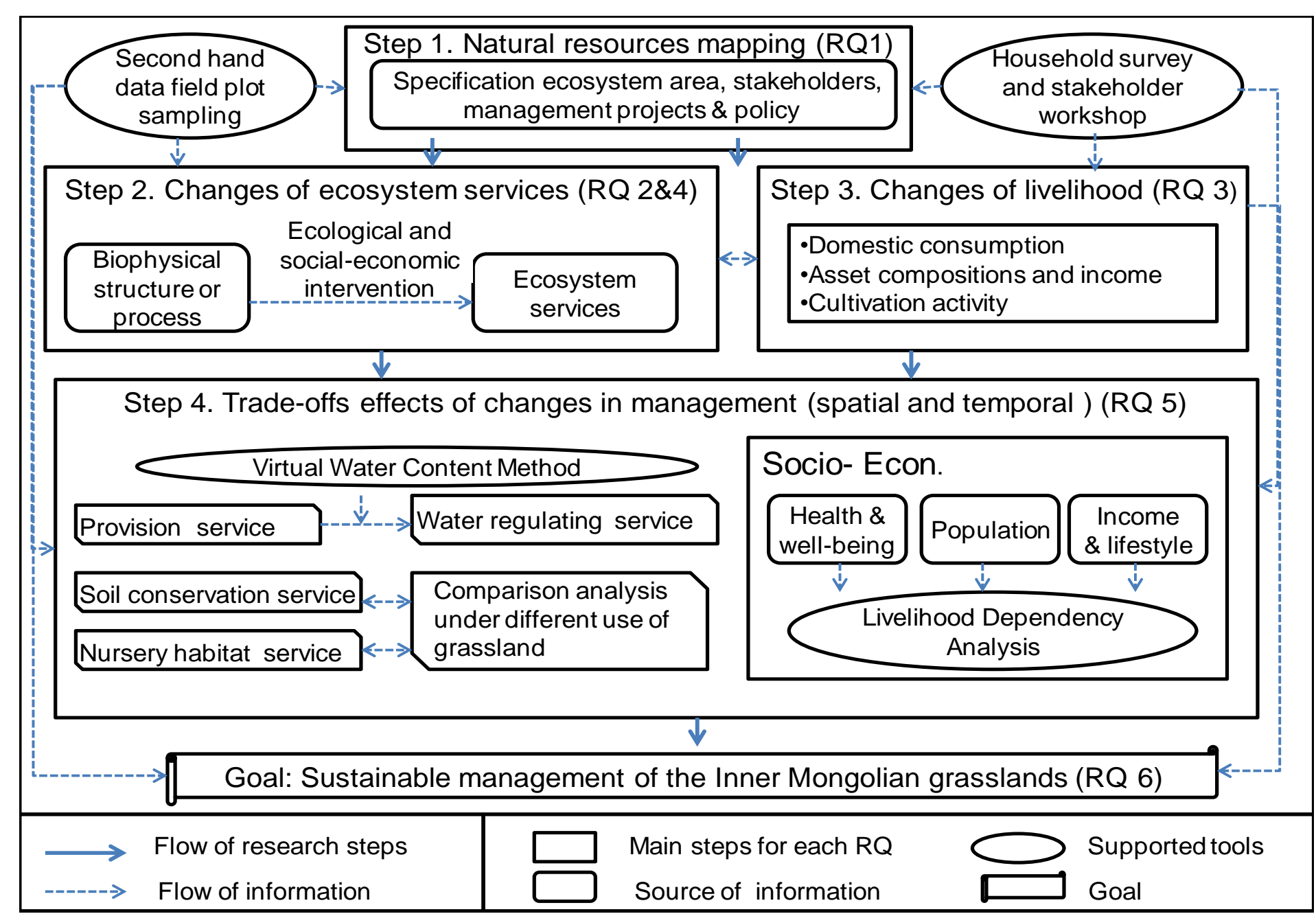


Appendix 5: Questionnaire for household investigation - grasslands' use-patterns at the community level

\section{No. of questionnaire:}

Date:

Y GPS coordinates:

E

Elevation

\section{Household investigation on grasslands' use-patterns at the community level}

Address: League City Banner (county) Township (Sumu) Village (Community) Name of respondent Tel.

1. Basic information

1.1 HOUSEHOLD INFORMATION

\begin{tabular}{|c|c|c|c|c|c|c|}
\hline & Gender & Age & Ethnic group & Education level & Main occupation & \multirow{9}{*}{$\begin{array}{l}\text { Please indicate where your family lives now: } \\
\text { Distance to highway } \begin{array}{l}\text { Distance to center of banner } \\
\text { How long do you live? }\end{array} \\
>\quad \text { If less than } 15 \text { years, where did you move } \\
\text { from? }\end{array}$} \\
\hline Respondent & & & & & & \\
\hline \multirow{2}{*}{\multicolumn{6}{|c|}{ Adults }} & \\
\hline & & & & & & \\
\hline & & & & & & \\
\hline \multirow{2}{*}{\multicolumn{6}{|c|}{ Children }} & \\
\hline & & & & & & \\
\hline & & & & & & \\
\hline Note: & $\begin{array}{c}\text { 1-Male } \\
\text { 2-Female }\end{array}$ & & $\begin{array}{l}\text { 1-Han, 2-Mongolian, 3-Hui, } \\
\text { 4-Manchu and 5-Other } \\
\text { (Oroqen/Daur/Ewenki/Xibo) }\end{array}$ & $\begin{array}{l}\text { 1-None, 2-Preliminary school } \\
\text { (number of years), 3-Middle } \\
\text { school, 4-High school, 5-College, } \\
\text { 6-university and above }\end{array}$ & $\begin{array}{l}\text { 1-Famer, 2-Herder, 3- Enterprise, 4- Service } \\
\text { Industry (Medical and Health, Catering, } \\
\text { Government, Organization, etc.), 5-Student, 6- } \\
\text { part time job in outside, 7-Others }\end{array}$ & \\
\hline
\end{tabular}

\subsection{LAND USE CHANGE}

\begin{tabular}{|c|c|c|c|c|}
\hline & \multirow[t]{2}{*}{ Type of vegetation } & $\begin{array}{c}\text { Current } \\
\text { (after 2010) }\end{array}$ & $\begin{array}{c}\text { Before } \\
\text { (before1995) }\end{array}$ & \multirow{2}{*}{$\begin{array}{l}\text { Distance to } \\
\text { house }(\mathrm{km})\end{array}$} \\
\hline & & Area(mu) & Area(mu) & \\
\hline \multicolumn{2}{|c|}{ Arable land } & & & \\
\hline \multirow{6}{*}{$\begin{array}{l}\frac{n}{0} \\
\frac{\pi}{\pi} \\
\tilde{n} \\
\frac{\pi}{0} \\
0\end{array}$} & Total & & & \\
\hline & Seasonal grazing & & & \\
\hline & Grazing prohibition & & & \\
\hline & Rotational grazing & & & \\
\hline & $\begin{array}{r}\text { Reconvert grain-land } \\
\text { to grasslands }\end{array}$ & & & \\
\hline & Mow grasslands & & & \\
\hline \multicolumn{2}{|c|}{ Forest } & & & \\
\hline \multicolumn{2}{|c|}{ Mining } & & & \\
\hline \multicolumn{2}{|c|}{ Others: } & & & \\
\hline
\end{tabular}

\section{Household income and expenditure}

\begin{tabular}{|l|l|l|l|l|l|l|}
\hline \multirow{2}{*}{$\begin{array}{l}\text { Types } \\
\text { CNY/Yr) }\end{array}$} & \multicolumn{3}{|c|}{ Current (after 2010) } & \multicolumn{3}{|c|}{ Before (before1995) } \\
\cline { 2 - 6 } & Income & Expenditure & $\begin{array}{c}\text { Net } \\
\text { income }\end{array}$ & Income & Expenditure & $\begin{array}{c}\text { Net } \\
\text { income }\end{array}$ \\
\hline Crop production & & & & & & \\
\hline Livestock & & & & & & \\
\hline $\begin{array}{l}\text { Compensation, } \\
\text { subside }\end{array}$ & & & & & \\
\hline Self-employ & & & & & \\
\hline Employ (job) & & & & & \\
\hline Others: & & & & & & \\
\end{tabular}


3. Information on agricultural activities

3.1 CROP

\begin{tabular}{|c|c|c|c|c|c|c|c|c|c|c|c|c|}
\hline \multirow{3}{*}{ Types of crop } & \multicolumn{6}{|c|}{ Current (after 2010) } & \multicolumn{6}{|c|}{ Before (before1995) } \\
\hline & \multirow{2}{*}{$\begin{array}{l}\text { Area } \\
(\mathrm{mu})\end{array}$} & \multirow{2}{*}{$\begin{array}{l}\text { Total Yield } \\
(\mathrm{kg} / \mathrm{yr})\end{array}$} & \multirow{2}{*}{$\begin{array}{l}\text { For self-consume } \\
\qquad(\mathrm{kg} / \mathrm{yr})\end{array}$} & \multicolumn{3}{|c|}{ For sell } & \multirow{2}{*}{$\begin{array}{l}\text { Area } \\
(\mathrm{mu})\end{array}$} & \multirow{2}{*}{$\begin{array}{c}\text { Total Yield } \\
\text { (kg/yr) }\end{array}$} & \multirow{2}{*}{$\begin{array}{l}\text { For self-consume } \\
\qquad(\mathrm{kg} / \mathrm{yr})\end{array}$} & \multicolumn{3}{|c|}{ For sell } \\
\hline & & & & $\begin{array}{l}\text { Amount } \\
(\mathrm{kg} / \mathrm{yr})\end{array}$ & Place & $\begin{array}{l}\text { Distance } \\
(\mathrm{km})\end{array}$ & & & & $\begin{array}{l}\text { Amount } \\
(\mathrm{kg} / \mathrm{yr})\end{array}$ & Place & $\begin{array}{l}\text { Distance } \\
(\mathrm{km})\end{array}$ \\
\hline \multicolumn{13}{|l|}{ Spring wheat } \\
\hline \multicolumn{13}{|l|}{ Maize } \\
\hline \multicolumn{13}{|l|}{ Rice } \\
\hline \multicolumn{13}{|l|}{ Glutinous millet } \\
\hline \multicolumn{13}{|l|}{ Potato } \\
\hline \multicolumn{13}{|l|}{ Beans } \\
\hline \multicolumn{13}{|l|}{ Vegetable } \\
\hline \multicolumn{13}{|l|}{ Fruit } \\
\hline \multicolumn{13}{|l|}{ Oil } \\
\hline \multicolumn{13}{|l|}{ Forage grass } \\
\hline Other: & & & & & & & & & & & & \\
\hline
\end{tabular}

Note: Reasons (1)Self- consume (2)Sell

Place for sell (1)Market in Gacha (Village) (2)Market in Sumu (Town) (3)Market in Banner (county) (4)Market in city or League (5) Outside of League (6)Sell to merchant 


\subsection{LIVESTOCK}

\begin{tabular}{|c|c|c|c|c|c|c|c|c|c|c|c|c|c|c|}
\hline \multirow{3}{*}{$\begin{array}{c}\text { Type of } \\
\text { livestock }\end{array}$} & \multicolumn{7}{|c|}{ Current (after 2010) } & \multicolumn{7}{|c|}{ Before (before1995) } \\
\hline & \multicolumn{2}{|c|}{ No. } & \multirow{2}{*}{$\begin{array}{l}\text { Ways of } \\
\text { breeding }\end{array}$} & \multirow{2}{*}{$\begin{array}{l}\text { No. of death } \\
\text { (accidental death } \\
\text { or missing) }\end{array}$} & \multicolumn{3}{|c|}{ For sell } & \multicolumn{2}{|c|}{ No. } & \multirow{2}{*}{$\begin{array}{l}\text { Ways of } \\
\text { breeding }\end{array}$} & \multirow{2}{*}{$\begin{array}{l}\text { No. of death } \\
\text { (accidental death } \\
\text { or missing) }\end{array}$} & \multicolumn{3}{|c|}{ For sell } \\
\hline & In Jul. & In Jan. & & & adults & Young & $\begin{array}{l}\text { Place } \\
\text { for sell }\end{array}$ & In Jul. & In Jan. & & & adults & Young & $\begin{array}{l}\text { Place } \\
\text { for sell }\end{array}$ \\
\hline \multicolumn{15}{|l|}{ Sheep } \\
\hline \multicolumn{15}{|l|}{ Goat } \\
\hline \multicolumn{15}{|l|}{ Cattle } \\
\hline \multicolumn{15}{|l|}{ Horse } \\
\hline \multicolumn{15}{|l|}{ Mules/asses } \\
\hline \multicolumn{15}{|l|}{ Pig } \\
\hline \multicolumn{15}{|l|}{ Chicken } \\
\hline \multicolumn{15}{|l|}{ Camel } \\
\hline Others & & & & & & & & & & & & & & \\
\hline
\end{tabular}

Note: Ways of breeding (1)Free grazing (2)Stable breeding in pens (3)Both, Please indicate the grazing period, from__(month)to__(month);

Place for sell (1)Market in Gacha (Village) (2)Market in Sumu (Town) (3)Market in Banner (county) (4)Market in city or League (5) Outside of League (6)sell to merchant

\section{Household consumption}

4.1 WATER CONSUMPTION

\begin{tabular}{|c|c|c|c|c|c|c|c|c|c|c|c|c|c|c|c|c|}
\hline \multirow{3}{*}{ A barrel $=\ldots$ $\mathrm{kg}$} & \multicolumn{8}{|c|}{ Current (after 2010) } & \multicolumn{8}{|c|}{ Before (before1995) } \\
\hline & \multicolumn{2}{|c|}{ Amount } & \multicolumn{2}{|c|}{$\begin{array}{l}\text { Water } \\
\text { source }\end{array}$} & \multicolumn{2}{|c|}{$\begin{array}{l}\text { Distance to } \\
\text { house }(\mathrm{km})\end{array}$} & \multicolumn{2}{|c|}{$\begin{array}{c}\text { Methods to } \\
\text { access }\end{array}$} & \multicolumn{2}{|c|}{ Amount } & \multicolumn{2}{|c|}{$\begin{array}{l}\text { Water } \\
\text { source }\end{array}$} & \multicolumn{2}{|c|}{$\begin{array}{l}\text { Distance to } \\
\text { house }(\mathrm{km})\end{array}$} & \multicolumn{2}{|c|}{$\begin{array}{c}\text { Methods to } \\
\text { access }\end{array}$} \\
\hline & 1 & 2 & 1 & 2 & 1 & 2 & 1 & 2 & 1 & 2 & 1 & 2 & 1 & 2 & 1 & 2 \\
\hline \multicolumn{17}{|l|}{ Domestic water (barrel/day) } \\
\hline \multicolumn{17}{|l|}{ Livestock (barrel/day) } \\
\hline \multicolumn{17}{|l|}{ Irrigation $\left(\mathrm{m}^{3} / \mathrm{yr}\right)$} \\
\hline Others & & & & & & & & & & & & & & & & \\
\hline
\end{tabular}

Note: Water source (1)Tap (2)Well (3)River (4)Cistern (rain) (5)Other

Methods to access (1) Walk (2) Bicycle (3)Motorcycle (4) Pull cart (5) Canal (6) Others 
4.2 FOOD CONSUMPTION

\begin{tabular}{|c|c|c|c|c|c|c|c|c|}
\hline \multirow{3}{*}{ Food types } & \multicolumn{4}{|c|}{ Current (after 2010) } & \multicolumn{4}{|c|}{ Before (before1995) } \\
\hline & \multirow{2}{*}{$\begin{array}{l}\text { Total amount } \\
(\mathrm{Kg} / \mathrm{yr})\end{array}$} & \multirow{2}{*}{$\begin{array}{l}\text { Self-produced } \\
\quad(\mathrm{Kg} / \mathrm{yr})\end{array}$} & \multicolumn{2}{|c|}{ Purchased } & \multirow{2}{*}{$\begin{array}{l}\text { Total amount } \\
(\mathrm{Kg} / \mathrm{yr})\end{array}$} & \multirow{2}{*}{$\begin{array}{l}\text { Self-produced } \\
\qquad(\mathrm{Kg} / \mathrm{yr})\end{array}$} & \multicolumn{2}{|c|}{ Purchased } \\
\hline & & & Amount (Kg/yr) & $\begin{array}{c}\text { Place of } \\
\text { Origin }\end{array}$ & & & Amount $(\mathrm{Kg} / \mathrm{yr})$ & Place of Origin \\
\hline \multicolumn{9}{|l|}{ Flour } \\
\hline \multicolumn{9}{|l|}{ Rice } \\
\hline \multicolumn{9}{|l|}{ Potato } \\
\hline \multicolumn{9}{|l|}{ Glutinous millet } \\
\hline \multicolumn{9}{|l|}{ Bean products } \\
\hline \multicolumn{9}{|l|}{ Vegetables } \\
\hline \multicolumn{9}{|l|}{ Fruits } \\
\hline \multicolumn{9}{|l|}{ Mutton } \\
\hline \multicolumn{9}{|l|}{ Beef } \\
\hline \multicolumn{9}{|l|}{ Pork } \\
\hline \multicolumn{9}{|l|}{ Chicken } \\
\hline \multicolumn{9}{|l|}{ Fish } \\
\hline \multicolumn{9}{|l|}{ Oil products } \\
\hline \multicolumn{9}{|l|}{ Milk } \\
\hline Eggs & & & & & & & & \\
\hline Others: & & & & & & & & \\
\hline
\end{tabular}




\subsection{FORAGE CONSUMPTION}

\begin{tabular}{|c|c|c|c|c|c|c|c|c|c|c|c|c|}
\hline \multirow{3}{*}{$\begin{array}{l}\text { Type of } \\
\text { livestock }\end{array}$} & \multicolumn{6}{|c|}{ Current (after 2010) } & \multicolumn{6}{|c|}{ Before (before1995) } \\
\hline & \multirow{2}{*}{$\begin{array}{c}\text { Total } \\
\text { amount } \\
(\mathrm{Kg} / \mathrm{yr})\end{array}$} & \multicolumn{2}{|c|}{ Purchased } & \multirow{2}{*}{$\begin{array}{l}\text { Total } \\
\text { amount } \\
(\mathrm{Kg} / \mathrm{yr})\end{array}$} & \multicolumn{2}{|c|}{ Purchased } & \multirow{2}{*}{$\begin{array}{c}\text { Total } \\
\text { amount } \\
(\mathrm{Kg} / \mathrm{yr})\end{array}$} & \multicolumn{2}{|c|}{ Purchased } & \multirow{2}{*}{$\begin{array}{c}\text { Total } \\
\text { amount } \\
(\mathrm{Kg} / \mathrm{yr})\end{array}$} & \multicolumn{2}{|c|}{ Purchased } \\
\hline & & $\begin{array}{c}\text { Amount } \\
(\mathrm{Kg} / \mathrm{yr})\end{array}$ & $\begin{array}{l}\text { Place of } \\
\text { Origin }\end{array}$ & & $\begin{array}{c}\text { Amount } \\
(\mathrm{Kg} / \mathrm{yr})\end{array}$ & $\begin{array}{l}\text { Place of } \\
\text { Origin }\end{array}$ & & Amount & $\begin{array}{l}\text { Place of } \\
\text { Origin }\end{array}$ & & $\begin{array}{c}\text { Amount } \\
(\mathrm{Kg} / \mathrm{yr})\end{array}$ & $\begin{array}{l}\text { Place of } \\
\text { Origin }\end{array}$ \\
\hline Sheep & & & & & & & & & & & & \\
\hline Goat & & & & & & & & & & & & \\
\hline Cattle & & & & & & & & & & & & \\
\hline Horse & & & & & & & & & & & & \\
\hline Mules/asses & & & & & & & & & & & & \\
\hline Pig & & & & & & & & & & & & \\
\hline Chicken & & & & & & & & & & & & \\
\hline Camel & & & & & & & & & & & & \\
\hline Others: & & & & & & & & & & & & \\
\hline
\end{tabular}

Major composition of crop forage (1) name:

$\%$ of total crop forage; (2) name:

$\%$ of total crop forage;

(3) name

$\%$ of total crop forage; (4) name:

$\%$ of total crop forage.

Note: (1)Corn straw (2)Corn (3) wheat bran (4) Soybean (5)Cottonseed (6)Additive (7)Others

Major composition of grass forage (1) name:

$\%$ of total grass forage; (2) name:

$\%$ of total grass forage;

(3) name:

$\%$ of total grass forage; (4) name:

$\%$ of total grass forage.

Note: (1)Carex (2)Caragana (3)Stipa (4)Splendid Achnatherum (5)Leymus chinensis (6)Potentilla (7)Artemisia frigida (8)Cleistogenes squarrosa (9)Allium mongolicum (10)Others 
4.4 FUEL CONSUMPTION

\begin{tabular}{|c|c|c|c|c|c|c|c|c|c|c|c|c|c|}
\hline \multirow{3}{*}{\multicolumn{2}{|c|}{ Type of bio-fuel }} & \multicolumn{6}{|c|}{ Current (after 2010) } & \multicolumn{6}{|c|}{ Before (before1995) } \\
\hline & & \multirow{2}{*}{$\begin{array}{l}\text { Total } \\
\text { amount }\end{array}$} & \multicolumn{2}{|c|}{ Purchased } & \multicolumn{3}{|c|}{ Gathered } & \multirow{2}{*}{$\begin{array}{c}\text { Total } \\
\text { amount }\end{array}$} & \multicolumn{2}{|c|}{ Purchased } & \multicolumn{3}{|c|}{ Gathered } \\
\hline & & & Amount & $\begin{array}{c}\text { Place of } \\
\text { Origin }\end{array}$ & Amount & Place & $\begin{array}{l}\text { Distance to } \\
\text { house }(\mathrm{km})\end{array}$ & & Amount & $\begin{array}{c}\text { Place of } \\
\text { Origin }\end{array}$ & Amount & Place & $\begin{array}{l}\text { Distance to } \\
\text { house }(\mathrm{km})\end{array}$ \\
\hline \multicolumn{14}{|l|}{ Dry dung } \\
\hline Hay & \multirow{3}{*}{ 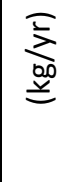 } & & & & & & & & & & & & \\
\hline Straw & & & & & & & & & & & & & \\
\hline \multicolumn{13}{|l|}{ Core-wood } & \\
\hline Other_ & _- & & & & & & & & & & & & \\
\hline
\end{tabular}

\begin{tabular}{|c|c|c|c|c|c|c|c|c|c|c|c|c|c|}
\hline \multirow{3}{*}{\multicolumn{2}{|c|}{$\begin{array}{c}\text { Type of other } \\
\text { fuel }\end{array}$}} & \multicolumn{6}{|c|}{ Current (after 2010) } & \multicolumn{6}{|c|}{ Before (before1995) } \\
\hline & & \multirow{2}{*}{$\begin{array}{c}\text { Total } \\
\text { amount }\end{array}$} & \multicolumn{2}{|c|}{ Purchased } & \multicolumn{3}{|c|}{ Gathered } & \multirow{2}{*}{$\begin{array}{c}\text { Total } \\
\text { amount }\end{array}$} & \multicolumn{2}{|c|}{ Purchased } & \multicolumn{3}{|c|}{ Gathered } \\
\hline & & & Amount & Place of & Amount & Placo & Distance to & & Amount & Place of & Amount & Placo & Distance to \\
\hline Coal & \multirow{3}{*}{ 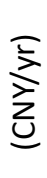 } & & & & & & & & & & & & \\
\hline Gas & & & & & & \multirow{3}{*}{\multicolumn{2}{|c|}{ None }} & & & & \multirow{3}{*}{\multicolumn{3}{|c|}{ None }} \\
\hline Electricity & & & & & & & & & & & & & \\
\hline \multicolumn{2}{|c|}{ Solar energy } & & & & & & & & & & & & \\
\hline Other & & & & & & & & & & & & & \\
\hline
\end{tabular}




\section{Perception on local ecosystem and willing to pay for ESs of grasslands}

Does the local grassland bring you cultural and landscape aesthetic enjoyment while providing basic means of productions for living? (What do you think of the unique grassland culture and natural scenery?) (1)Yes (2) No

If yes $\rightarrow$ If the local grassland is destroyed, are you willing to pay for the protection of the grassland from your personal income?
(1) YES, How much?
CNY/yr/capita
$\begin{array}{llllllllll}\text { (1) } 5 & \text { (2) } 10 & \text { (3) } 20 & \text { (4) } 30 & \text { (5) } 40 & \text { (6) } 50 & \text { (7) } 70 & \text { (8) } 100 & \text { (9) } 150 & \text { (10) } 200\end{array}$

(2) NO, Why?

How has the condition (environment) of grasslands changed in general? (1)Better, why?

(2) Worse, why?

Are you willingness to move outside of grasslands (1)Yes (2)No, why? . (3) No changes, why?

Perception of the next generation's probable career choices (1)Grazing with part time job in city, (2)Business, (3)Immigrate to city, (4)Crop cultivation, (5)Animal husbandry, (6) Others 
Appendix 6: List of potential ecosystem services for assessment based on the results of our literature review.

\begin{tabular}{|c|c|c|c|}
\hline Service/functions & Services & $\begin{array}{c}\text { de Groot et al. } \\
(2002)\end{array}$ & $\begin{array}{l}\text { Millennium Ecosystem } \\
\text { Assessment (2005) }\end{array}$ \\
\hline \multirow{5}{*}{$\begin{array}{l}\text { Production } \\
\text { function/service }\end{array}$} & Food & $\mathrm{X}$ & $\mathrm{X}$ \\
\hline & Raw material & $\mathrm{X}$ & \\
\hline & Genetic resources & $\mathrm{X}$ & \\
\hline & Fresh water & & $\mathrm{X}$ \\
\hline & Fuel & & $\mathrm{X}$ \\
\hline \multirow{4}{*}{$\begin{array}{l}\text { Habitat/supporting } \\
\text { service }\end{array}$} & Refugium functions & $\mathrm{X}$ & \\
\hline & Nursery & $X$ & \\
\hline & Primary production & & $\mathrm{X}$ \\
\hline & $\begin{array}{l}\text { Maintenance of } \\
\text { genetic diversity }\end{array}$ & $X$ & \\
\hline \multirow{10}{*}{$\begin{array}{l}\text { Regulating } \\
\text { function/service }\end{array}$} & Gas regulation & $\mathrm{X}$ & $X$ \\
\hline & Climate regulation & $\mathrm{X}$ & $\mathrm{X}$ \\
\hline & Pollination & $\mathrm{X}$ & \\
\hline & Water regulation & $\mathrm{X}$ & \\
\hline & Water supply & $\mathrm{X}$ & \\
\hline & Soil retention & $X$ & \\
\hline & Nutrient regulation & $\mathrm{X}$ & \\
\hline & $\begin{array}{l}\text { Disturbance } \\
\text { prevention }\end{array}$ & $X$ & \\
\hline & Biological control & $\mathrm{X}$ & $\mathrm{X}$ \\
\hline & Water purification & & $\mathrm{X}$ \\
\hline \multirow[t]{5}{*}{$\begin{array}{l}\text { Information/ } \\
\text { cultural service }\end{array}$} & $\begin{array}{l}\text { Aesthetic } \\
\text { information }\end{array}$ & $\mathrm{X}$ & $\mathrm{X}$ \\
\hline & Recreation & $\mathrm{X}$ & $\mathrm{X}$ \\
\hline & $\begin{array}{l}\text { Spiritual and historic } \\
\text { information }\end{array}$ & $\mathrm{X}$ & $\mathrm{X}$ \\
\hline & $\begin{array}{l}\text { Cultural and artistic } \\
\text { information }\end{array}$ & $X$ & \\
\hline & $\begin{array}{l}\text { Science and } \\
\text { education }\end{array}$ & $\mathrm{X}$ & $\mathrm{X}$ \\
\hline
\end{tabular}


Appendix 7: Soil properties as a function of study region and land utilization intensity. Abbreviations: AK, available potassium; AN, available nitrogen; AP, available phosphorus; SOM, soil organic matter.
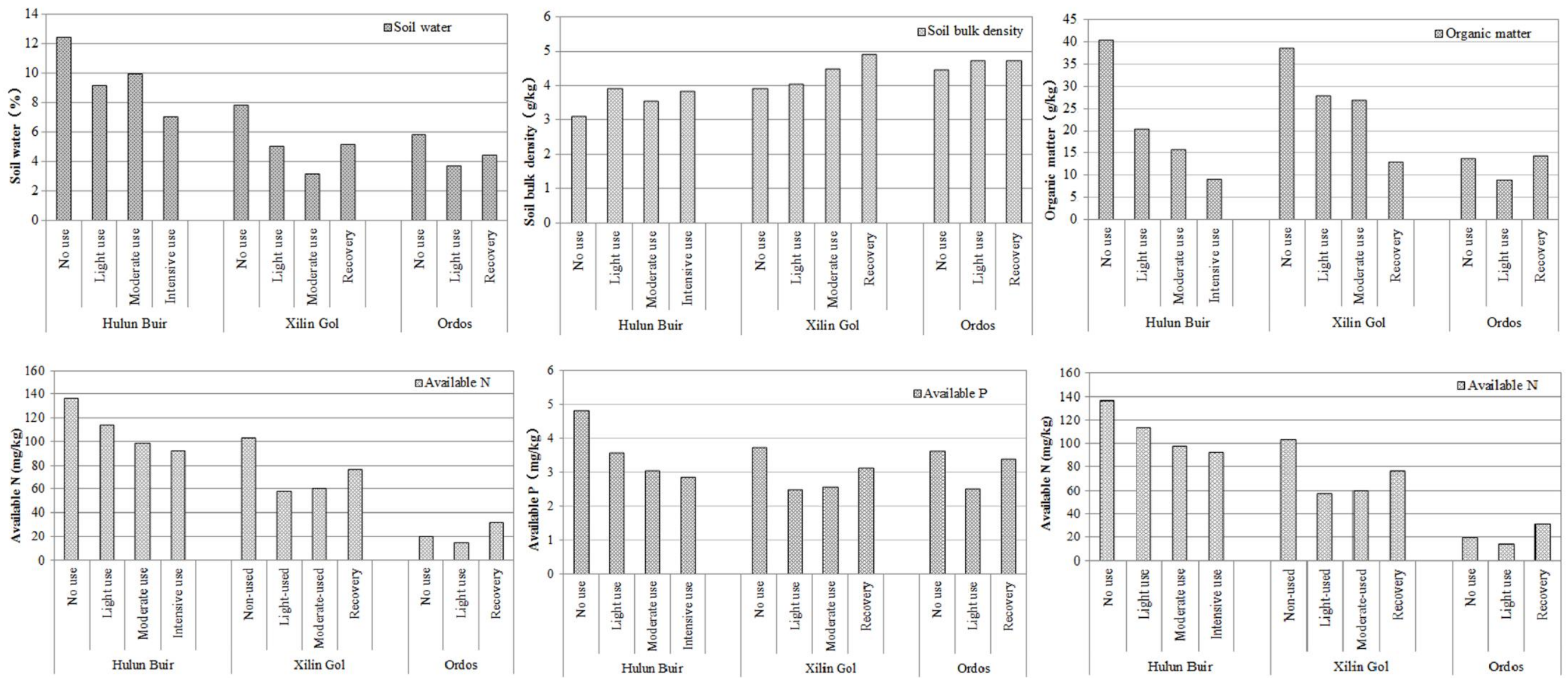
Appendix 8: Vegetation traits as a function of the study region and utilization intensity. (A) Primary production supporting services (AGB, total aboveground biomass). (B) Habitat supporting services (biodiversity).
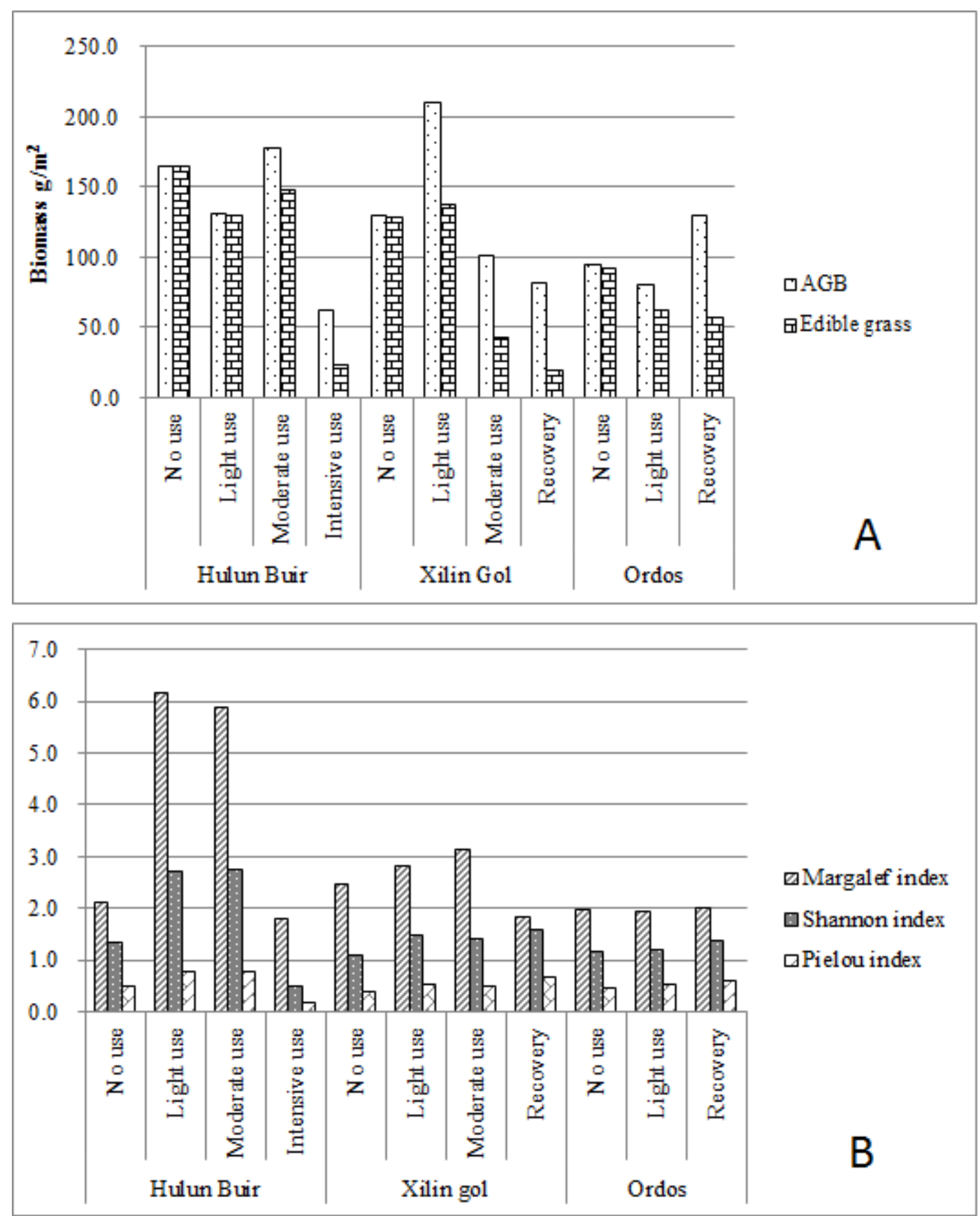
Appendix 9: Spatial and temporal land-cover changes in the Inner Mongolia Autonomous Region (Unit: $\mathbf{k m}^{2}$ )

\begin{tabular}{|c|c|c|c|c|}
\hline & \multicolumn{4}{|c|}{ Hulun Buir } \\
\hline & 1995 & 2000 & 2005 & 2010 \\
\hline Agricultural ecosystem & 15564.9 & 19851.88 & 19991.92 & 20754.49 \\
\hline Forest ecosystem & 122860.94 & 119782.96 & 120278.02 & 120940.47 \\
\hline $\begin{array}{l}\text { Water body and wetland } \\
\text { ecosystem }\end{array}$ & 5038.24 & 3424.88 & 3240.06 & 3722.39 \\
\hline Unban ecosystem & 1036.83 & 1027.93 & 1049.97 & 1212.22 \\
\hline Desert ecosystem & 9200.04 & 10252.98 & 9332.7 & 26775.54 \\
\hline Grassland ecosystem & 98842.79 & 98203.05 & 98651.06 & 79139.04 \\
\hline High cover grassland & 51398.35 & 53536.16 & 53034.87 & 54843.79 \\
\hline Middle cover grassland & 38917.79 & 37246.31 & 37284.32 & 15266.17 \\
\hline \multirow{3}{*}{ Low cover grassland } & 8526.65 & 7420.58 & 8331.87 & 9029.08 \\
\hline & \multicolumn{4}{|c|}{ Xilin Gol } \\
\hline & 1995 & 2000 & 2005 & 2010 \\
\hline Agricultural ecosystem & 4543.27 & 4492.31 & 4418.59 & 4383.17 \\
\hline Forest ecosystem & 1108.8 & 1650.21 & 2009.08 & 1698.22 \\
\hline $\begin{array}{l}\text { Water body and wetland } \\
\text { ecosystem }\end{array}$ & 1621.6 & 2078.84 & 1968.3 & 1931.63 \\
\hline Unban ecosystem & 748.7 & 792.21 & 925.32 & 1073.45 \\
\hline Desert ecosystem & 21875.66 & 22559.52 & 21572.38 & 21152.82 \\
\hline Grassland ecosystem & 56398.38 & 54723.32 & 55402.75 & 56057.15 \\
\hline High cover grassland & 14246.94 & 12315.34 & 12273.08 & 8885.59 \\
\hline Middle cover grassland & 30283.05 & 22573.02 & 22405.24 & 26975.56 \\
\hline \multirow[t]{3}{*}{ Low cover grassland } & 11868.39 & 19834.96 & 20724.43 & 20196 \\
\hline & \multicolumn{4}{|c|}{ Ordos } \\
\hline & 1995 & 2000 & 2005 & 2010 \\
\hline Agricultural ecosystem & 6498.54 & 5787.92 & 5054.79 & 4739.03 \\
\hline Forest ecosystem & 1506.48 & 2988.1 & 3038.45 & 3328.51 \\
\hline $\begin{array}{l}\text { Water body and wetland } \\
\text { ecosystem }\end{array}$ & 1157.83 & 1892.68 & 1312.08 & 1226.43 \\
\hline Unban ecosystem & 458.41 & 484.94 & 537.37 & 624.88 \\
\hline Desert ecosystem & 20743.97 & 21316.28 & 20791.58 & 20966.81 \\
\hline Grassland ecosystem & 170655.42 & 168550.73 & 170286.36 & 170134.83 \\
\hline High cover grassland & 100436.88 & 91283.26 & 91197.33 & 56912.53 \\
\hline Middle cover grassland & 57328.65 & 56382.54 & 54380.75 & 88394.74 \\
\hline Low cover grassland & 12889.89 & 20884.93 & 24708.28 & 24827.56 \\
\hline
\end{tabular}


Appendix 10: Spatial and temporal variation of overall habitat quality of grasslands in the Inner Mongolia Autonomous Region

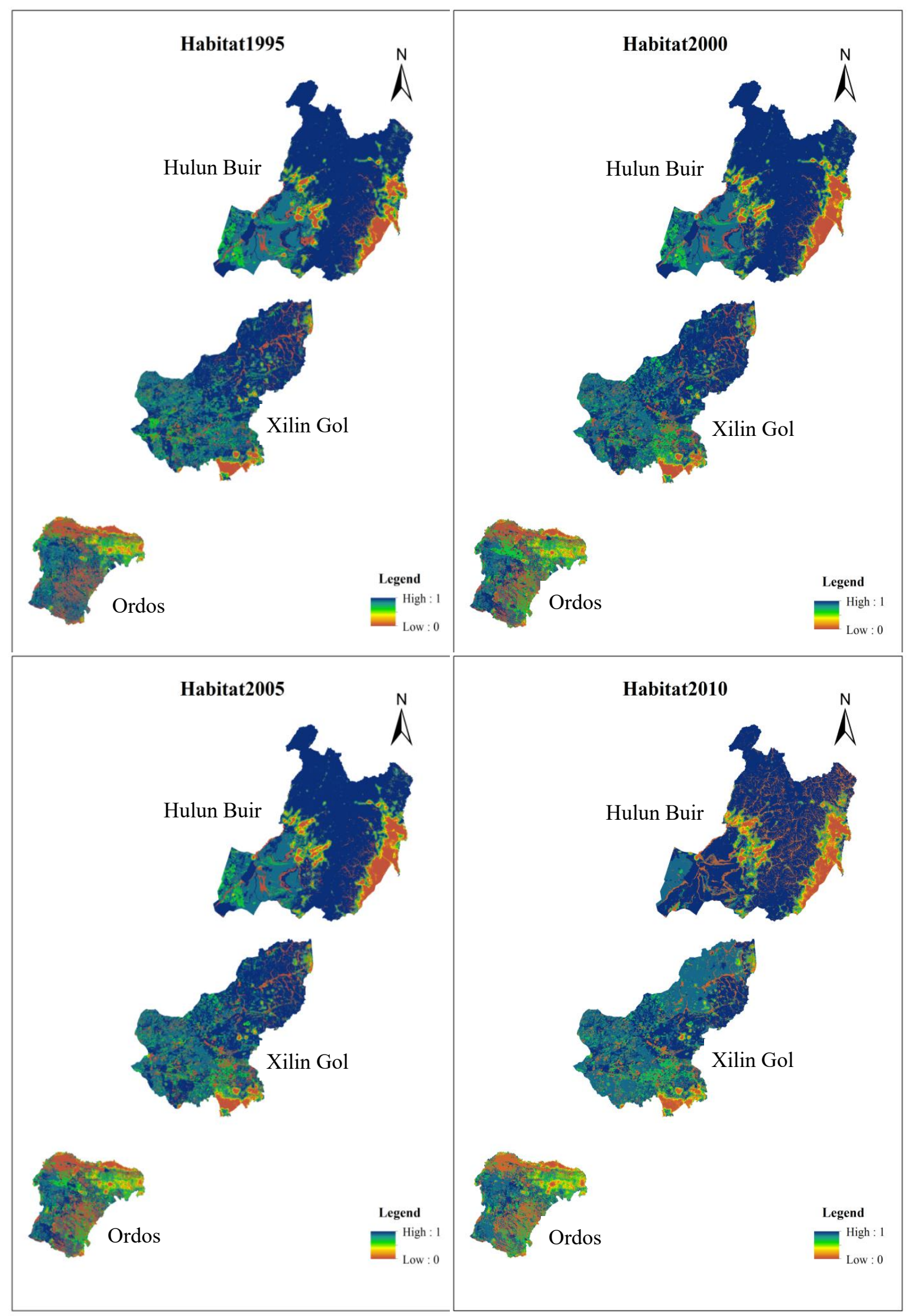




\section{REFERENCES}


Ayensu E., Claasen D.V., Collins M., Dearing A., Fresco L., Gadgil M., Gitay H., Glaser G., Juma C., Krebs J., Lenton R., Lubchenco J., McNeely J.A., Mooney H.A., PinstrupAndersen P., Ramos M., Raven P., Reid W.V., Samper C., Sarukhán J., Schei P., Tundisi J.G., Watson R.T., Guanhua X., Zakri A.H. 1999. International ecosystem assessment. Science 286: 685-686.

Abubakar S.M. 1997. Monitoring land degradation in the semiarid tropics using an inferential approach: the Kabomo Basin case study, Nigeria. Land Degradation Development 8: 311-323.

Abson D.J. and Termansen M. 2011. Valuing ecosystem services in terms of ecological risks and returns. Conservation Biology 25: 250-258.

Allison E.H., Horemans B.P. 2006. Putting the principles of the sustainable livelihoods approach into fisheries development policy and practice. Marine Policy 30: 757-766.

Alxa Right Banner Statistics Bureau (ARBSB). 2010. Annual Social and Economic Reports of Alxa Right Banner in 2010. Alxa Right Banner Statistics Bureau: Alxa league, China.

Akiyama T., Kawamura K. 2007. Grassland degradation in China: methods of monitoring, management and restoration. Grassland Science 53, 1-17.

Arrow K., Daily G., Dasgupta P., Levin S., M“aler K., Maskin E., Starrett D., Sterner T., Tietenberg T. 2000. Managing ecosystem resources. Environmental Science \& Technology 34: 1401-1406.

Babatunde R.O., and Qaim, M. 2010. Impact of off-farm income on food security and nutrition in Nigeria. Food Policy 35, 303-311

Bai Y., Wu J., Clark C.M., Naeemz S., Pan Q., Huang J., Hang L., Han X., 2010. Tradeoffs and thresholds in the effects of nitrogen addition on biodiversity and ecosystem functioning: Evidence from inner Mongolia Grasslands. Global Change Biology 16: $358-372$.

Bakelaar R.G., Odum E.P. 1978. Community and population level responses to fertilization in an old-field ecosystem. Ecology 59: 660-665.

Balmford A., Bruner A., Cooper P., Costanza R., Farber S., Green R.E. et al. 2002. Economic reasons for conserving wild nature. Science 297: 950-953.

Bai Y., Han X., Wu J., Chen Z., Li L. 2004. Ecosystem stability and compensatory effects in the Inner Mongolia grassland. Nature 431: 181-184.

Bao S.D. 2000. Soil Chemical Analysis of Agriculture. Chinese Agriculture Press: Beijing, China. (in Chinese).

Bao L. 2006. Review of Literature on China's Returning Grazing Land to Grassland Policy. Issues in Agricultural Economy 8: 62-65.

Bao X.J.R. 2009. An Empirical Research on Grassland Use Patterns in Xilingol League: A Case Study in Xilinhaote and Abage Inner Mongolia. Inner Mongolia Agricultural University: Hohhot, China. (in Chinese with English summary)

Barbier E.B. 2005. Natural Resources and Economic Development. Cambridge: Cambridge University Press.

Barthold F.K., Wiesmeier M., Breuer L., Frede H.G., Wu J., Blank F.B. 2013. Land use and climate control the spatial distribution of soil types in the grasslands of Inner Mongolia. Journal of Arid Environments 88: 194-205.

Bennett M.T. 2008. China's sloping land conversion program: institutional innovation or business as usual? Ecological Economics 65: 699-711. 
Bennett E.M., Peterson G.D., Gordon L.J. 2009. Understanding relationships among multiple ecosystem services. Ecology Letters 12: 1394-1404.

Benjamin B., Kroll F., Nedkov S., Müller F., 2012. Mapping ecosystem service supply, demand and budgets. Ecological Indicators 21: 17-29.

Bernard F., de Groot R.S., Campos J.J. 2009. Valuation of tropical forest services and mechanisms to finance their conservation and sustainable use: a case study of Tapant'1 National Park, Costa Rica. Forest Policy \& Economic 11:174-183.

Bessembinder J.J.E., Leffelaar P.A., Dhindwal A.S., Ponsioen T. 2005. Which crop and which drop, and the scope for improvement of water productivity. Agricultural Water Management 73: 113-130.

Bhatt B.P. and Sachan M.S. 2004. Firewood consumption patterns of different tribal communities in Northeast India. Energy Policy 32: 1-6.

Bjornstad D.J. and Kahn J.R. 1996. Structuring a research agenda to estimate environmental value The Contingent Valuation of Environmental Resources-Methodological Issues and Research Needs. Eds Bjornstad D.J. and Kahn J.R. (Cheltenham: Edward Elga): 263-274.

Blamey R., Bennett J. and Morrison M. 1999. Yea-saying in contingent valuation surveys. Land Economics 75: 126-141.

Blumenschein K., Johannesson M., Blomquist G.C., Liljas B. and O'Conor R.M. 1997. Hypothetical versus real payments in Vickrey auctions. Economics Letters 56: 177180.

Bolortsetseg B. and Tuvaansuren G. 1996. Potential impacts of climate change on pasture and cattle production in Mongolia. Water Air Soil Pollution 92: 95-105.

Burkhard B., Kroll F., Nedkov S., Müller F. 2012. Mapping ecosystem service supply, demand and budgets. Ecological Indicators 21: 17-29.

Brogaard S. and Xueyong Z. 2002. Rural reforms and changes in land management and attitudes: a case study from Inner Mongolia, China. Ambio 31: 219-225.

Brogaard S., Runnstrom M., Seaquist J.W. 2005. Primary production of Inner Mongolia, China, between 1982 and 1999 estimated by a satellite data-driven light-use efficiency model. Global and Planetary Change 45: 313-332.

Brouwer I.D., Hoorweg J.C., van Liere M.J. 1997. When households run out of fuel: Responses of rural households to decreasing fuelwood availability, Ntcheu District, Malawi. World Development 25: 255-266.

Brown A.J. 1993. A review of soil sampling for chemical analysis. Australian Journal of Experimental Agriculture 33(8): 983-1006.

Cao L., Tian W., Ni B., Zhang Y., Wang P. 2002. Preliminary study of airborne particulate matter in a Beijing sampling station by instrumental neutron activation analysis. Atmospheric Environment 36: 1951-1956.

Carney D. (Ed.) 1998. Sustainable Rural Livelihoods; Department of International Development: London, UK.

Carney K.M., Sydeman W.J. 1999. A review of human disturbance effects on nesting colonial waterbirds. Waterbirds 22(1): 68-79.

Carson R.T. 2000. Contingent valuation: a user's guide. Environmental Science \& Technology 34 1413-1418.

Castro A.J., Martin-Lopez B., Lopez E., Plieninger T., Alcaraz-Segura D., Vaughn C.C., Cabello J. 2015. Do protected areas networks ensure the supply of ecosystem services? 
Spatial patterns of two nature reserve systems in semi-arid Spain. Applied Geography 60: $1-9$.

Cavaliere A., Ricci E.C., Solesin M., Banterle A. 2014. Can Health and Environmental Concerns Meet in Food Choices? Sustainability 6: 9494-9509.

CBD (Convention on Biological Diversity) 2000. Fifth Ordinary Meeting of the Conference of the Parties to the Convention on Biological Diversity, Nairobi, Kenya, Decision Report V/6: paragraphs 4-5.

CCICED. 2007. Eco-compensation mechanisms and policies in China, China Council for International Cooperation on the Environment and Development. Science Press: Beijing, China.

Chaolun B., He B., Gao R., Wang L. 2008. Pumping decisions for sustainable development of groundwater resources in areas of grassland degradation: A case study in Lanqi Banner, Inner Mongolia, China. Hydrogeology Journal 16: 1101-1111.

Chen J., Huang D., Shiyomi M., Hori Y., Yamamura Y. 2007. Spatial heterogeneity and diversity of vegetation at the landscape level in Inner Mongolia, China, with special reference to water resources. Landscape \& Urban Planning 82: 222-232.

Chen J. and Su Y.L. 2008. Effects of grazing prohibition policies on rural household's livelihood in agro-pastoral transition area. Issues in Agricultural Economy 6: 73-79 (in Chinese with English summary).

Chen S.P., Bai Y.F., Lin G.H., Liang Y., Han X.G. 2005. Effects of grazing on photosynthetic characteristics of major steppe species in the Xilin River Basin, Inner Mongolia, China. Photosynthetica 43: 559-565.

Cheng X.L., An S.Q., Li G.Q., Chen X.L., Wang Y.J., Li. J. 2001. The correlation between the desertification of grass-land and the change of vegetation characteristics in Ordos. Journal of Nanjing University 37: 230-239.

Chinese Nutrition Society (CNS). 2010. 'Chinese Dietary Guidelines.'(Tibet People's Press: Lhasa, Tibet, China.)

Cinner J.E. and Bodin O. 2010. Livelihood diversification in tropical coastal communities: A network-based approach to analyzing livelihood landscapes. PLoS ONE 5: e11999.

Costanza R., d'Arge R., de Groot R.S., Farber S., Grasso M., Hannon B., Limburg K., Naeem S., O’Neill R.V., Paruelo J., Raskin R.G., Sutton P., van den BeltM.1998. The value of ecosystem services: putting the issues in perspective. Ecological Economics 25: $67-72$.

Costanza R., d'Arge R., de Groot R.S., G Farber S., Grasso M., Hannon B., Hanon B. et al. 1997. The value of the world's ecosystem services and natural capital. Nature 387: 253-260.

Crossman N.D., Burkhard B., Nedkov S., Willemen L., Petz K., Palomo I., Drakou E.G. Martín-Lopez B., McPhearson T., Boyanova K., Alkemade R., Egoh B., Dunbar M.B., Maes J. 2013. A blueprint for mapping and modelling ecosystem services. Ecosystem Services 4: 4-14.

Cummings R.G., Harrison G.W., Rutstrom E.E. 1995. Homegrown values and hypothetical surveys: is the dichotomous choice approach incentive-compatible? American Economic Review 85: 260-266.

Cummings R.G., Elliot S., Harrison G.W., Murphy J. 1997. Are hypothetical referenda incentive compatible? Journal of Political Economy 105: 609-21.

Dai X.G., Xu Y., Jia G., Fu C. 2009. Climate change impact and adaptation in Inner Mongolia. IOP Conference Series: Earth and Environmental Science 6: 342018. 
Daily G (Ed.), 1997. Nature's Services. Societal Dependence on Natural Ecosystems. Island Press: Washington DC, USA.

de Groot R.S., Wilson M.A., Bouman R.M.J.A. 2002. Typology for the Classification, Description and Valuation of Ecosystem Services, Goods and Services. Ecological Economics 41: 393-408.

de Groot R.S. and Hein L. 2007. Concept and valuation of landscape functions at different scales. In: Mander U, H Wiggering, K Helming (Eds.). Multifunctional Land Use: Meeting Future Demand for landscape Goods and Services (pp. 15-36). Springer: New York, USA.

Deng X.Z., Li Z.H., Gibson J. 2016. A review on trade-off analysis of ecosystem services for sustainable land-use management. Journal of Geographical Sciences 26: 953-968.

Deutsch L. and Folke C. 2005. Ecosystem subsidies to Swedish food consumption from 1962 to 1994. Ecosystems 8: 512-528.

DFID 2001. Integrating Trade into National Development Strategies' in Ministerial Round Table on Trade and Poverty in Least Developed Countries: Capturing the Gains from Trade. Department for International Development: London, UK.

Dong J., Liu J., Zhang G., Basara J. B., Greene S., Xiao X. 2013. Climate change affecting temperature and aridity zones: a case study in Eastern Inner Mongolia, China from 1960-2008. Theoretical and Applied Climatology 113: 561-572.

Dong J., Tao F., Zhang G. 2011. Trends and variation in vegetation greenness related to geographic controls in middle and eastern Inner Mongolia, China. Environmental Earth Sciences 62: 245-256.

Dong S.K., Gao H.W., Xu G.C., Hou X.Y., Long R.J., Kang M.Y., Lassoie J.P. 2007. Farmer and professional attitudes to the large-scale ban on livestock grazing of grasslands in China. Environmental Conservation 34: 246-254.

Du B.Z., Zhen L., de Groot R., Goulden C.E., Long X., Cao X.C., Wu R.Z., Sun C.Z. 2014. Changing patterns of basic household consumption in the Inner Mongolian grasslands a case study of policy-oriented adoptive changes in the use of grasslands. The Rangeland Journal 36(5): 505-517.

Du B.Z., Zhen L., de Groot R., Long X., Cao X.C., Wu R. 2015. Changing Food Consumption Patterns and Impact on Water Resources in the Fragile Grassland of Northern China. Sustainability 7: 5628-5647.

Dula, J. 2005. Discriminate analysis for dust storm prediction in the Gobi and steppe regions in Mongolia. Water, Air and Soil Pollution Focus 5, 37-49.

Dudley N. and Stolton S. 2003. Running pure: The importance of forest protected areas to drinking water. In Alliance for Forest Conservation and Sustainable Use. World Bank/World Wildlife Fund: London, UK.

Eastwood A., Nijnik M., Brooker R., Pakeman R.J., Artz R., Norton L., Ross L., Bullock J.M., Vellinga N., Albon S., Fielding D., Irvine R.J., Ramsay S., Cooksley S. 2013. Nature Conservation and Ecosystem Service Delivery. JNCC Report No. 492. JNCC: Peterborough, UK.

Ellis F. 1998. Household strategies and rural livelihood diversification. The Journal of Development Studies 35: 1-38.

Ellis F. 2000. Rural Livelihood Diversity in Developing Countries: Evidence and Policy Implications; Oxford University Press: Oxford, UK. 
Eigenbrod F., Armsworth P.R., Anderson B.J., Heinemeyer A., Gillings S., Roy D.B., Thomas C.D., Gaston K.J. 2010. The impac/t of proxy-based methods on mapping the distribution of ecosystem services. Journal of Applied Ecology 47: 377-385.

Engel S., Pagiola S., Wunder S. 2008. Designing payments for environmental services in theory and practice: an overview of the issues. Ecological Economics 65: 663-674.

Evans C.R.W., Krzic M., Broersma K., Thompson D.J. 2012. Long-term grazing effects on grassland soil properties in southern British Columbia. Canadian Journal of Soil Science 92: 685-693.

Fan G. 2003. Analysis on the Ecological Environment Management System. Northwest Agriculture and Forestry University Press 2003: 4.

Fan M.M., Li W.J., Zhang C.C., Li L.H. 2013. Impacts of nomad sedentarization on social and ecological systems at multiple scales in Xinjiang Uyghur Autonomous Region, China. AMBIO: 43: 673-686.

Food and Agriculture Organization (FAO). 2003. 'World Agriculture. Towards 2015/2030. An FAO Perspective' (Ed. J. Bruinsma). Earthscan Publications: London, UK.

Food and Agriculture Organization (FAO). 2009. Supply and Utilization Accounts of FAOSTAT, FAOSTAT Data Base; Food and Agriculture Organization: Rome, Italy.

Feng Z.M. and Shi D.F. 2006. Chinese food consumption and nourishment in the latest 20 years. Resources Science 28: 2-8 (in Chinese with English abstract).

Feng X.M. and Zhao Y.S. 2011. Grazing intensity monitoring in Northern China steppe: integrating CENTURY model and MODIS data. Ecological Indicators 11: 175-182.

Fogel R.W. Helmchen L.A. 2002. Economic and technological development and their relationships to body size and productivity. In: 'The nutrition transition - diet and disease in the developing world' (Eds. B. Caballero and B. M. Popkin), pp. 9-24. Academic Press: London, UK.

Gao C., Li Z., Cao J. 2013. Study of the Returning Grazing Land to Grassland Program and the Change in the Management Style of Grassland Animal Husbandry - Based on Empirical Analysis of Six Villages in Uxin Banner. Modernization of Management 01: 37-39.

Gerbens-Leenes P.W. Nonhebel S. 2002. Consumption patterns and their effects on land required for food. Ecological Economics 42: 185-199.

Gibson D.J. 2009. Grasses and grassland ecology. Oxford University Press, Oxford, UK

Grigg D. 1995. The nutrition transitionin Western Europe. Journal of Historical Geography 22: 247-261.

Gu Z.H., Shi P.J., Chen J. 2008. Estimation of grassland degradation based on historical maximum growth model using with remote sensing data, The International Archives of the Photogrammetry, Remote Sensing and Spatial Information Sciences XXXVII (B8): 895-900.

Gunderson L.H., and Holling C.S. 2001. Panarchy: Understanding Transformations in Human and Natural Systems. Island Press: Washington DC, USA.

Hadker N., Sharma S., David A., Muraleedharan T.R. 1997. Willingness to pay for Borivli National Park: evidence from a contingent valuation. Ecological Economics 21: 105122.

Haftay H., Yayneshet T., Animut G., Treydte A.C. 2013. Rangeland vegetation responses to traditional enclosure management in eastern Ethiopia. The Rangeland Journal 35, 29 36. 
Hanemann W.M. 1984. Welfare evaluations in contingent valuation experiments with discrete responses. American Agricultural Economics Association 166: 332-341.

Hanemann W.M. 1989. Welfare evaluations in contingent valuation experiments with discrete response data: reply. American Agricultural Economics Association 71: 1057-1061.

Hanemann W.M. 1994. Valuing the environment through contingent valuation. Journal of Economic Perspectives 8: 19-25.

Hawksworth D.L. and Bull A.T. (ed) 2008. Biodiversity and Conservation in Europe. Springer: Dordrecht, the Netherland.

Hanguan Q., Jia N., Niu H. 2003. Report on Grassland Degradation and Restoration in Golok Prefecture. Ascent: 4: 82-85.

Hashimoto S., Kawado M., Seko R., Kato M., Okabe N. 2005. Bias of vaccination coverage in a household questionnaire survey in Japan. J. Epidemiol. 15: 15-19.

Hoehn J.P. and Randall A. 1987. A satisfactory benefit cost indicator from contingent valuation. Journal of Environmental Economics \& Management 14: 1226-1247.

Hoekstra A.Y. and Chapagain A.K. 2008. 'Globalization of water. Sharing the planet's freshwater resources. Blackwell Publishing: London, UK.

Hoffmann C., Funk R., Li Y., Sommer M. 2008. Effect of grazing on wind driven carbon and nitrogen ratios in the grasslands of Inner Mongolia. Catena 75: 182-190.

Hoffmann C., Funk R., Reiche M., Li Y. 2011. Assessment of extreme wind erosion and its impacts in Inner Mongolia, China. Aeolian Research 3: 343-351.

Hulun Buir Statistics Bureau. 2012. Statistics of 2010 yearbook in Evenk Banner. Hulun Buir Statistic Bureau: Hulun Buir, China.

Inner Mongolia Statistics Bureau. 2015a. Statistical Bulletin of the Economic and Social Development of Inner Mongolia in 2015. Inner Mongolia Statistics Bureau: Hohhot, China.

Inner Mongolia Statistics Bureau. 2013. 'Rural Statistics Yearbook of Inner Mongolia Autonomous Region in 2010.' Inner Mongolia Statistics Bureau: Hohhot, China.

Inner Mongolia Statistics Bureau. 1997. Inner Mongolia Statistics Yearbook, China Statistics Press: Inner Mongolia Statistics Bureau, Hohhot, China (in Chinese).

Inner Mongolia Statistics Bureau. 2014. Inner Mongolia Statistics Yearbook, China Statistics Press: Inner Mongolia Statistics Bureau, Hohhot, China (in Chinese).

Inner Mongolia Statistics Bureau. 2015b. Inner Mongolia Statistics Yearbook, China Statistics Press: Inner Mongolia Statistics Bureau, Hohhot, China (in Chinese).

Inner Mongolia Statistics Bureau. 1996. Rural statistics yearbook of Inner Mongolia Autonomous Region in 1995. Inner Mongolia Statistic Bureau: Hohhot, China.

Inner Mongolia Statistics Bureau. 2011. Rural statistics yearbook of IMAR in 2010. Inner Mongolia Statistic Bureau: Hohhot, China.

IPBES (The Intergovernmental Platform on Biodiversity and Ecosystem Services). 2018. Conference report: Global Land Degradation Status and Restoration Assessment

Ji S.J., Geng Y., Li D.F., Wang G.H. 2009. Plant coverage is more important than species richness in enhancing aboveground biomass in a premature grassland, northern China. Agriculture, Ecosystems and Environment 129: 491-496.

Jiang A. 2003. Historical Change of China' Land Policies (1949-1978). Journal of Yuxi Normal College 10: 25-31. 
Jiang G., Han X., Wu J. 2006. Restoration and management of the Inner Mongolia grassland require a sustainable strategy. $A M B I O 35: 269-270$.

Jill M., Montaquila J., Michael B., Shelley P. National Center for Education Statistics. Undercoverage Bias in Estimates of Characteristics of Households and Adults in the 1996 National Household Education Survey; Working Paper No. 97-39; U.S. Department of Education: Washington, DC, USA, 1997.

John R., Chen J.Q., Lu N., Guo K., Liang C.Z., Wei Y.F., Noormets A., Ma K.P., Han X.G. 2008. Predicting plant diversity based on remote sensing products in the semi-arid region of Inner Mongolia. Remote Sensing of Environment 112: 2018-2032.

Jugder D. 2005. Discriminate analysis for dust storm prediction in the Gobi and steppe regions in Mongolia. Water, Air, \& Soil Pollution: Focus 5: 37-49.

Jun L. W., Ali S. H., Zhang Q. 2007. Property rights and grassland degradation: a study of the Xilingol Pasture, Inner Mongolia, China. Journal of Environmental Management 85: 461-470.

Katoh K., Takeuchi K., Jiang D., Nan Y., Kou Z. 1998. Vegetation restoration by seasonal exclosure in the Kerqin Sandy Land, Inner Mongolia. Plant Ecology 139: 133-144.

Kang L., Han X., Zhang Z., Sun O.J. 2007. Grassland ecosystems in China: review of current knowledge and research advancement. Philosophical Transactions of the Royal Society of London B: Biological Sciences 362(1482): 997-1008.

Kang M., Dai C., Ji W., Jiang Y., Yuan Z., Chen H.Y. H. 2013. Biomass and its allocation in relation to temperature, precipitation, and soil nutrients in Inner Mongolia grasslands, China. PLOS ONE, 8 (7): e76561.

Kaplowitz M.D., Hoehn J.P. 2001. Do focus groups and individual interviews reveal the same information for natural resource valuation? Ecological Economics 36: 237-247.

Kareiva P., Tallis H., Ricketts T.H., Daily G.C., Polasky S., 2011. Natural Capital. Theory and Practice of Mapping Ecosystem Services. Oxford University Press: Oxford, U.K.

Kawamura K., Akiyama T., Yokota H.O., Tsutsumi M., Yasuda T., Watanabe O., Wang S.P. 2005. Quantifying grazing intensities using geographic information systems and satellite remote sensing in the Xilingol steppe region, Inner Mongolia, China. Agriculture Ecosystems \& Environment. 107: 83-93.

Kim J.Y., Mjelde J.W., Kim T.K., Lee C.K. Ahn K.M. 2012. Comparing willingness to pay between residents and nonresidents when correcting hypothetical bias: case of endangered spotted seal in South Korea. Ecological Economics 78: 123-131.

Kling C.L., Feng H.L., Kurkalova L.A., Secchi S. Gassmand P.W. 2005. The conservation reserve program in the presence of a working land alternative: implications for environmental quality, program participation, and income transfer. American Journal of Agricultural Economics 87: 1231-1238.

König H.J., Zhen L., Helming K., Uthes S., Yang L., Cao X., Wiggering H. 2012. Assessing the impact of the sloping land conversion programme on rural sustainability in Guyuan, western China. Land Degradation and Development 2014, 25(4):385-396

König H.J., Zhen L., Helming K., Uthes S., Yang L., Cao X., Wiggering H. 2014a. Assessing the Impact of the Sloping Land Conversion Programme on Rural Sustainability in Guyuan, Western China. Land Degradation \& Development 25: 385-396.

König H.J., Podhora A., Helming K., Zhen L., Wang C., Wübbeke J., Baumeister T., Du B.Z., Yan H. M. 2014b. Confronting international research topics with stakeholders on multifunctional land use: the case of Inner Mongolia, China. iForest - Biogeosciences and Forestry 7: 403-413. 
König H.J., Podhora A., Zhen L., Helming K., Yan H., Du B.Z., Wunneke J., Wang C., Klinger J., Chen C., Uthes S. 2015. Knowledge Brokerage for Impact Assessment of Land Use Scenarios in Inner Mongolia, China Extending and Testing the FoPIA Approach. Sustainability 7: 5027-5049.

Krawczyk M. 2012. Testing for hypothetical bias in willingness to support a reforestation program. Journal of Forest Economics 18: 282-289.

Kumar P. (Ed.) 2010. The Economics of Ecosystems and Biodiversity. The Ecological and Economic Foundation, Earthscan Publications: Geneva, Switzerland.

Levin S.A. 1999. Fragile Dominion: Complexity and the Commons. Massachusetts: Perseus Books.

Li A., Wu J., Huang J. 2012. Distinguishing between human-induced and climate-driven vegetation changes: A critical application of RESTREND in inner Mongolia. Landscape Ecology 27: 969-982.

Li C., Hao X., Zhao M., Han G., Willms W.D. 2008. Influence of historic sheep grazing on vegetation and soil properties of a Desert Steppe in Inner Mongolia. Agriculture, Ecosystems and Environment 128: 109-116.

Li F. 2010. Eco-Compensation Mechanism in Ecologically Vulnerable Regions Based on Stakeholder's Analysis Chinese Academy of Sciences: Beijing, China (in Chinese with English summary)

Li F.R., Zhang H., Zhao L.Y., Shirato Y., Wang X.Z. 2003. Pedoecological effects of a sandfixing poplar (Populus simonii Carr.) forest in a desertified sandy land of Inner Mongolia, China. Plant and Soil 256: 431-442.

Li J. and Li S.Z. 2010. An attitudes and perceptions based investigation on types of rural residents and their willingness to accept eco-compensation in western China: a case on Zhouzhi County in Xi'an city. Resources Science 32: 1505-1512 (in Chinese with English summary)

Li J., Feldman M.W., Li S., Daily G.C. 2011. Rural household income and inequality under the sloping land conversion program in western China. Proceedings of the National Academy of Sciences of the United States of America 108: 7721-7726.

Li K., Liu X., Song L., Gong Y., Lu C., Yue P., Tian C., Zhang F. 2015. Response of alpine grassland to elevated nitrogen deposition and water supply in China. Oecologia. 177: $65-72$.

Li L. and Wu X. 2008. Analysis and Policy on Virtual Water Condition of Agricultural Products in Heilongiang Province. Science Economy Society 26: 41-46.

Li S., Zhang R., Buman A. 2005. Thinking about the effect of replacing cropland with pasture on farmers' income. Pratacultural Science 22: 69-71.

Li W.J., Ali S.H., Zhang Q. 2007. Property rights and grassland degradation: A study of the Xilingol Pasture, Inner Mongolia, China. Journal of Environmental Management 85: 461-470.

Li W. and Huntsinger L. 2011. China's grassland contract policy and its impacts on herder ability to benefit in Inner Mongolia: tragic feedbacks. Ecology and Society 16: 1-14.

Li Y., Zhao H., Zhao X., Zhang T., Li Y., Cui J. 2011. Effects of grazing and livestock exclusion on soil physical and chemical properties in desertified sandy grassland, Inner Mongolia, northern China. Environmental Earth Sciences 63: 771-783.

Li Z.H., Bao Y.J., Wang H.M., Xu T., Cheng Y., Gao J.X. 2008. Grasslands desertification and driving forces in Xilingol of Inner Mongolia. Ecology and Environmental Sciences 17: 2312-2318 (in Chinese with English abstract) 
Li Z.X., Shao L., Mingpei L.I., et al. 2014. Analysis of shale gas resource exploration potential of Yan'an Formation in northern Huangling mining area of Ordos basin. Coal Geology \& Exploration 186(2):869.

Lim B., Spanger-Siegfried E., Burton I., Malone E., Huq S. 2005. Adaptation Policy Frameworks for Climate Change: Developing Strategies, Policies, and Measures. Cambridge University Press: Cambridge, UK.

Liu W.Q., Ba L., Tian Y.P. 1998. The food consumption of urban and rural residents in Inner Mongolia. Journal of Inner Mongolia Finance and Economics College 3: 1-6 (in Chinese).

Liu J.G., Linderman M., Ouyang Z.Y., An L., Yang J., Zhang H. 2001. Ecological degradation in protected areas: The case of Wolong Nature Reserve for giant pandas. Science 292: 98-101.

Liu J.G., Daily G.C., Ehrlich P.R., Luck G.W. 2003. Effects of household dynamics on resource consumption and biodiversity. Nature 421: 530-533.

Liu J.G., Dietz T., Carpenter S.R., Alberti M., Folke C., Moran E., Pell A.N., Deadman P., Kratz T., Lubchenco J., Ostrom E., Ouyang Z., Provencher W., Redman C.L., Schneider S.H., Taylor W.W. 2007. Complexity of coupled human and natural systems. Science 317: 1513-1516.

Liu X.L. and Zhen L. 2007. Stakeholders' consumption of ecosystem services and willingness to accept: a case study in Jinghe Watershed. Resources Science 29: 103-108 (in Chinese with English summary)

Liu R. 2010. Grazing Ban, Grassland Rest and Rotational Grazing Measures Implemented under the Returning Grazing Land to Grassland Program Lead to Fast Recovery of Grassland Ecosystem. Inner Mongolia Prataculture 22 (4): 14-17.

Lu N., Chen S., Wilske B., Sun G., Chen J. 2011. Evapotranspiration and soil water relationships in a range of disturbed and undisturbed ecosystems in the semi-arid Inner Mongolia, China. Journal of Plant Ecology 4: 49-60.

Liu J., Wu J. G., Liu F. Q., Ha X.G.n. 2012. Quantitative assessment of bio-energy from crop stalk resources in Inner Mongolia, China. Applied Energy 93: 305-318.

Liu X., Wang Y., Peng J., Braimoh A. K. Yin H. 2013. Assessing vulnerability to drought based on exposure, sensitivity and adaptive capacity: a case study in middle Inner Mongolia of China. Chinese Geographical Science 23: 13-25.

Liu Z. and Lan J. 2015. The Sloping Land Conversion Program in China: Effect on the Livelihood Diversification of Rural Households. World Development 70: 147-161.

Loomis J., Traynor K., Brown T. 1999. Trichotomous choice: a possible solution to dual response objectives in dichotomous choice contingent valuation questions. Journal of Agricultural \& Resource Economics 24: 572-83.

Loomis J.B. and Walsh R.G. 1997. Recreation Economic Decisions: Comparing Benefits and Costs. Venture Publishing, Inc.: State College, PA.

Millennium Ecosystem Assessment. 2003. Ecosystems and Human Well-Being: A Framework for Assessment. Island Press: Washington DC, USA.

Millennium Ecosystem Assessment. 2005. Ecosystems and Human Well-being: Current State and Trends. Island Press: Washington DC, USA.

Millennium Ecosystem Assessment. 2005. Millennium Ecosystem Assessment Synthesis Report. Island Press: Washington DC, USA. 
Madubansi M., and Shackleton C.M. 2007. Changes in fuelwood use and selection following electrification in the Bushbuckridge lowveld, South Africa. Journal of Environmental Management 83: 416-426.

Medina-Roldan E., Paz-Ferreiro J., Bardgett R.D. 2012. Grazing exclusion affects soil and plant communities, but has no impact on soil carbon storage in an upland grassland. Agriculture, Ecosystems and Environment 149: 118-123.

Mennell S., Murcott A., van Otterloo A.H. 1992. The sociology of food: eating, diet and culture. Sage Publications: London, UK.

McCartney M.P., Acreman M.C., Bergkamp G. 2000. Freshwater ecosystem management and environmental security, Final Version of the Discussion Paper prepared for the Freshwater Ecosystem Management and Environmental Security Workshop held by the IUCN in San Jose, Costa Rica, June, 1999.

Mjelde J.W., Jin Y.H., Lee C.K., Kim T.K., Han S.Y. 2012. Development of a bias ratio to examine factors influencing hypothetical bias. Journal of Environmental Management 95: 39-48.

Min Q., Liu S., Yang X. 2004. Evaluation of the Ecosystem Services of the Inner Mongolia Steppe, Acta Agrestia Sinica 12: 165-169.

Munksgaard J., Wier M., Lenzen M., Dey C. 2005. Using input-output analysis to measure the environmental pressure of consumption at different spatial levels. Journal of Industrial Ecology 9: 169-185.

Munkhtsetseg E., Kimura R., Wang J. Shinoda M. 2007. Pasture yield response to precipitation and high temperature in Mongolia. Journal of Arid Environments 70: 94-110.

Murphy J., Allen P., Stevens T., Weatherhead D. 2005. A meta-analysis of hypothetical bias in stated preference valuation. Environmental and Resource Economics 30: 313-325.

Murphy J., Stevens T., Yadav L. 2010. A comparison of induced value and homegrown value experiments to test for hypothetical bias in contingent valuation. Environmental and Resource Economics 47: 111-123.

Molden D., Frenken K., Barker R., de Fraiture C., Mati B., Svendsen M., Sadoff C., Finlayson C.M. 2007.Trends in Water and Agricultural Development Pages 57-89 in Water for Food, Water for Life: A Comprehensive Assessment of Water Management in Agriculture. Molden D., Ed. International Water Management Institute: London, UK. Earthscan and Colombo, Srilanka.

National Statistics Bureau. 2015. National Annual Statistic Reports of China. National Bureau of Statistics of the People's Republic of China: Beijing, China.

NDRC. 2014. "Opinions on improving the policy of returning grazing to grassland" is the latest guidance to implementing the policy of "returning grazing to grassland", which Joint release by the National Development and Reform Commission, National Ministry of Finance and National Ministry of Agriculture (in Chinese)

NSBC. 2006. The Fifth Census in China. National Bureau of Statistics: Beijing, China.

Nie X. 2008. Performance Evaluation and Countermeasures to Problems in the Implementation of the Returning Grazing Land to Grassland Program in the Yellow River Basin. Dissertation, Gansu Agricultural University, Lanzhou, China

NSBC. 2006. The fifth census in China. National Bureau of Statistics: Beijing, China.

Nuñez D., Nahuelhual L., Oyarzún C. 2006. Forests and water: The value of native temperate forests in supplying water for human consumption. Ecological Economics 58: 606616. 
Ohte N., Koba K., Yoshikawa K., Sugimoto A., Matsuo N., Kabeya N., Wang L. 2003. Water utilization of natural and planted trees in the semiarid desert of Inner Mongolia, China. Ecological Applications 13: 337-351.

Ordos Statistics Bureau. 2011a. Statistics of 2010 yearbook in Dongsheng District. Ordos Statistics Bureau: Ordos, China.

Ordos Statistics Bureau. 2011b. Statistics of 2010 yearbook in Ejin Horo Banner. Ordos Statistics Bureau: Ordos, China.

Ostrom E. 2009. A General Framework for Analyzing Sustainability of Social-Ecological Systems. Science 325 (5939): 419-422.

Pagiola S., Arcenas A., Platais G. 2005. Can payments for environmental services help reduce poverty? An exploration of the issues and evidence to date from Latin America. World Development 33: 237-253.

Pahl-Wostl C.A. 2009. Conceptual framework for analysing adaptive capacity and multi-level learning processes in resource governance regimes. Global Environmental Change 19: 354-365.

Pan Y., Xu Z., Wu J. 2013. Spatial differences of the supply of multiple ecosystem services and the environmental and land use factors affecting them. Ecosystem Services 5: e4e10.

Popkin B.M. 2002. The dynamics of the dietary transition in the developing world. In The Nutrition Transition: Diet and Disease in the Developing World, Food Science and Technology International Series (pp. 111-129). Caballero B., Popkin B.M., Eds. Academic Press: London, UK.

Power A.G. 2010. Ecosystem services and agriculture: tradeoffs and synergies. Philosophical Transactions of the Royal Society B: Biological Sciences 365: 2959-2971.

Pricope N.G., Husak G., Lopez-Carr D., Funk C., Michaelsen J. 2013. The climate-population nexus in the East African Horn: Emerging degradation trends in rangeland and pastoral livelihood zones. Global Environmental Change 23: 1525-1541.

Prishchepov A.V., Radeloff V.C., Baumann M., Kuemmerle T., M“uller D. 2012. Effects of institutional changes on land use: agricultural land abandonment during the transition from state-command to market-driven economies in post-Soviet Eastern Europe. Environmental Research Letters 7: 024021

Prober S.M., Thiele K.R., Rundel P.W., Watson A. 2012. Climate adaptation in intact landscapes: a framework for managing change and resilience applied to the world's largest temperate woodland. Climatic Change 110: 227-248.

Qiu G.Y., Xie F., Feng Y.C., Tian F. 2011. Experimental studies on the effects of the " Conversion of Cropland to Grassland Program" on the water budget and evapotranspiration in a semi-arid steppe in Inner Mongolia, China. Journal of Hydrology 411: 120-129.

Qu F., Kuyvenhoven A., Shi X., Heerink N. 2011. Sustainable natural resource use in rural China: Recent trends and policies. China Economic Review 22: 444-460.

Raudsepp-Hearne C., Peterson G.D., Bennett E.M. 2010. Ecosystem service bundles for analyzing tradeoffs in diverse landscapes. Proceedings of the National Academy of Sciences of the United States 107: 5242-5247.

Receveur O., Boulay M., Kuhnlein H.V. 1997. Decreasing traditional food use affects diet quality for adult men in 16 Communities of the Canadian North-west Territories. Community and International Nutrition 127: 2179-2186. 
Reed M.S., Graves A., Dandy N., Posthumus H., Hubacek K., Morris J., Prell C., Quinn C.H., Stringer L.C. 2009. Who's in and why? A typology of stakeholder analysis methods for natural resource management. Journal of Environmental Management 90: 19331949.

Ren J.Z., Hu Z.Z., Zhao J., Zhang D.G., Hou F. J., Lin H. L., Mu X.D. 2008. A grassland classification system and its application in China. The Rangeland Journal 30(2): 199209.

Ren Y., Yu H., Feng D.F. 2006. The establishment of strategies for ecological compensation mechanism and policy framework. Environmental protection 10A: 18-23 (in Chinese with English summary)

Renault D. and Wallender W. 2000. Nutritional water productivity and diets. Agricultural Water Management 45: 275-296.

Robertson, G.P., Swinton, S.M. 2005. Reconciling agricultural productivity and environmental integrity: a grand challenge for agriculture. Frontiers in Ecology and the Environment, 3:38-46.Sievanen L., Crawford B., Pollnac R., Lowe C. 2005. Weeding through assumptions of livelihood approaches in ICM: Seaweed farming in the Philippines and Indonesia. Ocean \& Coastal Management 48: 297-313.

Rook A.J., Dumont B., Isselstein J., Osoro K., Wallis DeVries M.F., Parente G., Mills J. 2004. Matching type of livestock to desired biodiversity outcomes in pastures-a review. Biological Conservation 119: 137-150.

Sala O.E., Chapin F.S., Armesto J.J., Berlow E., Bloomfield J., Dirzo R., Huber-Sanwald E., Huenneke, L.F., Jackson R.B., Kinzig A., Leemans R., Lodge D.M., Mooney H.A., Oesterheld M., Poff N.L., Sykes M.T., Walker B.H., Walker M., Wall D.H. 2000. Global biodiversity scenarios for the year 2100. Science 287:1770-1774.

Schiborra A., Gierus M., Wan H.W., Bai Y.F., Taube F. 2009. Short-term responses of a Stipa grandis/Leymus chinensis community to frequent defoliation in the semi-arid grasslands of Inner Mongolia, China. Agriculture Ecosystems \& Environment 132: 82-90.

Schultz L., Folke C., Olsson P. 2007. Enhancing ecosystem management through socialecological inventories: lessons from Kristianstads Vattenrike, Sweden. Environmental Conservation 34: 140-152.

Spash C.L. and Hanley N. 1995. Preferences, information and biodiversity preservation. Ecological Economics 12: 191-208.

Spash C.L., Urama K., Burton R., Kenyon W., Shannon P., Hill G. 2009. Motives behind willingness to pay for improving biodiversity in a water ecosystem: economics, ethics and social psychology Ecological Economics 68: 955-964

Sternberg T., Thomas D., Middleton N. 2010. Drought dynamics on the Mongolian steppe, 1970-2006, International Journal of Climatology 31 (12): 1823-183.

Shi Z., Gao J., Yang X., Jia Z., Shang J., Feng C., Lü S. 2012. Response of Mongolian pine radial growth to climate in Hulunbuir Sand Land, Inner Mongolia, China. Journal of Food, Agriculture and Environment 10: 884-890.

Sun C., Ouyang X., Cai H., Luo Z., Li A. 2014. Household pathway selection of energy consumption during urbanization process in China. Energy Conversion and Management 84: 295-304.

Suškevics M. 2012. Legitimacy analysis of multi-level governance of biodiversity: evidence from 11 case studies across the EU. Environmental Policy and Governance 22: 217237. 
Swinton S.M., Lupi F., Robertson G.P., Hamilton S.K. 2007. Ecosystem services and agriculture: cultivating agricultural ecosystems for diverse benefits. Ecological Economics 64: 245-252.

Tabachnick B.G. and Fidell L.S. 2007. 'Using Multivariate Statistics.' 5th edn. Pearson Allyn and Bacon: Upper Saddle River, NJ.

Tallis H., and Polasky S. 2009. Mapping and valuing ecosystem services as an approach for conservation and natural-resource management. Annals of the New York Academy of Sciences 1162: 265-283.

Tallis H.T., Ricketts T., Guerry A.D., et al. 2013. InVEST 2.5.3 User's Guide. The Natural Capital Project, Stanford.

TEEB, 2010. 'The Economics of Ecosystems and Biodiversity: An Interim Report', European Commission, Brussels.

Thornley M. 1998. Grassland Dynamics: An Ecosystem Simulation Model. Wallingford: CAB International.

Tian X.Y. 2011. Effect of the Returning Grazing Land to Grassland Program on the Lives of Herders in China. Chinese Journal of Grassland 33 (4): 1-4.

Turner R.K., Paavola J., Cooper P., Farber S., Jessamy V., Georgiou S. 2003. Valuing nature: lessons learned and future research directions. Ecological Economics 46(2):493-510.

Uchida E., Xu J.T., Rozelle S. 2005. Grain for Green: cost-effectiveness and sustainability of China's conservation set-aside program. Land Economics 81: 247-264.

van Noordwijk M. and Leimona B. 2010. Principles for fairness and efficiency in enhancing environmental services in Asia: payments, compensation, or co-investment. Ecology \& Society 15: 17.

Vermaat J.E., Goosen H., Omtzigt N. 2008. Do biodiversity patterns in Dutch wetland complexes relate to variation in urbanization, intensity of agricultural land use or fragmentation? Biodiversity and Conservation in Europe. Hawksworth D.L. and A.T. Bull ed. Springer: Dordrecht, the Netherlands.

Wackernagel M., Schulz N.B., Deumling D., Linares A.C., Jenkins M., Kapos V., Monfreda C., Loh J., Myers N., Norgaard R., Randers J. 2002. Tracking the ecological overshoot of the human economy. National Academy of Sciences 99(14): 9266-9271.

Wan J.J., Wang J.A., Liu Z., et al. 2008. Drought resilience in view of income diversity of peasant household: A case study on Xinghe County, Inner Mongolia. Journal of Natural Disasters 17(1): 122-126.

Wang G. and Cheng G. 1999. The ecological features and significance of hydrology within arid inland river basins of China. Environmental Geology 37(3): 218-222.

Wang J.N., Wan J., Zhang H.Y. 2006. Relating knowledge for ecological compensation mechanics and policies in China. Environmental protection 10A: 24-8 (in Chinese with English summary).

Wang P.P. 2010. Protein functionality in food systems. Meat Research 135: 62-70 (in Chinese with English abstract).

Wang X.Y. 2009. Pastoral Communities under Environmental Pressure. Beijing: Social Sciences Academic Press, pp. 4-12 (In Chinese).

Wang Y.M. 2006. Mid-Term Benefit Analysis of the Returning Grazing Land to Grassland Program in Inner Mongolia. Animal Husbandry and Feed Science (Cows) 05: 44-47. 
Wang Z.G. 2011. Analysis of the dynamic relationship between Inner Mongolia's economic growth and energy production and consumption. Economic Forum 487: 83-88 (in Chinese).

Weber K.E. and Tiwari I.P. 1992. Research and Survey Format Design: An Introduction (Bangkok: Asian Institute of Technology), Bangkok, Thailand.

West Ujimqin Right Banner Statistics Bureau (WURBSB). 2010. Annual Social and Economic Reports of West Ujimqin Right Banner in 2010. West Ujimqin Right Banner Statistics Bureau: Xilin Gol League, China.

Werger M.J. and van Staalduinen M.A. 2010. Eurasian Steppes. Ecological Problems and Livelihoods in a Changing World. Springer Science \& Business Media: Berlin, Germany.

Whitehead J.C.and Cherry T.L. 2007. Willingness to pay for a green energy program: a comparison of ex-ante and ex-post hypothetical bias mitigation approaches. Resource \& Energy Economics 29: 247-261.

Wilske B., Lu N., Wei L., Chen S., Zha T., Liu C., Xu W., Noormets A., Huang J., Wei Y., Chen J., Zhang Z., Ni J., Sun G., Guo K., McNulty S., John R., Han X., Lin G., Chen J. 2009. Poplar plantation has the potential to alter the water balance in semiarid Inner Mongolia. Journal of Environmental Management 90: 2762-2770.

Wilson J.B., Peet R.K., Dengler J. Partel M. 2012. Plant species richness: the world records. Journal of Vegetation Science 23: 796-802.

Wu H., Aruhan, Guo T., Sun Z. 2011. Impacts of Land Use Change on Ecosystem Services Value in Duolun County of Inner Mongolia Based on RS and GIS. Scientia Georaphica Sinica 30: 110-116.

Wu R.Z., Zhen L, Du B.Z., Hu Y.F., Yan H.M., Cao X.C., Long X. 2012. Impact of ecological restoration project on livelihood of the herders in Inner Mongolia. Resources Science 34: 989-997 (in Chinese with English summary)

Wunder S. 2005. Payments for Environmental Services: Some Nuts and BoltsCIFOR (Center for International Forestry Research) Occasional Paper No. 42 (Bogor: CIFOR)

Wunder S. 2008. Payments for environmental services and the poor: concepts and preliminary evidence Environment and Development Economics 13: 279-297.

World Wildlife Fund for Nature (WWF). 2006. Living Planet Report 2006. Gland Switzerland: WWF.

World Wildlife Fund for Nature (WWF). 2007. 'Allocating scarce water. A primer on water allocation, water rights and water markets.' WWF-UK: Godalming, UK.

Xilin Gol Ecological Monitoring Station. 2008. Annual Report on Ecological Restoration Projects. Xilingol, Inner Mongolia: Xilingol Ecological Monitoring Station (in Chinese with English summary).

Xilin Gol Statistics Bureau. 2012. Statistics of 2010 yearbook in Zhengxiangbai Banner. Xilin Gol Statistic Bureau: Xilin Gol, China.

Xiao L. B., Fang X. Q., Ye Y. 2013. Reclamation and revolt: social responses in eastern Inner Mongolia to flood/drought-induced refugees from the north China plain 1644-1911. Journal of Arid Environments 88: 9-16.

Xiao L., Ren G.Z., Zhao X.G., Xiao Q.Y. 2007. Analysis on the Spatial and Temporal Variety of Virtual Water of Agricultural Products in Shaanxi. Journal of Arid Land Resources \& Environment 21: 104-108. 
Xie C., Zhao J.C., Liang D., Bennett J., Zhang L., Dai G.C., Wang X.H. 2006. Livelihood impacts of the conversion of cropland to forest and grassland program. Journal of Environmental Planning and Management 49: 555-570.

XLGLDRC. 2011. Report on ecosystem restoration programs in wind and sand source regions of Beijing-Tianjin. Xilin Gol Development and Reform Council: Xilingol, China (in Chinese)

Xu J.Y., Chen L.D., Lu Y.H. et al. 2006a. Local people's perceptions as decision support for protected area management in Wolong Biosphere Reserve, China. Journal of Environmental Management, 78(4):362-372. (in Chinese)

Xu Z., Long A., Zhang Z. 2003. Virtual water consumption calculation and analysis of Gansu Province in 2000. Acta of Geographica Sinica 58: 861-869.

Xu J.Y., Chen L.D., Lu Y.H., Fu B.J. 2007. Sustainability evaluation of the grain for green project: From local people's responses to ecological effectiveness in Wolong nature reserve. Environmental Management 40(1): 113-122.

Wu Z., Du W. 2008. Pastoral Nomad Rights in Inner Mongolia. Nomadic Peoples 12(2):13-33.

Xu Z.Q., Min Q.W., Wang Y.S., Li W.H. Xu Q. 2006b. Impact of human disturbances on soil nutrient contents of typical grasslands. Journal of Soil \& Water Conservation 20: 3842.

Xu J.T., Tao R., Xu Z.G., Bennett M.T. 2010. China's sloping land conversion program: does expansion equal success? Land Economics 86: 219-244.

Xu X., Duan X., Sun H., Sun Q. 2011. Green space changes and planning in the capital region of China. Environmental Management 47: 456-467.

Xu G.C., Kang M.Y., Jiang Y. 2012. Adaptation to the Policy-oriented Livelihood Change in Xilingol Grassland, Northern China. Procedia Environmental Sciences 13: 16681683.

Xu Z., Cheng S., Zhen L., Pan Y., Zhang X., Wu J., Zou X., Bijaya D. 2013. Impacts of dung combustion on the carbon cycle of alpine grassland of the north Tibetan plateau. Environmental Management 52: 441-449.

Xu W., Khoshroo N., Bjornlund H., Yin Y. 2014. Effects of "Grain for Green" reforestation program on rural sustainability in China: an AHP approach to peasant consensus of public land use policies. Stochastic Environmental Research and Risk Assessment 28(4): 867-880.

Yan L., Zhou G., Zhang F., Sui X., Ping X. 2012. Spatial heterogeneity of vegetation coverage and its temporal dynamics in desert steppe, Inner Mongolia. Acta Ecologica Sinica 32: 4017-4024.

Yan H., Zhan J., Liu B.. Yuan Y. 2014. Model Estimation of Water Use Efficiency for Soil Conservation in the Lower Heihe River Basin, Northwest China during 2000-2008. Sustainability 6: 6250-6266.

Yan Y., Hu Y., Yue L., Yu G., Biligejifu. 2012. Plant diversity change with different land use type and land use intensity: take Zhengxiangbai Banner as case study. Resources Science 34: 1032-1038.

Yang G.M. 2007. Theoretical Analysis and Case Study of Ecological Compensation Based on Ecosystem Services Assessment-Taking Xilingol Steppe as an Example Chinese Academy of Sciences: Beijing, China (in Chinese with English summary). 
Yao Z.Y., Wang T., Han Z.W., Zhang W.M., Zhao A.G. 2007. Migration of sand dunes on the northern Alxa Plateau, Inner Mongolia, China. Journal of Arid Environments 70: $80-93$.

Yin R.S. and Yin G.P. 2010. China's Primary Programs of Terrestrial Ecosystem Restoration: Initiation, Implementation, and Challenges. Environmental Management 45: 429-441.

Yu F. F., Price K. P., Ellis J., Shi P. 2003. Response of seasonal vegetation development to climatic variations in eastern central Asia. Remote Sensing of Environment 87: 42-54.

Yue G., Zhao H., Zhang T., Zhao X., Niu L., Drake S. 2008. Evaluation of water use of Caragana microphylla with the stem heat-balance method in Horqin Sandy Land, Inner Mongolia, China. Agricultural and Forest Meteorology 148: 1668-1678.

Zhai G.F. and Suzuki T. 2008. Public willingness to pay for environmental management, risk reduction and economic development: evidence from Tianjin, China. China Economic Review 19: 551-566 (in Chinese with English summary).

Zhang W. 1998. Changes in species diversity and canopy cover in steppe vegetation in Inner Mongolia under protection from grazing. Biodiversity and Conservation 7: 1365-1381

Zhang B., Li W., Xie G., Xiao Y. 2010. Water conservation of forest ecosystem in Beijing and its value. Ecological Economics 69: 1416-1426.

Zhang Q., Wang X. 2012. Climate Variability, Change of Land Use and Vulnerability in Pastoral Society: A Case from Inner Mongolia. Nomadic Peoples, 16(1): 68-87.

Zhao C.L., Sun Y.Z., Xiao L., et al. 2014. The occurrence of barium in a Jurassic coal in the Huangling Mine, Ordos Basin, northern China. Fuel 128: 428-432.

Zhang C.M., Ma Z.X., Zhai L.L., et al. 2014. The Evaluation of Comprehensive Transportation System in Inner Mongolia Based on Principal Component Analysis. Applied Mechanics \& Materials 505-506: 782-786.

Zhang M.D.A., Borjigin E., Zhang H.P. 2007. Mongolian nomadic culture and ecological culture: on the ecological reconstruction in the agro-pastoral mosaic zone in Northern China. Ecological Economics 62: 19-26.

Zhang Q.Y., Wu X.H., Zhao D.S., Dai E.F. 2013. Temporal-spatial changes in Inner Mongolian grassland degradation during past three decades. Agricultural Science \& Technology 14: 676-683.

Zhang Q. 2004. Residential energy consumption in China and its comparison with Japan, Canada, and USA. Energy Build 36: 1217-1225.

Zhao H.I., Zhao X.Y., Zhang T.H., Li Y.S., Han F.L., Zhou R.L. 1999. The time-space variation of groundwater and its causes in central decertified area in Naiman Banner of Mongolia in the past 20 Years. Journal of Desert Research 19: 7-11. (in Chinese with English abstract).

Zhao H.L., Yi X.Y., Zhou R.L., Zhao X.Y., Zhang T.H. Drake S. 2006. Wind erosion and sand accumulation effects on soil properties in Horqin Sandy Farmland, Inner Mongolia. Catena: 65 71-6579.

Zhao H.L., Li S.G., Zhang T.H., Ohkuro T., Zhou R.L. 2004. Sheep gain and species diversity: In sandy grassland, Inner Mongolia. Journal of Range Management 57: 187-190.

Zhao R., Huang X., Zhong T., Peng J, 2011. Carbon footprint of different industrial spaces based on energy consumption in China. Journal of Geographical Science 21: 285300 .

Zhao Y., Peth S., Horn R., Kummelbein J., Ketzer B., Gao Y., Doerner J., Bernhofer C., Peng X. 2010. Modelling grazing effects on coupled water and heat fluxes in Inner Mongolia grassland. Soil \& Tillage Research 109: 75-86. 
Zhao Y., Peth S., Krümmelbein J., Horn R., Wang Z., Steffens M., Hoffmann C., Peng X., 2007. Spatial variability of soil properties affected by grazing intensity in Inner Mongolia grassland. Ecological Modelling 205: 241-254.

Zhen L., Liu X.L., Wei Y.J. 2008. Consumption of ecosystem services: models, measurement and management framework. Resources Science 30: 100-106.

Zhen L., Ochirbat B., Lv Y., Wei Y.J., Liu X.L., Chen J.Q., Yao Z.J., Li F. 2010a. Comparing patterns of ecosystem service consumption and perceptions of range management between ethnic herders in Inner Mongolia and Mongolia. Environmental Research Letters 5: 1-11.

Zhen L., Cao S. Y., Cheng S. K., Xie G. D., Wei Y. J., Liu X. L., Li F. 2010b. Arable land requirements based on food consumption patterns: case study in rural Guyuan District, Western China. Ecological Economics 69: 1443-1453.

Zhen L., Li F., Huang H.Q., Dilly O., Liu J.Y., Wei Y.J., Yang L. Cao X.C. 2011 a. Households' willingness to reduce pollution threats in the Poyang Lake region, southern China. Journal of Geochemical Exploration 110: 15-22.

Zhen L., Liu X.L., Wei Y.J., Yang L., Long X., Du B.Z., Li F., Cao X. 2011b. Consumption of Ecosystem Services: A Conceptual Framework and Case Study in Jinghe Watershed, Journal of Resources and Ecology 2: 298-306.

Zhen L. and Zhang H.Y. 2011. Payment for ecosystem services in China: an overview. Living Reviews in Landscape Research 5: 5-21.

Zhen L., Deng X.Z., Wei Y.J., Jiang Q.O., Lin Y.Z., Helming K., Wang C., König H.J. 2014. Future land use and food security scenarios for the Guyuan district of remote western China. iForest - Biogeosciences and Forestry 7: 372-384.

Zheng H., Robinson B.E., Liang Y.C., Polasky S, Ma D.C., Wang F.C., Ruckelshaus M., Ouyang Z.Y. Daily G.C. 2013. Benefits, costs, and livelihood implications of a regional payment for ecosystem service program. Proceedings of the National Academy of Sciences of the United States of America 110: 16681-16686.

Zheng S., Li W., Lan Z., Ren H., Wang K. 2015. Functional trait responses to grazing are mediated by soil moisture and plant functional group identity. Scientific Reports 5: 18163.

Zhengxiangbai Banner Statistics Bureau (ZBSB). 2010. Annual Social and Economic Reports of Zhengxiangbai Banner in 2010. Zhengxiangbai Banner Statistics Bureau: Xilin Gol, China.

Zhou Z.C., Gan Z.T., Shangguan Z.P, Dong Z.B. 2010. Effects of grazing on soil physical properties and soil erodibility in semiarid grassland of the northern Loess Plateau (China). Catena 82: 87-91.

Zhou Z., Sun O.J., Huang J., Gao, Y.; Han, X. 2006. Land use affects the relationship between species diversity and productivity at the local scale in a semi-arid steppe ecosystem. Functional Ecology 20: 753-762.

Zimmer D. and Renault D. 2003. Virtual water in food production and global trade: Review of methodological issues and preliminary results. In Virtual Water Trade (No.12). Hoekstra A.Y., Ed. IHE: Delft, the Netherland.

Zwart S.J. and Bastiaanssen W.M.G. 2004. Review of measured crop water productivity values for irrigated wheat, rice, cotton and maize. Agricultural Water Management 69: 115-133. 


\section{Summary:}

Grassland degradation has become a major challenge in many parts of the world, especially in arid or semi-arid areas, such as the Chinese Inner Mongolian Autonomous Region (IMAR). Previous studies of the grassland ecosystems in IMAR focused on climate change and its environmental consequences or on the land-use conflicts between agrarian communities and nomads. For better planning and management, a more integrated analysis of the consequences of land-use change for the livelihood dependence and other benefits (services) of the grasslands in IMAR is needed.

Studies on ecosystem services of IMAR's grasslands are usually based on remote sensing data (TM images) to assess the total value of the grassland ecosystem services using benefit transfer. Thus far, to my knowledge no study collected original data on the detailed use of ecosystem services by pastoralists on the Mongolian Plateau or on their livelihood dependence on these services at the household level. Also, no data is available on the changes over time in contrasting situations for different grassland types (like meadow, steppe and desert steppe). I therefore aim to analyse the interactions between the people and the ecosystems in IMAR in an integrated manner, and especially focus on analysing the different utilization patterns of ecosystem services and the livelihood dependence of local herders and other stakeholders in selected study sites. The ultimate goal of my study is to contribute to sustainable management of the IMAR's ecosystems.

To achieve the goal of my $\mathrm{PhD}$ study, six research questions on the changes in land use, household consumption patterns and their impacts have been addressed and investigated for four selected study sites: Hulun Buir, Xilin Gol, Ordos and Alxa Right. These sites are in a 'transect' from southwest to northeast to capture the gradient in use of ecosystem services in IMAR.

After introducing the changes in national land-use policies and local socio- ecological systems in IMAR, Chapter 1 presents a methodological framework that combines quantitative and qualitative tools to analyse ecosystem services. It specifies an integrative approach in specific spatial and temporal contexts to evaluate trade-offs between human activities, use of ecosystem services and human well-being. This framework enables to analyse the effects of multiple factors (e.g. policies or climate and geographic conditions) on utilization patterns of ecosystem services and the influence on society. The data used to apply the framework stems from a bottom-up approach by using household surveys and other local field data. The framework was tested for IMAR to ensure its practical applicability in a data-poor environment and to illustrate that it enhances understanding of the causes and effects of changing land use patterns and dynamic processes that underlie the provision of ecosystem services. The framework should not only be applicable for IMAR's grasslands but also for other areas with similar conditions (e.g. livestock-production dominated grassland ecosystems).

Chapter 2 describes the changes in basic household utilization patterns of food, fuel and water in response to the restoration policies and their spatial distribution by grassland types in IMAR. Basic household consumption data were collected in the meadow steppe (Hulun Buir), typical steppe (Xilin Gol) and semi-desert steppe (Ordos) ecosystems using structured questionnaires administered to 209 herders and 
farmers. The results and their analysis show that the householders' intake comprised a low amount of crops, including staple foods, vegetables and fruit with a high amount of meat. This still dominated the food consumption patterns in 2010. However, the number of households that prefer this pattern is decreasing and now more crops and less meat are increasingly preferred. From 1995 to 2010, fuel consumption patterns changed from bio-fuels (especially dung) to mainly electricity and gas. However, biofuel remains a major energy source in the meadow steppe ecosystems. In all three surveyed grassland types, the use of coal, electricity and gas increased from 1995 to 2010. Beside the influences of different environmental conditions and economic development, the grassland restoration policy measures changed grazing activities and basic household consumption patterns. Grazing activities were less affected by the policy measures that aimed at seasonal grazing and rotational grazing than other policy measures. In those cases more herders preferred to maintain most of their basic consumption patterns (e.g. in Hulun Buir). However, when grazing was prohibited, immigration and livestock rearing control policy measures (e.g. in Xilin Gol and Ordos) fundamentally changed the basic household consumption patterns (especially for food and fuel).

Chapter 3 links livelihood's food-consumption responses to potential water consumption by using a Virtual Water Content (VWC) analysis. This chapter analysed water-resources use and its relation with changes in livelihoods and householdconsumption patterns (Chapter 2). The results show that compared to the direct water consumption, the indirect water consumption through food production was a major share of total water consumption. From 1995 to 2010, indirect water consumption decreased in Xilin Gol and Ordos because meat consumption decreased and fruit and vegetable consumption increased. When considering the amount of land per household, the grassland ecosystems in Ordos are still threatened by high waterconsumption pressures. This affects both water conservation and grassland productivity. The grassland ecosystem degradation in IMAR leads to a shortage of meat production and this causes people to purchase food from outside the region to reduce dependency on local ecosystems. This trend resulted in more diversified consumption, especially increased vegetable and fruit consumption, but the ability to purchase food also depends on income levels. Ordos' high income level thus reduced direct water consumption through adoption of diversified food-consumption patterns. Changing diet behaviour is therefore an important option to more sustainably use water.

Chapter 4 evaluates the effects of the government grassland-conservation policies on household livelihoods and their dependence on local grasslands. To ease the impact on the residents' livelihoods, national and regional governments have offered a series of top-down arrangements to stimulate sustainable use of the IMAR grasslands. Simultaneously, local households spontaneously developed bottom-up countermeasures. To analyse the effects of all these measures, I interviewed members of 135 households using a mix of qualitative and quantitative methods. The findings show that the implementation of the grassland conservation policies significantly affected household livelihoods and this in turn, affected household use of natural assets (primarily the land), their agricultural assets (farming and grazing activities) and their financial assets (income and consumption). The policy implementation thus resulted in fundamental transformation of their lifestyles. The households developed adaptation measures to account for the dependence of their livelihoods on local ecosystems by initializing strategies (e.g. seeking off-farm work, leasing pasture land, 
increasing purchases of fodder for stall-fed animals and altering their diet and fuel consumption) to compensate for their changing livelihoods. Before the policyimplementation, the annual household income and employment based on agricultural land still depended heavily on local grasslands and most households owned some livestock, which they raised to sell for income or for personal consumption, especially in the West Ujimqin and Zhengxiangbai Banners. However, from 1995 to 2010, the household dependence on local grasslands generally decreased. This indicates a transition from traditional pastoral grazing to control grazing, rising of modern dairy cattle (intensive animal husbandry), diversification of income sources and decreases in land-based employment and in the household food and fuel consumption. These changes increased the diversity of livelihoods, household resilience and environmental sustainability.

Chapter 5 presents the impact of conservation measures (changes in grasslandutilization patterns) on the provision of selected ecosystem services at the three study sites in IMAR. I examined five utilization patterns: no use (natural grasslands), light use, moderate use, intensive use and recovery sites (degraded sites protected from further use). Through household surveys and vegetation and soil surveys the differences in ecosystem services among the different grassland-utilization patterns were measured. I also identified spatial factors that confounded the quantification of ecosystem services in the different grassland types. The results show that light use generally provided higher levels of ecosystem services than intensive use and no use. Only supporting ecosystem services differed. Surprisingly, I found no consistently positive effects of the strict conservation activities across the sites, since the results varied spatially and with respect to differences in the land-use patterns. My results suggest that appropriate grassland-utilization patterns likely enhance the supply of ecosystem services and reduce negative effects on both household livelihoods and the environment. For example, in the Hulun Buir grasslands, the precipitation is $50 \%$ higher than in the other areas. Therefore the area tolerates a higher grazing intensity before degradation occurs and its grasslands provide more provisioning services but at the cost of decreased regulating and supporting services.

Chapter 6 describes two eco-compensation programs to restore grassland ecosystems in Inner Mongolia in Northern China: the Land Conversion Project (SLCP) and the Grazing Prohibition Project (GPP). A key challenge is to sustain the livelihood of residents, who earn most of their income from traditional animal husbandry. I surveyed 240 herders and 36 government representatives and used contingent valuation and logistic regression to analyse the resulting data. After implementing the financing programs, income from cultivation and animal grazing decreased, whereas income from compensation and off-farm activities increased. The herders preferred an annual payment of 99.2 US\$ ha ${ }^{-1}$ for participating in conservation activities, but the government prefers to provide only 83.8 US\$ ha ${ }^{-1}$, resulting in an annual gap of 15.4 US\$ $\mathrm{ha}^{-1}$. These currently too low payments probably lead some herders to expand their grazing into restricted grasslands or increase their number of animals, particularly if such payment program ends. The herders were most concerned about their economic loss, whereas the government considered both grassland restoration and income protection equally important. To create an improved and sustainable payment scheme, solutions are needed that enable the herders to sustain their livelihood, while conserving the grasslands. My findings can help to establish more effective payment schemes for the grasslands of IMAR and similar regions. 
Chapter 7 discusses the contribution of my $\mathrm{PhD}$ thesis to understanding interactions between grassland ecosystems and people in the IMAR by structurally and consistently analysing the relation between ecosystem services to livelihoods. The possible grassland-management strategies in the selected study sites were explored. By comparing remote-sensing data $(1995,2000,2005$ and 2010) with statistical data (field surveys and Inner Mongolia Statistics Bureau 2015b), 70\% of the grasslands in IMAR is estimated to suffer from grazing or overgrazing. This degradation greatly alters the local social-economic structure (livelihood of indigenous people) and grassland ecosystem functioning. To reduce the stress from grasslands degradation, my thesis provides solutions to more appropriate grassland utilization patterns. These solutions enhance the supply of ecosystem services and reduce the negative effects on both household livelihoods and the environment. Moreover, the design of suitable eco-compensation mechanisms could encourage more efficient grassland uses. My results show that the present grassland-conservation policy has decreased the trend of grasslands degradation, but the other key challenge to sustain the livelihood of herders, who earn most of their income from traditional animal husbandry, was not solved. They are still concerned about their economic losses, whereas the government considered both grassland restoration and income protection to be important. To create an improved and sustainable payment scheme, I recommend to implement solutions that enable the herders to sustain their livelihoods, while conserving the grasslands.

The Chinese government has implemented many environmental protection projects and policies since 1998. These policies should reduce ecosystem degradation and stimulate sustainable management in these grasslands. The implemented grassland conservation policies have decreased the trend of grasslands degradation. However, these policies mainly focus on single issues. The grassland-conservation policies therefore must become more integrated and their positive effects (in terms of providing social, economic and environmental benefits) should be better clarified and communicated to all involved stakeholders. Implementing sustainable grassland management not only requires appropriate policies but also increased participation of local stakeholders, and suitable financial compensation mechanisms to encourage efficient grassland uses. My thesis shows that appropriate grassland utilization likely enhances the supply of ecosystem services and reduces negative effects on both household livelihoods and the environment. 


\section{Acknowledgements}

I would like to thank my PhD committee: Prof. Dr. Rik leemans, Dr. Rudolf de Groot, Prof. Dr. Lin Zhen and Prof. Dr. Heqing Huang for their insightful ideas and continuous support to improve this $\mathrm{PhD}$ thesis.

I am thankful to Dr. Huimin Yan, Dr Yunfeng Hu, Dr Chunxia Lu and Prof. Dr. Gaodi Xie for their advice and guidance during my PhD journey. This thesis would not have been possible without the hearty friendship and support from Ruizi $\mathrm{Wu}$, Yuehan Dou, Xiaochang Cao, Haolyn Shang, Chao Wang, Jie Hu, Yunjie Wei, Zhichao Xue and Wanni Yang, all the IGSNRR and ESA colleagues and friends.

I owe my deepest gratitude to my family: my father Dr. Guanhua Du, mother Zhugai Wang, grandfather Xuezhen Du, grandmother Shulian Hou, husband An An and aunt Zhaosheng Du \& Zhonghui Du for their unconditional love and support.

The research reported in this thesis was financed in part by a grant from the Knowledge Innovation Program of the Chinese Academy of Sciences (KZCX2-EW306), the National Basic Research Programme of China (No. 2009CB421106), the National Key Project for Basic Research (973) (No. 2014CB954302), the National Natural Science Foundation of China (No. 41671517) and the National key Research and Development Program of China (No. 2016YFC0503700). 


\section{About the author}

Bingzhen Du commenced her PhD with the Environmental System Analysis Group of Wageningen University and Research (WUR) in 2013. Her PhD project is a joint doctoral program between the Graduate School for Socio-Economic and Natural Sciences of the Environment (SENSE, Wageningen) and the Institute of Geographic Science and Natural Resources Research (IGSNRR, Beijing). This PhD research is also part of an International Geosphere-Biosphere Programme (IGBP) project, which is led by IGSNRR.

Before Bingzhen Du started her PhD research, she has worked at IGSNRR since 2010. She participated in many rural household surveys in poorly developed area of China (e. g. Inner Mongolia, Gansu, Ningxia and Qinghai) under the leadership of Prof. Lin Zhen. During this time, Bingzhen became interested in the interaction between people and ecosystems and for her $\mathrm{PhD}$ she developed a conceptual framework and especially focused on analysing the different utilization patterns of ecosystem services and the livelihood dependence of local stakeholders.

In addition to her $\mathrm{PhD}$ work, she participated in several research projects on international cooperation and national issues related to eco-compensation (i.e. Payment for Ecosystem Services), which aim to help establish a Chinese ecocompensation mechanism to conserve natural resources (including grassland, forest and river basin). During her work with IGSNRR, she was also involved in several collaborative publications on related topics. 


\section{List of publications}

\section{$>$ Published papers related to thesis}

1. Chapter 2: Du B., Zhen L., de Groot R., Goulden C.E., Long X., Cao X., Wu R., Sun C. 2014. Changing patterns of basic household consumption in the Inner Mongolian grasslands a case study of policy-oriented adoptive changes in the use of grasslands. The Rangeland Journal 36: 505-517.

2. Chapter 3: Du B., Zhen L., de Groot R., Long X., Cao X., Wu R. 2015. Changing Food Consumption Patterns and Impact on Water Resources in the Fragile Grassland of Northern China, Sustainability 7(5): 5628-5647.

3. Chapter 4: Du B., Zhen L., Yan H., de Groot R. 2016. Effects of government grassland conservation policy on household livelihoods and dependence on local grasslands: evidence from Inner Mongolia, China. Sustainability 8:13-14.

4. Chapter 5: Du B., Zhen L., Hu Y., Yan H., De Groot R., Leemans R. 2018. Comparison of ecosystem services provided by grasslands with different utilization patterns in China's Inner Mongolia Autonomous Region. Journal of Geographical Sciences 28(10): 1398-1414.

5. Chapter 6: Zhen L., Li F., Yan H., Liu G., Liu J., Zhang H., Du B., Wu R., Sun C., Wang C. 2014. Herders' willingness to accept versus the public sector's willingness to pay for grassland restoration. Environmental research letters 9: 045003.

\section{Other published papers}

6. König H.J., Podhora A., Helming K., Zhen L., Wang C., Wubbeke J., Baumeister T., Du B., Yan H. 2014. Confronting international research topics with stakeholders on multifunctional land use the case of Inner Mongolia, China. IForest-Biogeosciences and Forestry 7:403-413.

7. König H.J., Podhora A., Zhen L., Helming K., Yan H., DU B., Wubbeke J., Wang C., Klinger J., Chen C., Uthes S. 2015. Knowledge Brokerage for Impact Assessment of land use scenarios in Inner Mongolia, China: extending and testing the FoPIA approach. Sustainability 7: 5027-5049.

8. Zhen L., Hu J., Du B., Liu J., Sun C., Wu R., Long X., Zhang Q. 2015. International experience of green development in Western China: an overall review of policy and practice. Chinese Journal of population Resources and Environments 13(4): 281-290.

9. Zhen L. \& Du B. 2017. Ecological footprint analysis based on changing food consumption in a poorly developed area of China. Sustainability 9: 13-23.

10. Zhen L., Du B., Wei Y., Xiao Y., Sheng W. 2018. Assessing the effects of ecological restoration approaches in the alpine rangelands of the Qinghai-Tibetan Plateau. Environmental Research Letters 13(9): 1-19.

11. Dou Y., Zhen L., de Groot R., Du B., Yu X. 2017. Assessing the Importance of the Cultural Ecosystem Services in Urban Areas of Beijing Municipality. Ecosystem Services 24: 79-90.

12. Cao X., Zhen L., Yang L., Long X., Du B., Wei Y., Li F. 2011. Stakeholder Perceptions of Changing Ecosystem Services Consumption in the Jinghe Watershed: A Household Survey and PRA. Journal of Resources and Ecology 2(4): 345-352. 
13. Zhen L., Liu X., Wei Y., Yang L., Long X., Du B., Li F., Cao X. 2011. Consumption of Ecosystem Services: A Conceptual Framework and Case Study in Jinghe Watershed. Journal of Resources and Ecology 2(4): 298-306.

14. Wang C., Zhen L., Du B. 2016. Assessment of the impact of China's Sloping Land Conservation Program on regional development in a typical hilly region of the loess plateau - A case study in Guyuan, Environmental Development 21: 6676.

15. Hu J., Zhen L., Sun C., Du B., Wang C. 2015. Ecological footprint of biological resource consumption in a typical area of the Grain for Green Project in northwestern China. Environments 2: 44-60. 


\section{SENSE}

Netherlands Research School for the

Socio-Economic and Natural Sciences of the Environment

\section{I P L O M A}

For specialised PhD training

The Netherlands Research School for the Socio-Economic and Natural Sciences of the Environment (SENSE) declares that

\section{Bingzhen Du}

born on 15 November 1981 in Henan, China

has successfully fulfilled all requirements of the Educational Programme of SENSE.

Wageningen, 30 January 2019

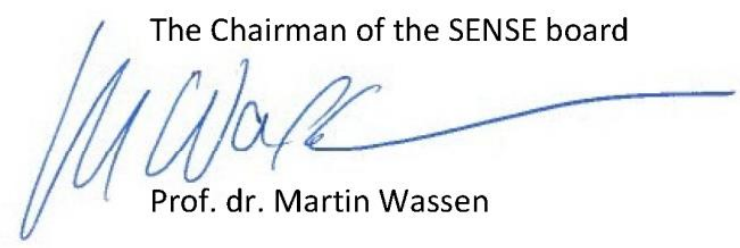

the SENSE Director of Education

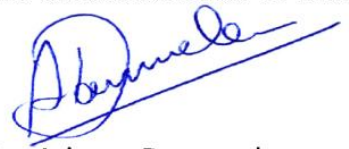

Dr. Ad van Dommelen

The SENSE Research School has been accredited by the Royal Netherlands Academy of Arts and Sciences (KNAW)

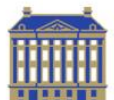

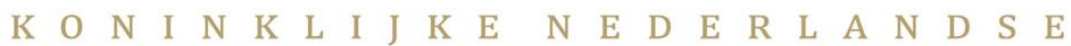

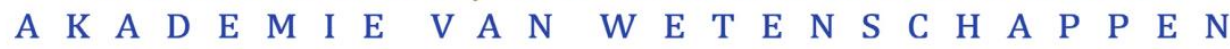




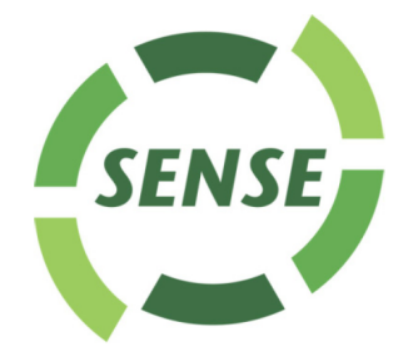

The SENSE Research School declares that Bingzhen Du has successfully fulfilled all requirements of the Educational PhD Programme of SENSE with a work load of $36.8 \mathrm{EC}$, including the following activities:

\section{$\underline{\text { SENSE PhD Courses }}$}

Environmental research in context (2014)

SENSE writing week (2014)

Multivariate analysis (2014)

Consumer - resource interaction (2014)

- Research in context activity: 'Preparing and creating accessible stakeholder video on 'Grassland restoration in Inner Mongolia' (and publishing in China's largest video website)' (2018)

\section{Other PhD and Advanced MSc Courses}

- Ecology: complex dynamics in environment systems, Institute of Geographic Sciences and Natural Resources Research, Chinese Academy of Sciences (2015)

- Basic theory and applications for natural resources and environmental management, Institute of Geographic Sciences and Natural Resources Research, Chinese Academy of Sciences (2015)

\section{Management and Didactic Skills Training}

- Supervising two MSc students with thesis entitled 'Integrated assessment of the benefits of restoring cultural services of urban ecosystems in Beijing' (2013) and 'Effect of grassland restoration programs on ecosystem services of three case studies in Inner Mongolia' (2018)

- Co-organisation of stakeholder workshops on impact assessment of multifunctional land use and scenarios in Inner Mongolia, China (2013)

\section{$\underline{\text { Oral Presentations }}$}

- Hydrological responses to climate change, and influences on its eco-environments in the source region of the Yellow river. 9th International Conference of Environment and Sustainable Development Mongolian Plateau and Surrounding Regions, 20-22 August 2013, Ulan-Ude, Russia

- Ecological mechanisms underpinning adaptation process of grassland ecosystem services in Inner Mongolia, China. 1st Asia Ecosystem Services Partnership Conference, 30 May-3 June 2016, Ansan-si, South Korea

- Ecological mechanisms underpinning adaptation process of grassland ecosystem services in Inner Mongolia, China. Global Land Programme 3rd Open Science Meeting, 23-27 October 2016, Beijing, China

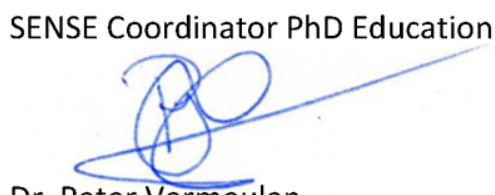

Dr. Peter Vermeulen 
The research described in this thesis was financed in part by a grant from the Knowledge Innovation Program of the Chinese Academy of Sciences (KZCX2-EW306), the National Basic Research Programme of China (No. 2009CB421106), the National Key Project for Basic Research (973) (No. 2014CB954302), the National Natural Science Foundation of China (No. 41671517) and the National key Research and Development Program of China (No. 2016YFC0503700).

Financial support from Wageningen University for printing this thesis is gratefully acknowledged.

Cover materials: http: //www/58pic.com/

Cover design: Bingzhen Du

Printed by: ProefschriftMaken.nl | Digiforce 